\title{
Identifizierung und Charakterisierung der Dihydroorotat Dehydrogenase als Zielstruktur von 1-Hydroxyquinolonen in Toxoplasma gondii
}

\author{
Dissertation \\ zur Erlangung des mathematisch-naturwissenschaftlichen Doktorgrades \\ "Doctor rerum naturalium" \\ der Georg-August-Universität Göttingen \\ im Promotionsprogramm Biologe \\ der Georg-August University School of Science (GAUSS)
}

vorgelegt von

JANA HEGEWALD

aus Erfurt

Göttingen, 2013 


\section{Betreuungsausschuss:}

Prof. Dr. Uwe Groß

(Institut für Medizinische Mikrobiologie, Abteilung Medizinische Mikrobiologie)

Prof. Dr. Jörg Stülke

(Institut für Mikrobiologie und Genetik, Abteilung Allgemeine Mikrobiologie)

\section{Mitglieder der Prüfungskommission:}

Referent: Prof. Dr. Uwe Groß

(Institut für Medizinische Mikrobiologie, Abteilung Medizinische Mikrobiologie)

Korreferent: Prof. Dr. Jörg Stülke

(Institut für Mikrobiologie und Genetik, Abteilung Allgemeine Mikrobiologie)

Weitere Mitglieder der Prüfungskommission:

Prof. Dr. Stefanie Pöggeler

(Abteilung Genetik eukaryotischer Mikroorganismen)

Prof. Dr. Ernst A. Wimmer

(Johann-Friedrich-Blumenbach-Institut für Zoologie und Anthropologie, Abteilung Entwicklungsbiologie)

PD Dr. Stefan Irniger

(Abteilung Molekulare Mikrobiologie und Genetik)

Prof. Dr. Rolf Daniel

(Abteilung genomische und angewandte Mikrobiologie)

Tag der mündlichen Prüfung: 23.10.2013 
„Der Fortgang der wissenschaftlichen Entwicklung ist im Endeffekt eine ständige Flucht vor dem Staunen.“ 


\section{Danksagung}

\section{Danksagung}

Mein besonderer Dank geht an Herrn Dr. Wolfgang Bohne, für die Bereitstellung dieses wirklich spannenden Themas, die hervorragende Betreuung, die vielen Ratschläge und Hilfestellungen auch während dem Schreiben dieser Arbeit und die gebotene Möglichkeit zu wissen, was die Molekularbiologie alles leisten kann.

Ein großer Dank geht an Herrn Prof. Dr. Uwe Groß, für die Möglichkeit der Durchführung meiner Dissertation im Institut für Medizinische Mikrobiologie, die vielen Anregungen während meiner Jahresberichte und die Übernahme des Referats meiner Doktorarbeit.

Des Weiteren möchte ich Herrn Prof. Dr. Jörg Stülke für die Übernahme des Korreferats meiner Doktorarbeit danken.

Bedanken möchte ich mich außerdem bei den weiteren Mitgliedern meines Prüfungskomitees, Frau Prof. Dr. Stefanie Pöggeler, Herr Prof. Dr. Rolf Daniel, Herr PD Dr. Stefan Irniger und Herr Prof. Dr. Ernst A. Wimmer.

Ein lieber Dank geht an die Mitarbeiter und ehemaligen Mitarbeiter der AG Toxoplasma, Izabela Swierzy, Kristin Graumann, Martin Thiele, Ayu Dewi, San San Lin, Herrn Prof. Dr. Carsten Lüder, aber auch Herrn Dr. Raimond Lugert, für ihre stetige Hilfsbereitschaft und die guten Tipps, aber auch die vielen netten Gespräche und die unglaublich freundliche Atmosphäre. Es hat mir immer viel Freude bereitet mit euch arbeiten zu dürfen.

Ganz besonders herzlich möchte ich meiner Familie und vor allem Martin Thiele danken, für den unermüdlichen Zuspruch und stets vorhandenen Rückhalt, das Korrekturlesen, den Spaß und all die Unterstützung während meiner gesamten Promotionszeit.

All meinen Freunden danke ich für ihren Glauben an mich, die vielen aufbauenden Worte und unterhaltsamen Stunden sowie den mentalen Beistand. 


\section{Inhaltsverzeichnis}

Danksagung

Inhaltsverzeichnis

$\begin{array}{lll}\text { Abbildungsverzeichnis } & \text { VII }\end{array}$

Tabellenverzeichnis $\quad$ X

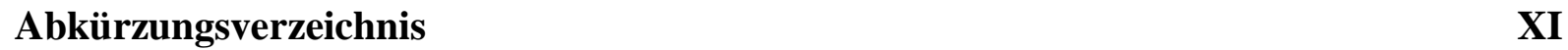

1 Einleitung 1

1.1 Toxoplasma gondii und Plasmodium spp. als Vertreter der Apicomplexa 1

1.1.1 Zellstruktur 1

1.1.2 Lebenszyklus 3

1.1.2.1 Plasmodium spp. 3

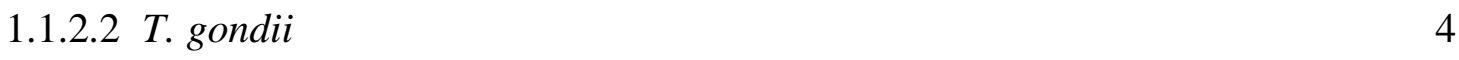

1.1.3 Medizinische Bedeutung 5

1.1.3.1 Plasmodium spp.

$\begin{array}{ll}\text { 1.1.3.2 T. gondii } & 6\end{array}$

$\begin{array}{lll}\text { 1.1.4 Therapie und Komplikationen } & 7\end{array}$

$\begin{array}{ll}\text { 1.1.4.1 Plasmodium spp. } & 7\end{array}$

$\begin{array}{ll}\text { 1.1.4.2 T. gondii } & 8\end{array}$

1.2 Mitochondrien als „Drug Targets“ der Apicomplexa 9

1.2.1 Bedeutung der mitochondrialen Elektronentransportkette (ETC) 10

1.2.1.1 Oxidative Phosphorylierung 12

$\begin{array}{ll}\text { 1.2.1.2 Pyrimidin-de-novo-Synthese } & 13\end{array}$

1.3 1-Hydroxyquinolone 16

$\begin{array}{lll}1.4 \text { Zielsetzung } & 18\end{array}$

2 Material und Methoden $\quad 20$

$\begin{array}{lll}2.1 & \text { Material } & 20\end{array}$

$\begin{array}{ll}2.1 .1 & \text { Zell- und Bakterienkultur } \\ & 20\end{array}$

$\begin{array}{ll}\text { 2.1.1.1 Toxoplasma gondii Stämme } & 20\end{array}$ 
$\begin{array}{ll}\text { 2.1.1.2 Wirtszellinie } 20 & 20\end{array}$

2.1.1.3 Kompetente Escherichia coli Stämme 20

$\begin{array}{lll}2.1 .2 & \text { Plasmide } & 21\end{array}$

2.1.3 Oligonukleotide (Primer) 21

2.1.4 Medien und Zusätze für die Zell- und Bakterienkultur 26

2.1.4.1 T. gondii Zellkultur 26

$\begin{array}{ll}\text { 2.1.4.2 E. coli Kultur } & 27\end{array}$

2.1.5 Antibiotika und antiparasitäre Wirkstoffe 27

2.1.6 Antikörper und Fluoreszenzmarker 28

$\begin{array}{lll}2.1 .7 & \text { Enzyme } & 29\end{array}$

2.1.8 Substrate der Enzymaktivitätsmessung 29

2.1.9 Molekulargewichtsmarker 29

2.1.10 Chemikalien 30

2.1.11 Kommerzielle Kits 31

2.1.12 Verbrauchsmaterialien 32

2.1.13 Geräte 32

$\begin{array}{ll}2.2 \text { Methoden } & 34\end{array}$

$\begin{array}{lll}2.2 .1 & \text { Zellkultur } & 34\end{array}$

2.2.1.1 Kultivierung der humanen Vorhautfibroblasten (HFF) 34

2.2.1.2 Kultivierung von T. gondii 34

2.2.1.3 Kryokonservierung und Auftauen der Zellen 34

2.2.1.4 Stabile Transfektion von T. gondii 35

2.2.1.5 Einzelklonierung transgener T. gondii Linien 36

2.2.1.6 Bestimmung der T. gondii Wachstumsrate 37

2.2.1.6.1 Replikationsassay 37

2.2.1.6.2 Plaque-Assay 37

2.2.1.7 Immunfluoreszenztest (IFT) 38

2.2.1.8 Analyse des mitochondrialen Membranpotentials $\left(\Delta \Psi_{\mathrm{m}}\right)$ mit $\begin{array}{ll}\text { MitoTracker Red } & 38\end{array}$

2.2.2 Allgemeine molekularbiologische Methoden - Nukleinsäuren 39

2.2.2.1 Isolierung von Nukleinsäuren und cDNA Synthese 39

2.2.2.2 Polymerase Kettenreaktion (PCR) 40 
2.2.2.2.1 Konventionelle PCR 40

2.2.2.2.2 Real-Time PCR (RT-PCR) 40

2.2.2.3 DNA-Konzentrationsbestimmung 41

2.2.2.4 DNA-Präzipitation 42

2.2.2.5 DNA-Sequenzierung 42

$\begin{array}{ll}\text { 2.2.2.6 Plasmid-Klonierung } & 42\end{array}$

2.2.3 Molekularbiologische Methoden der Proteinanalyse 44

2.2.3.1 Herstellung von T. gondii Lysat 44

2.2.3.2 SDS-PAGE 44

2.2.3.3 Coomassie-Färbung 45

2.2.3.4 Semi-Dry Western Blot 45

2.2.3.5 Immundetektion 46

2.2.3.5.1 Alkalische Phosphatase Detektion 46

2.2.3.5.2 Chemilumineszenz (ECL) Detektion 47

2.2.3.5.3 Strippen der Nitrozellulosemembran $\quad 47$

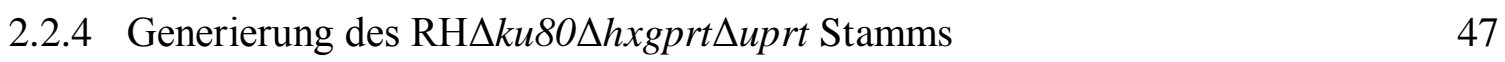

2.2.5 Komplementierung der 3L-H11 Mutante mit dem uprt Gen 48

2.2.6 Nachweis des DHODH N302S-Allels durch eine RestriktionsfragmentLängenpolymorphismus-Analyse (RFLP) 48

2.2.7 TgDHODH Allelaustausch 48

2.2.8 Expression, Aufreinigung und Aktivitätsmessung der TgDHODH 49

2.2.8.1 Bestimmung der DHODH Proteinkonzentration 51

2.2.8.2 Analyse der DHODH Enzymaktivität 51

2.2.9 Expression eines CAT-ScDHODH Fusionskonstrukts in T. gondii 53

2.2.9.1 Zelluläre Lokalisation und Quantifizierung des Expressionslevels $\quad 54$

2.2.9.2 CAT-ScDHODH Enzymaktivität 55

2.2.10 Bioinformatik 55

3 Ergebnisse $\quad 56$

3.1 Phänotypische Charakterisierung 1-Hydroxyquinolon-resistenter Mutanten 56

3.1.1 3L-H11 und 3F-A6 Parasiten zeigen eine partielle 1-Hydroxyquinolon$\begin{array}{ll}\text { Resistenz } & 56\end{array}$ 
3.1.2 Uprt komplementierte 3L-H11 Parasiten besitzen eine nochmals gesteigerte Resistenz gegenüber 1-Hydroxyquinolonen

3.1.3 Ein Mediumwechsel unter erneuter Zugabe von Compound B hat keinen Einfluss auf die Replikationsrate der Parasiten

3.1.4 Die Resistenzausprägung ist nicht an ein nachweisbares mitochondriales Membranpotential $\left(\Delta \Psi_{\mathrm{m}}\right)$ gebunden

3.1.5 Untersuchung des Parasitenwachstums in Abhängigkeit glykolytischer Energiegewinnung

3.1.5.1 Die Wachstums-Regeneration der Wildtyp Parasiten ist abhängig von Glucose

3.1.5.2 3L-H11 und 3F-A6 Parasiten zeigen nach einer Hemmung der Glykolyse eine gesteigerte Compound B-Sensitivität

3.1.5.3 1-Hydroxyquinolon-sensitive und -resistente Parasiten zeigen keinen Unterschied im Expressionsmuster glykolytischer Gene und des Glucosetransporters TgGT1

3.2 Identifizierung der T. gondii Dihydroorotat Dehydrogenase (TgDHODH) als Targetprotein der 1-Hydroxyquinolone

3.2.1 Resistenzmutanten zeigen keine Unterschiede im Expressionsgehalt mitochondrialer Dehydrogenasen

3.2.2 DNA-Sequenzanalysen identifizieren eine einzelne Mutation der TgDHODH von 3L-H11 und 3F-A6 Parasiten

3.2.2.1 Punktmutation N302S lokalisiert in einem hoch-konserviertem Bereich der kodierenden Sequenz

3.2.3 Eine Expression des N302S-Allels vermittelt partielle Resistenz gegenüber 1-Hydroxyquinolonen

3.2.4 Funktionelle Expression der TgDHODH in Escherichia coli

3.2.4.1 Generierung multipler Fusionskonstrukte

3.2.4.2 Komplementierung eines Uracil-auxotrophen E. coli Stamms durch TgDHODH

3.2.4.3 Sensitivitätstestung gegenüber Compound B

3.2.5 Biochemische Charakterisierung der TgDHODH als 1-Hydroxyquinolon Target 
3.2.5.1 Expression und Aufreinigung His-getaggter TgDHODH aus E. coli 82

3.2.5.1.1 C-terminaler His-Tag 82

3.2.5.1.2 N-terminaler His-Tag 83

3.2.5.2 Die Aktivität von TgDHODH wird direkt durch 1-Hydroxyquinolone inhibiert $\quad 84$

3.2.5.3 Compound $\mathrm{B}$ ist für $\mathrm{Q}_{\mathrm{D}}$ ein kompetitiver, für $\mathrm{DHO}$ ein unkompetitiver Inhibitor

3.2.5.4 Mutation N302S führt zu einer Reduktion der katalytischen Effizienz gegenüber DHO

3.2.6 Saccharomyces cerevisiae DHODH (ScDHODH) exprimierende T. gondii zeigen eine partielle 1-Hydroxyquinolon-Resistenz

\section{Diskussion}

4.1 TgDHODH als Zielstruktur der 1-Hydroxyquinolone 93

4.1.1 1-Hydroxyquinolone als „Multi-Target” Inhibitoren 96

4.2 Die Inhibierung von TgDHODH induziert eine Hemmung der de-novoPyrimidinsynthese

4.3 Einflüsse der N302S Mutation auf enzymkinetische Parameter von TgDHODH

4.3.1 Mutation N302S wirkt sich auf die katalytische Fitness von TgDHODH aus

4.4 Metabolische Anpassung 1-Hydroxyquinolon-behandelter Parasiten

\section{Zusammenfassung}

6 Summary

7 Literaturverzeichnis 
Abbildungsverzeichnis

\section{Abbildungsverzeichnis}

Abbildung 1.1: Schematische Struktur eines Tachyzoiten von T. gondii und Merozoiten von P. falciparum

Abbildung 1.2: Lebenszyklus von Plasmodium spp. und T. gondii

Abbildung 1.3: Modell der mitochondrialen Elektronentransportkette von T. gondii und Plasmodium

Abbildung 1.4: Modell der Pyrimidin-de-novo-Synthese von T. gondii und Plasmodium sowie des Salvage Pathway von T. gondii

Abbildung 1.5: Struktur von Ubiquinon, HDQ und Compound B

Abbildung 2.1: Schematischer Aufbau des ptubCAT-ScDHODH Vektors

Abbildung 3.1: Die T. gondii Klone 3L-H11 und 3F-A6 zeigen eine partielle 1-Hydroxyquinolon-Resistenz

Abbildung 3.2: Uprt komplementierte 3L-H11 Parasiten zeigen eine vergleichbare, relative uprt mRNA Expression wie der RH Stamm

Abbildung 3.3: Eine Komplementierung der 3L-H11 Mutante mit uprt führt zu einer gesteigerten 1-Hydroxyquinolon-Resistenz

Abbildung 3.4: Die Zugabe von frischem Compound B hat keinen Einfluss auf die partielle 1-Hxdroxyquinolon-Resistenz von 3L-H11 und 3F-A6 Parasiten

Abbildung 3.5: Die 1-Hydroxyquinolon-Resistenz der 3L-H11 und 3F-A6 Parasiten ist nicht an ein nachweisbares mitochondriales Membranpotential $(\Delta \Psi \mathrm{m})$ gebunden

Abbildung 3.6: Eine Behandlung der RH Parasiten mit Compound B, führt bei gleichzeitiger Reduktion der Glucosekonzentration zu einer vollständigen Inhibierung der Wachstums-Regeneration

Abbildung 3.7: $\Delta$ tggt1 Parasiten zeigen im Vergleich zum Wildtyp RH Stamm unter einer Behandlung mit Compound B, auch bei einer hohen Glucosekonzentration, eine vollständige Wachstumsinhibierung

Abbildung 3.8: Unter einem Mangel an Glucose besitzen 3L-H11 und 3F-A6 Parasiten eine deutlich gesteigerte Compound B-Sensitivität

Abbildung 3.9: Eine Inhibierung der Glykolyse durch 2-DOG führt zu einer Reduktion der partiellen Compound B-Resistenz bei 3L-H11 und 3F-A6 Parasiten

Abbildung 3.10: 3L-H11 und 3F-A6 Parasiten zeigen keine ausgeprägten Veränderungen im Expressionsmuster glykolytischer Gene 
Abbildung 3.11: 3L-H11 und 3F-A6 Parasiten zeigen keine ausgeprägte Veränderung in der Genexpression des Glucosetransporters TgGT1

Abbildung 3.12: 3L-H11 und 3F-A6 Parasiten zeigen keine ausgeprägten Veränderungen im Expressionsmuster mitochondrialer Dehydrogenasen

Abbildung 3.13: 3L-H11 und 3F-A6 Parasiten zeigen eine Punktmutation in der kodierenden Sequenz der TgDHODH, bei der es nachfolgend zu einer Aminosäuresubstitution kommt

Abbildung 3.14: Punktmutation N302S lokalisiert in einem hoch-konservierten Bereich von TgDHODH

Abbildung 3.15: Generierung einer N302S Knock-In Mutante durch einen Allelaustausch 75 Abbildung 3.16: Das N302S-Allel ist in der Lage eine partielle Resistenz gegenüber 1-Hydroxyquinolonen zu vermitteln

Abbildung 3.17: N302S KI Parasiten zeigen in vitro keinen Wachstumsdefekt

Abbildung 3.18: Schematische Darstellung der Konstruktion unterschiedlicher Fusionsvarianten der E. coli DHODH (EcDHODH) und TgDHODH

Abbildung 3.19 Eine Expression der Tgdhodh-kodierenden Fusionskonstrukte 1-6 führt zur funktionellen Komplementierung einer Uracil-auxotrophen Mutante von E. coli

Abbildung 3.20: Durch TgDHODH funktionell komplementierte Bakterien zeigen unter einer Kultivierung mit Compound B keine Wachstumsinhibierung

Abbildung 3.21: Western Blot Analysen des TgDHODH Proteinlevels nach Expression der C-terminal His-getaggten Fusionskonstrukte 4 und 6

Abbildung 3.22: Expression und Aufreinigung von TgDHODH

Abbildung 3.23: 1-Hydroxyquinolone sind wirkungsvolle Inhibitoren der Wildtyp TgDHODH Aktivität, zeigen jedoch einen Effektivitätsverlust gegenüber der N302S DHODH

Abbildung 3.24: Inhibitionskinetiken zeigen, dass Compound B ein unkompetitiver Inhibitor für DHO und ein kompetitiver Inhibitor für $\mathrm{Q}_{\mathrm{D}}$ ist

Abbildung 3.25: Die N302S TgDHODH zeigt einen verminderten $\mathrm{K}_{\mathrm{M}^{-}}$Wert für $\mathrm{Q}_{\mathrm{D}}$, jedoch einen gesteigerten $\mathrm{K}_{\mathrm{M}}$-Wert für DHO

Abbildung 3.26: Schematische Darstellung der durch die zytosolische ScDHODH (Klasse 1) und mitochondriale TgDHODH (Klasse 2) katalysierten enzymatischen Reaktion 
Abbildungsverzeichnis

Abbildung 3.27: CAT-ScDHODH exprimierende Klone von T. gondii bestätigen eine zytosolische Lokalisation des Fusionsproteins, unterscheiden sich jedoch hinsichtlich der Gen- und Proteinexpression

Abbildung 3.28: Compound B und HDQ haben keinen Einfluss auf die Enzymaktivität des CAT-ScDHODH Fusionsproteins

Abbildung 3.29: CAT-ScDHODH exprimierende Parasiten zeigen eine partielle Resistenz gegenüber 1-Hydroxyquinolonen

Abbildung 4.1: Adaptationsmodell 1-Hydroxyquinolon-sensitiver Parasiten (RHAuprt und RH) und von Parasiten mit einer partiellen 1-Hydroxyquinolon-Resistenz (3F-A6, 3L-H11 und 3L-H11/uprt kompl.) 
Tabellenverzeichnis

\section{Tabellenverzeichnis}

Tabelle 2.1: Sequenzierungsprimer Ubiquinon/Ubiquinol-interagierender Enzyme 21

Tabelle 2.2: Klonierungs- und Kontrollprimer für T gondii 23

Tabelle 2.3: Klonierungsprimer zur Expression der TgDHODH in E. coli 24

Tabelle 2.4: Primer der quantitativen Real-Time PCR (RT-PCR) 25

Tabelle 2.5: Verwendete Antibiotika und antiparasitäre Wirkstoffe 27

Tabelle 2.6: Verwendete Antikörperverdünnungen für Western Blot (WB) Analysen und $\begin{array}{ll}\text { Immunfluoreszenztests (IFTs) } & 28\end{array}$

Tabelle 2.7: Zur Messung der Enzymaktivität verwendete Substrate 29

Tabelle 2.8: PCR-Programm der Phusion- und Taq-Polymerase 40

Tabelle 2.9: LightCycler $^{\circledR}$ RT-PCR-Programm 41

Tabelle 2.10: Zusammensetzung 10\%iger und 12\%iger SDS-Gellösungen 45

Tabelle 3.1: Kinetische Parameter aufgereinigter Wildtyp und N302S TgDHODH und Inhibitionskinetiken von HDQ und Compound B 85 
Abkürzungsverzeichnis

\begin{tabular}{|c|c|}
\hline \multicolumn{2}{|c|}{ Abkürzungsverzeichnis } \\
\hline$\infty$ & unendlich \\
\hline$\Delta \Psi_{\mathrm{m}}$ & Mitochondriales Membranpotential \\
\hline $1 \% \mathrm{P} / \mathrm{S}$ & 1\% Penicillin/Streptomycin \\
\hline A & Ampere \\
\hline Abb. & Abbildung \\
\hline AIDS & engl.: Acquired Immune Deficiency Syndrome \\
\hline Amp & Ampicillin \\
\hline AK & Antikörper \\
\hline AnTc & Anhydrotetracyclin \\
\hline AP & Alkalische Phosphatase \\
\hline APS & Ammoniumperoxodisulfat \\
\hline AS & Aminosäure \\
\hline ATP & Adenosintriphosphat \\
\hline BCIP & 5-Bromo-4-Chloro-3-Indolylphosphat \\
\hline bp & Basenpaare \\
\hline BSA & Rinderalbumin (engl.: Bovine Serum Albumin) \\
\hline CAT & Chloramphenicol Acetyltransferase \\
\hline cDNA & komplementäre DNA \\
\hline $\mathrm{Cp}$ & engl.: Crossing Point \\
\hline Cy3 & Carbocyanin 3 \\
\hline Cyt b & Cytochrom b \\
\hline $\mathrm{Da} / \mathrm{kDa}$ & Dalton/Kilodalton \\
\hline DCIP & 2,6-Dichlorindophenol \\
\hline $\mathrm{ddH}_{2} \mathrm{O}$ & doppelt destilliertes Wasser \\
\hline DHFR-TS & Dihydrofolatreduktase-Thymidylatsynthase \\
\hline $\mathrm{DHO}$ & Dihydroorotat \\
\hline DHODH & Dihydroorotat Dehydrogenase \\
\hline DMEM & Dulbecco's Modified Eagle's Medium \\
\hline DMSO & Dimethylsulfoxid \\
\hline DNA & Desoxyribonukleinsäure \\
\hline DNase & Desoxyribonuklease \\
\hline dNTP & Desoxynucleosidtriphosphat \\
\hline DTT & Dithiothreitol \\
\hline
\end{tabular}


Abkürzungsverzeichnis

E. coli

ECL

EDTA

ENU

et al.

ETC

$\mathrm{EtOH}$

$\mathrm{FADH}_{2}$

FCS

FMN

G3PDH

GSH

$\mathrm{h}$

HDQ

HEPES

HFF

HRP

Hs

HXGPRT

IFN- $\gamma$

IFT

IPTG

$\mathrm{kb}$

$\mathrm{k}_{\text {cat }}$

$\mathrm{K}_{\mathrm{M}}$

LB

M

MQO

mRNA

$\mathrm{NADH}$

$\mathrm{NaN}_{3}$

NBT

OD

P. falciparum
Escherichia coli

engl.: Enhanced Chemiluminescence

Ethylendiamintetraacetat

$\mathrm{N}$-Nitroso- $N$-Ethylurea

und andere (et alii)

Elektronentransportkette (engl.: Electron Transport Chain)

Ethanol

Flavin-Adenin-Dinukleotid

fötales Kälberserum

Flavinmononukleotid

Glycerin-3-Phosphat Dehydrogenase

Glutathion

Stunde

1-Hydroxy-2-dodecyl-4(1H)quinolone

2-(4-(2-Hydroxyethyl)-1-piperazinyl)-ethansulfonsäure

Humane Vorhautfibroblasten (engl.: Human Foreskin Fibroblast)

Meerrettichperoxidase (engl.: Horseradish Peroxidase)

Homo sapiens

Hypoxanthin-Xanthin-Guanin-Phosphoribosyltransferase

Interferon- $\gamma$

Immunfluoreszenztest

Isopropyl- $\beta$-D-thiogalactopyranosid

Kilobasen

Wechselzahl

Michaelis-Menten-Konstante

engl.: Lysogeny Broth (Bakterien-Nährmedium)

Molar

Malat:Quinon Oxidoreduktase

messenger Ribonukleinsäure

Nicotinamid-Adenin-Dinukleotid

Natriumazid

Nitroblau-Tetrazoliumchlorid

Optische Dichte

Plasmodium falciparum 
PBS

PCR

Pf

PFA

p. i.

Q

$\mathrm{QD}_{\mathrm{D}}$

QH2

RFLP

RNA

RT

RT-PCR

$\mathrm{S}$

S. cerevisiae

SAG 1

Sc

SD

SDH

SDS

SDS-PAGE

spp.

T25/T75

T. gondii

$\mathrm{Tg}$

Tris

TWEEN $^{\circledR}-20$

U

UMP

UTR

$\mathrm{V} \max$

$\mathrm{v} / \mathrm{v}$

$\mathrm{w} / \mathrm{v}$

WB

X-Gal
Phosphatgepufferte Salzlösung (engl.: Phosphate Buffered Saline) Polymerase-Kettenreaktion

P. falciparum

Paraformaldehyd

nach Infektion (lat.: post infectum)

Ubiquinon

Decylubiquinon

Ubiquinol

Restriktionsfragment-Längenpolymorphismus

Ribonukleinsäure

Raumtemperatur

Real-Time-quantitative-PCR

Sekunde

Saccharomyces cerevisiae

Oberflächen Antigens 1 (engl.: Surface Antigen 1)

S. cerevisiae

Standardabweichung (engl.: Standard Deviation)

Succinat Dehydrogenase

Natriumdodecylsulfat (engl.: Sodium Dodecyl Sulfate)

Natriumdodecylsulfat-Polyacrylamidgelelektrophorese

Spezies einer Gattung (lat.: species pluralis)

$25 \mathrm{~cm}^{2} / 75 \mathrm{~cm}^{2}$ Zellkulturflasche

Toxoplasma gondii

T. gondii

Tris(hydroxymethyl)-aminomethan

Polyoxyethylen(20)-sorbitan-monolaurat

Einheit zur Angabe der Enzymaktivität (engl.: Unit)

Uridin-5‘-Monophosphat

untranslatierter Bereich (engl.: Untranslated Region)

maximale Umsatzgeschwindigkeit

Volumenanteil pro Volumen

Gewichtsanteil pro Volumen

Western Blot

5-Brom-4-chlor-3-indoxyl- $\beta$-D-galactopyranosid 


\section{Einleitung}

\subsection{Toxoplasma gondii und Plasmodium spp. als Vertreter der Apicomplexa}

Das Phylum der Apicomplexa beinhaltet einige der bedeutendsten protozoischen Parasiten, darunter viele tierpathogene Vertreter wie Theilerien, Babesien und Eimerien, welche große landwirtschaftliche Schäden herbeiführen. Der Stamm umfasst jedoch auch eine Vielzahl humanpathogener Arten. Obwohl Kryptosporidien schwere Durchfallerkrankungen auslösen können, basiert die medizinische Relevanz des Phylums vor allem auf der durch Toxoplasma gondii und Plasmodium spp. verursachten Schadwirkung. Die durch Plasmodium ausgelöste Malaria gilt als die bedeutendste durch Parasiten hervorgerufene Infektionskrankheit und führt jährlich zu über einer Million Todesfälle. T. gondii gehört weltweit zu den erfolgreichsten Parasiten und hat durch teils sehr hohe Seroprävalenzen sowie erheblicher Morbidität und Mortalität bei immunsupprimierten Personen, aber auch bei einer diaplazentaren Infektion des Fötus (kongenitale Toxoplasmose) enorme Bedeutung erlangt.

\subsubsection{Zellstruktur}

Ihre Namensgebung verdanken die Apicomplexa einer Ansammlung von charakteristischen Strukturen an der anterioren Spitze der Zelle, dem Apikalkomplex (Levine et al. 1980) (Abb. 1.1). Dieser Komplex besteht aus Zytoskelett-Komponenten (Konoid, apikaler Polring und subpellikuläre Mikrotubuli) sowie den sekretorischen Organellen Rhoptrien, Mikronemen und Dichter Granula (Tomley and Soldati 2001). Der Apikalkomplex nimmt sowohl essentielle Funktion während der Parasitenreplikation, aber auch bei der Invasion der Wirtszelle ein (Hu et al. 2006). Dabei besitzt das Konoid eine mechanische Rolle bei der Invasion der Wirtszelle. Der sekretorische Inhalt der Rhoptrien und Mikronemen wird weiterhin für die Motilität des Parasiten, der Adhäsion und Invasion der Wirtszelle sowie der Bildung der parasitophoren Vakuole benötigt (Soldati et al. 2001; Morrissette and Sibley 2002). Innerhalb der Wirtszelle tragen die Produkte der Dichten Granula zur Modifikation der den Parasiten umgebenden parasitophoren Vakuole bei und nehmen eine bedeutende Funktion in der Parasit-WirtInteraktion ein (Cesbron-Delauw et al. 2008; Yin et al. 2013). Apicomplexa zeichnen sich weiterhin durch ein plastidartiges Organell, dem Apicoplasten, aus. Diese multimembranöse Struktur besitzt ein stark reduziertes, zirkuläres Genom und ist vermutlich durch den Vorgang der sekundären Endosymbiose entstanden (Kohler et al. 1997). Trotz einiger Unklarheiten über den Ursprung des phototrophen Vorfahren, wird heute davon ausgegangen, dass ein 
auxotropher Protist eine photosynthetisch aktive Rotalge aufgenommen hat (Waller et al. 2003; Janouskovec et al. 2010; van Dooren and Striepen 2013), welche ihrerseits den Chloroplasten durch Endosymbiose eines prokaryotischen Cyanobakteriums erhalten hat (Delwiche and Palmer 1997). Oft als Relikt eines Chloroplasten bezeichnet, sind die Funktionen des Apicoplasten keineswegs obsolet (van Dooren and Striepen 2013). Zwar handelt es sich um ein photosynthetisch-inaktives Plastid, für die Überlebensfähigkeit des Parasiten ist der Apicoplast dennoch essentiell, denn er beinhaltet die Stoffwechselwege der Typ II Fettsäure- und Häm-Synthese sowie der Isoprenoid-Biosynthese (Ralph et al. 2004; Parsons et al. 2007; Striepen 2011). Vertreter der Apicomplexa besitzen weiterhin spezifische Organellen der eukaryotischen Zelle (Nucleus, Endoplasmatisches Retikulum und GolgiApparat). Interessanterweise lässt sich bei den meisten Apicomplexa (darunter auch T. gondii und Plasmodium) nur ein einzelnes, teilweise sehr langes Mitochondrium nachweisen (Divo et al. 1985; Melo et al. 2000; Lemgruber and Lupetti 2012), das wie im Falle von T. gondii als tubuläre Struktur nahezu den gesamten Zellkörper umgibt (Nishi et al. 2008).

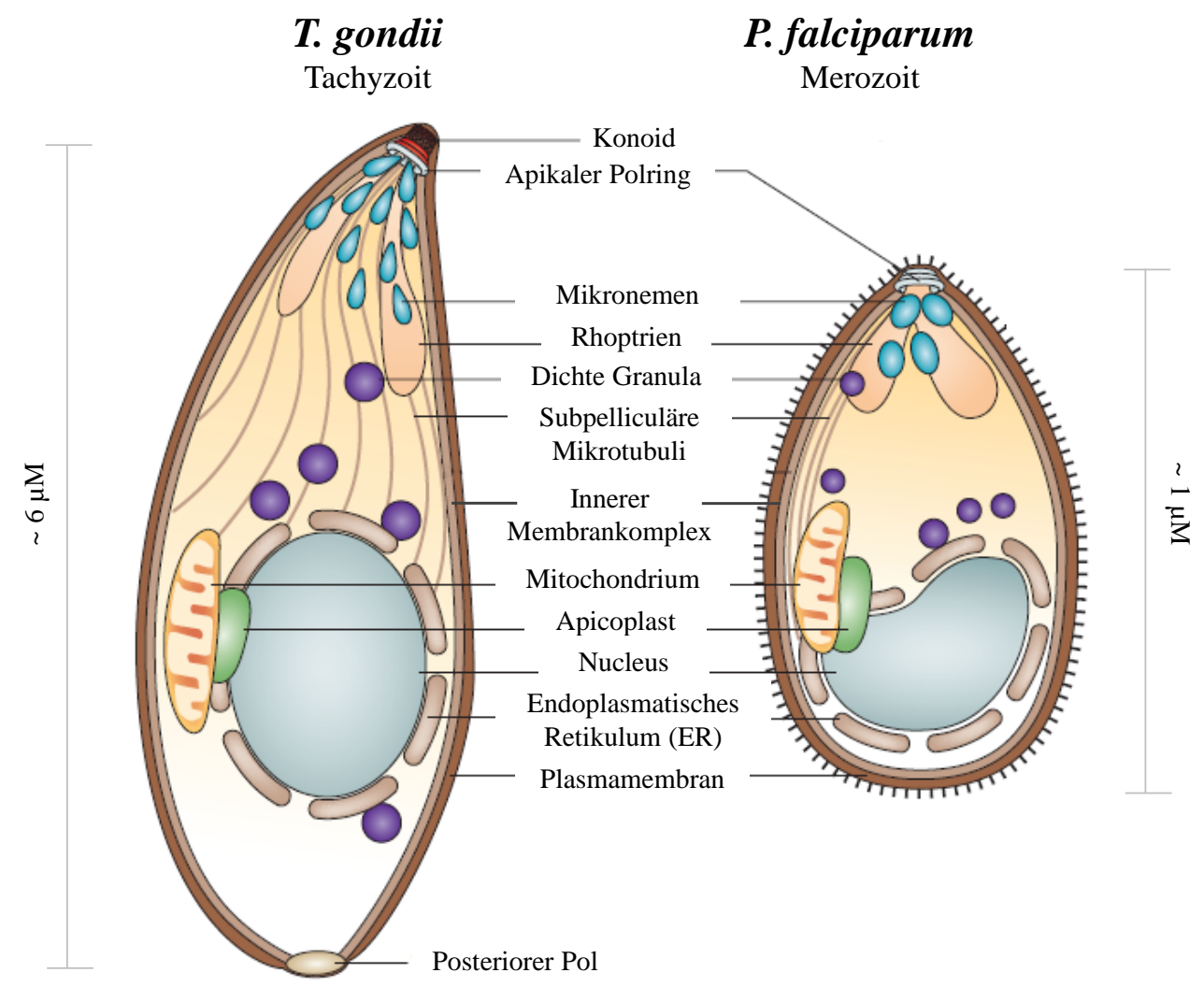

Abbildung 1.1: Schematische Struktur eines Tachyzoiten von T. gondii und Merozoiten von P. falciparum. Abbildung verändert nach Baum et al. (2006). 


\section{Einleitung}

\subsubsection{Lebenszyklus}

Da es sich bei T. gondii und Plasmodium spp. um obligat intrazelluläre Parasiten handelt, stellt die Invasion der Wirtszelle einen essentiellen Schritt innerhalb des Lebenszyklus dar. Während viele Pathogene darauf angewiesen sind, durch Endo- oder Phagozytose von der Zelle aufgenommen zu werden, ist der Invasionsvorgang der meisten Apicomplexa ein aktiv durch den Parasiten gesteuerter Prozess (Dubremetz 1998; Cesbron-Delauw et al. 2008; Sibley 2011; Meissner et al. 2013). Toxoplasmen und Plasmodien gelangen auf diese Weise innerhalb weniger Sekunden in die Wirtszelle (Vanderberg et al. 1990; Morisaki et al. 1995; Hakansson et al. 1999). Obwohl es mittlerweile Zweifel daran gibt, dass die Invasion der Zelle mit der Fähigkeit des Parasiten verbunden ist sich ,gleitend“ fortzubewegen (Meissner et al. 2013), unterstützen viele Studien den als gliding motility bezeichneten Prozess als treibende Kraft der Invasion (Dobrowolski et al. 1997; Hakansson et al. 1999; Siden-Kiamos et al. 2006; Soldati-Favre 2008; Gubbels and Duraisingh 2012).

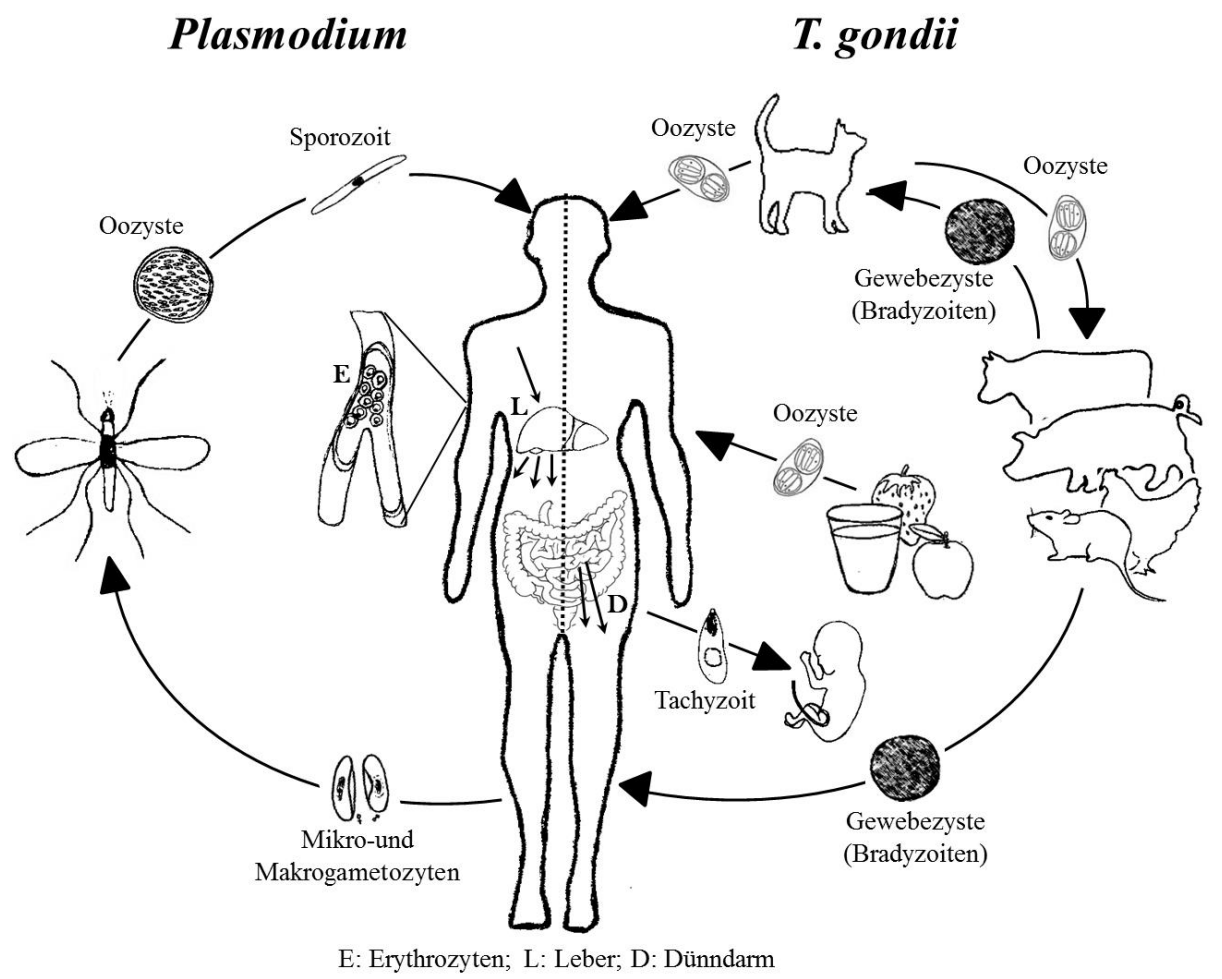

Abbildung 1.2: Lebenszyklus von Plasmodium spp. und T. gondii.

\subsubsection{Plasmodium spp.}

Die Sporozoiten von Plasmodium spp. werden mit dem Stich einer infizierten weiblichen Mücke der Gattung Anopheles übertragen (Abb. 1.2). Bereits nach kurzer Zeit in der Blutzirkulation befallen die Sporozoiten Hepatozyten und durchlaufen über mehrere Tage 
hinweg eine (asexuelle) exoerythrozytäre Schizogonie. Jeder Schizont enthält am Ende dieser Teilungsphase insgesamt 10.000 bis 30.000 Merozoiten, welche nach erfolgter Ruptur in den Blutkreislauf entlassen werden und Erythrozyten invadieren. Im Vergleich zu P. falciparum, $P$. malariae und $P$. knowlesi verfügen $P$. vivax und $P$. ovale über ein als Hypnozoit bezeichnetes Ruhestadium. Diese Leberschizonten können über lange Zeit hinweg in der Leber persistieren und noch nach Jahren $\mathrm{zu}$ einem Rückfall führen. Innerhalb der Erythrozyten entwickeln sich die Merozoiten über ein Ringstadium (junger Trophozoit) zum reifen Trophozoiten, der durch wiederholte asexuelle Teilungsvorgänge (erythrozytäre Schizogonie) einen Schizonten bildet und neue Merozoiten entlässt. Die Dauer des erythrozytären Zyklus hängt von der Art ab und variiert zwischen 24 und 72 Stunden (Daneshvar et al. 2010; Singh and Daneshvar 2013). Unbehandelt kann somit in kürzester Zeit eine hohe Parasitendichte erreicht werden. Ein Teil der Merozoiten differenziert sich im Laufe der Infektion zu Mikro- und Makrogametozyten, welche während einer Blutmahlzeit durch die Anopheles-Mücke aufgenommen werden. Im Zuge der sexuellen Vermehrung entwickelt sich im Mitteldarm ein beweglicher Ookinet, der das Mitteldarmepithel durchwandert und zu einer Oozyste heranwächst. In ihr werden tausende von Sporozoiten gebildet, die in die Epithelzellen der Speicheldrüsen eindringen und beim nächsten Stich der Mücke, mit dem Speichel, injiziert werden (Fujioka and Aikawa 2002).

\subsubsection{T. gondii}

Trotz des sehr weitreichenden Spektrums möglicher Zwischenwirte (Säugetiere und Vögel) beschränkt sich der Endwirt von T. gondii auf die Familie der Katzen (Felidae). Mit dem Kot ausgeschiedene Oozysten (bis zu 100 Millionen pro Tag) beginnen, abhängig von der Luftzufuhr und Temperatur, nach einigen Tagen zu sporulieren (Dubey et al. 1998). Die Infektion der Zwischenwirte erfolgt durch die orale Aufnahme Oozysten kontaminierter Erde, Wasser oder Nahrungsmitteln (Abb. 1.2). Im Dünndarm des Zwischenwirts dringen die nach Auflösung der Oozystenwand frei werdenden Sporozoiten in Epithelzellen ein und wandeln sich in Tachyzoiten um. Dieses schnell replizierende Stadium des Parasiten ist für die akute Phase der Infektion verantwortlich und bewirkt bereits nach 24 bis 48 Stunden eine Lyse der Wirtszelle. T. gondii ist in der Lage nahezu jede kernhaltige Zelle zu infizieren, darunter auch zirkulierende Zellen des Immunsystems. Hierdurch ist es dem Parasiten möglich endotheliale Barrieren zu überqueren und sich mit dem Blutstrom auszubreiten (Unno et al. 2008; Harker et al. 2013). Als Antwort auf zellulären Stress, wie zum Beispiel der inflammatorischen Immunantwort des Wirtes, differenzieren sich Tachyzoiten zu Bradyzoiten, welche sich nur 
noch verlangsamt replizieren können und die chronische Phase der Toxoplasmose einleiten. Gleichzeitig bildet die Membran der parasitophore Vakuole die Wand einer Gewebezyste aus, die es dem Parasiten ermöglicht zeitlebens in seinem Wirt zu persistieren. Die Zysten lassen sich in verschiedenen Wirtsorganen finden, hauptsächlich jedoch in Gehirn, Auge sowie Skelett- und Herzmuskulatur (Dubey 1988; Dubey 1997; Weiss and Kim 2000). Diese Zysten sind sowohl für den End- als auch Zwischenwirt infektiös. Menschen infizieren sich vor allem durch den Verzehr von rohem oder ungenügend gegartem Fleisch. Im Dünndarm differenzieren sich die freigewordenen Bradyzoiten $\mathrm{zu}$ Tachyzoiten und wandern in extraintestinale Organe ab (Dubey 1998b). Der sexuelle Vermehrungszyklus von T. gondii verläuft im Intestinaltrakt der Katze. Reife Oozysten gelangen dabei nach der Ruptur der Darmepithelzellen ins Darmlumen, wo sie mit dem Kot ausgeschieden werden und abhängig von den jeweiligen Umweltbedingungen für 12 bis 18 Monate überdauern können (Frenkel et al. 1975; Hill et al. 2005).

\subsubsection{Medizinische Bedeutung}

\subsubsection{Plasmodium spp.}

Als Erreger der Malaria gehören Plasmodien zu den weltweit bedeutendsten protozoischen Parasiten. Laut der Weltgesundheitsorganisation (WHO) ist Malaria in 104 Ländern endemisch, betroffen sind dabei vor allem Asien, Lateinamerika und Afrika, während aus Europa bisher nur importierte Fälle berichtet wurden. 2011 lebten damit rund 3,3 Milliarden Menschen in Malaria-Risikogebieten. Allein 2010 erkrankten schätzungsweise 219 Millionen Menschen an einer Malaria und 1,24 Millionen verstarben an den Folgen einer Infektion, die meisten davon waren Kinder unter fünf Jahren. Afrikanische Länder südlich der Sahara leiden am meisten unter der Malaria, schätzungsweise $80 \%$ aller Erkrankungen und $90 \%$ der Todesfälle werden aus diesen Ländern beschrieben, wobei Kinder unter fünf Jahren und schwangere Frauen am stärksten betroffen sind (Murray et al. 2012; WHO 2012).

$\mathrm{Zu}$ der Gattung Plasmodium wurden bisher vier humanpathogene Arten gezählt: P. malariae, $P$. vivax, $P$. ovale und $P$. falciparum. Seit einigen Jahren wird jedoch auch der ursprünglich bei Affen beschriebene Malariaerreger P. knowlesi als fünfte humanpathogene Art angesehen (White 2008; Singh and Daneshvar 2013). Die erythrozytäre Phase der Infektion ist für nahezu alle klinischen Symptome und Pathologien verantwortlich. Die Symptome einer Malaria können dabei vielfältig sein und variieren mit der Art des Erregers und dem Immunstatus der Patienten. Der Krankheitsverlauf einer Malaria tertiana ( $P$. vivax und $P$. 
ovale) und Malaria quartana ( $P$. malariae) ist nur selten letal und geht meist mit Rückfallfieber, Anämie und Splenomegalie einher (Taylor et al. 2010). Die weitaus größte medizinische Bedeutung geht jedoch von einer Malaria tropica aus ( $P$. falciparum). Eine unkomplizierte Malaria ist dabei mit grippeartigen Symptomen wie Kopf- und Gliederschmerzen, Abgeschlagenheit, Fieber und Schüttelfrost verbunden. Bei nichtimmunen Personen (Kleinkinder und Reisende), schwangeren Frauen und nicht rechtzeitig behandelten Patienten können in Folge einer schweren Malaria jedoch massive Komplikationen wie zerebrale Malaria und hochgradige Anämie auftreten (Grobusch and Kremsner 2005; Lamikanra et al. 2007; Taylor et al. 2010).

\subsubsection{T. gondii}

T. gondii ist einer der weltweit erfolgreichsten protozoischen Parasiten (McFadden et al. 2001). Schätzungen gehen davon aus, dass ein Drittel der Weltbevölkerung mit T. gondii infiziert ist (Weiss and Dubey 2009). Allerdings weichen die Annahmen über Seroprävalenzen je nach Land, innerhalb eines Landes je nach dem geographischen Gebiet und innerhalb eines Gebietes zwischen verschiedenen ethnischen Gruppen voneinander ab. Für Frauen im gebärfähigen Alter mitteleuropäischer Länder (Österreich, Belgien, Frankreich, Deutschland und Schweiz) wurden in den 1990ern Seroprävalenzen zwischen 37\% und 58\% beschrieben (Tenter et al. 2000). Molekulare Analysen konnten zeigen, dass sich die meisten Stämme von T. gondii in drei klonale Linien einteilen lassen (Typ I-, Typ-II- und Typ-IIIStämme), die sich hinsichtlich ihrer genetischen Diversität lediglich in ungefähr $2 \%$ unterscheiden (Darde 2008). Typ-I Toxoplasmen zeigen in Mäusen die höchste Virulenz (Kim and Weiss 2004), doch während Stämme aller drei Linien bereits aus Menschen isoliert wurden, gehen die meisten Toxoplasmose-Fälle auf den Genotyp-II zurück (Howe and Sibley 1995).

Die Toxoplasmose verläuft zumindest bei immunkompetenten Personen meist selbstlimitierend und asymptomatisch, kann aber dennoch mit grippeähnlichen Symptomen oder einer Lymphadenopathie einhergehen. Nur sehr selten werden schwere Komplikationen wie eine Myokarditis oder Enzephalitis beobachtet (Montoya and Liesenfeld 2004; Saadatnia and Golkar 2012). Während eine Primärinfektion auch bei schwangeren Frauen meist ohne erkennbare Symptome verläuft, ist $T$. gondii in der Lage die Plazenta zu passieren und den Fötus zu infizieren. Die Folgen einer solchen kongenitalen Toxoplasmose reichen dabei von Hydrozephalie und geistiger Behinderungen bis zum Tod des Embryos (Foulon et al. 2000; Gilbert et al. 2006). T. gondii ist ein bedeutsamer opportunistischer Parasit und kann auch bei 
immunsupprimierten Personen, wie AIDS- oder organtransplantierten Patienten, zu einer lebensbedrohlichen Erkrankung führen. Diese wird meistens auf die Reaktivierung einer chronischen Infektion zurückgeführt. Am häufigsten wird dabei eine ToxoplasmoseEnzephalitis diagnostiziert (Israelski et al. 1993; Contini 2008). Weiterhin können Neugeborene, immunsupprimierte sowie immunkompetente Personen in Folge einer Toxoplasmose schwere Augenerkrankungen zeigen (okuläre Toxoplasmose). Die Toxoplasma-Retinochorioiditis stellt dabei die bei weitem häufigste Komplikation dar und trägt weltweit deutlich zur Belastung durch Augenerkrankungen bei (Jones et al. 2006; Saadatnia and Golkar 2012).

\subsubsection{Therapie und Komplikationen}

\subsubsection{Plasmodium spp.}

Die Therapie einer Malaria richtet sich vor allem nach der Art, dem Schweregrad der Erkrankung und dem Infektionsgebiet (Resistenzlage). Aufgrund weitverbreiteter Resistenzen ist Malaria grundsätzlich in Kombination zu behandeln. Die Behandlung der Malaria tertiana, Malaria quartana und unkomplizierten Malaria tropica erfolgt mit Chloroquin oder in Chloroquin-resistenten Gebieten mit Artemether (Artemisinin-Derivat)/Lumefantrin, Atovaquon/Proguanil oder alternativ Chinin in Kombination mit Doxycyclin bzw. Clindamycin. Mefloquin sollte aufgrund möglicher neuropsychiatrischer Reaktionen das Mittel der letzten Wahl sein. Um Rezidive durch Hypnozoiten zu vermeiden, wird bei einer Malaria tertiana zudem Primaquin verabreicht. Eine schwere $P$. falciparum Malaria wird mit Chinin (in Kombination mit Doxycyclin bzw. Clindamycin) oder Artesunat therapiert (Bartlett et al. 2011; Kappagoda et al. 2011; Brodt 2012).

Eines der größten Hindernisse bei der Behandlung einer Malaria ist die besorgniserregende und mitunter rasante Resistenzentwicklung gegenüber in großem Maßstab eingesetzter Medikamente (Travassos and Laufer 2009). So galt Chloroquin seit 1946 als Medikament der ersten Wahl und wurde weltweit zur Behandlung und Prophylaxe von Malaria eingesetzt. Erste Berichte über Resistenzen traten jedoch bereits 1961 auf und mit Beginn der 1980er Jahre konnte Chloroquin, durch die stetige Zunahme erfolgloser Behandlungen, in vielen Teilen Südostasiens und Südamerikas nicht mehr eingesetzt werden. Zeitgleich wurden die ersten bedrohlichen Resistenzfälle aus Ostafrika beschrieben, die sich im Laufe der Jahre bis nach Westafrika ausgebreitet hatten (White 1992). Die Unwirksamkeit von Chloroquin ging mit teilweise fatalen Folgen einher. So führte die zunehmende Verbreitung der Chloroquin- 
Resistenz in Afrika zu einem drastischen Anstieg der Krankheitslast bei Kindern, welche sich auch in einer deutlich erhöhten Mortalitätsrate darstellte (Zucker et al. 2003). Mit der Verbreitung der Chloroquin-Resistenz führten ab 1993 immer mehr Länder eine Primärtherapie aus Sulfadoxin und Pyrimethamin (SP) ein, jedoch wurde dabei eine außergewöhnlich schnelle Ausbreitung erster Resistenzfälle beobachtet, wodurch die Wirksamkeit von SP in Südostasien und Südamerika bereits nach fünf Jahren deutlich eingeschränkt war (Sibley et al. 2001). Doch auch gegenüber aktuell eingesetzter Therapeutika wie Artesunat und Mefloquin wurden bereits erste Resistenzfälle nachgewiesen (Noedl et al. 2008; Wongsrichanalai and Meshnick 2008; Dondorp et al. 2009; Phyo et al. 2012). Weiterhin ist Atovaquon zwar ein sehr effektives Antimalaria-Medikament, dennoch kommt es unter einer Monotherapie sehr schnell zu einer Resistenzentwicklung (Mather et al. 2007). Alternative Behandlungsmöglichkeiten sind demnach von essenzieller Bedeutung, jedoch ist die Anzahl wirksamer Medikamente limitiert.

\subsubsection{T. gondii}

Eine akute Toxoplasmose erfordert bei immunkompetenten Personen in der Regel keine Therapie. Sollte aufgrund schwerwiegender oder persistierender Symptome eine Behandlung zwingend notwendig sein, wird eine Kombinationstherapie aus Pyrimethamin und Sulfadiazin (Gruppe der Sulfonamide) angeraten. Da ihre synergistische Wirkungsweise auf einer Hemmung der Folsäuresynthese des Parasiten basiert, werden beide Medikamente (zur Verminderung einer toxischen Wirkung) zusammen mit Folinsäure verabreicht (Montoya and Liesenfeld 2004). Schwangere Frauen dürfen aufgrund der potentiellen teratogenen Wirkung erst ab der 16. Schwangerschaftswoche mit Pyrimethamin und Sulfonamiden behandelt werden. Um eine diaplazentare Infektion (kongenitale Toxoplasmose) zu verhindern, wird eine während der Schwangerschaft erworbene Primärinfektion daher mit Spiramycin therapiert. Zur Behandlung immunsupprimierter Patienten oder im Falle einer reaktivierten Toxoplasmose sowie Chorioretinitis wird gleichermaßen eine Therapie aus Pyrimethamin und Sulfonamid vorgeschlagen. Alternativ kann Pyrimethamin auch mit Clindamycin oder Atovaquon kombiniert werden (Kappagoda et al. 2011; Brodt 2012). Im Vergleich zu Tachyzoiten, bleiben Gewebezysten (Bradyzoiten) von nahezu allen derzeitigen medikamentösen Behandlungen jedoch unbeeinflusst (Suzuki et al. 2010).

Während Medikament-Resistenzen bei der Therapie einer bestehen Toxoplasmose des Menschen bisher noch nicht beschrieben wurden (McFadden et al. 2001), führen vor allem Unverträglichkeiten und Reaktivierungen einer bestehenden Infektion häufig zum 


\section{Einleitung}

Behandlungsversagen. So sprechen $10 \%$ der AIDS-Patienten mit einer ToxoplasmoseEnzephalitis nicht auf eine Therapie an und 10\% bis $20 \%$ der behandelten Patienten erleiden während einer Langzeit-Therapie mit Sulfadoxin und Pyrimethamin einen Rückfall (Aspinall et al. 2002). Weiterhin ist die Behandlung einer bestehenden Enzephalitis oder okulären Toxoplasmose, vor allem bei AIDS-Patienten, häufig durch unerwünschte Nebenwirkungen limitiert. Berichte über Toxizitätsraten bei Behandlungen mit Sulfadiazin, Pyrimethamin und Clindamycin (in Kombinationstherapie) variieren dabei zwischen 38\% und 70\% (Leport et al. 1988; Porter and Sande 1992; Rothova et al. 1993). Mitunter wird bei besonders schweren Verlaufsformen ein vollständiger Behandlungsabbruch notwendig, wobei Raten von bis zu 45\% beschrieben wurden (Haverkos 1987; Renold et al. 1992).

\subsection{Mitochondrien als „Drug Targets“ der Apicomplexa}

Um eine fortbestehende, effektive und gut-verträgliche Therapie sowohl der Toxoplasmose als auch Malaria zu gewährleisten ist es daher entscheidend, neue antiparasitäre Wirkstoffe zu identifizieren. Vor allem in der Anfangsphase solcher Wirkstoffscreenings hat sich dabei $T$. gondii (nicht zuletzt durch die einfache in vitro Kultivierbarkeit) als gutes Modellsystem der Apicomplexa herausgestellt. Obwohl T. gondii und Plasmodium spp. als Vertreter der Apicomplexa eukaryotischen Ursprungs sind, unterscheiden sie sich vor allem durch strukturelle und metabolische Unterschiede von ihrem humanen Wirt und bieten damit potentielle therapeutische Angriffsziele. So konnte beispielsweise in Zellkulturen gezeigt werden, dass eine Behandlung mit dem bakteriellen DNA-Gyrase Inhibitor Ciprofloxacin, die DNA-Replikation des Apicoplasten, nicht jedoch des Nucleus blockiert wird, was sich letal auf den Parasiten auswirkt (Fichera and Roos 1997; Weissig et al. 1997; Ralph et al. 2001; Goodman et al. 2007).

Mitochondrien nehmen durch ihre Funktionen in der Biosynthese, Bioenergetik und dem Stoffwechsel nicht nur bei Vertretern der Apicomplexa eine zentrale Bedeutung ein. Ihre Relevanz wird unter anderem dadurch unterstrichen, dass bisher kein eukaryotischer Vertreter identifiziert wurde, der sich durch das vollständige Fehlen eines Mitochondriums oder eines abgeleiteten Organells auszeichnet (Dyall and Johnson 2000; Shiflett and Johnson 2010). Vertreter der Apicomplexa besitzen das kleinste bisher bekannte mitochondriale Genom (Wilson and Williamson 1997; Mather et al. 2007). Kryptosporidien haben dabei ihr eigenes mitochondriales Genom sogar vollständig verloren (Abrahamsen et al. 2004) und besitzen nur noch ein als Mitosom bezeichnetes Organell mitochondrialen Ursprungs. Der fortbestehende Erhalt dieser reduzierten Organellen verdeutlicht dennoch ihre bedeutende Rolle in der 
Zellphysiologie der Apicomplexa (Mather et al. 2007). Die Mitochondrien von T. gondii und Plasmodium werden daher als vielversprechendes therapeutisches Target angesehen, vor allem weil sich die innere Struktur deutlich von den Mitochondrien der Säugetierzelle unterscheidet (Mather et al. 2007; Mather and Vaidya 2008). So konnte beispielsweise gezeigt werden, dass das aktuell zur Behandlung der Malaria eingesetzte Artemisinin selektiv mit dem Mitochondrium von Plasmodium interagiert. Der Wirkmechanismus von Artemisinin besteht darin, hohe Konzentrationen an ROS (reaktive Sauerstoffspezies) freizusetzen, welche die Funktion der Mitochondrien dramatisch beeinträchtigen. Im Gegensatz dazu wurden Mitochondrien von Säugetieren durch eine Behandlung mit Artemisinin nicht beeinflusst, was auf mögliche strukturelle Unterschiede in der mitochondrialen Elektronentransportkette (ETC) der Organismen zurückgeführt wurde (Wang et al. 2010).

\subsubsection{Bedeutung der mitochondrialen Elektronentransportkette (ETC)}

Tatsächlich spielt die ETC der Apicomplexa bei der Identifizierung antiparasitärer Targets eine besondere Rolle, denn diese besitzt abhängig von der jeweiligen Spezies vielfältige, aber vor allem essentielle Funktionen. Die in der inneren Mitochondrienmembran lokalisierte ETC höherer Eukaryoten besteht für gewöhnlich aus vier integralen Enzymkomplexen: der NADH Dehydrogenase (Komplex I), Succinat Dehydrogenase (SDH, Komplex II), dem Cytochrombc $_{1}$-Komplex (Komplex III) und der Cytochrom-c-Oxidase (Komplex IV). Komplex IV katalysiert dabei den finalen Schritt der ETC und überträgt die in die ETC eingeschleusten Elektronen auf molekularen Sauerstoff. Ubiquinon (Coenzym Q) und Cytochrom c wirken dabei als mobile Elektronentransporter und übertragen die Elektronen zwischen Komplex I und III bzw. III und IV. Die ETC von T. gondii und Plasmodium ist funktionell und in beiden Spezies kommt neben den Elektronentransportern, Komplex II bis IV vor (Abb. 1.3). Genomanalysen des Malariaerregers weisen dennoch darauf hin, dass die strukturelle Zusammensetzung der Komplex-Untereinheiten im Vergleich zu höheren Eukaryoten viel einfacher aufgebaut ist (Vaidya and Mather 2009). Einer der auffälligsten Unterschiede, welcher das einzelne Mitochondrium beider Parasiten von den Mitochondrien der Wirtszelle unterscheidet, ist das Fehlen des konventionellen Rotenon-sensitiven Multienzym-Komplex I. Doch werden die aus der Oxidation von NADH gewonnenen Elektronen durch eine alternative, nicht-protonenpumpende NADH Dehydrogenase (NDH2) auf Ubiquinon übertragen (Gardner et al. 2002; Biagini et al. 2006). Diese liegt im Falle von T. gondii in zwei Isoformen vor (Saleh et al. 2007). Neben SDH und NDH2 existieren stromaufwärts des Cytochrom- $\mathrm{bc}_{1}-$ Komplex drei weitere mitochondriale Dehydrogenasen, welche nachweislich 
Elektronen auf Ubiquinon übertragen: die Malat:Quinon Oxidoreduktase (MQO) Glycerin-3Phosphat Dehydrogenase (G3PDH) und Dihydroorotat Dehydrogenase (DHODH).

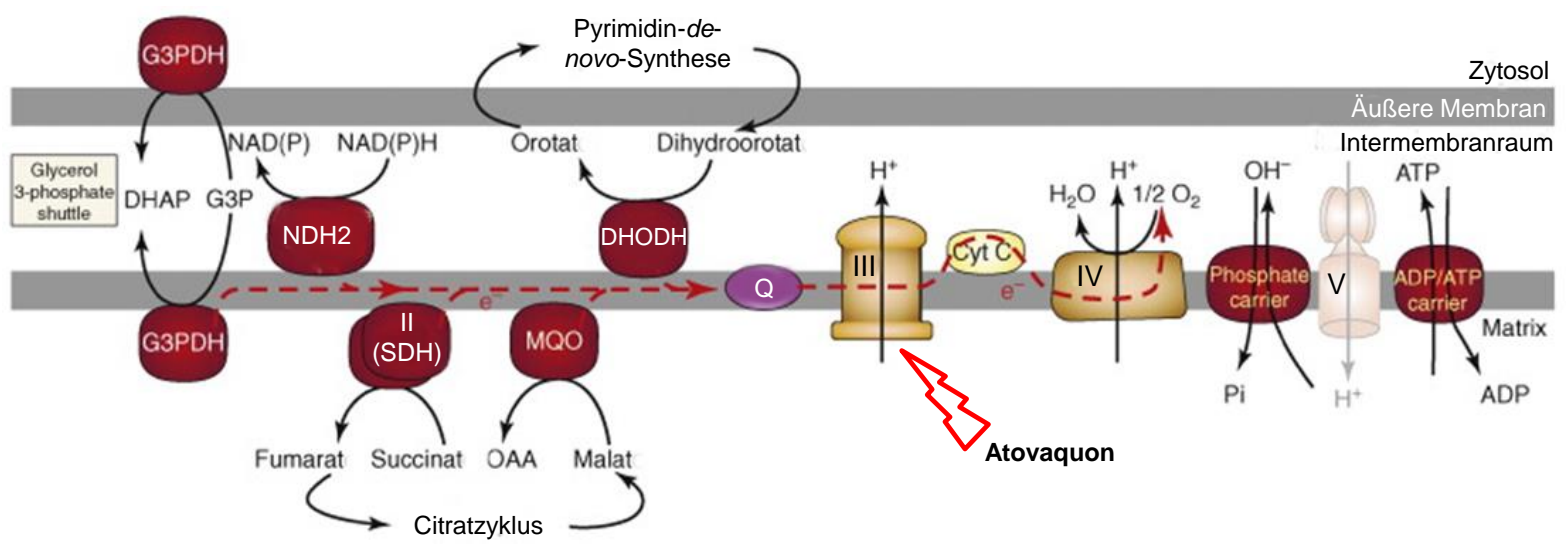

Abbildung 1.3: Modell der mitochondrialen Elektronentransportkette von $T$. gondii und Plasmodium (nach Seeber et. al, 2008). Elektronen gelangen über die alternative NADH Dehydrogenase (NDH2), SuccinatDehydrogenase (SDH), Malat:Quinon Oxidoreduktase (MQO), Glycerin-3-Phosphat Dehydrogenase (G3PDH) und Dihydroorotat Dehydrogenase (DHODH) zu Ubiquinon (Q), welches die Elektronen auf den Cytochrombc $_{1}$-Komplex (Komplex III; wird durch Atovaquon effektiv inhibiert) überträgt. Cytochrom c transportiert die Elektronen anschließend zur Cytochrom-c-Oxidase (Komplex VI), wo sie molekularen Sauerstoff zu Wasser $\left(\mathrm{H}_{2} \mathrm{O}\right)$ reduzieren. Komplex III und IV nutzen die Energie aus dem Elektronentransport, um Protonen in den Intermembranraum zu pumpen, wodurch entlang der inneren mitochondrialen Membran ein elektrochemischer Gradient entsteht. Die ATP-Synthase (Komplex V) koppelt den dadurch angetriebenen (kontrollierten) Rückstrom der Protonen in die Matrix mit der Synthese von ATP. Das aktive Zentrum der NDH2 von T. gondii (zwei Isoformen) befindet sich nicht, wie dargestellt, auf der zytosolischen Seite, sondern der Matrixseite der Mitochondrien und oxidiert somit mitochondriales NADH (Lin et al. 2008). Abbildung verändert nach Seeber et al. (2008).

Dass es sich bei der ETC der Apicomplexa um ein äußerst wirksames Angriffsziel handelt, wurde nicht zuletzt auch dadurch gezeigt, dass sowohl Toxoplasmose als auch Malaria erfolgreich durch Atovaquon behandelt werden können (Abb. 1.3). Atovaquon ähnelt in seiner Struktur Ubiquinon und inhibiert durch Bindung an die Ubiquinol-Oxidationsseite $\left(\mathrm{Q}_{\mathrm{o}}\right)$

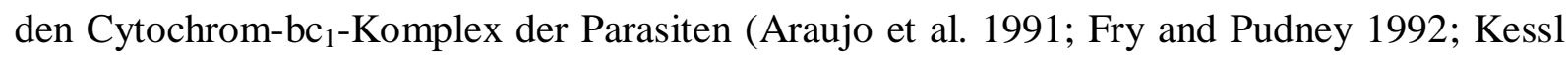
et al. 2003). In Folge der ETC-Hemmung kommt es innerhalb von Minuten zu einem Zusammenbruch des mitochondrialen Membranpotentials $\left(\Delta \Psi_{\mathrm{m}}\right)$, was letal für den Parasiten ist, während Atovaquon keinen Effekt auf das Membranpotential der Säugetierzelle ausübt (Srivastava et al. 1997). Die Tatsache, dass der Cytochrom-bc $c_{1}-$ Komplex von Plasmodium mit einer rund 1.000-fach niedrigeren Konzentration inhibiert wird als der Säugetierkomplex (Fry and Pudney 1992) lässt sich sehr wahrscheinlich auf strukturelle Variationen zwischen den Organismen zurückführen. Denn anhand vergleichender Sequenzanalysen der Cytochrom b 
(Cyt b) Untereinheit konnten Unterschiede in der Quinon-Bindungsseite des humanen Proteins nachgewiesen werden, die möglicherweise die spezifische Toxizität und die erhöhte Affinität von Cyt b gegenüber Atovaquon erklären (Vaidya et al. 1993).

Aufgrund struktureller Unterschiede würde sich auch Komplex IV als weiteres mögliches Target anbieten, dennoch wurde bisher noch kein Wirkstoff dieses Enzymkomplexes beschrieben, möglicherweise da Säugetiere höchst sensitiv auf eine Hemmung dieses Komplexes reagieren (Mather et al. 2007). Des Weiteren konnte MQO zwar bereits bei einigen Bakterienarten identifiziert werden, mit Ausnahme der Apicomplexa ist das Enzym jedoch bei Eukaryoten nicht bekannt. Interessanterweise hat Theileria zwar die MalatDehydrogenase verloren MQO dennoch erhalten, was darauf hindeutet, dass dieses Enzym möglicherweise ein essentielles Enzym der Gattung darstellt (Mather et al. 2007).

\subsubsection{Oxidative Phosphorylierung}

Einer der interessantesten Prozesse innerhalb der ETC ist die zentrale Rolle der oxidativen Phosphorylierung im katabolen Stoffwechsel der Zelle. Mitochondrien werden in diesem Zusammenhang oft als "Energiekraftwerke" bezeichnet, denn die meisten Eukaryoten sind nicht nur in der Lage ATP durch die Glykolyse zu generieren, sondern synthetisieren den Großteil ihres ATP-Gehalts durch die oxidative Phosphorylierung. Dabei werden die im Citratzyklus, in Form von NADH und $\mathrm{FADH}_{2}$ gewonnenen Elektronen verwendet, um einen elektrochemischen Protonengradienten entlang der inneren mitochondrialen Membran aufzubauen. Dieser Gradient treibt die Generierung von ATP durch die ATP-Synthase (Komplex V) an (Abb. 1.3). Zusätzlich schleusen DHODH und G3PDH Elektronen reduzierter Komponenten des Zytosols sowie SDH und MQO Elektronen von Zwischenprodukten des Citratzyklus, über Ubiquinon, in die ETC der Apicomplexa ein (Seeber et al. 2008).

Entsprechend der Anpassung an das intrazelluläre Wirtshabitat konnten genomische Analysen der Apicomplexa auffallende metabolische Unterschiede, vor allem hinsichtlich der mitochondrialen Funktion, aufdecken. So befällt Cryptosporidium vorrangig Enterozyten und hat, vermutlich durch die anaeroben Bedingungen im Verdauungstrakt des Wirtes, die Funktion der ATP Synthese vollständig verloren (Xu et al. 2004; Seeber et al. 2008). Obwohl das einzelne Mitochondrium für beide Vertreter essentiell ist, unterscheiden sich Toxoplasmen und Plasmodien dennoch hinsichtlich der Bedeutung der oxidativen Phosphorylierung deutlich voneinander. So finden intraerythrozytäre Merozoiten von Plasmodium ein Milieu, das reich an Glucose ist. Hinsichtlich der Energieversorgung des 
Parasiten wurde die oxidative Phosphorylierung daher vermutlich entbehrlich. Obwohl zumindest für $P$. yoelii eine funktionelle ETC und oxidative Phosphorylierung nachgewiesen wurde (Uyemura et al. 2004), zeichnet sich das erythrozytäre Stadium von Plasmodium in erster Linie durch eine glykolytische Energiegewinnung aus (Jacobasch et al. 1990; Gardner et al. 2002; Biagini et al. 2006). Übereinstimmend konnte gezeigt werden, dass der ATPGehalt von P. falciparum minimal oder gar nicht durch mitochondriale Inhibitoren wie Oligomycin beeinflusst wird, während der ATP-Spiegel durch eine Behandlung mit Inhibitoren des Glukosetransporters deutlich reduziert wird (Fry et al. 1990). Zudem wandelt der Parasit nahezu die gesamte Glucose in Laktat um (Sherman 1979) und mit $P$. falciparum infizierte Erythrozyten zeigen im Gegensatz zu nicht infizierten Zellen eine erhöhte Aktivität glykolytischer Enzyme sowie der Laktat Dehydrogenase (Roth et al. 1988). Im Gegensatz zu Plasmodien proliferieren sich Tachyzoiten von $T$. gondii in nahezu jeder kernhaltigen Zelle (Saliba and Kirk 2001) und sehen sich hinsichtlich einer ausreichenden Versorgung mit Kohlenstoffen und anderer essentieller Nährstoffe daher jeweils unterschiedlichen Bedingungen gegenübergestellt. Sie verfügen wie Plasmodium über alle Enzyme der Glykolyse und des Citratzyklus (Fleige et al. 2007; Fleige et al. 2008). Die Mehrheit der für die Motilität extrazellulärer Parasiten benötigten Energie wird aus der glykolytischen Aktivität gewonnen (Pomel et al. 2008; Lin et al. 2009; Lin et al. 2011b). Dennoch verfügt der Parasit über eine funktionelle oxidative Phosphorylierung (Vercesi et al. 1998) und die weitläufige Meinung, dass Toxoplasmen ebenso wie Plasmodien ihre Energie hauptsächlich aus Glykolyse beziehen (Denton et al. 1996) konnte eindeutig wiederlegt werden. Denn eine Behandlung intrazellulärer Tachyzoiten mit Oligomycin führt $\mathrm{zu}$ einer Reduktion des intrazellulären ATP-Gehalts von etwa 70\%, weshalb der Parasit zum Erhalt der ATPHomöostase an eine oxidative Phosphorylierung gebunden ist (Lin 2009). Die Herkunft von Acetyl-CoA ist bis heute noch ungeklärt. Die einzig bisher bekannte Pyruvatdehydrogenase, welche durch eine oxidative Decarboxylierung von Pyruvat, Glykolyse und Citratzyklus normalerweise miteinander verbindet, lokalisiert nicht wie üblich in den Mitochondrien, sondern im Apicoplasten der Parasiten (Foth et al. 2005; Fleige et al. 2007). Dennoch konnte zumindest für T. gondii gezeigt werden, dass Glucose und Glutamin durch den Citratzyklus verstoffwechselt werden (MacRae et al. 2012).

\subsubsection{Pyrimidin-de-novo-Synthese}

Trotz des vorrangig glykolytischen Energiemetabolismus reagieren Plasmodien äußerst sensitiv auf eine Behandlung mit Inhibitoren der ETC (Mather and Vaidya 2008), weshalb 
auch die ETC des Malariaerregers als vielversprechendes Angriffsziel angesehen wird (Mather et al. 2007; Mather and Vaidya 2008). Neben dem energetischen Aspekt besitzt die Atmungskette eukaryotischer Zellen noch eine weitere wichtige Funktion, denn Ubiquinon fungiert als Elektronenakzeptor der membranständigen Dihydroorotat Dehydrogenase (DHODH). Pyrimidine nehmen neben ihrer Bedeutung in der Biosynthese von Glykoproteinen und Phospholipiden, als Grundbausteine der DNA und RNA eine überlebenswichtige Rolle in der Zellfunktion ein (Bader et al. 1998). Toxoplasmen und Plasmodien besitzen alle sechs Enzyme der Pyrimidin-de-novo-Synthese, die benötigt werden um Uridin-5'-Monophosphat (UMP) zu synthetisieren, dem Vorläufermolekül der RNA(UTP, CTP) und DNA-Nukleotide (dTTP, dCTP) (Hill et al. 1981; Asai et al. 1983). Die Synthese beginnt mit dem Aufbau von Carbamoylphosphat aus L-Glutamin, ATP und Hydrogencarbonat durch die Carbamoylphosphat Synthetase II (CPS II). Carbamoylphosphat und L-Aspartat werden anschließend durch die Aspartat Transcarbamoylase (ATC) zu Carbamoylaspartat umgewandelt, aus welchem durch Abspaltung von Wasser durch die Dihydroorotase (DHOase) Dihydroorotat entsteht. DHODH katalysiert im vierten Schritt die Oxidation von Dihydroorotat zu Orotat. Aufgrund der Reduktion von Ubiquinon bildet DHODH ein funktionelles Bindeglied zwischen der Pyrimidin-de-novo-Synthese und der ETC (Abb. 1.4). In den beiden finalen Schritten erfolgt durch die Orotat Phosphoribosyltransferase (OPRT) eine Übertragung von Phosphoribosylpyrophosphat (PRPP) auf Orotat. Die Decarboxylierung des daraus synthetisierten Orotidin-5 ‘Monophosphat (OMP) erfolgt durch die Orotidin-5'-Monophosphat-Decarboxylase (OMPDC), wodurch letztlich UMP gebildet wird. Im Gegensatz zu Plasmodium besitzt $T$. gondii weiterhin die Möglichkeit UMP über einen Pyrimidin Salvage Pathway zu generieren (Iltzsch 1993; Ajioka and Soldati 2007). Zwar können dabei keine Nukleotide direkt aus der Wirtszelle gewonnen werden, jedoch ist der Parasit in der Lage die Nukleobase Uracil sowie die Nukleoside Cytidin, Desoxycytidin, Uridin und Desoxyuridin aufzunehmen und zu verwerten. Lediglich Uracil wird dabei unmittelbar durch die Uracil Phosphoribosyltransferase (UPRT) in UMP umgewandelt (Abb. 1.4). Dem Genom von Plasmodium fehlen jedoch wichtige Komponenten des Salvage Pathways (Patel et al. 2008), weshalb der Parasit zum Überleben auf eine de-novo-Biosynthese und damit auf die Aktivität von DHODH angewiesen ist (Hyde 2007; Davies et al. 2009; Phillips and Rathod 2010; Rodrigues et al. 2010). 


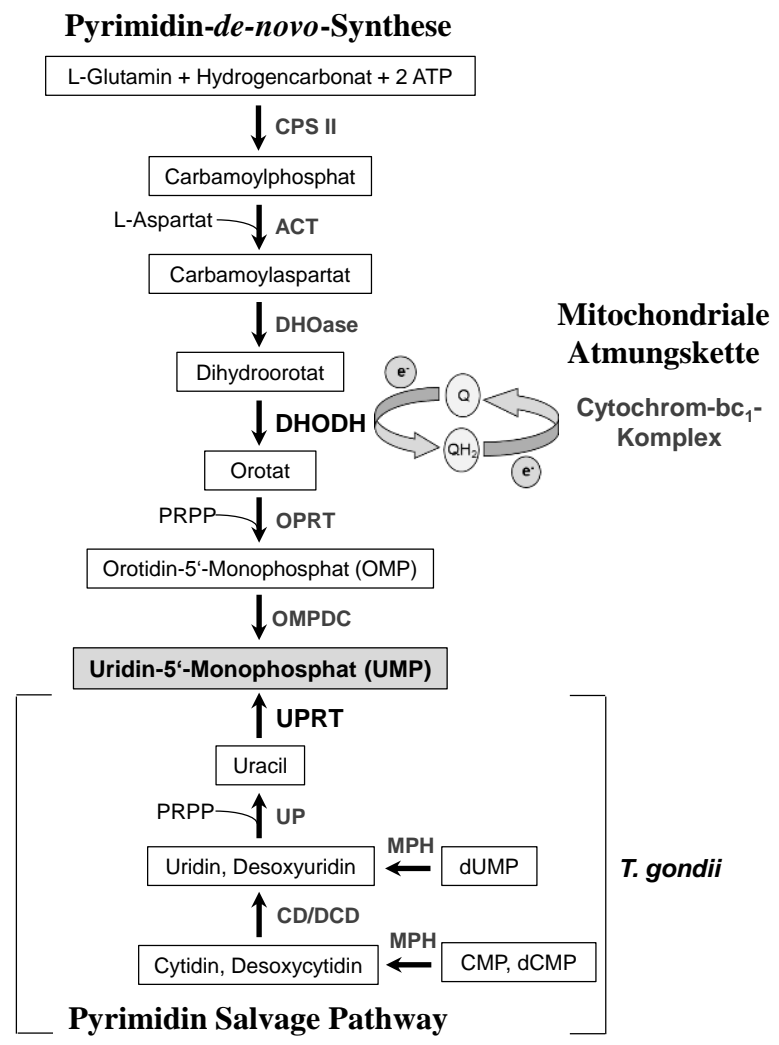

Abbildung 1.4: Modell der Pyrimidin-de-novo-Synthese von T. gondii und Plasmodium sowie des Salvage Pathway von T. gondii. Sowohl der de-novo-Syntheseweg als auch der Salvage Pathway resultieren in der Bildung von Uridin-5'-Monophosphat (UMP), aus dem alle weiteren Pyrimidinnukleotide synthetisiert werden können. DHODH stellt durch Reduktion von Ubiquinon ein Bindeglied zwischen der Pyrimidin-de-novoSynthese und der ETC dar. Innerhalb des Salvage Pathways von T. gondii wird lediglich Uracil unmittelbar durch die Uracil Phosphoribosyltransferase (UPRT) in UMP umgewandelt. Cytidin und Desoxycytidin müssen zunächst durch die Cytidin/Desoxycytidin Deaminase (CD/DCD) in Uridin/Desoxyuridin und anschließend durch die Uridin Phosphorylase (UP) in Uracil umgewandelt werden. Des Weiteren können die Nukleotide dUMP, dCMP und CMP, welche während der Degradierung parasitären Nukleinsäuren entstehen, durch die Nucleosid 5'-Monophosphat Phosphohydrolase (MPH) zurückgewonnen werden (Iltzsch 1993; Ajioka and Soldati 2007). CPS II, Carbamoylphosphat Synthetase II; ATC, Aspartat Transcarbamoylase; DHOase, Dihydroorotase; DHODH, Dihydroorotat Dehydrogenase; OPRT, Orotat Phosphoribosyltransferase; PRPP, Phosphoribosylpyrophosphat; OMPDC, Orotidin-5'-Monophosphat-Decarboxylase; UPRT, Uracil Phosphoribosyltransferase. Abbildung verändert nach Fox und Bzik (2010).

Tatsächlich konnte für $P$. falciparum gezeigt werden, dass die wachstumsinhibierende Wirkung von Atovaquon auf einem Verlust der Regeneration von Ubiquinon als Elektronenakzeptor basiert. Denn eine Exprimierung der zytosolischen DHODH von Saccharomyces cerevisiae (ScDHODH) geht mit einer Resistenz der transgenen Parasiten gegenüber Inhibitoren des Cytochrom-bc $c_{1}$-Komplexes einher. Die ScDHODH ist Ubiquinon unabhängig, da sie im Gegensatz zur DHODH der Apicomplexa Fumarat als 
Elektronenakzeptor verwendet. Mit der Möglichkeit Pyrimidine unabhängig von Ubiquinon zu generieren, wird die ETC für den Parasiten daher entbehrlich (Painter et al. 2007). Baldwin et al. (2005) konnten weiterhin einen kompetitiven Inhibitor von Ubiquinon identifizieren, welcher im Vergleich zur humanen DHODH eine 12.500-fach gesteigerte Aktivität gegenüber DHODH von $P$. falciparum (PfDHODH) besitzt. Darüber hinaus wurden aktuell zwei Triazolopyrimidin-Derivate (Compound 37 und 38) beschrieben, welche PfDHODH und DHODH von $P$. vivax mit nanomolaren Konzentrationen hemmen, im in-vivo Mausmodell hohe Wirksamkeit nachweisen und in vitro, inhibitorische Aktivität selbst gegenüber Chloroquin-, Pyrimethamin- und Atovaquon-resistenter Stämme besitzen (Coteron et al. 2011).

Obwohl der de-novo-Syntheseweg für T. gondii in vitro nicht essentiell ist (Fox and Bzik 2002), konnte das Tgdhodh Gen, selbst unter Anwesenheit von Uracil nicht deletiert werden und scheint demnach aus bisher noch ungeklärten Gründen auch für T. gondii unerlässlich zu sein (Hortua Triana et al. 2012).

\subsection{1-Hydroxyquinolone}

Die Identifizierung von Wirkstoffzielen, die einzigartige biologische Aspekte des Parasiten erfassen, stellen in der Entwicklung neuer Therapeutika einen wesentlichen Schritt dar (Baldwin et al. 2002). Die Tatsache, dass sich die alternative NADH Dehydrogenase (NDH2) bei Pflanzen, Pilzen und vielen Bakterien finden lässt, in den Mitochondrien von Säugetieren jedoch nicht identifiziert wurde (Kerscher 2000), macht sie zu einer vielversprechenden Zielstruktur. Auf der Suche nach neuen Wirkstoffen wurde 2004, durch biochemische Analysen, ein neuer Inhibitor der NDH2 von Yarrowia lipolytica beschrieben. 1-Hydroxy-2Dodecyl-4(1)quinolon (HDQ, Abb. 1.5) hemmt die NDH2 mit einer $\mathrm{IC}_{50}$ von $200 \mathrm{nM}$ und kann damit als hoch-affiner Inhibitor dieses Enzyms angesehen werden (Eschemann et al. 2005). Da auch die Atmungskette von T. gondii und Plasmodium statt einer konventionellen, eine alternative NADH Dehydrogenase besitzt, schien HDQ ebenso als potentieller Inhibitor der Apicomplexa geeignet zu sein. Tatsächlich konnte anhand von in vitro Wachstumsassays gezeigt werden, dass HDQ die Replikationsfähigeit von $P$. falciparum und $T$. gondii höchst effektiv im nanomolaren Bereich hemmt, während keine nachteiligen Auswirkungen auf die humanen Wirtszellen beobachtet werden konnten (Saleh et al. 2007). Zudem wurde durch frühere Studien der Arbeitsgruppe gezeigt, dass eine Behandlung der Toxoplasmen mit HDQ zu einer Depolarisierung des inneren mitochondrialen Membranpotentials $\left(\Delta \Psi_{\mathrm{m}}\right)$ führt und es anschließend zu einer Reduktion der parasitären ATP-Menge von rund 70\% kommt (Lin et al. 
2009). Hinsichtlich der inhibitorischen Aktivität scheint ein wichtiger struktureller Aspekt von HDQ die Länge der an Position zwei lokalisierten Alkyl-Seitenkette zu sein. Während Derivate mit einer Länge von C6, C8, C12 (HDQ) und C14 eine starke antiparasitäre Wirkung besitzen, zeigt ein Derivat mit einer C5-Seitenkette keine wachstumsinhibierende Wirkung gegenüber T. gondii (Saleh et al. 2007). Durch neu-synthetisierte Derivate von HDQ (darunter auch Compound B) konnte weiterhin nachgewiesen werden, dass ein Wechsel der DodecylSeitenkette von Position C2 auf Position C3 die antiparasitäre Aktivität von HDQ nicht beeinflusst. Zudem verstärkt eine zusätzliche Methylgruppe den inhibitorischen Effekt, denn Compound B hemmt das Wachstum von T. gondii im niedrig nanomolaren Bereich $\left(\mathrm{IC}_{50}=\right.$ 0,8 nM). Durch eine Untersuchung der in vivo Effizienz von HDQ und Compound B in einem akuten Toxoplasmose-Mausmodell wurde zudem nachgewiesen, dass beide Wirkstoffe den prozentualen Anteil infizierter Peritonealzellen vermindern und die Parasitenlast der Lunge und Leber reduzieren. Ein Mausmodell der Toxoplasmose-Enzephalitis ergab weiterhin eine tendenzielle Dezimierung der Parasitenmenge des Gehirns (Bajohr et al. 2010). Die strukturelle Ähnlichkeit von HDQ, Compound B und Ubiquinon (Abb. 1.5) lässt eine Inhibierung Ubiquinon/Ubiquinol-interagierender Enzyme der ETC als Wirkmechanismus vermuten. Tatsächlich konnte durch Inhibitionskinetiken bereits nachgewiesen werden, dass HDQ die Aktivität der ersten Isoform der NDH2 von T. gondii (TgNDH2-I) nachweislich hemmt und TgNDH2-I damit eine Zielstruktur von HDQ darstellt (Lin et al. 2008). Jedoch zeigen $n d h 2-I$ Knock-Out Mutanten nur eine geringfügig reduzierte Wachstumsrate (Lin et al. 2011), sodass davon auszugehen ist, dass neben $n d h 2-I$ noch weitere Zielmoleküle existieren, deren Hemmung maßgeblich für die wachstumsinhibierende Wirkung der 1-Hydroxyquiolone verantwortlich ist.

Ubiquinon<smiles>CCCCC(C)(C)C1=C(C)C(=O)C(O)=C(O)C1=O</smiles>

HDQ<smiles>CNc1cc(=O)c2ccccc2n1O</smiles>

Compound B<smiles>CN=Cc1c(C)n(O)c2ccccc2c1=O</smiles>

Abbildung 1.5: Struktur von Ubiquinon, HDQ und Compound B. 


\subsection{Zielsetzung}

Trotz intensiver Forschungsbemühungen stellt die medikamentöse Bekämpfung von Toxoplasma gondii und Plasmodium vor allem durch rasche Resistenzentwicklungen und Unverträglichkeiten immer noch eine Herausforderung dar. Die Identifizierung neuer antiparasitärer Wirkstoffe sowie die Charakterisierung der entsprechenden Wirkmechanismen sind demnach von essenzieller Bedeutung. Kürzlich wurden 1-Hydroxyquinolone wie 1-Hydroxy-2-Dodecyl-4(1)quinolon (HDQ) und Compound B beschrieben, die sowohl die Replikation von $T$. gondii als auch die Replikation von $P$. falciparum in nanomolaren Konzentrationen effektiv hemmen. Eine erste Analyse des Wirkmechanismus zeigte, dass 1-Hydroxyquinolone als spezifische Inhibitoren der mitochondrialen Atmungskette von $T$. gondii wirken. HDQ und Compound B weisen strukturelle Ähnlichkeit zu Ubiquinon auf und mit der Suche nach Zielstrukturen konnte durch Inhibitionskinetiken bereits eine Aktivitätshemmung der ersten Isoform der alternativen NADH Dehydrogenase von $T$. gondii (TgNDH2-I) nachgewiesen werden. Jedoch zeigten ndh2-I Knock-Out Mutanten nur eine geringfügig reduzierte Wachstumsrate, sodass davon auszugehen ist, dass zusätzliche Target(s) existieren, deren Hemmung entscheidend zu der wachstumsinhibierenden Wirkung der 1-Hydroxyquinolone beiträgt. Im Rahmen dieser Arbeit sollten daher mit Hilfe von Resistenzmutanten neue Zielstrukturen von 1-Hydroxyquinolonen identifiziert werden. Neben einer anfänglichen, phänotypischen Charakterisierung der Mutanten, sollten quantitative RT-PCR Analysen der sechs Ubiquinon-reduzierenden Dehydrogenasen von T. gondii zunächst Aufschluss über mögliche Veränderungen im Expressionsmuster dieser Enzyme geben. Ein wichtiger Aspekt dieser Arbeit war es weiterhin, die Gene der mitochondrialen Dehydrogenasen zu amplifizieren und durch DNA-Sequenzierungen auf Abweichungen in der kodierenden Sequenz zu untersuchen. Identifizierte Mutationen sollten durch Transfektionsversuche in HDQ-sensitive Parasiten eingebracht und auf ihr resistenzvermittelndes Potential hin untersucht werden.

Frühere Studien der Arbeitsgruppe konnten weiterhin zeigen, dass eine Behandlung von $T$. gondii mit HDQ zu einer Inhibition der oxidativen Phosphorylierung und dadurch zu einem drastischen Verlust des parasitären ATP-Gehalts führt. Dennoch besitzen 1-Hydroxyquinolone nur eine parasitostatische Wirkung, denn die Parasiten zeigen im späteren Verlauf der Behandlung eine Regeneration des Wachstums. Im Hinblick auf die Inhibierung der Parasitenreplikation sowie der Resistenzausprägung gegenüber 1-Hydroxyquinolonen war ein weiteres Ziel dieser Arbeit, den Aspekt einer metabolischen 


\section{Einleitung}

Adaptation der Parasiten näher zu untersuchen. In diesem Zusammenhang sollte vor allem der Einfluss eines Glucosemangels näher untersucht und damit das kompensatorische Potential der glykolytischen Energiegewinnung analysiert werden. 


\section{Material und Methoden}

\subsection{Material}

\subsubsection{Zell- und Bakterienkultur}

\subsubsection{Toxoplasma gondii Stämme}

\section{$\mathrm{RH}$}

RHAuprt

3L-H11

3F-A6

RH $\Delta h x g p r t$

$\mathrm{RH} \Delta k u 80 \Delta h x g p r t$

$\mathrm{RH} \Delta k u 80 \Delta h x g p r t \Delta u p r t$

$\Delta$ tggt1
Wildtyp

Uracil-Phosphoribosyltransferase-defiziente

Mutante des RH Stamms

Durch chemische Mutagenese generierte Mutante des RHAuprt Stamms

Durch chemische Mutagenese generierte Mutante des RHAuprt Stamms

Hypoxanthin-Xanthin-Guanin-Phosphoribosyl-

Transferase-defiziente Mutante des RH Stamms

Ku80-defiziente Mutante des RH $\Delta$ hxgprt Stamms

(Freundlicherweise zur Verfügung gestellt von:

Vern Carruthers)

Uracil-Phosphoribosyltransferase-defiziente

Mutante des RH $\Delta k u 80 \Delta h x g p r t$ Stamms

Glukosetransporter (GT1)-defiziente Mutante des

RH $\Delta$ hxgprt Stamms

(Freundlicherweise zur Verfügung gestellt von N.

Gupta, Humboldt Universität Berlin)

\subsubsection{Wirtszellinie}

Humane Vorhaut Fibroblasten (HFF)

Arbeitsgruppeneigene Zellcharge

\subsubsection{Kompetente Escherichia coli Stämme}

$\operatorname{ATCC}^{\circledR} 12632^{\mathrm{TM}}$

BL21-CodonPlus(DE3)-RP

DH5 $\alpha$ (High Efficiency)
LGC Standards, Wesel

Agilent Technologies, Böblingen

New England Biolabs, Frankfurt 


\subsubsection{Plasmide}

\begin{tabular}{|c|c|}
\hline pASK-IBA16 & $\begin{array}{l}\text { E. coli Expressionsvektor mit einem AnTc- } \\
\text { induzierbaren Promoter (IBA GmbH, Göttingen) }\end{array}$ \\
\hline pDrive & PCR-Klonierungsvektor (Qiagen, Hilden) \\
\hline pET-16b & $\begin{array}{l}\text { E. coli Expressionsvektor mit einem N- } \\
\text { terminalen His } 10 \text {-Tag (Merck, Mannheim) }\end{array}$ \\
\hline pminCAT/HXGPRT & $\begin{array}{l}\text { T. gondii Expressionsplasmid mit einer CAT- und } \\
\text { HXGPRT-Resistenzkassette }\end{array}$ \\
\hline pSKupDH & $\begin{array}{l}\text { NIH AIDS Reagent Program (\# 2850) } \\
\text { T. gondii Expressionsplasmid, das für ein uprt- } \\
\text { Minigen und eine Pyrimethamin-Resistenz- } \\
\text { kassette codiert (Sternisek 2009) }\end{array}$ \\
\hline ptubCAT-HSTK & $\begin{array}{l}\text { T. gondii Expressionsplasmid, das für eine CAT- } \\
\text { HSTK Fusionssequenz und eine HXGPRT- } \\
\text { Resistenzkassette codiert (Radke and White } \\
\text { 1999) }\end{array}$ \\
\hline ptubYFPYFP-sagCAT & $\begin{array}{l}\text { T. gondii Expressionsplasmid, das für ein } \\
\text { Tandem-YFP-YFP Protein, eine CAT-Resistenz- } \\
\text { kassette und die 3' UTR der T. gondii DHFR-TS } \\
\text { codiert (Gubbels et al. 2003) }\end{array}$ \\
\hline $\mathrm{R} 11 \Delta \mathrm{Bg} 1$ & $\begin{array}{l}\text { Targeting-Vektor zur Deletion des endogenen } \\
\text { uprt Gens von } T \text {. gondii (Donald and Roos 1995) }\end{array}$ \\
\hline
\end{tabular}

\subsubsection{Oligonukleotide (Primer)}

Tabelle 2.1: Sequenzierungsprimer Ubiquinon/Ubiquinol-interagierender Enzyme

\begin{tabular}{llcc} 
Primer & \multicolumn{1}{c}{ Sequenz $\left(\mathbf{5}^{\circ} \rightarrow \mathbf{3}^{\circ}\right)$} & $\begin{array}{c}\text { Annealing- } \\
\text { Temp. }\end{array}$ & $\begin{array}{c}\text { Elongations- } \\
\text { zeit }\end{array}$ \\
\hline TgNDH2-I (Genomische DNA) & TCCGAACGACTCCGTCAATCCTCT & $60 \mathrm{~s}$ \\
\hline $\begin{array}{l}\text { cosIko+ } \\
\text { RT-AND1/ORF4- }\end{array}$ & GGACTCCAAAAGTGTTCACATCGG & \multirow{2}{*}{$60 \mathrm{~s}$} \\
\hline $\begin{array}{l}\text { RT-AND1/ORF3+ } \\
\text { RT-AND1/ORF6- }\end{array}$ & GGTTCGCTGTCAGTCGACTCACGG & $62^{\circ} \mathrm{C}$ & \\
\hline $\begin{array}{l}\text { NDH2-1/1+ } \\
\text { RT-AND1/2- }\end{array}$ & TGCGACCTCGCCAGAAAGACC & $55^{\circ} \mathrm{C}$ & 1 min, $20 \mathrm{~s}$ \\
\hline
\end{tabular}


Fortsetzung Tab. 2.1: Sequenzierungsprimer Ubiquinon/Ubiquinol-interagierender Enzyme

\begin{tabular}{|c|c|c|c|}
\hline NDH2-1/6+ & TTCAACGCGTTTCCGAGTGTCGA & \multirow{2}{*}{$55^{\circ} \mathrm{C}$} & \multirow{2}{*}{$30 \mathrm{~s}$} \\
\hline NDH2-1/4- & CTCTCCGCCGCCCTCTTC & & \\
\hline \multicolumn{4}{|c|}{ TgNDH2-II (cDNA) } \\
\hline TgNDH2-II/21+ & TCGATGCGAGTCGCGTGTAGA & \multirow{2}{*}{$55^{\circ} \mathrm{C}$} & \multirow{2}{*}{$60 \mathrm{~s}$} \\
\hline TgNDH2-II/22- & AAAGGCGGTCGCGTTCTTTCTCA & & \\
\hline RT-AND2/1+ & GCCGCCAGGGTGGACATTTC & \multirow{2}{*}{$55^{\circ} \mathrm{C}$} & \multirow{2}{*}{$60 \mathrm{~s}$} \\
\hline TgNDH2-II/24- & TATCACTGGTTTGCGACTACGAAGTA & & \\
\hline \multicolumn{4}{|l|}{ MQO (cDNA) } \\
\hline MQO 9+ & GGGCATCAGACCCACAAGAACC & \multirow{2}{*}{$50^{\circ} \mathrm{C}$} & \multirow{2}{*}{$1 \mathrm{~min}, 40 \mathrm{~s}$} \\
\hline MQO 10- & ATAGCCCTGTGCGTATGTGAGAT & & \\
\hline MQO 11+ & TCCCGAAGCTGAACACCGTGCTCT & \multirow{2}{*}{$50^{\circ} \mathrm{C}$} & \multirow{2}{*}{$30 \mathrm{~s}$} \\
\hline MQO 12- & TTGCGCAGAAATCCAAATGATGATG & & \\
\hline \multicolumn{4}{|l|}{ SDH (cDNA) } \\
\hline SDH 13+ & GATCCCCAAGCCGTCCTTTCACCTT & \multirow{2}{*}{$60^{\circ} \mathrm{C}$} & \multirow{2}{*}{$60 \mathrm{~s}$} \\
\hline SDH 14- & ATGAGACAGCCGGCGGGGAAGATTC & & \\
\hline SDH 15+ & TCCGCTCACACCTGCACTGGAGAC & \multirow{2}{*}{$60^{\circ} \mathrm{C}$} & \multirow{2}{*}{$60 \mathrm{~s}$} \\
\hline SDH 16- & CAGCGATGAAACGCGCCAAGAAG & & \\
\hline \multicolumn{4}{|l|}{ G3PDH (cDNA) } \\
\hline G3PDH 1+ & AGTTAGCTTTGTCCCCTTCTCTCT & \multirow{2}{*}{$50^{\circ} \mathrm{C}$} & \multirow{2}{*}{$1 \mathrm{~min}, 20 \mathrm{~s}$} \\
\hline G3PDH 2- & GTATACCAGTGCGGAAGAACAAT & & \\
\hline G3PDH3+ & ACAAAGAGACAGGGGAGGAGTT & \multirow{2}{*}{$60^{\circ} \mathrm{C}$} & \multirow{2}{*}{$1 \mathrm{~min}, 40 \mathrm{~s}$} \\
\hline G3PDH4- & CTCTGAGTCGACGGAAGGTATT & & \\
\hline \multicolumn{4}{|l|}{ DHODH (cDNA) } \\
\hline DHODH $1+$ & TGTCCGTCAACACTCCGTCTTCACC & \multirow{2}{*}{$58^{\circ} \mathrm{C}$} & \multirow{2}{*}{$60 \mathrm{~s}$} \\
\hline DHODH 2- & GCTTCCAGCTGCGTCTGAGCGTAGT & & \\
\hline DHODH $3+$ & TACGAAGATCGGTCGGTCATCAATC & \multirow{2}{*}{$58^{\circ} \mathrm{C}$} & \multirow{2}{*}{$60 \mathrm{~s}$} \\
\hline DHODH 4- & CTCCGGCGGCGATCGTCACAGTC & & \\
\hline DHODH 5+ & GCACCGGCAGCTCTTTTGA & \multirow{2}{*}{$61^{\circ} \mathrm{C}$} & \multirow{2}{*}{$40 \mathrm{~s}$} \\
\hline DHODH 6- & TTCGCCTTTCGTTTCGCTGCTTCT & & \\
\hline \multicolumn{4}{|c|}{ Cytochrom b (cDNA) } \\
\hline Cyt b 1+ & GGACTACTGGTTTAGATCTTGAAGG & \multirow{2}{*}{$60^{\circ} \mathrm{C}$} & \\
\hline Cyt b 2- & GTTTTGCTTGGAAGCTGTAGTCA & & \\
\hline
\end{tabular}

Sense-Primer sind mit einem (+), Antisense-Primer mit einem (-) gekennzeichnet. 
Tabelle 2.2: Klonierungs- und Kontrollprimer für $T$ gondii

\begin{tabular}{|c|c|c|c|}
\hline Primer & Sequenz $\left(5^{6} \rightarrow 3^{\circ}\right)$ & $\begin{array}{l}\text { Annealing- } \\
\text { Temp. }\end{array}$ & $\begin{array}{l}\text { Elonga- } \\
\text { tionszeit }\end{array}$ \\
\hline NotI-DHODH (S) & ATGCGGCCGCCATTTCCAAGGGCGTTT & & \\
\hline DHODH-HindIII (A) & $\begin{array}{l}\text { CGCCTTG } \\
\text { TAAAGCTTTCAGTCGAATTTCGGAGCC } \\
\text { TGCAG }\end{array}$ & $65^{\circ} \mathrm{C}$ & $40 \mathrm{~s}$ \\
\hline HindIII-3’DHODH (S) & ATAAGCTTGACAACATGTCTGGGGTCG & & \\
\hline 3’DHODH-EcoRV (A) & $\begin{array}{l}\text { GTCGT } \\
\text { TAGATATCAATCTCCGGATGGATGTTC } \\
\text { ATACA }\end{array}$ & $65^{\circ} \mathrm{C}$ & $20 \mathrm{~s}$ \\
\hline $\begin{array}{l}1+ \\
2-\end{array}$ & $\begin{array}{l}\text { CACTCCGTCTTCACCGAAAT } \\
\text { GGATGTTACCGGCTCGTAGA }\end{array}$ & $(1+/ 2-) 55^{\circ} \mathrm{C}$ & $1 \mathrm{~min}, 40 \mathrm{~s}$ \\
\hline $3-$ & CTTCAGCGTGCTTGTCGAAT & $(1+/ 3-) 64^{\circ} \mathrm{C}$ & $1 \mathrm{~min}, 30 \mathrm{~s}$ \\
\hline $\begin{array}{l}4+ \\
5-\end{array}$ & $\begin{array}{l}\text { TACGACTCACTATAGGGCGAATTG } \\
\text { TCTTCTTCATAAGTGTCCAGATTCC }\end{array}$ & $55^{\circ} \mathrm{C}$ & $60 \mathrm{~s}$ \\
\hline $\begin{array}{l}\text { DHODH 7+ } \\
\text { DHODH 8- }\end{array}$ & $\begin{array}{l}\text { CGAAGTGGGTTCGATCACGCC } \\
\text { TGCGTCTGAGCGTAGTCAGCG }\end{array}$ & $63^{\circ} \mathrm{C}$ & $10 \mathrm{~s}$ \\
\hline AvrII-ScDHODH (S) & $\begin{array}{l}\text { ATCCTAGGATGACAGCCAGTTTAACTA } \\
\text { CCAAG } \\
\text { TAGGCGCGCCTTAAATGCTGTTCAACT } \\
\text { TCCCACG }\end{array}$ & $68^{\circ} \mathrm{C}$ & $30 \mathrm{~s}$ \\
\hline AscI-3’DHFR (S) & $\begin{array}{l}\text { ATGGCGCGCCAGAAGCTGCCCGTCTCT } \\
\text { CGTT } \\
\text { TAGCGGCCGCCCGCGGTGTCACTGTAG } \\
\text { CCTGCCAGAACACTTG }\end{array}$ & $68^{\circ} \mathrm{C}$ & $20 \mathrm{~s}$ \\
\hline DHODH-BamHI (A) & $\begin{array}{l}\text { ATCATATGGTGAGCAGTATGATCTACT } \\
\text { CCTTC } \\
\text { TAGGATCCTCAGTCGAATTTCGGAGCC } \\
\text { TGCAG }\end{array}$ & $68^{\circ} \mathrm{C}$ & $40 \mathrm{~s}$ \\
\hline
\end{tabular}

Sense-Primer sind mit einem (+) oder (S), Antisense-Primer mit einem (-) oder (A) gekennzeichnet. Mit Ausnahme der Kontrollprimer 1+/2-, 1+/3-, 4+/5- und DHODH 7+/DHODH 8- (Taq-Polymerase) erfolgte die DNA-Amplifikation mit der Phusion-Polymerase. 
Tabelle 2.3: Klonierungsprimer zur Expression der TgDHODH in E. coli

\begin{tabular}{llcc} 
Primer & \multicolumn{1}{c}{ Sequenz $\left(\mathbf{5}^{\circ} \rightarrow \mathbf{3}^{\circ}\right)$} & $\begin{array}{c}\text { Annealing- } \\
\text { Temp. }\end{array}$ & $\begin{array}{c}\text { Elonga- } \\
\text { tionszeit }\end{array}$ \\
\hline Fusionskonstrukt 1 & & & \\
\hline MT 7+ & TATCTAGATAACGAGGGCAAAAAATGTACTA & & \\
& CGAGCCGGTAACATCCGTC & $65^{\circ} \mathrm{C}$ & $20 \mathrm{~s}$ \\
MT 10- & TAAAGCTTTCAGTCGAATTTCGGAGCCTGCAG & & \\
\hline
\end{tabular}

\begin{tabular}{lllll}
\hline Fusionskonstrukt 2 & & & \\
\hline MT 8+ & TATCTAGATAACGAGGGCAAAAAATGTACTA & & \\
& CCCCTTTGTCCGTAAAGCGTTATTTCGTTACTT & & \\
& CAGCAGC & $65^{\circ} \mathrm{C}$ & $20 \mathrm{~s}$ \\
MT 10- & TAAAGCTTTCAGTCGAATTTCGGAGCCTGCAG & & \\
\hline
\end{tabular}

\begin{tabular}{lllll}
\hline Fusionskonstrukt 3 & & & \\
\hline MT 9+ & TATCTAGATAACGAGGGCAAAAAATGTACTA & & \\
& CCCCTTTGTCCGTAAAGCGTTATTTCAACTGG & $65^{\circ} \mathrm{C}$ & $20 \mathrm{~s}$ \\
& ACCCGGAAACGGCTCAC & & \\
MT 10- & TAAAGCTTTCAGTCGAATTTCGGAGCCTGCAG & & \\
\hline Fusionskonstrukt 4 & & & \\
\hline MT 7+ & TATCTAGATAACGAGGGCAAAAAATGTACTA & \\
& CGAGCCGGTAACATCCGTC & & \\
DHODH_LQAPKF & TAAAGCTTTCAGTGATGGTGATGGTGATGGCC & $65^{\circ} \mathrm{C}$ & \\
D_RGH6 (A) & CCGGTCGAATTTCGGAGCCTGCAG & & \\
\hline
\end{tabular}

\begin{tabular}{llll}
\hline Fusionskonstrukt 5 & & & \\
\hline MT 8+ & TATCTAGATAACGAGGGCAAAAAATGTACTA & & \\
& CCCCTTTGTCCGTAAAGCGTTATTTCGTTACTT & & \\
& CAGCAGC & $65^{\circ} \mathrm{C}$ & \\
DHODH_LQAPKF & TAAAGCTTTCAGTGATGGTGATGGTGATGGCC & & \\
D_RGH6 (A) & CCGGTCGAATTTCGGAGCCTGCAG & \\
\hline Fusionskonstrukt 6 & & \\
\hline MT 9+ & TATCTAGATAACGAGGGCAAAAAATGTACTA & \\
& CCCCTTTGTCCGTAAAGCGTTATTTCAACTGG & \\
& ACCCGGAAACGGCTCAC & \\
DHODH_LQAPKF & TAAAGCTTTCAGTGATGGTGATGGTGATGGCC & \\
D_RGH6 (A) & CCGGTCGAATTTCGGAGCCTGCAG & \\
\hline
\end{tabular}

Sense-Primer sind mit einem (+) oder (S), Antisense-Primer mit einem (-) oder (A) gekennzeichnet. 
Tabelle 2.4: Primer der quantitativen Real-Time PCR (RT-PCR)

\begin{tabular}{|c|c|c|c|c|}
\hline Primer & Sequenz $\left(5^{6} \rightarrow 3^{6}\right)$ & $\begin{array}{l}\text { Produkt- } \\
\text { größe (bp) }\end{array}$ & $\begin{array}{l}\text { Annealing- } \\
\text { Temp. }\end{array}$ & $\begin{array}{l}\text { Elonga- } \\
\text { tionszeit }\end{array}$ \\
\hline \multicolumn{5}{|l|}{$\overline{\text { G3PDH }}$} \\
\hline $\begin{array}{l}\text { G3PDH 5+ } \\
\text { G3PDH 6- }\end{array}$ & $\begin{array}{l}\text { CGGGAAGTGGACTACCTACAGAC } \\
\text { AGTTTCTCCATATTCTACGCAACC }\end{array}$ & 597 & $63^{\circ} \mathrm{C}$ & $25 \mathrm{~s}$ \\
\hline \multicolumn{5}{|l|}{ DHODH } \\
\hline $\begin{array}{l}\text { DHODH 3+ } \\
\text { DHODH 4- }\end{array}$ & $\begin{array}{l}\text { TACGAAGATCGGTCGGTCATCAATC } \\
\text { CTCCGGCGGCGATCGTCACAGTC }\end{array}$ & 1014 & $58^{\circ} \mathrm{C}$ & $50 \mathrm{~s}$ \\
\hline \multicolumn{5}{|l|}{ TgNDH2-I } \\
\hline $\begin{array}{l}\text { Tgndh2-I 5+ } \\
\text { Tgndh2-I 2- }\end{array}$ & $\begin{array}{l}\text { ATCCTCGTCGACCAGCAAATGAAG } \\
\text { AGTCAACTGCATCTGGAGGTAC }\end{array}$ & 535 & $60^{\circ} \mathrm{C}$ & $25 \mathrm{~s}$ \\
\hline \multicolumn{5}{|l|}{ TgNDH2-II } \\
\hline $\begin{array}{l}\text { Tgndh2-II 23+ } \\
\text { Tgndh2-II 24- }\end{array}$ & $\begin{array}{l}\text { ATCCGGAAGAAAGTGATGAACAACT } \\
\text { TATCACTGGTTTGCGACTACGAAGTA }\end{array}$ & 1177 & $55^{\circ} \mathrm{C}$ & $50 \mathrm{~s}$ \\
\hline \multicolumn{5}{|l|}{ SDH } \\
\hline $\begin{array}{l}\text { SDH } 15+ \\
\text { SDH } 16-\end{array}$ & $\begin{array}{l}\text { TCCGCTCACACCTGCACTGGAGAC } \\
\text { CAGCGATGAAACGCGCCAAGAAG }\end{array}$ & 1187 & $58^{\circ} \mathrm{C}$ & $50 \mathrm{~s}$ \\
\hline \multicolumn{5}{|l|}{ MQO } \\
\hline $\begin{array}{l}\text { MQO 11+ } \\
\text { MQO 12- }\end{array}$ & $\begin{array}{l}\text { TCCCGAAGCTGAACACCGTGCTCT } \\
\text { TTGCGCAGAAATCCAAATGATGATG }\end{array}$ & 358 & $57^{\circ} \mathrm{C}$ & $1 \mathrm{~min}, 30 \mathrm{~s}$ \\
\hline \multicolumn{5}{|l|}{ ScDHODH } \\
\hline $\begin{array}{l}\text { ScDHODH 1+ } \\
\text { ScDHODH 2- }\end{array}$ & $\begin{array}{l}\text { TCATTGATGTGGAGAAGGAGAGTG } \\
\text { GTACCAATCTGTAGCATAGAGGCA }\end{array}$ & 217 & $63^{\circ} \mathrm{C}$ & $20 \mathrm{~s}$ \\
\hline \multicolumn{5}{|l|}{ Tubulin } \\
\hline $\begin{array}{l}\text { Tub 3+ } \\
\text { Tub 4- }\end{array}$ & $\begin{array}{l}\text { CGCCACGGCCGCTACCTGACTG } \\
\text { TACGCGCCTTCCTCTGCACCCATCT }\end{array}$ & 434 & $60^{\circ} \mathrm{C}$ & $20 \mathrm{~s}$ \\
\hline \multicolumn{5}{|l|}{ UPRT } \\
\hline $\begin{array}{l}\text { Uprt fwd (S) } \\
\text { Uprt rev (A) }\end{array}$ & $\begin{array}{l}\text { GACGAAACAACTGCGGAGCCTAAGC } \\
\text { TCACCAATGCCGGGGACGATGTA }\end{array}$ & 293 & $68^{\circ} \mathrm{C}$ & $12 \mathrm{~s}$ \\
\hline TgGT1 & & & & \\
\hline $\begin{array}{l}\text { GT1 1+ } \\
\text { GT1 2- }\end{array}$ & $\begin{array}{l}\text { CCATCATGCAGCAGTTCACTGGCA } \\
\text { TGGCTGCTCCCTGCTTGATCTCAG }\end{array}$ & 384 & $68^{\circ} \mathrm{C}$ & $20 \mathrm{~s}$ \\
\hline
\end{tabular}


Fortsetzung Tab. 2.4: Primer der quantitativen Real-Time PCR (RT-PCR)

\begin{tabular}{|c|c|c|c|c|}
\hline HK & & & & \\
\hline $\begin{array}{l}\text { HK 3+ } \\
\text { HK 4- }\end{array}$ & $\begin{array}{l}\text { GTGCCGTGTTGGACTCATCATC } \\
\text { GCACGGGCGCCAAATACTC }\end{array}$ & 261 & $58^{\circ} \mathrm{C}$ & $20 \mathrm{~s}$ \\
\hline \multicolumn{5}{|l|}{ GPI } \\
\hline $\begin{array}{l}\text { GPI 1+ } \\
\text { GPI 2- }\end{array}$ & $\begin{array}{l}\text { CTCGGCTGTGGGCATTCTTCCTCT } \\
\text { GCGCTTCCCGTTGCTCTCCAT }\end{array}$ & 262 & $60^{\circ} \mathrm{C}$ & $20 \mathrm{~s}$ \\
\hline \multicolumn{5}{|l|}{ TPI I } \\
\hline $\begin{array}{l}\text { TPI I 3+ } \\
\text { TPI I 4- }\end{array}$ & $\begin{array}{l}\text { ACCGGGGAGATCAGCGTGGAAATG } \\
\text { AACTCGCGGATATGCTCGTGGACT }\end{array}$ & 353 & $61^{\circ} \mathrm{C}$ & $20 \mathrm{~s}$ \\
\hline \multicolumn{5}{|l|}{ TPI II } \\
\hline $\begin{array}{l}\text { TPI II 1+ } \\
\text { TPI II 2- }\end{array}$ & $\begin{array}{l}\text { CTCCGCGCCAGTCTCCTT } \\
\text { ATAGCCGCCATGTTCAGTGC }\end{array}$ & 391 & $57^{\circ} \mathrm{C}$ & $20 \mathrm{~s}$ \\
\hline \multicolumn{5}{|l|}{ PGK I } \\
\hline $\begin{array}{l}\text { PGK I 3+ } \\
\text { PGK I 4- }\end{array}$ & $\begin{array}{l}\text { GGGAGGCGCCAAGGTTC } \\
\text { TGTCGACGCCCATCCATC }\end{array}$ & 311 & $57^{\circ} \mathrm{C}$ & $20 \mathrm{~s}$ \\
\hline \multicolumn{5}{|l|}{ PGK II } \\
\hline $\begin{array}{l}\text { PGK II 3+ } \\
\text { PGK II 4- }\end{array}$ & $\begin{array}{l}\text { GCGCTGGCCAAGGAGAAGG } \\
\text { CTATTGCCGCCACAGAGTCACC }\end{array}$ & 328 & $60^{\circ} \mathrm{C}$ & $20 \mathrm{~s}$ \\
\hline \multicolumn{5}{|l|}{ PK I } \\
\hline $\begin{array}{l}\text { PK I 1+ } \\
\text { PK I 2- }\end{array}$ & $\begin{array}{l}\text { GGCCGCCACATCCGCATTATTC } \\
\text { CGCAGGGTAGTCCACGCAGGTTTC }\end{array}$ & 396 & $60^{\circ} \mathrm{C}$ & $20 \mathrm{~s}$ \\
\hline \multicolumn{5}{|l|}{ PK II } \\
\hline $\begin{array}{l}\text { PK II 1+ } \\
\text { PK II 2- }\end{array}$ & $\begin{array}{l}\text { ACCGGCGAGCTGGGATTATGAAGA } \\
\text { CTGGGCGAAGAACGGAAAGAA }\end{array}$ & 319 & $61^{\circ} \mathrm{C}$ & $20 \mathrm{~s}$ \\
\hline
\end{tabular}

\subsubsection{Medien und Zusätze für die Zell- und Bakterienkultur}

\subsubsection{T. gondii Zellkultur}

\section{Medien}

DMEM mit 4,5 g/l D-Glukose, 0,58 g/l L-Glutamin, 3,7 g/l NaHCO 3

DMEM ohne L-Glutamin, 4,5 g/l D-Glukose, 3,7 g/1 NaHCO 3

DMEM ohne D-Glukose, ohne L-Glutamin, 3,7 g/1 NaHCO 3 


\section{Medienzusätze}

Fötales Kälberserum (FCS)

Dialysiertes FCS

L-Glutamin (200 mM)

Alle aufgeführten Medien und Zusätze wurden durch Biochrom (Berlin) bezogen.

\subsubsection{E. coli Kultur}

\section{Medien}

\begin{tabular}{ccc}
\multicolumn{1}{c}{ LB-Medium } & \multicolumn{2}{c}{ M63-Minimalmedium } \\
& Stocklösung $(5 \mathrm{x})$ & Gebrauchslösung (1x) \\
$10 \mathrm{~g} / \mathrm{l} \mathrm{Trypton}$ & $10 \mathrm{~g} / \mathrm{l}\left(\mathrm{NH}_{4}\right)_{2} \mathrm{SO}_{4}$ & M63 Medium (1x) \\
$5 \mathrm{~g} / \mathrm{l} \mathrm{Hefeextrakt}$ & $68 \mathrm{~g} / \mathrm{K} \mathrm{KH}_{2} \mathrm{PO}_{4}$ & $1 \mathrm{ml} / 1 \mathrm{MgSO}_{4} \cdot 7 \mathrm{H}_{2} \mathrm{O}$ \\
$5 \mathrm{~g} / \mathrm{l} \mathrm{NaCl}$ & $2,5 \mathrm{mg} / 1 \mathrm{FeSO}_{4} \cdot 7 \mathrm{H}_{2} \mathrm{O}$ & $1 \% \mathrm{Glucose}(\mathrm{v} / \mathrm{v})$ \\
in ddH & $\mathrm{in} \mathrm{ddH}_{2} \mathrm{O}$ & in $\mathrm{ddH}_{2} \mathrm{O}$ \\
$\rightarrow$ Autoklavieren & $\rightarrow$ Autoklavieren &
\end{tabular}

\section{Medienzusätze}

Anhydrotetracyclin 5-200 ng/ml Stocklösung $10 \mathrm{mg} / \mathrm{ml}$ in DMF

Uracil $\quad 10 \mu \mathrm{g} / \mathrm{ml} \quad$ Stocklösung $0,022 \mathrm{~g} / \mathrm{ml}$ in $\mathrm{KOH}$

Beide Substanzen wurden durch Sigma-Aldrich, München bezogen.

\subsubsection{Antibiotika und antiparasitäre Wirkstoffe}

Alle verwendeten Substanzen wurden, sofern nicht anders angegeben, durch Sigma-Aldrich (München) bezogen.

Tabelle 2.5: Verwendete Antibiotika und antiparasitäre Wirkstoffe

\begin{tabular}{lll}
\hline Substanz & Stocklösung & Endkonzentration \\
\hline 5-Fluorodeoxyuridin (FUDR) & $10 \mathrm{mM} \mathrm{ddH}{ }_{2} \mathrm{O}$ & $5 \mu \mathrm{M}$ \\
Ampicillin & $50 \mathrm{mg} / \mathrm{ml} \mathrm{in} \mathrm{EtOH}$ & $50 \mu \mathrm{g} / \mathrm{ml}$ \\
Atovaquon & $5 \mathrm{mM} \mathrm{in} \mathrm{DMSO}$ & $100 \mathrm{nM}$ \\
Chloramphenicol (T. gondii) & $100 \mathrm{mM} \mathrm{in} \mathrm{EtOH}$ & $20 \mu \mathrm{M}$ \\
Chloramphenicol (E. coli) & $34 \mathrm{mg} / \mathrm{ml} \mathrm{in} \mathrm{EtOH}$ & $34 \mu \mathrm{g} / \mathrm{ml}$ \\
\hline
\end{tabular}


Material und Methoden

Fortsetzung Tab. 2.5: Verwendete Antibiotika und antiparasitäre Wirkstoffe

Compound B

2,5 $\mathrm{mM}$ in DMSO

$0,01-30 \mu \mathrm{M}$

(Tietze and Ma 2010)

HDQ

2,5 $\mathrm{mM}$ in DMSO

$0,01-30 \mu \mathrm{M}$

(Eschemann et al. 2005)

Mycophenolsäure (MPA)

$25 \mathrm{mg} / \mathrm{ml}$ in $\mathrm{EtOH}$

$25 \mu \mathrm{g} / \mathrm{ml}$

Penicillin/Streptomycin

$10.000 \mathrm{U} / \mathrm{ml} / 10.000 \mu \mathrm{g} / \mathrm{ml} \quad 1 \%(\mathrm{v} / \mathrm{v})$

(Biochrom, Berlin)

Pyrimethamin

$2 \mathrm{mM}$ in $\mathrm{EtOH}$

$1 \mu \mathrm{M}$

Xanthin

$50 \mathrm{mg} / \mathrm{ml}$ in $\mathrm{KOH}$

$50 \mu \mathrm{g} / \mathrm{ml}$

\subsubsection{Antikörper und Fluoreszenzmarker}

Tabelle 2.6: Verwendete Antikörperverdünnungen für Western Blot (WB) Analysen und Immunfluoreszenztests (IFTs)

\begin{tabular}{ll}
\hline Primärantikörper & Gebrauchsverdünnung \\
\hline Maus anti-(His) $)_{5}$, BSA-frei & WB 1:1000 \\
(Qiagen, Hilden) & WB 1:2000; IFT 1:1000 \\
Kaninchen anti-CAT & \\
$\left(3^{\prime}-5^{\prime}\right.$ Inc) & WB 1:500 \\
Kaninchen Anti-SAGI & \\
(Arbeitsgruppeneigenes Serum)
\end{tabular}

\section{Sekundärantikörper}

AP-konjugiertes Ziege anti-Maus IgG WB 1:3000

(Dianova, Hamburg)

Cy3-konjugiertes Affe anti-Kaninchen IgG IFT 1:300

(Dianova, Hamburg)

HRP-konjugiertes Affe anti-Kaninchen IgG WB 1:5000

(Dianova, Hamburg)

Um zwischen Parasiten mit einem intakten mitochondrialen Membranpotential $\left(\Delta \Psi_{\mathrm{m}}\right)$ und einem depolarisiertem $\Delta \Psi_{\mathrm{m}} \mathrm{zu}$ differenzieren, wurden die Zellen mit dem Fluorophor MitoTracker ${ }^{\circledR}$ Red $\left(\mathrm{CM}-\mathrm{H}_{2}\right.$ XRos, Life Technologies, Darmstadt) markiert. Die Verdünnung 
der Stocklösung (100 mM in DMSO) auf die im Assay verwendete Endkonzentration von 0,5 $\mu \mathrm{M}$ erfolgte mit DMEM (10\% FCS (v/v)).

\subsubsection{Enzyme}

Antarktische Phosphatase

DNase I (Amplification Grade)

Lysozym (aus Hühnereiweiß)

M-MLV Reverse Transkriptase,

RNase H Minus, Point Mutant

Phusion High-Fidelity DNA-Polymerase

Protease-Inhibitor-Cocktail, EDTA frei

Taq-DNA-Polymerase

Restriktionsenzyme

RNase A
New England Biolabs, Frankfurt

Sigma-Aldrich, München

Sigma-Aldrich, München

Promega, Mannheim

New England Biolabs, Frankfurt

Roche, Mannheim

Roche, Mannheim

New England Biolabs, Frankfurt

Sigma-Aldrich, München

\subsubsection{Substrate der Enzymaktivitätsmessung}

Mit Ausnahme von Decylubiquinon ( $Q_{D}$, Enzo Life Sciences, Lörrach) wurden alle hier angegebenen Reagenzien von Sigma-Aldrich (München) bezogen. Die Stocklösungen von DHO, DCIP und Fumarat wurden vor jeder Aktivitätsmessung der Enzyme frisch angesetzt. Da die Messung in einem Gesamtvolumen von $200 \mu$ l stattfand, wurde die für jede der verwendeten Substrate und Inhibitoren benötigte Arbeitskonzentrationen als 20-fach konzentrierte Lösungen hergestellt.

Tabelle 2.7: Zur Messung der Enzymaktivität verwendete Substrate

\begin{tabular}{llll}
\hline Substrat & Lösungsmittel & Stocklösung & Arbeitskonzentration \\
\hline 2,6-Dichlorindophenol (DCIP) & $\mathrm{ddH}_{2} \mathrm{O}$ & $1,2 \mathrm{mM}$ & $60 \mu \mathrm{M}$ \\
Decylubiquinon (QD) & $\mathrm{EtOH}$ & $10 \mathrm{mM}$ & $5-300 \mu \mathrm{M}$ \\
Dihydroorotat (DHO) & $\mathrm{ddH}_{2} \mathrm{O}$ & $10 \mathrm{mM}$ & $5-1000 \mu \mathrm{M}$ \\
Fumarat (Natrium-Fumarat) & $\mathrm{ddH}_{2} \mathrm{O}$ & $2 \mathrm{mM}$ & $1000 \mu \mathrm{M}$ \\
\hline
\end{tabular}

\subsubsection{Molekulargewichtsmarker}

GeneRuler $^{\mathrm{TM}} 100$ bp und 1 kb DNA Ladder

Prestained Protein Marker, Broad Range peqGOLD Proteinmarker IV
Thermo Fisher Scientific, Schwerte

New England Biolabs, Frankfurt

Peqlab Biotechnologie, Erlangen 


\subsubsection{Chemikalien}

0,05\% Trypsin-EDTA

2-Deoxy-D-Glucose (2-DOG)

6x DNA Loading Dye

Acrylamid/Bisacrylamid (30\%)

Adenosintriphosphat (ATP)

Aminocapronsäure

Ammoniumperoxodisulfat (APS)

Ammoniumsulfat $\left(\left(\mathrm{NH}_{4}\right)_{2} \mathrm{SO}_{4}\right)$

Bacto ${ }^{\mathrm{TM}}$ Agar

Bacto ${ }^{\mathrm{TM}}$ Hefeextrakt

Bacto $^{\mathrm{TM}}$ Trypton

Bromphenolblau

BSA

Calciumchlorid $\left(\mathrm{CaCl}_{2}\right)$

Coomassie Brilliantblau R 250

Diäthanolamin

Dikaliumhydrogenphosphat/

Kaliumdihydrogenphosphat

$\left(\mathrm{K}_{2} \mathrm{HPO}_{4} / \mathrm{KH}_{2} \mathrm{PO}_{4}\right)$

DMSO, Hybri-Max

dNTP-Mix (jeweils $10 \mathrm{mM}$ pro dNTP)

DTT

$\mathrm{ECL}^{\mathrm{TM}}$-Detektionsreagenz

EDTA

Eisen(II)-sulfat $\left(\mathrm{FeSO}_{4} \cdot 7 \mathrm{H}_{2} \mathrm{O}\right)$

Essigsäure

Ethanol

Ethidiumbromid

Glucose

Glutathion

Glycerin $87 \%$

HEPES
Gibco, Darmstadt

Sigma-Aldrich, München

Thermo Fisher Scientific, Schwerte

Carl Roth, Karlsruhe

Sigma-Aldrich, München

Sigma-Aldrich, München

Merck, Mannheim

Merck, Darmstadt

BD, Heidelberg

BD, Heidelberg

BD, Heidelberg

Amresco, Solon, USA

Biomol, Hamburg

Merck, Mannheim

Merck, Mannheim

Merck, Mannheim

Carl Roth, Karlsruhe

Sigma-Aldrich, München

Roche, Mannheim

Sigma-Aldrich, München

GE Healthcare, München

Merck, Mannheim

Carl Roth, Karlsruhe

Carl Roth, Karlsruhe

Merck, Mannheim

AppliChem, Darmstadt

Merck, Darmstadt

Sigma-Aldrich, München

Carl Roth, Karlsruhe

Biochrom, Berlin 
Imidazol

Isopropanol

Kaliumchlorid $(\mathrm{KCl})$

Kaliumhydroxid (KOH)

Magermilchpulver

Magnesiumchlorid $\left(\mathrm{MgCl}_{2}\right)$

Magnesiumsulfat $\left(\mathrm{MgSO}_{4} \cdot 7 \mathrm{H}_{2} \mathrm{O}\right)$

Methanol

Mowiol 4-88

Natriumacetat $\left(\mathrm{C}_{2} \mathrm{H}_{3} \mathrm{NaO}_{2}\right)$

Natriumazid $\left(\mathrm{NaN}_{3}\right)$

Natriumchlorid $(\mathrm{NaCl})$

Natriumdodecylsulfat (SDS)

Ni-NTA-Agarose

Paraformaldehyd (PFA)

PBS (Dulbecco w/o Ca2+, Mg2+)

Salzsäure (37\%)

TEMED

Tris(hydroxymethyl)-aminomethan

Triton X-100

Tween-20

\subsubsection{Kommerzielle Kits}

\section{DNA-Aufreinigung}

QIAquick ${ }^{\circledR}$ PCR Purification Kit

\section{DNA-Gelextraktion}

QIAquick $^{\circledR}$ Gel Extraction Kit

\section{DNA-Ligation}

Quick Ligation Kit $^{\mathrm{TM}}$ (T4 DNA Quick Ligase) New England Biolabs, Frankfurt

\section{Isolierung genomischer DNA}

QIAamp ${ }^{\circledR}$ DNA Mini Kit
Sigma-Aldrich, München

Carl Roth, Karlsruhe

Merck, Darmstadt

Merck, Darmstadt

Sucofin

Merck, Darmstadt

Merck, Darmstadt

Carl Roth, Karlsruhe

Merck, Darmstadt

Merck, Mannheim

Merck, Mannheim

Merck, Mannheim

Merck, Mannheim

Qiagen, Hilden

Merck, Mannheim

Biochrom, Berlin

Merck, Mannheim

Carl Roth, Karlsruhe

Merck, Mannheim

Merck, Darmstadt

Sigma-Aldrich, München
Qiagen, Hilden

Qiagen, Hilden 


\section{Isolierung von Gesamt-RNA}

GenElute $^{\mathrm{TM}}$ Mammalian Total RNA Kit

PCR-Klonierung

QIAGEN $^{\circledR}$ PCR Cloning Kit

\section{Plasmid-Präparation}

GenElute $^{\mathrm{TM}}$ Plasmid Maxi Prep Kit Sigma

GenElute $^{\mathrm{TM}}$ Plasmid Mini Prep Kit Sigma

\section{Quantitative Real-Time PCR}

LightCycler $^{\circledR}$. FastStart DNA Master ${ }^{\text {Plus }}$

SYBR Green I

\subsubsection{Verbrauchsmaterialien}

Chromatografie-Säulen

Einmalkanülen (20 G, 26 G)

Einmalküvetten

Elektroporationsküvetten

Deckgläschen

Kryoröhrchen

Nitrozellulosemembran

PD-10 Säulen

Spritzen $(10 \mathrm{ml}, 30 \mathrm{ml}, 50 \mathrm{ml})$

Spritzenfilter, Filtropur S 0,2 mM

Vacuum-Filter

Vivaspin 15

Whatman-Filterpapier

Zellschaber

Zellkulturflaschen und -platten

\subsubsection{Geräte}

Acrylamid Gel-Caster

Agarose-Gelelektrophorese

Chemilumineszenz-Detektion
Sigma-Aldrich, München

\author{
Qiagen, Hilden
}

Sigma-Aldrich, München

Sigma-Aldrich, München

Roche, Mannheim
Poly-Prep, BioRad, München

B. Braun, Meldungen

1, $5 \mathrm{ml}$ halbmikro, Brand, Wertheim

Gene Pulser Cuvette 0,2 cm, BioRad, München

Ø 13 mm, Thermo Fisher Scientific, Schwerte

$2 \mathrm{ml}$ Nunc, Thermo Fisher Scientific, Schwerte

Hybond ECL, GE Healthcare, München

GE Healthcare, München

Terumo, Eschborn

Sarstedt, Nümbrecht

Corning Incorporated, Amsterdam (NL)

10.000 MWCO PES, Sartorius, Göttingen

Grade 4, Rettberg, Göttingen

Breite 13 mm, Biochrom, Berlin

Greiner Bio-One, Frickenhausen
Mini Protean II, BioRad, München

Keutz Labortechnik, Reiskirchen

ImageQuant LAS-4000, Fujifilm, Düsseldorf 
ElectroCell Manipulator

Fluoreszenzmikroskop

Fluoreszenz-Spektrometer

Geldokumentationsanlage

Inkubator

Laborwaagen

LightCycler $^{\circledR}$

Magnetrührer

Netzteil

Neubauer-Zählkammer

$\mathrm{pH}-$ Meter

Photometer

Pipetten

Pipettierhilfe

Plattformschüttler

Rotator

Schüttelinkubator

SDS-PAGE System

Semi-Dry Blotgerät

Sterilbank

Thermocycler

Thermomixer

Ultraschall-Homogenisator

UV-Tisch

Vortexer

Wasserbad

Zellkulturmikroskop

Zentrifugen
Typ 600 BTX, Holliston, MA, (USA)

Axiovert 200 M, Zeiss, Göttingen

Perkin-Elmer LS 50B

BioDoc II, Biometra, Göttingen

Heracell 240, Heraeus, Hanau

CP 224 S und LP 6200 S, Sartorius, Göttingen

Roche, Basel, Schweiz

RCT basic, IKA Labortechnik, Staufen

Standard Power Pack P25, Biometra, Göttingen

Roth, Karlsruhe

766, Calimatic, Knick, Berlin

Ultraspec 1000, Pharmacia Biotech, Freiburg

Reference, Eppendorf, Hamburg

Pipetboy accu-jet pro, Brand, Wertheim

Duomax 1030, Heidolph, Schwabach

Heidolph, Schwabach

SM 30 Control (Schüttler) + TH 30

(Inkubationshaube), Edmund Bühler, Hechingen

Mini-Protean 3 cell, BioRad, München

Sartorius, Göttingen

BDK-S 1800, BDK Luft- und Reinraum

Technik, Sonnenbühl

T3, Biometra, Göttingen

Compact, Eppendorf, Hamburg

Sonifier 250 Branson, USA

TFX-20M, Gibco BRL, Eggenstein

Reax Top, Heidolph, Kelheim

GFL, Burgwedel

DM IL, Leica, Heidelberg

Megafuge 2.0, Heraeus, Hanau

Megafuge 2.0 RS, Heraeus, Hanau

Centrifuge 5424, Eppendorf, Hamburg

Centrifuge 5417R, Eppendorf, Hamburg

Avanti TM J-25 BeckmannCoulter, Krefeld 


\subsection{Methoden}

\subsubsection{Zellkultur}

\subsubsection{Kultivierung der humanen Vorhautfibroblasten (HFF)}

Die Kultivierung der als Wirtszellen dienenden HFF erfolgte in T75 Zellkulturflaschen (75 $\mathrm{cm}^{2}$ ) bei $37^{\circ} \mathrm{C}$ und einer mit Wasserdampf gesättigten Atmosphäre von $5 \% \mathrm{CO}_{2}$. Nach Absaugen des Mediums wurde der Monolayer zunächst mit $2 \mathrm{ml}$ 0,05\% Trypsin-EDTA gewaschen, anschließend mit $3 \mathrm{ml}$ 0,05\% Trypsin-EDTA überschichtet und so lange inkubiert, bis eine Dissoziation und ein erstes Ablösen der adhärenten Zellen vom Untergrund erkennbar war. Nach Absaugen des Trypsin-EDTA Gemischs, wurden die Zellen durch Abklopfen vollständig vom Boden der Kulturflasche gelöst. In Abhängigkeit des gewünschten Verdünnungsfaktors (Splitrate) wurden die HFF in frischem, auf $37^{\circ} \mathrm{C}$ vorgewärmten DMEM mit 10\% FCS (v/v), $100 \mathrm{U} / \mathrm{ml}$ Penicillin und $100 \mu \mathrm{g} / \mathrm{ml}$ Streptomycin (1\% (v/v), P/S) aufgenommen und auf neue Zellkulturflaschen oder -platten verteilt. Die vollständige Konfluenz der Fibroblasten wurde nach ungefähr 7 Tagen erreicht.

\subsubsection{Kultivierung von $T$. gondii}

Zur Subkultivierung von T. gondii wurden stets in T25 Flaschen $\left(25 \mathrm{~cm}^{2}\right)$ kultivierte HFF verwendet. Nach einem Austausch des Mediums gegen $37^{\circ} \mathrm{C}$ erwärmtes DMEM mit $1 \%$ FCS $(\mathrm{v} / \mathrm{v})$, und $1 \% \mathrm{P} / \mathrm{S}(\mathrm{v} / \mathrm{v})$ erfolgte die Infektion der Zellen mit jeweils rund $6 \times 10^{5} \mathrm{bzw} .3 \times 10^{5}$ Parasiten. Nach einer 2- bzw. 3-tägigen Inkubation bei $37^{\circ} \mathrm{C}$ und einer mit Wasserdampf gesättigten Atmosphäre von $5 \% \quad \mathrm{CO}_{2}$ zeigte sich eine nahezu vollständige Zelllyse der Wirtszellen und die extrazellulären Parasiten wurden erneut passagiert.

\subsubsection{Kryokonservierung und Auftauen der Zellen}

Zur Konservierung der HFF einer T75 Zellkulturflasche wurde zunächst wie in Abschnitt 2.2.1.1 beschrieben mittels Trypsin-EDTA Behandlung eine Zellsuspension hergestellt. Diese wurde bei 400 x g für 10 min zentrifugiert und das Pellet, nach Absaugen des Überstandes, in $3 \mathrm{ml}$ eiskaltem DMEM mit 40\% FCS (v/v) resuspendiert. Nach einer Inkubationszeit von 5 bis $10 \mathrm{~min}$ auf Eis wurde die Zellsuspension vorsichtig mit $3 \mathrm{ml}$ 2fach-Einfriermedium versetzt, zu je $1 \mathrm{ml}$ in Kryoröhrchen aliquotiert und diese sofort bei $-80^{\circ} \mathrm{C}$ eingefroren.

Zur Kryokonservierung extrazellulärer T. gondii wurden diese zunächst für 10 min bei 1.314 $\mathrm{x} g$ zentrifugiert und das überstehende Medium entfernt. Das mit $1 \mathrm{ml}$ eiskaltem DMEM mit $1 \%$ FCS resuspendierte Pellet wurde für 5 bis 10 min auf Eis inkubiert und anschließend mit 1 
$\mathrm{ml}$ 2fach-Einfriermedium vermischt. Aliquots von $0,5 \mathrm{ml}$ wurden sofort bei $-80^{\circ} \mathrm{C}$ eingefroren.

Die dauerhafte Lagerung der Proben (HFF und T. gondii) erfolgte in flüssigem Stickstoff. Das Auftauen der Aliquots geschah (zügig) in einem auf $37^{\circ} \mathrm{C}$ erwärmtem Wasserbad und sofortiger Überführung des Inhalts in Zellkulturflaschen mit vorgewärmten DMEM mit 10\% FCS (HFF) bzw. 1\% FCS (T. gondii). Um letzte Reste des DMSOs zu entfernen, wurde nach $24 \mathrm{~h}$ ein Mediumwechsel vorgenommen.

2fach-Einfriermedium

$20 \%$ DMSO (v/v)

in DMEM mit $1 \%$ FCS und $1 \% \mathrm{P} / \mathrm{S}$

\subsubsection{Stabile Transfektion von $T$. gondii}

Aus einer frisch lysierten T25 Kulturflasche wurden die extrazellulären Parasiten zunächst bei 1.314 x g für 10 min pelletiert. Um überflüssiges Medium zu entfernen, wurde der Überstand abgesaugt, das Pellet mit $10 \mathrm{ml}$ Cytomix resuspendiert (Waschschritt) und die Parasitenanzahl mittels einer Neubauer-Zählkammer bestimmt. Nach einem weiteren Zentrifugationsschritt für 10 min bei 1.314 x g erfolgte die Einstellung der Parasitenkonzentration auf $\sim 3 \times 10^{7} / \mathrm{ml}$ mit steril filtriertem Cytomix/ATP/GSH. Pro Transfektionsansatz wurden $370 \mu \mathrm{l}$ der Parasitensuspension mit $30 \mu \mathrm{g}$ linearisiertem Plasmid $(30 \mu \mathrm{l})$ steril vermischt. Die vorhergehende Isolierung der Plasmid-DNA erfolgte mit dem GenElute Plasmid Maxi Prep Kit. Sollte das Plasmid nicht-homolog (ungerichtet) ins Genom integriert werden, wurden dem Ansatz zusätzlich 20 U Restriktionsenzym hinzugefügt. Das Gesamtvolumen von $400 \mu 1$ wurde, unter Vermeidung von Blasen, in eine 0,2 cm Elektroporationsküvette pipettiert und mit einem BTX Eclectro Cell Manipulator 600 unter folgenden Einstellungen elektroporiert: $1,4 \mathrm{kV}$ (Ladespannung), $24 \Omega$ (Widerstand) und $25 \mu \mathrm{F}$ (Kondensator-Kapazität). Im Anschluss an eine 15-minütige Ruhephase bei RT wurden die transfizierten Parasiten in eine T25 Zellkulturflasche überführt und unter den unter 2.2.1.2 aufgeführten Bedingungen kultiviert. Im Falle einer Selektion mit Chloramphenicol wurde dem Medium sofort die in der Tabelle 2.5 aufgeführte Konzentration zugegeben. Eine Selektion mit Pyrimethamin bzw. MPA und Xanthin erfolgte erst $24 \mathrm{~h}$ nach erfolgter Transfektion. 
Cytomix

$120 \mathrm{mM} \mathrm{KCl}$

$0,15 \mathrm{mM} \mathrm{CaCl}_{2}$

$10 \mathrm{mM} \mathrm{K}_{2} \mathrm{HPO}_{4} / \mathrm{KH}_{2} \mathrm{PO}_{4}, \mathrm{pH} 7,6$

25 mM HEPES

2 mM EDTA $(\mathrm{pH} 8,0)$

$5 \mathrm{mM} \mathrm{MgCl}_{2}$

$\rightarrow \mathrm{pH}$ 7,6 mit $\mathrm{KOH}$

$\rightarrow$ Sterilfiltration
Cytomix/ATP/GSH

$12 \mathrm{mg}$ ATP

15 mg Glutathion

$10 \mathrm{ml}$ Cytomix

$\rightarrow$ Sterilfiltration

\subsubsection{Einzelklonierung transgener $T$. gondii Linien}

Um aus einer transgenen T. gondii Linie Einzelklone mit einem definierten Genotyp zu erhalten, wurde die nach Roos et al. (1994) beschriebene Methode der seriellen Verdünnung verwendet. Dazu wurden in jedes Well einer 96-Well-Zellkulturplatte $200 \mu 1$ einer HFFSuspension ausgesät und bis zu ihrer Konfluenz kultiviert. Nach Absaugen des Mediums wurde in den Wells zunächst ein Volumen von $100 \mu 1$ DMEM (1\% FCS) vorgelegt. Um die $\mathrm{zu}$ klonierenden extrazellulären Parasiten einer frisch lysierten T25 Kulturflasche von Zelltrümmern der Wirtszellen zu trennen, wurden diese bei $34 \mathrm{x}$ g für 5 min zentrifugiert. Der Parasiten-Überstand wurde durch eine weitere Zentrifugation bei $1.314 \mathrm{x}$ g pelletiert und in einem definierten Volumen resuspendiert. Die anschließende Bestimmung der Parasitenanzahl erfolgte mit einer Neubauer-Zählkammer. Insgesamt $100 \mu$ l einer auf 2000 Parasiten/10 $\mathrm{ml}$ eingestellten Parasitensuspension wurden daraufhin in die erste Reihe der 96-Well-Platte (A1-H1) pipettiert und bis zur sechsten Reihe der Platte mit einem Faktor von zwei seriell verdünnt. In jedem Well der letzten Reihe lagen daher theoretisch 0,625 Parasiten vor. Das gleiche Verfahren wurde auch für die Reihen sieben bis zwölf der Zellkulturplatte durchgeführt und diese (ohne sie dabei zu bewegen) für sechs Tage kultiviert. Die Identifizierung einzelner Klone erfolgte mikroskopisch, durch die Bestimmung der in den Wells befindlichen Anzahl an Parasiten-Plaques. Der Inhalt der Wells mit einem einzelnen Plaque wurde vollständig in eine T25 Kulturflasche überführt und bis zur vollständigen Lyse des Monolayers kultiviert. 


\subsubsection{Bestimmung der $T$. gondii Wachstumsrate}

\subsection{Replikationsassay}

Um intrazelluläre Replikationsraten sowie Wachstumskinetiken der Parasiten zu bestimmen, wurden konfluente, in 24-Well-Platten auf Deckgläschen kultivierte, HFF zunächst mit $3 \times 10^{4}$ Parasiten infiziert. Diese verblieben entweder unbehandelt oder wurden gleichzeitig mit 100 nM HDQ, Compound B oder Atovaquon behandelt. Nach Erreichen des jeweiligen Untersuchungszeitpunktes wurden die Zellen einmal mit 1x PBS (1 ml) gewaschen und für 15 min mit $500 \mu 1$ 4\% PFA/PBS fixiert. Im Anschluss an einen weiteren Waschschritt mit 1x PBS, erfolgte die Permeabilisierung mit $500 \mu 1$ 0,25\% Triton X-100/PBS für 15 min. Nach drei weiteren Waschschritten mit 1x PBS wurden die Deckgläschen kurz in $\mathrm{ddH}_{2} \mathrm{O}$ getaucht, die beschichtete Seite mit Mowiol eingedeckelt und die Proben über Nacht bei $4^{\circ} \mathrm{C}$ getrocknet. Die Bestimmung der durchschnittlichen Anzahl intrazellulärer Parasiten erfolgte mikroskopisch durch die Auszählung der Parasiten von mindestens 100 zufällig ausgewählten parasitophoren Vakuolen. Die Herstellung der angegebenen Lösungen von PFA und Triton X100 erfolgte jeweils mit $1 \mathrm{x}$ PBS.

\section{$\underline{\text { Mowiol }}$}

7,81 $\mathrm{ml} \mathrm{87 \%} \mathrm{Glycerin}$

2,4 g Mowiol 4-88

$6 \mathrm{ml} \mathrm{ddH_{2 } \mathrm { O }}$

$12 \mathrm{ml} \mathrm{0,2} \mathrm{M}$ Tris pH 8,5

$\rightarrow$ bei RT lösen und anschließend bei $50{ }^{\circ} \mathrm{C}$ für $2 \mathrm{~h}$ rühren

$\rightarrow$ Zentrifugation bei 5.000 x g für $15 \mathrm{~min}$

$\rightarrow$ Überstand bei $-20^{\circ} \mathrm{C}$ einfrieren

\subsection{Plaque-Assay}

Der von Roos et al. (1994) beschriebene Plaque-Assay eignet sich besonders um die Replikationsrate von $T$. gondii über mehrere Generationen hinweg zu untersuchen und damit die Vitalität verschiedener Parasitenstämme zuverlässig zu vergleichen. Konfluente HFF, in T25 Zellkulturflaschen, wurden dazu mit jeweils 200 Parasiten infiziert und für insgesamt 6 Tage (ohne diese dabei zu bewegen) kultiviert. Sechs Tage p. i. wurden die Zellen zunächst einmal mit 1x PBS gewaschen und der Monolayer für 5 min mit $-20^{\circ} \mathrm{C}$ Methanol fixiert und anschließend für weitere $5 \mathrm{~min}$ mit Kristallviolett-Lösung gefärbt. Überschüssiges Kristallviolett wurde nach Absaugen der Färbelösung durch mehrmaliges Spülen mit 1x PBS entfernt und der Zellrasen schließlich luftgetrocknet. Die durchschnittliche Fläche von 
mindestens 50 zufällig ausgewählten Plaques wurde durch das Bildverarbeitungsprogramm Image J berechnet.

Kristallviolett-Lösung

$6,25 \mathrm{~g}$ Kristallviolett

$62,5 \mathrm{ml} \mathrm{EtOH}$ (absolut)

$250 \mathrm{ml} 1 \%$ Ammoniumoxalat ( $/ \mathrm{v}$ in $\left.\mathrm{ddH}_{2} \mathrm{O}\right)$

\subsubsection{Immunfluoreszenztest (IFT)}

Konfluente, in 24-Well-Platten auf Deckgläschen kultivierte, HFF wurden mit $\sim 3 \times 10^{4}$ Parasiten infiziert und nach Erreichen des jeweiligen Untersuchungszeitpunktes zunächst einmal mit 1x PBS (1 ml) gewaschen. Nach einer Fixierung der Zellen für 15 min mit $500 \mu 1$ 4\% PFA/PBS, erfolgte ein weiterer Waschschritt mit 1x PBS und eine anschließende Permeabilisierung für 15 min mit $500 \mu 1$ 0,25\% Triton X-100/PBS. Nach einer Blockierung mit 1\% BSA/PBS für $1 \mathrm{~h}$ erfolgte die Inkubation mit $300 \mu 1$ des Primärantikörpers (in 1\% BSA/PBS) für $1 \mathrm{~h}$. Zur Entfernung ungebundener Antikörper wurden die Zellen dreimal mit 1x PBS für jeweils 5 min gewaschen und für $1 \mathrm{~h}$ mit $300 \mu 1$ des Sekundärantikörpers inkubiert (in 1\% BSA/PBS). Nach drei weiteren Waschschritten mit 1x PBS wurden die Deckgläschen kurz in $\mathrm{ddH}_{2} \mathrm{O}$ getaucht und die beschichtete Seite mit Mowiol eingedeckelt. Nach einer Trocknung der Proben über Nacht bei $4^{\circ} \mathrm{C}$ wurden diese unter dem Fluoreszenzmikroskop ausgewertet. Die Herstellung der angegebenen Lösungen von PFA, Triton X-100 und BSA erfolgte jeweils mit 1x PBS.

\subsubsection{Analyse des mitochondrialen Membranpotentials $\left(\Delta \Psi_{m}\right)$ mit MitoTracker Red}

Für eine Analyse des mitochondrialen Membranpotentials $\left(\Delta \Psi_{\mathrm{m}}\right)$ von T. gondii wurde MitoTracker Red (Fluorophor) verwendet. Dieser kationische Farbstoff diffundiert passiv durch die Zellmembran, wo er akkumuliert und durch die Oxidation respiratorisch aktiver Zellen in die fluoreszierende Form umgewandelt wird. Parasiten mit einem vorhandenen $\Delta \Psi \mathrm{m}$ können durch fluoreszenzmikroskopische Analysen somit von Toxoplasmen ohne nachweisbares $\Delta \Psi \mathrm{m}$ differenziert werden. Dadurch ist es unter anderem möglich, Auswirkungen antiparasitärer Substanzen auf das $\Delta \Psi \mathrm{m} z u$ untersuchen. Konfluente, in 24-Well-Platten auf Deckgläschen kultivierte, HFF wurden zunächst mit 3x10 4 Parasiten infiziert. Im Falle unbehandelter Kontrollen wurden die Zellen 24 h p. i., nach einer Behandlung mit 1-Hydroxyquinolonen 48 h p. i. (zur Entfernung extrazellulärer Parasiten) einmal mit DMEM (10\% FCS) gewaschen. Nach einer Verdünnung von MitoTracker Red auf 
$0,5 \mu \mathrm{M}$ wurde jeweils $1 \mathrm{ml}$ des Medium in die Wells pipettiert und bei $37^{\circ} \mathrm{C}$ für $45 \mathrm{~min}$ inkubiert. Anschließend wurden die Zellen für jeweils 5 min dreimal mit DMEM (10\% FCS) gewaschen, gefolgt von zwei weiteren Waschschritten mit 1x PBS. Nach einer Fixierung der Zellen für 15 min mit $500 \mu 1$ 4\% PFA/PBS erfolgte ein weiterer Waschschritt mit 1x PBS und eine anschließende Permeabilisierung für 15 min mit $500 \mu 1$ 0,25\% Triton X-100/PBS. Nach drei weiteren Waschschritten mit 1x PBS wurden die Deckgläschen kurz in $\mathrm{ddH}_{2} \mathrm{O}$ getaucht, die beschichtete Seite mit Mowiol eingedeckelt und die Proben über Nacht bei $4^{\circ} \mathrm{C}$ getrocknet. Die Bestimmung des prozentualen Anteils parasitophorer Vakuolen mit Parasiten, die ein nachweisbares $\Delta \Psi \mathrm{m}$ besitzen, wurde durch Fluoreszenzmikroskopie von mindestens 100 zufällig ausgewählten Vakuolen ermittelt. Die Herstellung der angegebenen Lösungen von PFA und Triton X-100 erfolgte jeweils mit 1x PBS, MitoTracker Red wurde mit DMEM (10\% FCS) verdünnt.

\subsubsection{Allgemeine molekularbiologische Methoden - Nukleinsäuren}

\subsubsection{Isolierung von Nukleinsäuren und cDNA Synthese}

Extraktion genomischer DNA erfolgte mit dem QIAamp DNA Mini Kit. Gesamt-RNA wurde durch das GenElute Mammalian Total RNA Kit isoliert und zur Denaturierung kontaminierter DNA (nach Herstellerprotokoll) mit DNase I behandelt. Etwa $5 \mu \mathrm{g}$ der isolierten Gesamt-RNA wurden mittels der M-MLV Reversen Transkriptase und unter Verwendung eines Oligo(dT) $)_{18}$ Primers für die cDNA-Synthese eingesetzt. Die reverse Transkription erfolgte in einem $50 \mu \mathrm{l}$ Ansatz für $1 \frac{1 / 2}{\mathrm{~h}}$ bei $37^{\circ} \mathrm{C}$. Für eine anschließende Aufreinigung der cDNA wurde das QIAquick PCR Purification Kit verwendet und die DNA

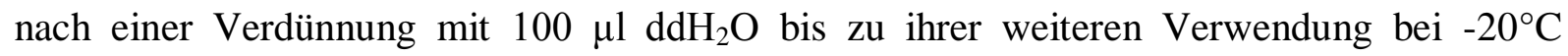
gelagert.

cDNA-Synthese

34,5 $\mu$ l Gesamt-RNA

$10 \mu 1$ M-MLV 5x Puffer

2,5 $\mu \mathrm{l}$ dNTP-Mix (2,5 mM)

$2 \mu \mathrm{l}$ Oligo(dT) ${ }_{18}$ Primer $(10 \mu \mathrm{M})$

$1 \mu$ l Reverse-Transkriptase (200 U) 


\subsubsection{Polymerase Kettenreaktion (PCR)}

\subsection{Konventionelle PCR}

Die Bedingungen der konventionellen PCR im Thermocycler richtete sich jeweils nach den spezifischen Eigenschaften der verwendeten Polymerase, der Template DNA (cDNA, genomische- oder Plasmid-DNA), der Schmelztemperatur $\left(\mathrm{T}_{\mathrm{M}}\right)$ des Primerpaars und der Größe (bp) des PCR-Produkts. Die Amplifikation wurde dabei in einem PCR-Ansatz von 50 $\mu 1$ und (abhängig von der verwendeten Polymerase) mit dem unter Tabelle 2.8 aufgeführten PCR-Programm durchgeführt. Die zur Amplifikation des PCR-Produkts eingesetzte Annealing-Temperatur und Elongationszeit sind in den Tabellen 2.1 - 2.3 der Primerpaare aufgelistet.

$\underline{\text { PCR-Ansatz }}$

Template-DNA $50-100$ ng

Sensen Primer $(5 \mu \mathrm{M}) \quad 5 \mu \mathrm{l}$

Antisense Primer $(5 \mu \mathrm{M}) \quad 5 \mu \mathrm{l}$

dNTP-Mix $1 \mu l$

Puffer Phusion (5x) $10 \mu \mathrm{l} / \operatorname{Taq}$ (10x) $5 \mu \mathrm{l}$

DNA Polymerase Phusion (2 U/ $\mu \mathrm{l}) 0,5 \mu \mathrm{l} / \mathrm{T} a q(5 \mathrm{U} / \mu \mathrm{l}) 0,25 \mu \mathrm{l}$

PCR- $\mathrm{H}_{2} \mathrm{O}$ ad $50 \mu \mathrm{l}$

Tabelle 2.8: PCR-Programm der Phusion- und Taq-Polymerase

Phusion-Polymerase

Taq-Polymerase

\begin{tabular}{lcccccr}
\hline Anfängliche Denaturierung & $98^{\circ} \mathrm{C}$ & $30 \mathrm{~s}$ & & $94^{\circ} \mathrm{C}$ & $3 \mathrm{~min}$ & \\
\hline Denaturierung & $98^{\circ} \mathrm{C}$ & $10 \mathrm{~s}$ & 30 & $94^{\circ} \mathrm{C}$ & $30 \mathrm{~s}$ & 35 \\
Annealing & $\mathrm{x}^{\circ} \mathrm{C}$ & $30 \mathrm{~s}$ & Zyklen & $\mathrm{x}^{\circ} \mathrm{C}$ & $60 \mathrm{~s}$ & Zyklen \\
Elongation & $72^{\circ} \mathrm{C}$ & $\mathrm{x} \mathrm{s}$ & & $72^{\circ} \mathrm{C}$ & $\mathrm{x} \mathrm{s}$ & \\
\hline Finale Elongation & $72^{\circ} \mathrm{C}$ & $10 \mathrm{~min}$ & $72^{\circ} \mathrm{C}$ & $7 \mathrm{~min}$ & \\
Kühlung & $4^{\circ} \mathrm{C}$ & $\infty$ & $4^{\circ} \mathrm{C}$ & $\infty$ \\
\hline
\end{tabular}

\subsection{Real-Time PCR (RT-PCR)}

Die relative mRNA Menge der untersuchten Gene wurde mit Hilfe des LightCycler FastStart DNA Master ${ }^{\text {Plus }}$ SYBR Green I Kits quantifiziert. Dazu wurde Gesamt-RNA isoliert, revers transkribiert und die gewonnene cDNA durch LightCycler ${ }^{\circledR}$ RT-PCR analysiert. Die Amplifikation wurde dabei in einem RT-PCR-Ansatz von $20 \mu 1$ für insgesamt 40 Zyklen mit 
dem unter Tabelle 2.9 aufgeführten RT-PCR-Programm durchgeführt. Die verwendeten Annealing-Temperaturen und Elongationszeiten sind in Tabelle 2.4 aufgeführt.

$\underline{\text { RT-PCR-Ansatz }}$

Template-cDNA $\quad 5 \mu 1$

Sense Primer $(5 \mu \mathrm{M}) \quad 1 \mu \mathrm{l}$

Antisense Primer $(5 \mu \mathrm{M}) \quad 1 \mu \mathrm{l}$

Master-Mix $4 \mu 1$

PCR- $\mathrm{H}_{2} \mathrm{O} \quad 9 \mu \mathrm{l}$

Tabelle 2.9: LightCycler $^{\circledR}$ RT-PCR-Programm

Fluoreszenzmessung

\begin{tabular}{llllcc}
\hline & Anfängliche Denaturierung & $95^{\circ} \mathrm{C}$ & $10 \mathrm{~min}$ & & - \\
\hline \multirow{3}{*}{ Amplifikation } & Denaturierung & $95^{\circ} \mathrm{C}$ & $10 \mathrm{~s}$ & 40 & - \\
& Annealing & $\mathrm{x}^{\circ} \mathrm{C}$ & $10 \mathrm{~s}$ & Zyklen & einmalig \\
& Elongation & $72^{\circ} \mathrm{C}$ & $\mathrm{x} \mathrm{s}$ & & - \\
\multirow{2}{*}{ Schmelzkurve } & Annealing & $95^{\circ} \mathrm{C}$ & $0 \mathrm{~s}$ & - \\
& Schmelzung & $65^{\circ} \mathrm{C}$ & $15 \mathrm{~s}$ & kontinuierlich \\
\hline & Kühlung & $95^{\circ} \mathrm{C}$ & $0 \mathrm{~s}$ & - \\
\hline
\end{tabular}

Die Messung der Probe erfolgte stets als Doppelbestimmung. Routinemäßig wurde nach jeder PCR-Amplifikation eine Schmelzkurvenanalyse durchgeführt. Crossing Point (Cp) Werte wurden zur Quantifizierung der Genexpression zweier Proben herangezogen und durch die mRNA Expression des konstitutiv exprimierten Tubulin Gens normalisiert.

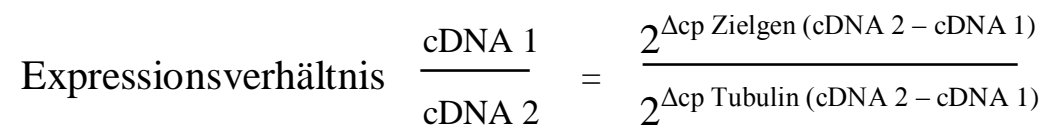

\subsubsection{DNA-Konzentrationsbestimmung}

Für die Ligation und Sequenzierung amplifizierter DNA-Produkte war es erforderlich, die DNA-Konzentration $(\mathrm{ng} / \mu \mathrm{l})$ des Amplifikats abzuschätzen. Dies erfolgte optisch über den Vergleich der Banden-Fluoreszenzintensität der zu analysierenden Probe. Als Referenz dienten dabei die definierten Banden des aufgetrennten DNA-Größenmarkers. 


\subsubsection{DNA-Präzipitation}

Zur Fällung gelöster DNA wurde die Probe mit einem Zehntel des Gesamtvolumens 3 M Natriumacetat $(\mathrm{pH} \mathrm{5,0)}$ und einem Volumen Isopropanol versetzt, mehrmals invertiert und anschließend für 30 min bei 20.240 x g zentrifugiert. Der Überstand wurde entfernt und das DNA-Pellet, nach einem Waschschritt mit 70\% Ethanol (v/v), erneut für $10 \mathrm{~min}$ bei $10.000 \mathrm{x}$ g zentrifugiert. Nach Abnahme des Ethanols wurde das Pellet für 10 bis 15 min luftgetrocknet und die DNA mit dd $\mathrm{H}_{2} \mathrm{O}$ resuspendiert. Die Lufttrocknung und Resuspension der für die Transfektion von T. gondii verwendeten Plasmid-DNA erfolgte jeweils unter sterilen Bedingungen.

\subsubsection{DNA-Sequenzierung}

Für eine Sequenzierung der kodierenden Gensequenzen der sechs Ubiquinon-reduzierenden mitochondrialen Dehydrogenasen (ndh2-I, ndh2-II, sdh, mqo, dhodh, g3pdh) und des Cytochrom b Gens wurde genomische DNA oder cDNA beider Resistenzmutanten (3L-H11, 3F-A6) sowie von Wildtyp RHAuprt Parasiten mit den unter Tabelle 2.1 aufgeführten Primern durch konventionelle PCR amplifiziert. Die nachfolgende DNA Sanger Sequenzierung der jeweiligen PCR-Produkte erfolgte mit den genannten Primern durch die Firma SeqLab (Sequence Laboratories, Göttingen).

\subsubsection{Plasmid-Klonierung}

Für alle in dieser Arbeit hergestellten Plasmide erfolgte die PCR-Amplifizierung der Inserts mit der Phusion High-Fidelity DNA-Polymerase. Die anschließende Aufreinigung der amplifizierten PCR-Produkte erfolgte durch eine Agarosegel-Extraktion der DNA (QIAquick Gel Extraction Kit). Für einen effektiven Restriktionsverdau wurden die Amplifikate zunächst in den pDrive Vektor subkloniert. Die Phusion Polymerase erzeugt im Gegensatz zur Taq-Polymerase keinen unspezifischen Adenin-Überhang am 3'-Ende des PCR-Produkts, dieser wird für eine Ligation des PCR-Fragments in den pDrive Vektor jedoch benötigt. Das Amplifikat wurde daher, in einem $20 \mu \mathrm{l}$ Ansatz, für einen finalen Elongationsschritt bei $72^{\circ} \mathrm{C}$ für $30 \mathrm{~min}$ mit der Taq-Polymerase inkubiert und (entsprechend der Anleitung des Herstellers) in den pDrive Vektor kloniert. Der Vektor wurde anschließend, entsprechend dem Herstellerprotokoll, in chemisch kompetente DH5a Bakterien transformiert und diese anschließend auf Ampicillin-Platten ausplattiert und über Nacht bei $37^{\circ} \mathrm{C}$ inkubiert. Zur Identifizierung positiver Transformanten durch das Blau-Weiß-Screening wurde die LB-Agarplatte vor dem Ausplattieren der Bakterien mit $40 \mu 1 \mathrm{X}-\mathrm{Gal}$ (Stocklösung $40 \mathrm{mg} / \mathrm{ml}$ 
in DMF) sowie $40 \mu \mathrm{l}$ IPTG (Stocklösung $1 \mathrm{M}$ in $\mathrm{ddH}_{2} \mathrm{O}$ ) versetzt und für $5 \mathrm{~min}$ bei $37^{\circ} \mathrm{C}$ inkubiert. Blaue Kolonien (mit einem religiertem Vektor) konnten somit von weiteren Analysen ausgeschlossen werden.

Adenin-Überhang

$15 \mu 1$ PCR-Produkt

$2 \mu 110 x$ Puffer

$1 \mu \mathrm{l}$ dNTP-Mix

$1 \mu \mathrm{ldd} \mathrm{d}_{2} \mathrm{O}$

$1 \mu 1$ Taq-Polymerase

Die Isolierung der Plasmid-DNA aus E. coli erfolgte mit dem GenElute Plasmid Mini Prep Kit. Der nachfolgende Verdau des in den pDrive Vektor subklonierten PCR-Fragments mit den jeweiligen Restriktionsenzymen erfolgte nach Angabe des Herstellers. Für den Verdau von $\sim 2 \mu \mathrm{g}$ DNA wurden von jedem der verwendeten Restriktionsenzyme insgesamt $5 \mathrm{U}$ eingesetzt und der Ansatz für mindestens $2 \mathrm{~h}$ bei $37^{\circ} \mathrm{C}$ inkubiert. Das geschnittene Produkt wurde schließlich erneut durch Isolation aus einem Agarosegel aufgereinigt und in den finalen, durch eine Behandlung mit antarktischer Phosphatase, dephosphorylierten Vektor kloniert. Die Ligation erfolgte dabei mit Hilfe der Quick T4 DNA Ligase (Quick Ligation Kit) in einem molaren Verhältnis von Insert zu Vektor von 3:1, wobei stets 50 ng des Vektors eingesetzt wurden. Für die benötigte Menge Insert-DNA galt dabei:

Masse $_{\text {Insert }}(\mathrm{ng})=3 \mathrm{x}$ Masse Vektor $_{(\mathrm{ng})} *$ Länge $_{\text {Insert }}(\mathrm{bp}) /$ Länge Vektor $_{(\mathrm{bp})}$

Die Selektion von DH5a Bakterien mit denen in dieser Arbeit transformierten Plasmiden erfolgte stets mit Ampicillin (Amp), während BL21-CodonPlus(DE3)-RP Bakterien, zum Erhalt des pACYC Plasmids (Gene für die $\arg U$ und proL tRNA), nach der erfolgten Transformation mit den unter Tabelle 2.5 angegebenen Konzentrationen von Amp und Chloramphenicol selektioniert wurden.

Für eine langfristige Lagerung der transformierten Bakterien wurden $350 \mu 1$ der über Nacht bei $37^{\circ} \mathrm{C}$ kultivierten Bakteriensuspension mit $350 \mu \mathrm{LB}-$ Medium mit 30\% (v/v) Glycerin versetzt und bei $-80^{\circ} \mathrm{C}$ eingefroren. 


\subsubsection{Molekularbiologische Methoden der Proteinanalyse}

\subsubsection{Herstellung von $T$. gondii Lysat}

Die Herstellung des T. gondii Lysat erfolgte bei $4^{\circ} \mathrm{C}$. Extrazelluläre Parasiten $\left(\sim 6 \times 10^{7}\right)$ wurden dafür zunächst für 10 min bei 1.314 x g zentrifugiert. Nach einem Waschschritt mit 1x PBS wurde das Pellet in $1 \mathrm{ml} 1 \mathrm{x}$ PBS resuspendiert, welches zuvor mit einem EDTA-freien Protease-Inhibitor-Cocktail versetzt wurde. Die Lysierung der Zellen erfolgte durch drei Einfrier-/Auftau-Zyklen mit flüssigem Stickstoff und anschließender Erwärmung in einem $37^{\circ} \mathrm{C}$ Wasserbad sowie einer zweimaligen Sonifikation der Proben auf Eis für 10 min bei einer Intensität von 2-3 und einem Unterbrechungszyklus von 30\%. Zwischen beiden Schritten wurde die Parasitensuspension für $10 \mathrm{~min}$ auf Eis inkubiert. Unlösliches Material wurde durch Zentrifugation bei 20.800 x g für 20 min entfernt. Die im Überstand befindlichen Proteine wurden sofort verwendet oder bis zur weiteren Verarbeitung bei $-20^{\circ} \mathrm{C}$ eingefroren.

\subsubsection{SDS-PAGE}

Proteingemische wurden durch SDS-PAGE nach ihrem Molekulargewicht aufgetrennt. Die Acrylamidlösung des 10\%igen oder 12\%igen Trenngels wurde dafür zunächst zwischen zwei Glasplatten einer vorbereiteten Gelkammer pipettiert und sofort mit Isopropanol überschichtet. Nach vollständiger Polymerisation des Trenngels (15 bis 20 min) wurde das verbliebene Isopropanol vorsichtig durch spülen mit $\mathrm{H}_{2} \mathrm{O}$ entfernt, die Sammelgellösung auf das Trenngel pipettiert und der Kamm eingesetzt. Die Denaturierung der Proteinproben erfolgte durch Zugabe von 5x-SDS-Probenpuffer und anschließender Erhitzung für 5 min bei $95^{\circ} \mathrm{C}$. Nach einem kurzen Zentrifugationsschritt wurden die Proben (zusammen mit dem Proteinmarker) aufgetragen und elektrophoretisch bei $25 \mathrm{~mA}$ pro Gel in 1x-SDS-Laufpuffer aufgetrennt.

$$
\begin{gathered}
\frac{\text { SDS-Laufpuffer }(10 \mathrm{x})}{30,3 \mathrm{~g} / \mathrm{l} \mathrm{Tris}} \\
144,1 \mathrm{~g} / \mathrm{l} \mathrm{Glycerin} \\
10 \mathrm{~g} / \mathrm{l} \mathrm{SDS} \\
\text { in ddH } \mathrm{H}_{2} \mathrm{O} \\
\rightarrow \mathrm{pH} 8,3-8,5 \text { mit Glycin einstellen } \\
\rightarrow 1 \mathrm{x}-\mathrm{SDS} \text {-Puffer mit } \mathrm{ddH}_{2} \mathrm{O} \text { herstellen }
\end{gathered}
$$

\section{SDS-Probenpuffer $(5 \mathrm{x})$}

$5,7 \mathrm{ml} 87 \%$ Glycerin

$1 \mathrm{~g} \mathrm{SDS}$

$$
\text { 3,125 ml } 1 \text { M Tris-HCl (pH 6.8) }
$$

$100 \mu 1$ 0,5 \% (w/v) Bromphenolblau

$$
\begin{aligned}
& 0,25 \mathrm{~g} \text { DTT } \\
& \rightarrow \text { in } 10 \mathrm{ml} \mathrm{ddH}_{2} \mathrm{O}
\end{aligned}
$$


Tabelle 2.10: Zusammensetzung 10\%iger und 12\%iger SDS-Gellösungen

\begin{tabular}{lccc}
\multicolumn{2}{c}{ Trenngel } & Sammelgel \\
\hline & $\mathbf{1 2 \%}$ & $\mathbf{1 0 \%}$ & $\mathbf{4 , 4 \%}$ \\
$2 \mathrm{M}$ Tris-HCl, pH 8,8 & $0,94 \mathrm{ml}$ & $0,94 \mathrm{ml}$ & - \\
$0,5 \mathrm{M}$ Tris-HCl, pH 6,8 & - & - & $0,625 \mathrm{ml}$ \\
$10 \%$ SDS (w/v) & $0,1 \mathrm{ml}$ & $0,1 \mathrm{ml}$ & $0,1 \mathrm{ml}$ \\
Acrylamid/Bisacrylamid & $2 \mathrm{ml}$ & $1,67 \mathrm{ml}$ & 0,36 \\
ddH ${ }_{2} \mathrm{O}$ & $1,94 \mathrm{ml}$ & $2,27 \mathrm{ml}$ & $1,47 \mathrm{ml}$ \\
APS & $20 \mu \mathrm{l}$ & $20 \mu \mathrm{l}$ & $12,5 \mu \mathrm{l}$ \\
TEMED & $10 \mu \mathrm{l}$ & $10 \mu \mathrm{l}$ & $10 \mu \mathrm{l}$ \\
Bromphenolblau & - & - & $10 \mu \mathrm{l}$ \\
\hline
\end{tabular}

Alle Mengenangaben beziehen sich auf jeweils ein Gel.

\subsubsection{Coomassie-Färbung}

Für eine Färbung der im SDS-Gel aufgetrennten Proteine wurde das Gel für insgesamt $1 \mathrm{~h}$ in die Färbelösung aus Coomassie Blau gelegt und auf einem Plattformschüttler inkubiert. Um die Proteinbanden sichtbar zu machen wurde das Gel anschließend solange in Entfärber geschwenkt, bis der Hintergrund vollständig entfärbt war.

Coomassie-Färbelösung

$10 \%$ Essigsäure (v/v)

$30 \% \mathrm{EtOH}(\mathrm{v} / \mathrm{v})$
Entfärber

$10 \%$ Essigsäure (v/v)

$30 \% \mathrm{EtOH}(\mathrm{v} / \mathrm{v})$

$0,25 \%$ Coomassie Brilliant Blue (w/v)

\subsubsection{Semi-Dry Western Blot}

Um im SDS-Gel elektrophoretisch aufgetrennte Proteine spezifisch durch Antikörper zu färben, wurden diese zunächst durch die Semi-Dry Blot-Methode auf eine Nitrozellulosemembram übertragen. Filterpapiere wurden dazu auf die Größe des SDS-Gels zugeschnitten $(8 \times 5 \mathrm{~cm})$, in dem jeweiligen Transferpuffer getränkt und der Blot unter dem unten angegebenen Schema in der Semi-Dry Blotkammer (luftblasenfrei) aufgebaut. Der Transfer erfolgte für $1 \frac{1}{1 / 2} \mathrm{~h}$ bei $32 \mathrm{~mA}$ pro Gel $\left(0,8 \mathrm{~mA}\right.$ pro $\left.\mathrm{cm}^{2}\right)$. 
Material und Methoden

\section{Kathode (-)}

9 Filterpapiere mit 40 mM 6-Aminocapronsäure, $20 \%$ Methanol (v/v), pH 7,6

SDS-Polyacrylamidgel

Nitrozellulosemembran

3 Filterpapiere mit 25 mM Tris-HCl, $20 \%$ (v/v) Methanol, pH 10,4

6 Filterpapiere 0,3 M Tris-HCl, $20 \%$ (v/v) Methanol, pH 10,4

Anode (+)

\subsubsection{Immundetektion}

Die Schritte der Immundetektion wurden auf einem Plattformschüttler (wenn nicht anders angegeben) bei RT durchgeführt. Im Anschluss des Transfers wurde die Membran zur Blockierung unspezifischer Bindestellen $1 \mathrm{~h}$ mit Blockierlösung gesättigt, für $5 \mathrm{~min}$ mit Waschpuffer gewaschen und über Nacht bei $4^{\circ} \mathrm{C}$ mit dem Primärantikörper inkubiert. Zur Entfernung ungebundener Antikörper wurde die Membran am folgenden Tag dreimal für jeweils 10 min mit Waschpuffer gewaschen und für $1 \frac{1 / 2}{h}$ mit dem Sekundärantikörpers inkubiert. Nachdem die Membran erneut dreimal für 10 min gewaschen wurde, erfolgte die anschließende Immundetektion mittels der Alkalischen Phosphatase oder ECL Detektionsmethode. Die unter Tabelle 2.6 aufgelistete Verdünnung der Primär- und Sekundärantikörper erfolgte jeweils mit Inkubationslösung.

$\begin{array}{ccc}\text { Waschpuffer } & \text { Blockierlösung } & \text { Inkubationslösung (für AK) } \\ 0.05 \% \text { Tween-20 (v/v) } & 5 \% \text { Milchpulver (w/v) } & 5 \% \text { Milchpulver (w/v) } \\ \text { in 1x PBS, pH 7,4 } & 0,2 \% \text { Tween-20 (v/v) } & 0,2 \% \text { Tween-20 (v/v) } \\ & 0,02 \% \mathrm{NaN}_{3}(\mathrm{v} / \mathrm{v}) & \text { in 1x PBS, pH 7,4 } \\ & \text { in 1x PBS, pH 7,4 } & \end{array}$

\subsection{Alkalische Phosphatase Detektion}

Bei der AP-Reaktion wurde die Nitrozellulosemembran zunächst zweimal für 5 min mit $37^{\circ} \mathrm{C}$ vorgewärmten Substratpuffer gewaschen. Die Proteindetektion erfolgte durch die anschließende Zugabe der AP-Reaktionslösung, bis eine ausreichende Färbung der Proteinbande zu erkennen war. Durch gründliches Spülen mit 0,5 M EDTA (pH 8,0) wurde die Färbereaktion abgestoppt. 
Substratpuffer

2\% Diäthanolamin (v/v), $\mathrm{pH} 9,5$ (mit $\mathrm{HCl}$ einstellen)

$$
0,05 \mathrm{mM} \mathrm{MgCl} 2
$$

in physiologischer Kochsalzlösung $\underline{\text { AP-Reaktionslösung }}$

$9 \mathrm{ml}$ Substratpuffer

$1 \mathrm{ml} \mathrm{NBT}(1 \mathrm{mg} / \mathrm{ml}$ in DMF)

$100 \mu \mathrm{lBCIP}\left(5 \mathrm{mg} / \mathrm{ml}\right.$ in $\left.\mathrm{ddH}_{2} \mathrm{O}\right)$

\subsection{Chemilumineszenz (ECL) Detektion}

Für eine Proteindetektion mittels Chemilumineszenz (ECL) wurden beide Komponenten der ECL-Detektionsreagenz in einem Verhältnis von 1:1 gemischt und für 1 min auf die Membran gegeben. Überschüssige Flüssigkeit wurde nach Ablauf der Inkubationszeit mit einen Papiertuch vorsichtig abgesaugt. Die densitometrische Quantifizierung des Proteinlevels erfolgte in der Geldokumentationsanlage (ImageQuant LAS-4000) durch das Programm Multi Gauge V.3.1 (Fujifilm, Düsseldorf).

\subsection{Strippen der Nitrozellulosemembran}

Zur Durchführung einer weiteren Immundetektion der auf die Membran transferierten Proteine können bereits gebundene Antikörper durch das „Stripping“-Verfahren wieder entfernt werden. Dazu wird die Nitrozellulosemembran zunächst 5 min mit $\mathrm{ddH}_{2} \mathrm{O}$ gewaschen und anschließend für 5 min in $0,2 \mathrm{M} \mathrm{NaOH}$ inkubiert. Nach zwei weiteren Waschschritten für 5 min mit $\mathrm{ddH}_{2} \mathrm{O}$ können unspezifische Bindungsstellen erneut blockiert und die Proteine wie unter 2.2.3.5 angegeben nachgewiesen werden.

\subsubsection{Generierung des RH $\Delta k u 80 \Delta h x g p r t \Delta u p r t$ Stamms}

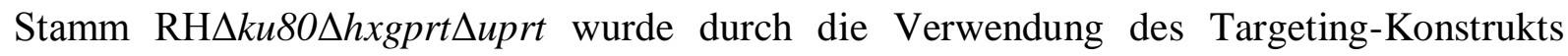
$\mathrm{R} 11 \Delta \mathrm{Bgl}$ generiert, welches freundlicherweise durch Donald und Roos zur Verfügung gestellt wurde (Donald and Roos 1995). Plasmid R11 $\Delta \mathrm{Bgl}$ beinhaltet eine genomische Sequenz des uprt Gens von $11 \mathrm{~kb}$, welche eine Deletion von zwei Exons umfasst. Insgesamt $10^{7}$ Parasiten

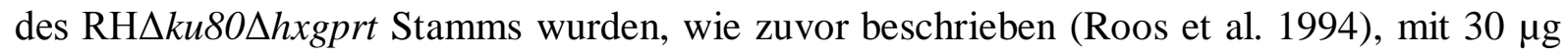
des NotI linearisierten Plasmids elektroporiert. Da eine Deletion des uprt Gens mit einer Resistenz von T. gondii gegenüber 5-Fluorodeoxyuridin (FUDR) einhergeht (Donald and Roos 1995), erfolgte die anschließende Selektion stabiler Transfektanten mit der unter 2.1.5 angegebenen FUDR-Konzentration. Die Überprüfung einzelner Klone erfolgte durch RT-PCR Analysen mit dem Primerpaar Uprt fwd und Uprt rev (Tabelle 2.4). 


\subsubsection{Komplementierung der 3L-H11 Mutante mit dem uprt Gen}

Zur Komplementierung der 3L-H11 Mutante mit dem uprt Gen wurde der durch Sternisek (2009) klonierte pSKupDH Vektor verwendet. Das im Vektor integrierte uprt-Minigen besteht aus der kodierenden Sequenz sowie der 5'-Promotersequenz und der 3'-UTR des uprt Gens. $30 \mu \mathrm{g}$ des Plasmids wurden, im Anschluss einer NotI-Linearisierung, durch Elektroporation in $10^{7}$ 3L-H11 Parasiten transfiziert. Zur Generierung einer stabil transfizierten Linie wurden die Parasiten mit der unter Tabelle 2.5 angegebenen Konzentrationen an Pyrimethamin selektioniert. Die Analyse der uprt Genexpression erfolgte durch quantitative RT-PCR mit den unter Tabelle 2.4 angegebenen Primern Uprt fwd und Uprt rev.

\subsubsection{Nachweis des DHODH N302S-Allels durch eine Restriktionsfragment- Längenpolymorphismus-Analyse (RFLP)}

Durch die N302S Punktmutation wurde eine neue Fnu4HI Schnittstelle innerhalb der kodierenden Sequenz des dhodh N302S-Allels gebildet. Diese wurde verwendet, um durch RFLP-Analysen zwischen dem Wildtyp und dem mutierten Allel zu unterscheiden. Die für die Amplifikation der cDNA verwendeten Primer waren DHODH 7+ und DHODH 8-. Das daraus synthetisierte 132 bp lange PCR-Produkt, welches Codon 302 einschließt, wurde anschließend aufgereinigt, mit Fnu4HI verdaut und in einem 2\%igem Agarosegel aufgetrennt. Während das Wildtyp-Fragment unverdaut bleibt, wird das N302S PCR-Fragment in zwei Produkte mit einer Größe von 103 und 29 bp geschnitten.

\subsubsection{TgDHODH Allelaustausch}

Um die Bedeutung der N302S Punktmutation zu untersuchen wurde das endogene DHODH Wildtyp-Allel direkt am ursprünglichen Locus durch die Integration des N302S-Allels ersetzt („Knock-In“-Strategie). Grundlage dieser Gen-Insertion ist eine einfache homologe Rekombination zwischen dem Ziel-Locus und einem homologen DNA Fragment, welches die jeweilige Modifikation enthält. Die Generierung eines N-terminal verkürzten DHODH N302S Fragments erfolgte durch die PCR-Amplifikation von cDNA der 3L-H11 Parasiten mit dem Primerpaar NotI-DHODH und DHODH-HindIII. Das amplifizierte PCR-Produkt wurde anschließend mit NotI/HindIII verdaut und an einen 500 bp umfassenden Bereich des dhodh 3، untranslatierten Bereichs (3'UTR) ligiert. Dieses wurde vor der Ligation ebenfalls mit HindIII und EcoRV verdaut. Die Amplifikation der 3'UTR erfolgte durch die Primer 
HindIII-3'DHODH und 3'DHODH-EcoRV mithilfe von cDNA der RHAuprt Parasiten. Das Gesamtprodukt wurde anschließend in den NotI/EcoRV geschnittenen pminCAT/HXGPRT Vektor kloniert, wodurch die Chloramphenicol Expressionskasette (CAT) ersetzt wurde. DNA-Sequenzanalysen bestätigten die korrekte Sequenzabfolge. Zur Kontrolle wurde ein gleichermaßen konstruierter Targeting-Vektor, der für das Wildtyp dhodh Allel (N302) kodiert, durch Amplifikation der cDNA von RH $\Delta$ uprt Parasiten kloniert. Jeweils $30 \mu \mathrm{g}$ beider Plasmide wurden im Anschluss einer XbaI-Linearisierung durch Elektroporation in $10^{7}$

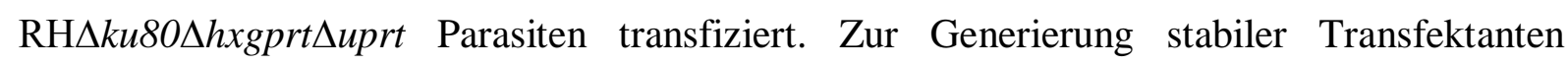
wurden die Parasiten mit denen unter Punkt 2.1.5 angegebenen Konzentrationen an MPA und Xanthin selektioniert. Die Überprüfung der homologen Integration am dhodh Locus erfolgte durch PCR Analysen einzelner Klone. Genomische DNA wurde dafür mit dem Primer 1+, der außerhalb des Targeting-Konstrukts im 5'UTR Bereich lokalisiert und Primer 2-, welcher an eine Sequenz des Exon 2 bindet, amplifiziert (Abb. 3.15). Während das PCR-Produkt des

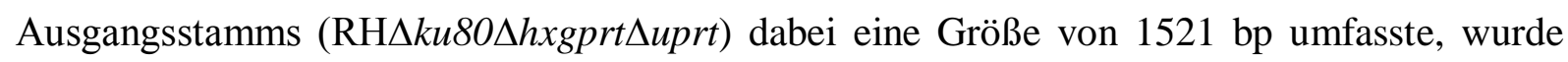
die erfolgreiche homologe Integration des Targeting-Vektors in den dhodh Locus durch ein Produkt von 631 bp angezeigt. Die Überprüfung des durch homologe Rekombination integrierten N302S Allels erfolgte weiterhin durch die Amplifikation genomischer DNA mit dem Primerpaar 1+/3-, wobei Primer 3- im Exon 3 bindet. Für Knock-In Parasiten ergab sich dabei ein PCR-Produkt von 824 bp und von 2829 bp für den parentalen Stamm. Zur Bestätigung eines verkürzten, endogenen Wildtyp Allels stromabwärts des integrierten Knock-In Allels wurden zudem der Primer 4+ (bindet im pKS+ Vektor) und der Intron 1 spezifische Primer 5- verwendet. Codon 302 wurde zusätzlich durch Sequenzierungen der dhodh cDNA analysiert, welche mit den Primern DHODH 5+ und DHODH 6- amplifiziert wurde.

\subsubsection{Expression, Aufreinigung und Aktivitätsmessung der TgDHODH}

Die Strategie der T. gondii DHODH Klonierung und nachfolgenden Aufreinigung erfolgte, mit einigen Modifikationen, nach Hortua Triana et al. (2012). Die N-terminal verkürzte Sequenz des Tgdhodh Gens, welche für die Aminosäuren Val178-Asp592 kodiert, wurde dafür mittels PCR von cDNA der Wildtyp Parasiten bzw. (im Falle des mutierten N302S Allels) von 3L-H11 Parasiten amplifiziert. Die verwendeten Primer waren NdeI-DHODH und DHODH-BamHI. Das 1248 bp PCR-Produkt wurde anschließend mit NdeI und BamHI verdaut und entsprechend der Herstelleranleitung in den (mit NdeI und BamHI geschnittenen) pET-16b Expressionsvektor kloniert, mit einem His ${ }_{10}$-Tag am N-terminus des Konstrukts. Die 
Richtigkeit des Leserahmens wurde durch DNA-Sequenzierungen überprüft. Kompetente $E$. coli BL21-CodonPlus (DE3)-RP Bakterien wurden entsprechend dem Protokoll des Herstellers mit den Expressionsplasmiden transformiert und in $250 \mathrm{ml}$ LB-Medium mit Ampicillin und Chloramphenicol bei $37^{\circ} \mathrm{C}$ kultiviert. Nach Erreichung einer $\mathrm{OD}_{600}$ von 0,5 wurden dem Medium 0,1 mM FMN zugefügt und die Bakterien bei RT für weitere $18 \mathrm{~h}$ kultiviert. Dabei konnte festgestellt werden, dass die DHODH Expression auch ohne die Zugabe von IPTG ausreichend stark war (Abb. 3.22). Alle anschließenden Schritte der Proteinaufreinigung wurden, wenn nicht anders angegeben, auf Eis oder in einem $4{ }^{\circ} \mathrm{C}$ Kühlraum durchgeführt. Die Bakterien wurden zunächst durch Zentrifugation bei 3.500 x g für $15 \mathrm{~min}$ geerntet und in $10 \mathrm{ml}$ Resuspension-Puffer resuspendiert. Für eine Zelllyse wurde die Suspension zunächst für $30 \mathrm{~min}$ (auf Eis) mit $1 \mathrm{mg} / \mathrm{ml}$ Lysozym und drei Einfrier-/AuftauZyklen mit flüssigen Stickstoff und anschließender Erwärmung in einem $37^{\circ} \mathrm{C}$ Wasserbad behandelt. Anschließend erfolgte eine zweimalige Sonifikation der Proben auf Eis für jeweils 10 min bei einer Intensität von 3 und einem Unterbrechungszyklus von 30\%. Zwischen beiden Schritten wurde die Suspension für 10 min auf Eis inkubiert. Nach einer Behandlung für 10 min mit RNase A $(10 \mu \mathrm{g} / \mathrm{ml})$ und DNase I $(5 \mu \mathrm{g} / \mathrm{ml})$ wurde das Lysat bei $5.000 \mathrm{x}$ g für 30 min zentrifugiert. Die Hälfte des Überstandes wurde auf $800 \mu 1$ der Ni-NTA-Agarose gegeben (welche zuvor mit Waschpuffer A equilibriert wurde) und für $20 \mathrm{~min}$ (im Kühlschrank) unter ständiger Rotation inkubiert. Nach einem Zentrifugationsschritt bei $500 \mathrm{x}$ g für 2 min wurde der Überstand verworfen und das Zellpellet (an Ni-NTA-Agarose gebundene Proteine) einmal mit $5 \mathrm{ml}$ Waschpuffer A gewaschen. Im Anschluss an eine nochmalige Zentrifugation bei $500 \mathrm{x}$ g für 2 min wurde das Pellet mit dem Rest der Proteinsuspension für weitere $20 \mathrm{~min}$ (im Kühlschrank) inkubiert. Das Lysat-Ni-NTA Gemisch wurde anschließend (im $4^{\circ} \mathrm{C}$ Kühlraum) auf eine Chromatographie-Säule gegeben und zweimal hintereinander mit jeweils $500 \mu \mathrm{l}$ Waschpuffer A, Waschpuffer B und Waschpuffer C gewaschen. Das rekombinante Protein wurde durch eine zweimalige Zugabe von $500 \mu 1$ Elutionspuffer eluiert. Unter Verwendung von PD-10 Säulen wurde das Imidazol durch einen Pufferaustausch mit dem finalen Puffer entfernt. Die Ermittlung der elektrophoretischen Reinheit der $\sim 47 \mathrm{kDa}$ rekombinanten TgDHODH erfolgte durch Auftrennung in einem 10\%igem SDS-Gel und anschließender Coomassie-Färbung. Zur Aufkonzentration der Proteine wurden Zentrifugalkonzentratoren (Vivaspin 15) mit einer Membrandurchlässigkeit (MWCO) von 10.000 Dalton (nach Herstelleranleitung) verwendet. 


\begin{tabular}{|c|c|c|}
\hline Resuspension-Puffer & Waschpuffer A & Waschpuffer B \\
\hline 50 mM Tris, $\mathrm{pH} 8,5$ & $50 \mathrm{mM}$ Tris, $\mathrm{pH} 8,0$ & $50 \mathrm{mM}$ Tris, $\mathrm{pH} 8,0$ \\
\hline 2 mM $\beta$-Mercaptoethanol & $2 \mathrm{mM} \beta$-Mercaptoethanol & $2 \mathrm{mM} \beta$-Mercaptoethan \\
\hline $1 \%$ Triton $\mathrm{X}-100(\mathrm{v} / \mathrm{v})$ & $1 \%$ Triton $\mathrm{X}-100(\mathrm{v} / \mathrm{v})$ & $1 \%$ Triton $\mathrm{X}-100(\mathrm{v} / \mathrm{v})$ \\
\hline $10 \%$ Glycerin (v/v) & $300 \mathrm{mM} \mathrm{NaCl}$ & $300 \mathrm{mM} \mathrm{NaCl}$ \\
\hline $0,5 \mathrm{mM}$ FMN & 20 mM Imidazol & 50 mM Imidazol \\
\hline \multicolumn{3}{|l|}{ Protease-Inhibitor-Cocktail } \\
\hline Waschpuffer C & $\underline{\text { Elutionspuffer }}$ & $\underline{\text { Finaler Puffer }}$ \\
\hline 50 mM Tris, $\mathrm{pH} 8,0$ & $50 \mathrm{mM}$ Tris, $\mathrm{pH} 8,0$ & 50 mM Tris, $\mathrm{pH} 8,0$ \\
\hline $2 \mathrm{mM} \beta$-Mercaptoethanol & $2 \mathrm{mM} \beta$-Mercaptoethanol & 0,1 Triton $X-100(v / v)$ \\
\hline $1 \%$ Triton X-100 (v/v) & $1 \%$ Triton X-100 (v/v) & $10 \%$ Glycerin (v/v) \\
\hline $300 \mathrm{mM} \mathrm{NaCl}$ & $300 \mathrm{mM} \mathrm{NaCl}$ & $300 \mathrm{mM} \mathrm{NaCl}$ \\
\hline 100 mM Imidazol & 300 mM Imidazol & \\
\hline
\end{tabular}

\subsubsection{Bestimmung der DHODH Proteinkonzentration}

Da für die katalytische Aktivität der DHODH ein gebundener Flavin (FMN)-Cofaktor unerlässlich ist, wurde die Konzentration des aktiven Proteins durch Messung der FMN-Konzentration bestimmt. Zur Freisetzung des gebundenen FMN wurden Aliquots des aufgereinigten Wildtyp Proteins und der N302S TgDHODH für 10 min bei $99^{\circ} \mathrm{C}$ denaturiert und anschließend zentrifugiert. Die Flavinkonzentration des Überstandes wurde in Doppelbestimmungen spektrophotometrisch mit einer Anregungs-Wellenlänge von $465 \mathrm{~nm}$ und einer Emissionswellenlänge von $518 \mathrm{~nm}$ bestimmt. Die Aufnahme der entsprechenden FMN-Standardgerade erfolgte über Konzentrationen von 12,5 nM, 25 nM, 50 nM, 100 nM, $200 \mathrm{nM}$ und $400 \mathrm{nM}$.

\subsubsection{Analyse der DHODH Enzymaktivität}

Die Messung der DHODH Enzymaktivität wurde, wie zuvor durch Zameitat et al. (2006) beschrieben, in einem Gesamtvolumen von $200 \mu \mathrm{l}$ in DHODH Assaypuffer bei RT durchgeführt. Die Produktion von Orotat wurde dabei photometrisch bei $300 \mathrm{~nm}(\varepsilon=2.95$ $\mathrm{mM}^{-1} \mathrm{~cm}^{-1}$ ), unter der Verwendung von Dihydroorotat (DHO) als Substrat und Decylubiquinon ( $Q_{D}$ ) als Elektronenakzeptor, bestimmt. $Q_{D}$ ist ein, mit einer erhöhten Löslichkeit, synthetisches Analogon von Ubiquinon (Patel et al. 2008) und wurde bereits erfolgreich bei der enzymatischen Untersuchung der PfDHODH verwendet (Baldwin et al. 2002). In einem alternativen Assay wurde 2,6-Dichloroindophenol (DCIP) als finaler 
Elektronenakzeptor eingesetzt und die Reduktion von DCIP bei $600 \mathrm{~nm}\left(\varepsilon=18.8 \mathrm{mM}^{-1} \mathrm{~cm}^{-1}\right)$ gemessen. Da DCIP auch in der Abwesenheit des Elektronen-Überträgers $Q_{D}$ eine geringe Aktivität als direkter Elektronenakzeptor besitzt (Zameitat et al. 2006), wurden die Werte der DHODH Aktivität ohne $Q_{D}$ von den gemessenen Werten mit $Q_{D}$ subtrahiert.

\section{DHODH Assaypuffer}

$50 \mathrm{mM}$ Tris- $\mathrm{HCl}, \mathrm{pH} 8,0$

\section{$150 \mathrm{mM} \mathrm{KCl}$}

$0,1 \%$ Triton $\mathrm{X}-100(\mathrm{v} / \mathrm{v})$

Die Michaelis-Menton-Konstante $\left(\mathrm{K}_{\mathrm{M}}\right)$ für DHO wurde in der Gegenwart von $100 \mu \mathrm{M} \mathrm{Q}_{\mathrm{D}}$ durch Variation der Konzentration von DHO (5-1000 $\mu \mathrm{M})$ ermittelt, während der $\mathrm{K}_{\mathrm{M}}$-Wert für $\mathrm{Q}_{\mathrm{D}}$ bei einer konstanten Konzentration von $1000 \mu \mathrm{M}$ DHO durch variierende Konzentrationen von $Q_{D}(5-300 \mu \mathrm{M})$ bestimmt wurde. Mit Ausnahme der Wechselzahl ( $\left.\mathrm{k}_{\mathrm{cat}}\right)$ wurden alle kinetischen Parameter durch die Statistiksoftware GraphPad Prism (Version 6.0) analysiert.

Die Wechselzahl $\left(\mathrm{k}_{\mathrm{cat}}\right)$ ist ein direktes Maß der Anzahl an Substratmolekülen, die pro Sekunde von einem gesättigten Enzymmolekül umgesetzt werden. Ihre Berechnung erfolgte durch die maximale Umsatzgeschwindigkeit (Vmax, $\mathrm{nM} / \mathrm{s}$ ) und der unter 2.2.8.1 gemessenen Proteinkonzentration $\left(\mathrm{E}_{0}, \mathrm{nM}\right)$.

$\mathrm{k}_{\mathrm{cat}}=\mathrm{Vmax} / \mathrm{E}_{0}$

Da sich die Umsatzgeschwindigkeit des Enzyms über die Konzentrationsänderung pro Zeiteinheit definiert $(V \max =\Delta \mathrm{c} / \mathrm{t})$, wurde Vmax mithilfe des Lambert-Beerschen Gesetzes berechnet $(\Delta \mathrm{E}=\varepsilon * \Delta \mathrm{c} * \mathrm{~d} \rightarrow \Delta \mathrm{c}=\Delta \mathrm{E} / \varepsilon * \mathrm{~d})$, wobei $\Delta \mathrm{E}$ als Extinktion, $\varepsilon(\mathrm{M} / \mathrm{cm})$ als der molare Extinktionskoeffizient und $\mathrm{d}(\mathrm{cm})$ als die Schichtdicke der Küvette definiert sind. Für $\mathrm{k}_{\mathrm{cat}}\left(\mathrm{s}^{-1}\right)$ ergibt sich daraus folgende Formel:

$$
\mathrm{k}_{\mathrm{cat}}=\Delta \mathrm{c} /\left(\mathrm{t} * \mathrm{E}_{0}\right)=(\Delta \mathrm{E} / \varepsilon * \mathrm{~d}) /\left(\mathrm{t} * \mathrm{E}_{0}\right)
$$

Zur Durchführung der Inhibitionsstudien mit HDQ und Compound B wurden die zu untersuchenden Konzentrationen (bis $30 \mu \mathrm{M}$ ) als 20-fach konzentrierte Lösungen erstellt. Die daraus resultierende finale Konzentration von 5\% DMSO (v/v) hatte keine Auswirkung auf die Enzymaktivität. HDQ und Compound B wurden dem Gemisch aus Enzym und Assaypuffer direkt, für eine Präinkubationszeit von $20 \mathrm{~s}$, zugefügt und die Enzymreaktion 
anschließend durch die Substrat-Zugabe eingeleitet. Zur Berechnung der halbmaximal inhibitorischen Konzentration $\left(\mathrm{IC}_{50}\right)$ von $\mathrm{HDQ}$ und Compound $\mathrm{B}$ wurden Dosis-Wirkungskurven für das Wildtyp und das N302S Protein generiert. Dabei handelt es sich um diejenige Konzentration eines Inhibitors, welche zu einer halbmaximalen Hemmung der Enzymaktivität führt. Die Messung der Enzymaktivität erfolgte in Gegenwart von $1 \mathrm{mM}$ DHO sowie $100 \mu \mathrm{M} \mathrm{Q}_{\mathrm{D}}$ und variierenden Inhibitorkonzentrationen von $0,01 \mu \mathrm{M}$ bis $30 \mu \mathrm{M}$. Die unter jeder der einzelnen Inhibitorkonzentrationen gemessene anfängliche Reaktionsgeschwindigkeit $\left(\mathrm{v}_{\mathrm{i}}\right)$ wurde dabei relativ zu der Enzymaktivität kalkuliert, welche ohne Anwesenheit des Inhibitors gemessen wurde $\left(\mathrm{v}_{0}\right)$. $\mathrm{IC}_{50}$-Werte wurden durch nichtlineareRegressionsanalysen mit GraphPad Prism ermittelt.

Die Ermittlung des Inhibitionstyp und der Inhibitionskonstante $\left(\mathrm{K}_{\mathrm{i}}\right)$ erfolgten in getrennten Versuchsansätzen sowohl für DHO als auch $\mathrm{Q}_{D}$. Dabei wurde die Reaktionsgeschwindigkeit der TgDHODH ohne Inhibitor und zusätzlich auch unter verschiedenen Konzentrationen von Compound B gemessen. Die eingesetzten Inhibitorkonzentrationen richteten sich dabei nach der Hälfte sowie dem 3-fachen des gemessenen $\mathrm{K}_{\mathrm{M}}$-Wertes. Inhibitionskinetiken wurden daher für den Wildtyp unter Anwesenheit von 0,25 $\mu \mathrm{M}$ und 1,5 $\mu \mathrm{M}$ Compound B sowie für das N302S Protein mit Konzentrationen von 0,8 $\mu \mathrm{M}$ und 4,8 $\mu \mathrm{M}$ durchgeführt. Die Erhebung der Daten erfolgte gegenüber variierenden Konzentrationen von DHO (15 bis $1000 \mu \mathrm{M})$ und einer konstanten Konzentration von $100 \mu \mathrm{M} \mathrm{Q}_{\mathrm{D}}$ oder variierenden Konzentrationen von $\mathrm{Q}_{\mathrm{D}}(8$ bis $300 \mu \mathrm{M}$ ) bei $1000 \mu \mathrm{M}$ DHO. Der durch GraphPad Prism statistisch errechnete Inhibitionstyp wurde durch die doppelt-reziproke Darstellung des Lineweaver-Burk-Plots visuell bestätigt.

\subsubsection{Expression eines CAT-ScDHODH Fusionskonstrukts in T. gondii}

Die kodierende Sequenz des Saccharomyces cerevisiae DHODH Gens ural (bezeichnet als Scdhodh) wurde vom Stamm RH2817 mit dem Primerpaar AvrII-ScDHODH und ScDHODH-AscI amplifiziert. Das PCR-Fragment wurde anschließend AscI verdaut und an den DHFR-TS 3'UTR ligiert. Das DHFR-TS 3'UTR Fragment wurde durch die Primer AscI-3'dhfr und 3'dhfr-NotI aus dem ptubYFPYFP-sagCAT Vektor amplifiziert und vor der Ligation mit $A s c$ I verdaut. Nach einem Restriktionsverdau des Gesamtprodukts mit AvrII und NotI wurde dieses schließlich in den AvrII/NotI verdauten ptubCAT-HSTK Vektor kloniert, wodurch die HSTK-3'dhfr Region ersetzt wurde. Das finale Fusinskonstrukt CAT-ScDHODH des ptubCAT-ScDHODH Vektors (Abb. 2.1) beginnt mit der kodierenden 
Sequenz der Chloramphenicol Acetyltransferase (cat), gefolgt von der vollständigen kodierenden Sequenz des Scdhodh Gens. DNA-Sequenzanalysen bestätigten die korrekte Sequenzabfolge. Zusammen mit $20 \mathrm{U}$ NotI wurden insgesamt $30 \mu \mathrm{g}$ des NotI-linearisierten Plasmids durch Elektroporation in $10^{7} \mathrm{RH} \Delta$ hxgprt Parasiten transfiziert. Die Selektion einer stabil transfizierten Linie erfolgte mithilfe der in den Vektor integrierten HXGPRT-Resistenzkassette mit MPA und Xanthin. Alle nachfolgenden Untersuchungen wurden mit den Einzelklonen CAT-ScDHODH Klon 6 und CAT-ScDHODH Klon 7 sowie dem Parentalstamm RHAhxgprt durchgeführt.

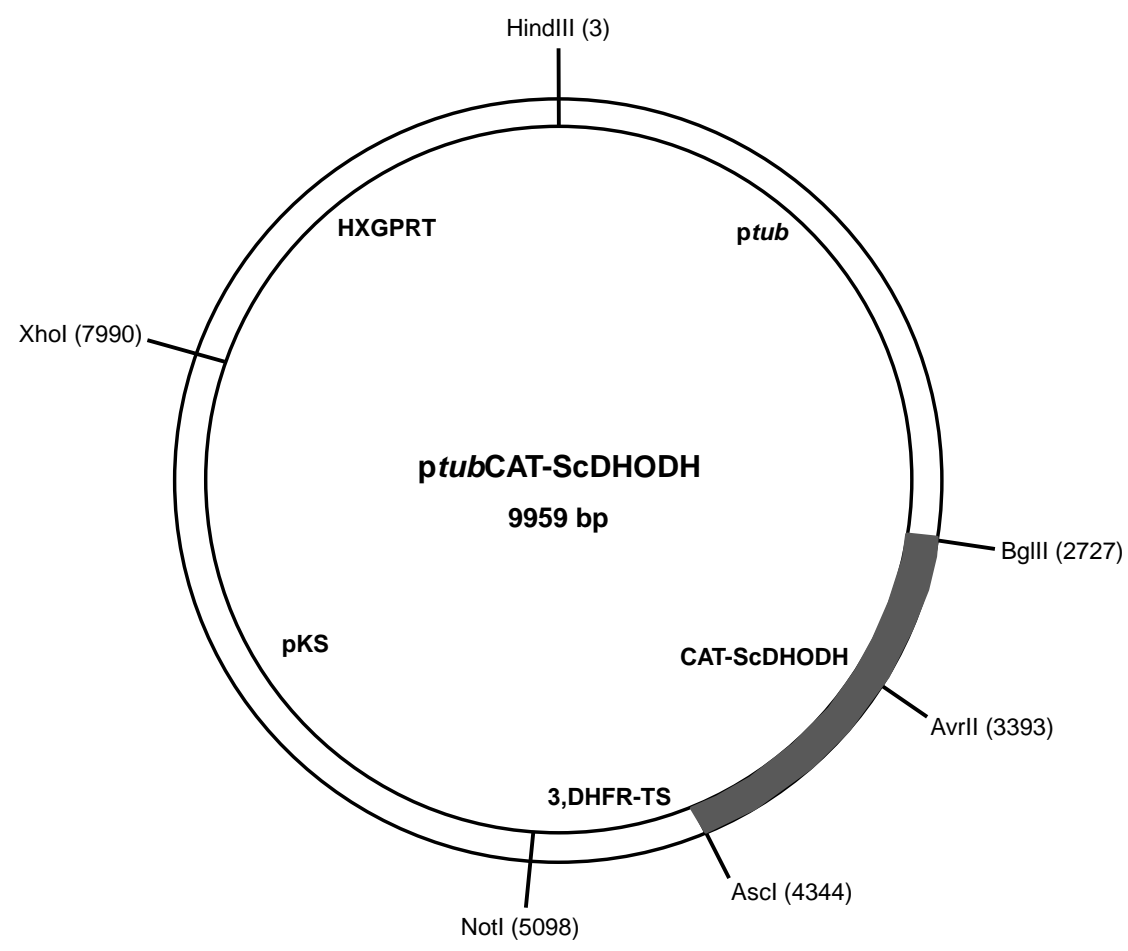

Abbildung 2.1: Schematischer Aufbau des ptubCAT-ScDHODH Vektors.

\subsubsection{Zelluläre Lokalisation und Quantifizierung des Expressionslevels}

Die Immundetektion des CAT-ScDHODH Fusionsproteins ( 60,7 kDa, errechnet aus der Aminosäuresequenz) erfolgte mit den unter 2.2.3.1 hergestellten Parasitenlysaten. Aliquots der Lysate wurden durch SDS-PAGE (12\%) elektrophoretisch aufgetrennt. Das Fusionsprotein wurde, nach dem Transfer auf eine Nitrozellulosemembran, mithilfe des anti-CAT Primärantikörpers und HRP-konjugierten anti-Kaninchen IgG Sekundärantikörpers durch Chemilumineszenz (ECL) detektiert und quantifiziert. Für eine ParasitenLadungskontrolle wurde die Membran gestrippt und mit einem Kaninchen anti-SAG1 Serum und nachfolgend dem HRP-konjugiertem anti-Kaninchen IgG Sekundär-AK inkubiert. Die Analyse der Scdhodh Genexpression erfolgte durch quantitative RT-PCR mit den Primern ScDHODH 1+ und ScDHODH 2- (Tabelle 2.4). Zur Lokalisierung des CAT-fusionierten 
ScDHODH mittels IFT wurden $T$. gondii infizierte HFF zunächst mit dem anti-CAT Primärantikörper und anschließend mit dem Cy3-konjugierten anti-Kaninchen IgG Sekundärantikörper inkubiert. Alle verwendeten Antikörper-Verdünnungen sind in Tabelle 2.6 aufgeführt.

\subsubsection{CAT-ScDHODH Enzymaktivität}

Die Analyse der ScDHODH Aktivität erfolgte, wie durch Patel et al. (2008) beschrieben, mit DCIP und Fumarat. Insgesamt $20 \mu 1$ des unter 2.2.3.1 hergestellten Parasitenlysats wurden verwendet um die Enzymaktivität bei RT in einem finalem Volumen von $200 \mu 1$ ( in DHODH Assaypuffer) zu untersuchen Die innerhalb von einer Minute photometrisch bei $600 \mathrm{~nm}(\varepsilon=$ $18.8 \mathrm{mM}^{-1} \mathrm{~cm}^{-1}$ ) gemessene Reduktion von DCIP erfolgte dabei in Anwesenheit von $1 \mathrm{mM}$ DHO, 1 mM Fumarat und $60 \mu \mathrm{M}$ DCIP. Die Inhibition der ScDHODH Aktivität durch HDQ und Compound B wurde unter Konzentrationen von jeweils $10 \mu \mathrm{M}$ und $30 \mu \mathrm{M}$ analysiert.

\subsubsection{Bioinformatik}

Genomische und cDNA Sequenzen sowie Proteinstrukturen wurden über die Toxoplasma gondii Genom-Datenbank (ToxoDB) und dem „National Center for Biotechnology Information (NCBI)“ bezogen. Die in dieser Arbeit verwendeten Primer wurden mit Hilfe der Primerdesign-Software „Primer3“ entworfen (www.bioinfo.ut.ee/primer3-0.4.0) und durch Sigma-Aldrich synthetisiert. Multiple Sequenzalignments wurden mit ClustalW2 erstellt, welches über die EMBL-EBI Website (www.ebi.ac.uk/Tools/msa/clustalw2) frei zugänglich war. 


\section{Ergebnisse}

Um diejenigen 1-Hydroxyquinolon Target(s) in $T$. gondii zu identifizieren, deren Hemmung zu einer Inhibition des Parasitenwachstums führt, wurden die durch chemische Mutagenese gewonnenen $T$. gondii Klone 3L-H11 und 3F-A6 sowohl phänotypisch charakterisiert als auch hinsichtlich ihrer resistenzdeterminierenden Faktoren genetisch analysiert.

\subsection{Phänotypische Charakterisierung 1-Hydroxyquinolon-resistenter Mutanten}

\subsubsection{L-H11 und 3F-A6 Parasiten zeigen eine partielle 1-Hydroxyquinolon-Resistenz}

Aus einem vorherigen Experiment der Arbeitsgruppe konnten, durch (ENU-induzierte) chemische Mutagenese, zwei T. gondii Klone (3L-H11 und 3F-A6) isoliert werden, die sich durch eine partielle Resistenz gegenüber 1-Hydroxy-2-Dodecyl-4(1)quinolon (HDQ) auszeichnen. Für eine detaillierte Untersuchung der 1-Hydroxyquinolon-Sensitivität wurden beide Klone über einen Zeitraum von 60 h mit 100 nM HDQ bzw. dem Derivat Compound B behandelt und hinsichtlich ihrer Wachstumskinetik untersucht (Abb. 3.1). Als Referenzstämme dienten der Wildtyp RH Stamm sowie eine Uracil-Phosphoribosyltransferase (UPRT)-Deletionsmutante (RHAuprt), welche als Ausgangsstamm für die chemische Mutagenese verwendet wurde. Um erste Hinweise auf mögliche Resistenzdeterminanten zu gewinnen, wurde die Parasitenreplikation zudem in Anwesenheit von $100 \mathrm{nM}$ Atovaquon, einem mitochondrialen Cytochrom-bc $c_{1}-$ Komplex Inhibitor, analysiert. Wie bereits in vorangegangenen Studien der Arbeitsgruppe gezeigt werden konnte, wurden RHAuprt Parasiten nach einer Behandlung mit HDQ permanent inhibiert und wiesen über den gesamten Untersuchungszeitraum hinweg jeweils nur einen Parasiten pro parasitophorer Vakuole auf (Naujoks 2008; Sternisek 2009). Diese Hypersensitivität konnte auch für Compound B beobachtet werden (Abb. 3.1). Im Gegensatz dazu zeichneten sich der RH Stamm und die Mutanten 3L-H11 und 3F-A6 durch ein biphasisches Wachstumsbild aus. Innerhalb der ersten $24 \mathrm{~h}$ einer Behandlung mit HDQ oder Compound B zeigten alle Parasiten eine vergleichbare, sehr deutlich ausgeprägte Inhibierungsphase. Im weiteren Verlauf regenerierten sich die Parasiten jedoch und zeigten ein wiedereinsetzendes Wachstum. Diese parasitostatische, jedoch nicht letale Wirkung der 1-Hydroxyquinolone wurde für den RH Stamm bereits durch Saleh et al. (2007) beschrieben. Während sich der RH Stamm jedoch stark verlangsamt replizierte, besaßen beide Mutanten ein deutliches Resistenzpotential und zeigten bereits ab der 36. Stunde nach Infektion (p. i.) ein signifikant erhöhtes Wachstum. 
Nach 60 h p. i. besaßen 3L-H11 und 3F-A6 Parasiten eine um das rund 5-fache gesteigerte Wachstumsrate und wiesen folglich eine sehr deutliche, jedoch partielle Resistenz gegenüber HDQ und Compound B auf. Im Vergleich dazu erbrachte die Untersuchung der Sensitivität gegenüber Atovaquon ein vergleichbares Inhibitionsniveau für RH, 3L-H11 und 3F-A6 Parasiten, während die Mutante RHAuprt auch unter Anwesenheit dieses Quinon-Derivats dauerhaft gehemmt wurde. Trotz der gesteigerten Toleranz gegenüber HDQ und Compound B zeigten unbehandelte Wachstumskontrollen der Resistenzmutanten, im Vergleich zu den Referenzstämmen RH und RH $\Delta u p r t$, eine unveränderte Teilungsrate.

Compound B

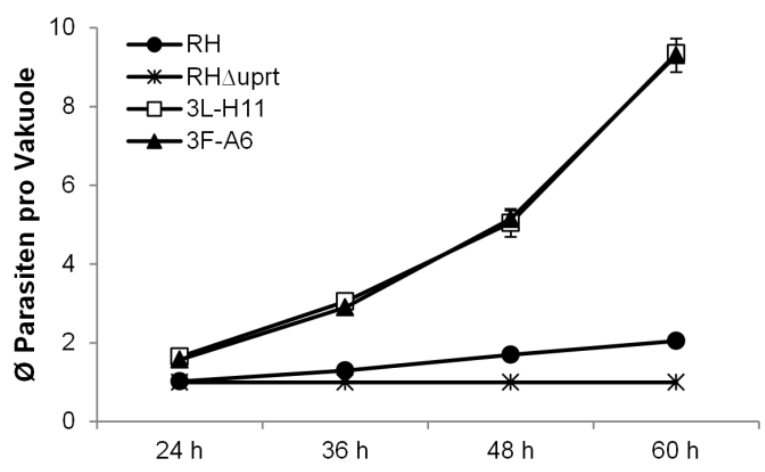

Atovaquon

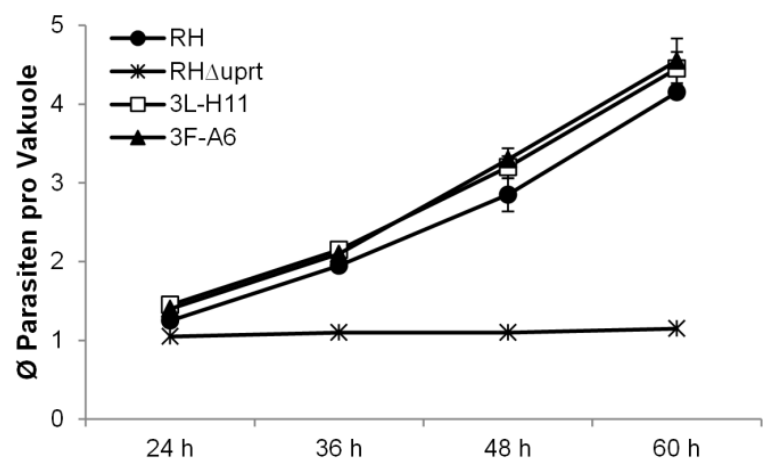

HDQ

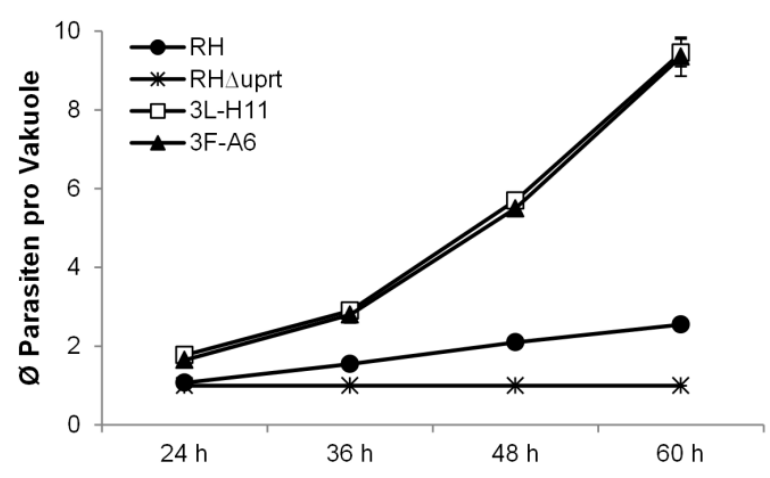

Unbehandelte Kontrolle

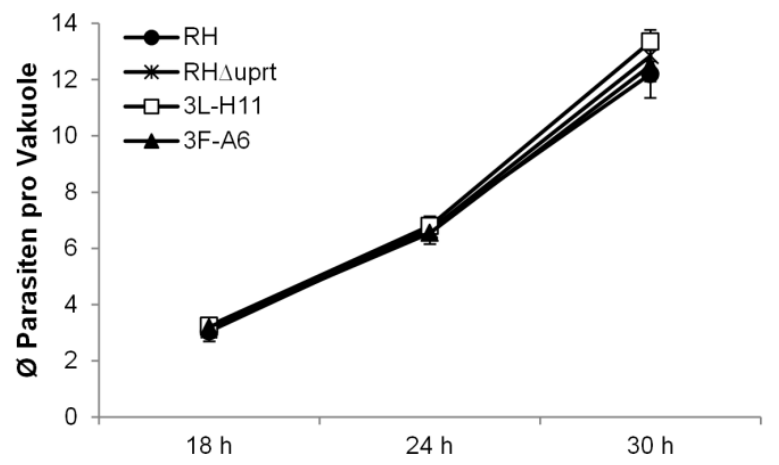

Abbildung 3.1: Die T. gondii Klone 3L-H11 und 3F-A6 zeigen eine partielle 1-Hydroxyquinolon-Resistenz. Wachstumskinetiken von 3L-H11 und 3F-A6 Parasiten wurden im Vergleich zum Wildtyp RH Stamm und RHAuprt Parasiten unter Behandlung mit Compound B, HDQ und Atovaquon verglichen. Eine Analyse der Replikationsrate erfolgte nach 24 h, 36 h, 48 h und 60 h p. i., während eine unbehandelte Wachstumskontrolle nach 18 h, 24 h und 30 h untersucht wurde. Konfluente HFF wurden dazu mit jeweils $\sim 3 \times 10^{4}$ Parasiten infiziert und mit einer Endkonzentration von $100 \mathrm{nM}$ der einzelnen Compounds behandelt. Alle Proben wurden zu den angegebenen Zeitpunkten fixiert und die durchschnittliche Anzahl intrazellulärer Parasiten durch Auszählung der Parasiten von mindestens 100 zufällig ausgewählten parasitophoren Vakuolen bestimmt. Die Darstellung der Ergebnisse erfolgt als Mittelwert $(\mathrm{MW}) \pm$ Standardabweichung des MW von Proben-Doppelbestimmungen eines repräsentativen Experiments $(\mathrm{n}=2)$. 


\subsubsection{Uprt komplementierte 3L-H11 Parasiten besitzen eine nochmals gesteigerte Resistenz gegenüber 1-Hydroxyquinolonen}

In den Untersuchungen von Sternisek (2009) konnte bereits eine negative Korrelation zwischen der HDQ-Sensitivität und dem uprt Expressionslevel nachgewiesen werden. Während das Wachstum der uprt Knock-Out Mutante (RH $\Delta u p r t)$ vollständig inhibiert wurde, zeigten uprt komplementierte Parasiten eine dem Wildtyp vergleichbare Sensitivität gegenüber HDQ. Da die ENU-induzierte Generierung der Resistenzmutanten 3L-H11 und 3F-A6 mit der RHAuprt Mutante erfolgte, wurde der Einfluss einer uprt Komplementierung auf die Parasitenresistenz untersucht. Dafür wurde die 3L-H11 Mutante mit einem uprt-Minigen transfiziert und mit Hilfe einer in das Plasmid integrierten PyrimethaminResistenzkassette selektioniert. Die Genexpression der stabil transfizierten Linie wurde zunächst mittels RT-PCR analysiert und unter Verwendung des konstitutiv exprimierten Tubulins, im Hinblick auf den RH Stamm, relativ quantifiziert. Dabei konnte eine rund 1,5-fache und damit vergleichbare Expressionsstärke ermittelt werden (Abb. 3.2 A). RH $\Delta u p r t$ und 3L-H11 Parasiten zeigten durch die Disruption des uprt Genlocus wie erwartet keine Expression (Abb. 3.2 B).
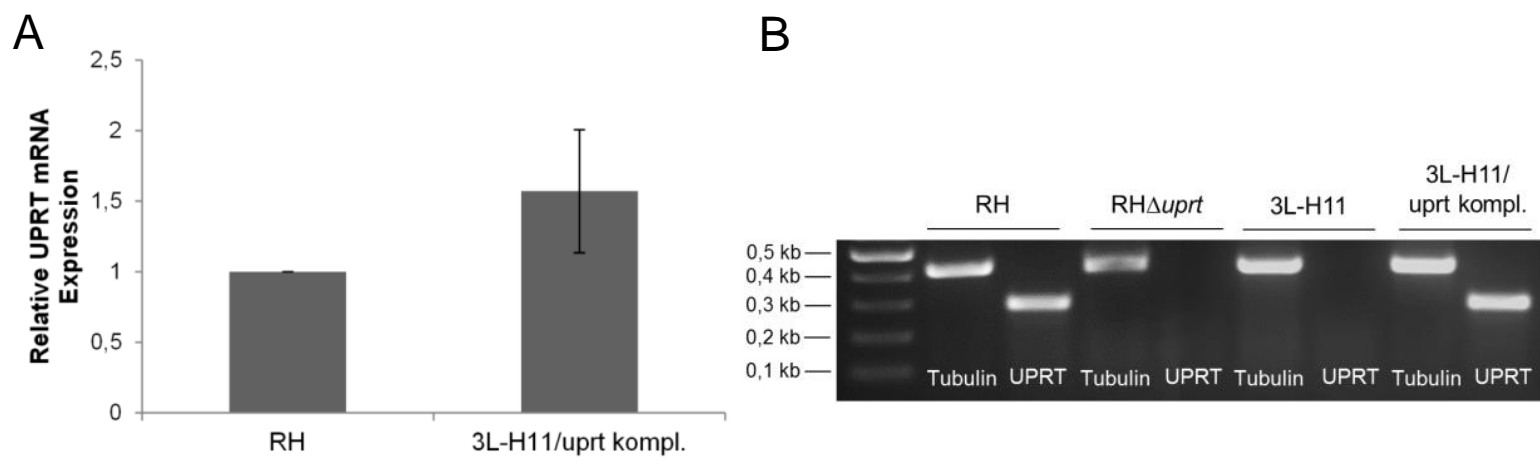

Abbildung 3.2: Uprt komplementierte 3L-H11 Parasiten zeigen eine vergleichbare, relative uprt mRNA Expression wie der RH Stamm. (A) RH, RHAuprt, 3L-H11 Parasiten und die uprt komplementierte 3L-H11 Linie (3L-H11/uprt kompl.) wurden hinsichtlich der uprt mRNA-Expression untersucht. Dafür wurde 24 h p. i. Gesamt-RNA isoliert, revers transkribiert und gewonnene cDNA durch LightCycler Real-Time PCR analysiert. Crossing Point (Cp) Werte wurden zur Quantifizierung herangezogen und durch die mRNA Expression von $\beta$-Tubulin normalisiert. Die Genexpression der 3L-H11/uprt kompl. Mutante ist als x-fache Änderung der Genexpression gegenüber dem Wildtyp RH Stamm angegeben. Die Darstellung der Ergebnisse erfolgt als Mittelwert $(\mathrm{MW}) \pm$ Standardabweichung des MW von Proben-Doppelbestimmungen eines repräsentativen Experiments $(n=2)$. (B) Eine Überprüfung der RT-PCR Produkte für $\beta$-Tubulin und UPRT erfolgte durch Auftrennung in einem 1\%-Agarosegel für RH, RHAuprt, 3L-H11 und 3L-H11/uprt kompl. Parasiten. 
Um die funktionelle Bedeutung der uprt Komplementierung hinsichtlich der Resistenz gegenüber 1-Hydroxyquinolonen und Atovaquon zu analysieren, wurde die Replikationsrate der Parasiten über einen Zeitraum von $60 \mathrm{~h}$ analysiert (Abb. 3.3).

Compound B
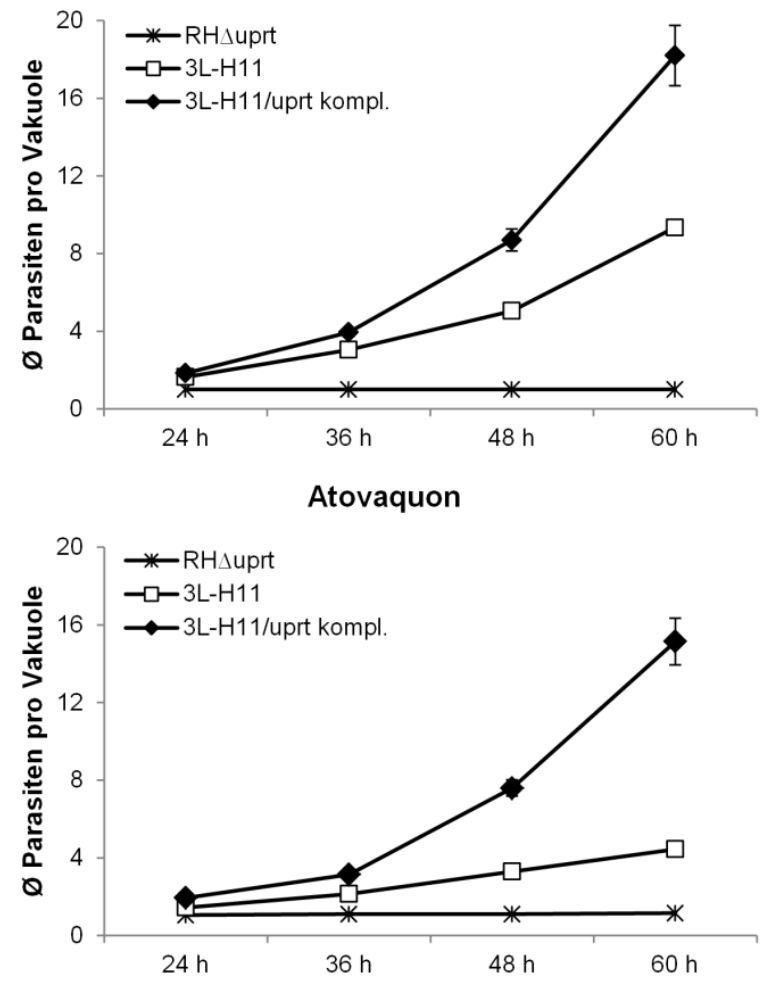

HDQ

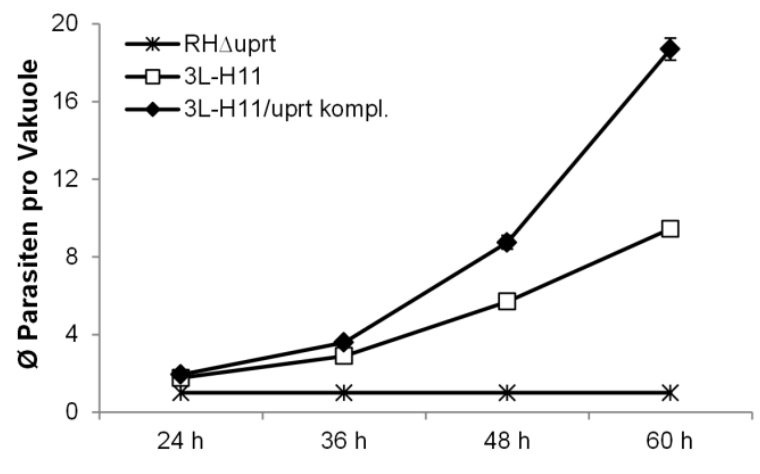

Unbehandelte Kontrolle

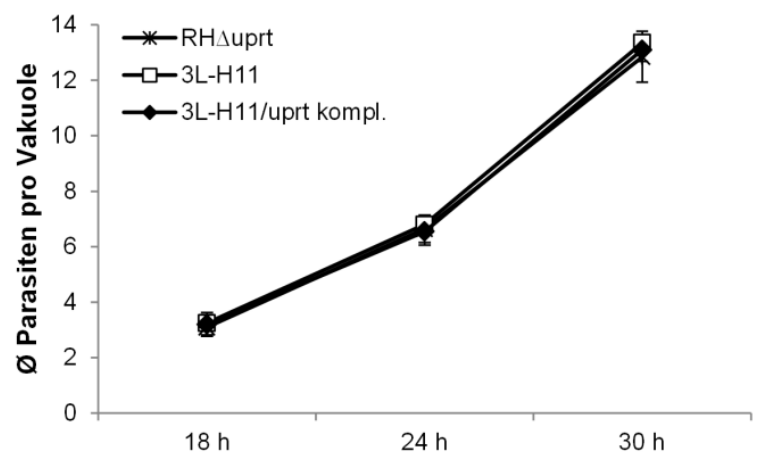

Abbildung 3.3: Eine Komplementierung der 3L-H11 Mutante mit uprt führt zu einer gesteigerten 1-Hydroxyquinolon-Resistenz. Wachstumskinetiken von RHAuprt, 3L-H11 Parasiten und einer uprt komplementierten 3L-H11 Linie, unter einer Behandlung mit Compound B, HDQ und Atovaquon. Eine Analyse der Replikationsrate erfolgte nach 24 h, 36 h, 48 h und 60 h p. i., während eine unbehandelte Wachstumskontrolle nach 18 h, 24 h und 30 h untersucht wurde. Konfluente HFF wurden dazu mit jeweils $\sim 3 \times 10^{4}$ Parasiten infiziert und mit einer Endkonzentration von $100 \mathrm{nM}$ der jeweiligen Compounds behandelt. Alle Proben wurden zu den angegebenen Zeitpunkten fixiert und die durchschnittliche Anzahl intrazellulärer Parasiten durch Auszählung der Parasiten von mindestens 100 zufällig ausgewählten parasitophoren Vakuolen bestimmt. Die Darstellung der Ergebnisse erfolgt als Mittelwert (MW) \pm Standardabweichung des MW von Proben-Doppelbestimmungen eines repräsentativen Experiments $(n=2)$.

Ähnlich der hypersensitiven RHAuprt und der 3L-H11 Mutante zeigten 3L-H11/uprt kompl. Parasiten nach einer Behandlung mit Compound B oder HDQ bis $24 \mathrm{~h}$ p. i. eine starke Wachstumshemmung. Im späteren Verlauf regenerierten sich auch diese Parasiten und wiesen im Vergleich zur 3L-H11 Mutante bis circa 36 h p. i. keinen Unterschied hinsichtlich des Wachstums auf. Bereits 48 h p.i. zeichnete sich die uprt komplementierte Linie jedoch durch eine erhöhte Resistenz aus und besaß 60 h nach einer Behandlung mit Compound B oder 
HDQ eine um das 2-fache gesteigerte Teilungsrate. Erstaunlicherweise konnten auch bezüglich der Sensitivität gegenüber Atovaquon signifikante Unterschiede festgestellt werden. Obwohl das Wachstum der 3L-H11 und 3L-H11/uprt kompl. Parasiten bis 36 h p. i. gleichermaßen inhibiert wurde, konnte 48 h p. i. eine um das doppelte und 60 h p. i. eine um das 3-fache gesteigerte Teilungsrate beobachtet werden. Im Vergleich dazu zeigten unbehandelte Kontrollen keine Veränderungen der Wachstumsrate.

\subsubsection{Ein Mediumwechsel unter erneuter Zugabe von Compound B hat keinen Einfluss auf die Replikationsrate der Parasiten}

Die Entstehung von Wirkstoffresistenzen und der damit einhergehende Sensitivitäts-Verlust können vielfältige Ursachen haben, darunter auch Mechanismen die an der Detoxifikation antimikrobieller Substanzen beteiligt sind. Um die Beteiligung einer metabolischen Detoxifikation als Resistenzmechanismus zu untersuchen, wurde der Einfluss frischer Compound B Zugabe auf das Parasitenwachstum analysiert. Dabei wurden RH $\Delta$ uprt, 3L-H11 und 3F-A6 Parasiten über einen Zeitraum von 48 h kultiviert (Abb. 3.4).

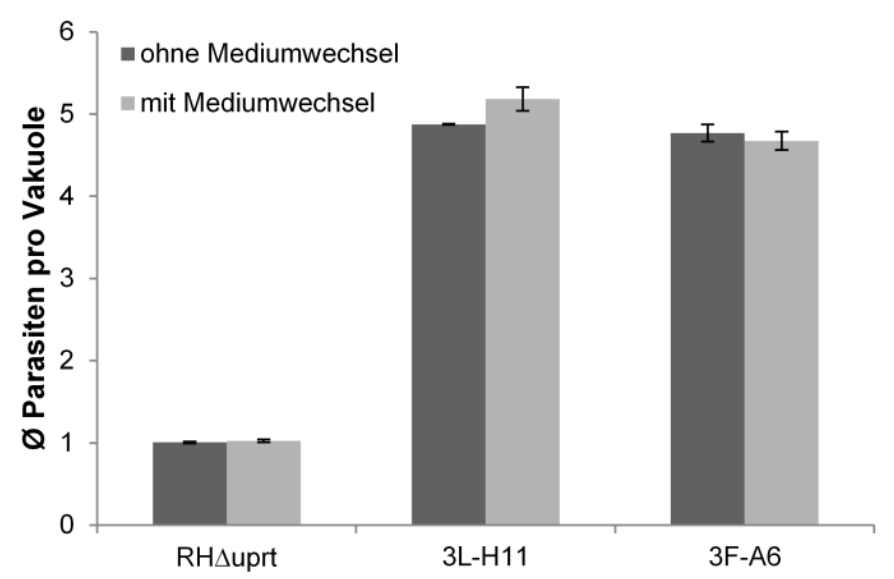

Abbildung 3.4: Die Zugabe von frischem Compound $B$ hat keinen Einfluss auf die partielle 1-Hxdroxyquinolon-Resistenz von 3L-H11 und 3F-A6 Parasiten. Konfluente HFF wurden mit jeweils $\sim 3 \times 10^{4}$ RHAuprt, 3L-H11 sowie 3F-A6 Parasiten infiziert und für insgesamt $48 \mathrm{~h}$ mit $100 \mathrm{nM}$ Compound B behandelt (ohne Mediumwechsel). Im Falle eines Mediumwechsels wurde das Medium nach $24 \mathrm{~h}$ vollständig entfernt und gegen neues, mit frischem Compound B versetztes Kulturmedium ausgetauscht. Die Zellen wurden im Anschluss für weitere $24 \mathrm{~h}$ kultiviert. Die durchschnittliche Anzahl intrazellulärer Parasiten wurde durch Auszählung der Parasiten von mindestens 100 zufällig ausgewählten parasitophoren Vakuolen bestimmt. Die Darstellung der Ergebnisse erfolgt als Mittelwert $(\mathrm{MW}) \pm$ Standardabweichung des MW von ProbenDoppelbestimmungen eines repräsentativen Experiments $(\mathrm{n}=2)$. 
Während im Falle eines Mediumwechsels 24 h nach Infektion das gesamte Zellkulturmedium abgesaugt und gegen neues, mit frischem Compound B versetztes Medium ausgetauscht wurde, blieb das Medium in der Kontrollprobe über den gesamten Untersuchungszeitraum unverändert. Hinsichtlich des Parasitenwachstums ließen sich jedoch keine Unterschiede erkennen. Mit oder ohne Mediumwechsel blieb das 1-Hydroxyqinolon-Resistenzniveau der 3L-H11 und 3F-A6 Parasiten erhalten und ist demnach scheinbar nicht das Ergebnis einer gesteigerten Detoxifikationsrate.

\subsubsection{Die Resistenzausprägung ist nicht an ein nachweisbares mitochondriales Membranpotential $\left(\Delta \Psi_{m}\right)$ gebunden}

Frühere Studien konnten bereits nachweisen, dass $T$. gondii über eine funktionelle Atmungskette verfügt und dass das Tachyzoitenwachstum unmittelbar an eine ausreichende ATP-Generierung durch die oxidative Phosphorylierung gebunden ist (Vercesi et al. 1998; Lin et al. 2009). Zudem wurde durch unsere Arbeitsgruppe gezeigt, dass eine Behandlung des RH Stamms mit HDQ zu einer Depolarisierung des inneren mitochondrialen Membranpotentials $\left(\Delta \Psi_{\mathrm{m}}\right)$ führt (Lin et al. 2009). Für beide Resistenzmutanten wurde mit Hilfe von MitoTracker gefärbten Parasiten daher überprüft, ob während des Wachstums unter 1-Hydroxyquinolonen, ein mitochondriales Membranpotential nachgewiesen werden kann. Unbehandelte Kontrollen der 3L-H11 und 3F-A6 Mutanten zeigten, ebenso wie der parentale Stamm RHAuprt, in über $90 \%$ der untersuchten Parasiten ein ausgeprägtes mitochondriales Membranpotential. Dieses stellt sich unter dem Fluoreszenzmikroskop in einer deutlichen Färbung des singulären Mitochondriums von T. gondii dar (Abb. 3.5 A). Nach einer Kultivierung mit Compound B für 48 h konnte jedoch für beide Resistenzmutanten, ebenso wie für die RHAuprt Mutante, bei circa $95 \%$ der Parasiten kein mitochondriales Membranpotential mehr nachgewiesen werden (Abb. 3.5 B). Eine Behandlung mit Compound B führt damit sowohl bei 3L-H11 als auch 3F-A6 Parasiten zu einem Zusammenbruch des mitochondrialen Membranpotentials, das erstaunlicherweise auch nach dem Wiedereinsetzen der Parasitenreplikation nicht regeneriert wird. Beide Klone sind demnach in der Lage sich moderat zu replizieren, ohne das hierfür ein nachweisbares Membranpotential notwendig ist. 


\section{Ergebnisse}

\section{A}
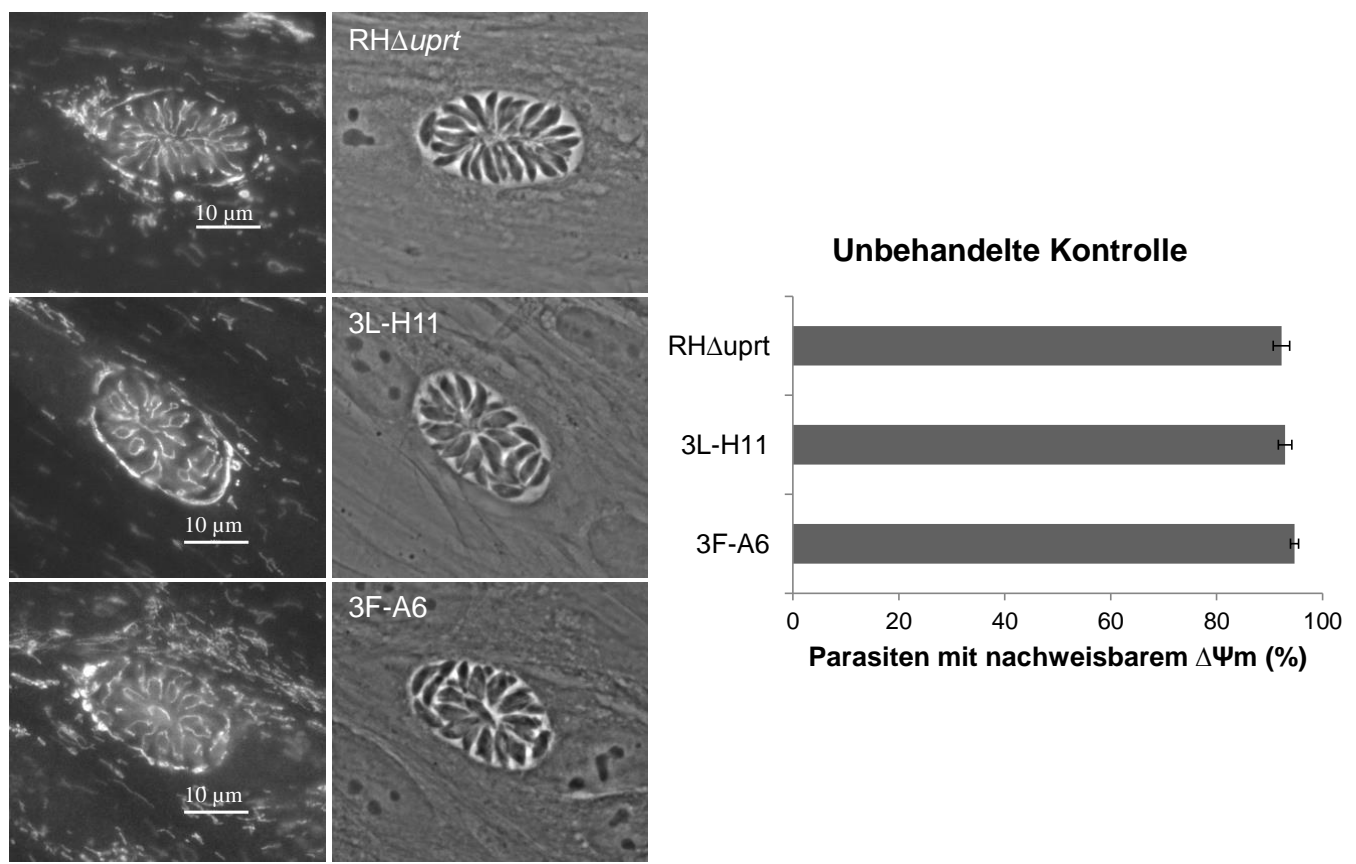

B
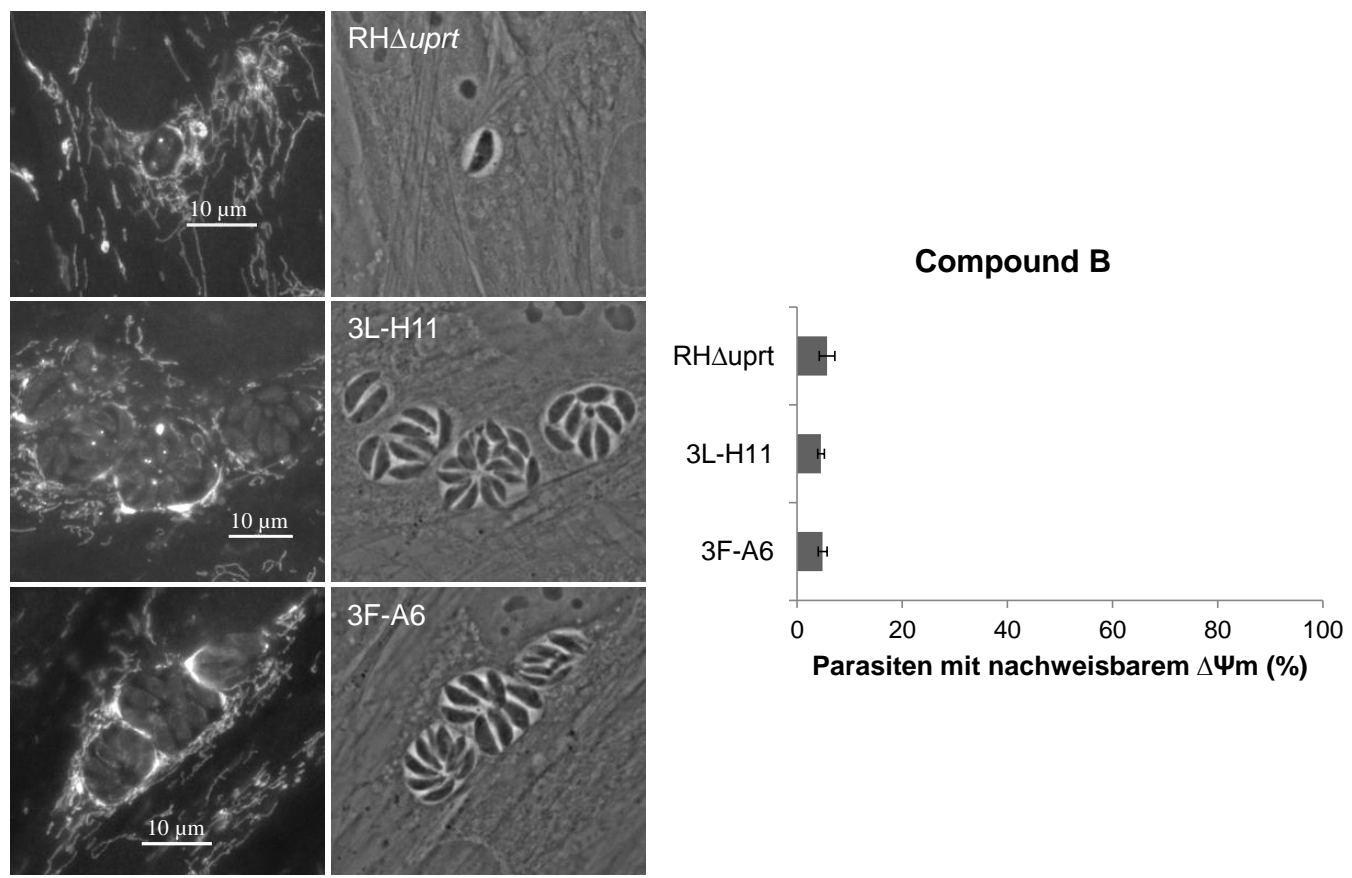

Parasiten mit nachweisbarem $\Delta \Psi \mathrm{m}(\%)$

Abbildung 3.5: Die 1-Hydroxyquinolon-Resistenz der 3L-H11 und 3F-A6 Parasiten ist nicht an ein nachweisbares mitochondriales Membranpotential $(\Delta \Psi \mathbf{m})$ gebunden. Für eine Detektion des $\Delta \Psi \mathrm{m}$ wurden konfluente HFF mit jeweils $\sim 3 \times 10^{4}$ RH $\Delta$ uprt, 3L-H11 bzw. 3F-A6 Parasiten infiziert und für (A) eine unbehandelte Kontrolle $24 \mathrm{~h}$ p. i. und (B) nach einer Behandlung mit $100 \mathrm{nM}$ Compound B für $48 \mathrm{~h}$ mit MitoTracker Red gefärbt und fixiert. Die Bestimmung des prozentualen Anteils parasitophorer Vakuolen mit Parasiten die ein nachweisbares $\Delta \Psi \mathrm{m}$ besaßen, wurde durch Fluoreszenzmikroskopie von mindestens 100 zufällig ausgewählten Vakuolen ermittelt. Die Darstellung der Ergebnisse erfolgt als Mittelwert (MW) \pm Standardabweichung des MW von Proben-Doppelbestimmungen eines repräsentativen Experiments $(n=2)$. Maßstabsbalken $=10 \mu \mathrm{m}$. 


\subsubsection{Untersuchung des Parasitenwachstums in Abhängigkeit glykolytischer Energiegewinnung}

Eine alternative Möglichkeit zur Kompensation des Energiedefizits aus der Atmungskette stellt die ATP-Gewinnung aus der Glykolyse dar. Im Hinblick auf die Inhibierung der Parasitenreplikation sowie der Resistenzausprägung gegenüber 1-Hydroxyquinolonen wurde daher der Einfluss eines Glucosemangels näher untersucht.

\subsubsection{Die Wachstums-Regeneration der Wildtyp Parasiten ist abhängig von Glucose}

Obwohl sich eine Behandlung mit HDQ oder Compound B in den ersten $24 \mathrm{~h}$ stark inhibierend auf das Wachstum des Wildtyp RH Stamms auswirkt, besitzen 1-Hydroxyquinolone nur eine parasitostatische Wirkung. Analysen der Wachstumskinetik zu späteren Zeitpunkten sprechen aufgrund einer Regeneration des Wachstums für eine Adaption der Parasiten. Um die Rolle der Glykolyse bei einer möglichen metabolischen Anpassung zu untersuchen, wurden RH Parasiten daher in einem definiertem Medium mit Glutamin als C-Quelle, jedoch einer stark erniedrigten Glucosekonzentration kultiviert.
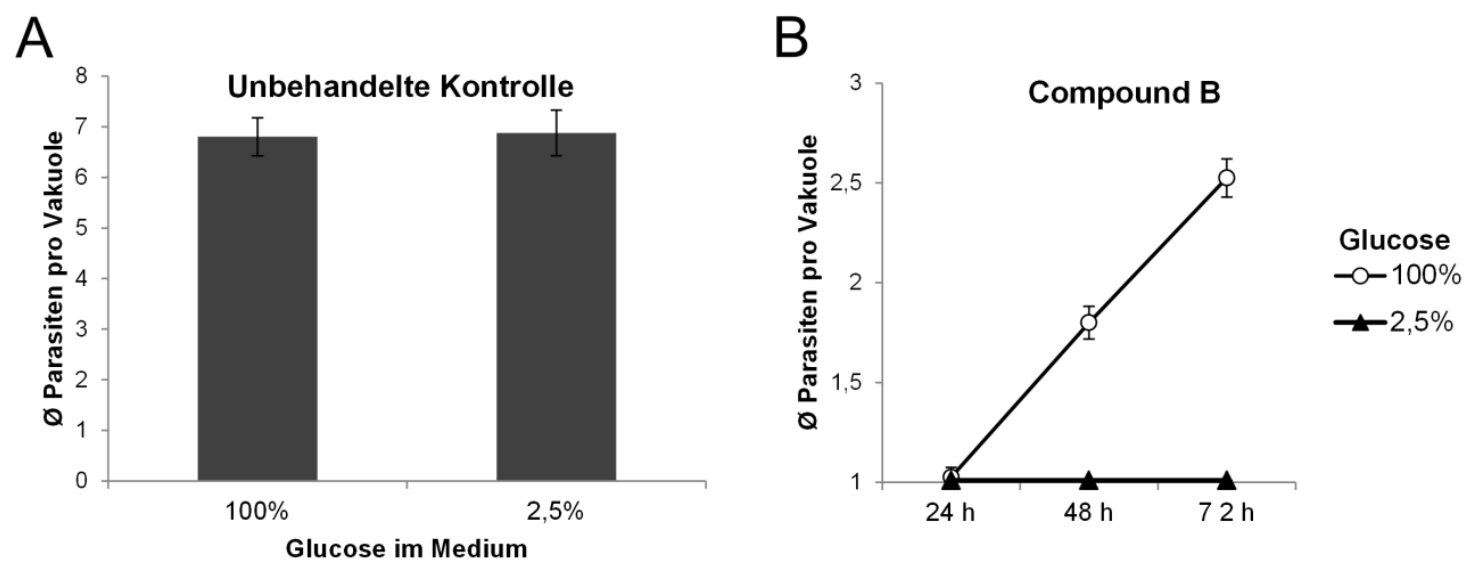

Abbildung 3.6: Eine Behandlung der RH Parasiten mit Compound B, führt bei gleichzeitiger Reduktion der Glucosekonzentration zu einer vollständigen Inhibierung der Wachstums-Regeneration. Konfluente HFF wurden mit $\sim 3 \times 10^{4}$ RH Parasiten infiziert und in Zellkulturmedium (mit dialysiertem FCS) mit $4 \mathrm{mM} \mathrm{L-}$ Glutamin und $25 \mathrm{mM} \mathrm{( \bumpeq} \mathrm{100 \% )} \mathrm{bzw.} \mathrm{0,625} \mathrm{mM} \mathrm{( \bumpeq} \mathrm{2,5 \% )} \mathrm{Glucose} \mathrm{kultiviert.} \mathrm{Eine} \mathrm{Analyse} \mathrm{der}$ Parasitenreplikation erfolgte nach Fixierung (A) einer unbehandelten Kontrolle nach 24 h p. i. und (B) einer Behandlung mit $100 \mathrm{nM}$ Compound für 48 h. Die durchschnittliche Anzahl intrazellulärer Parasiten wurde durch Auszählung der Parasiten von mindestens 100 zufällig ausgewählten parasitophoren Vakuolen bestimmt. Die Darstellung der Ergebnisse erfolgt als Mittelwert $(\mathrm{MW}) \pm$ Standardabweichung des MW von ProbenDoppelbestimmungen eines repräsentativen Experiments $(\mathrm{n}=2)$. 
Unabhängig von dem Glucoseanteil des Zellkulturmediums zeigten unbehandelte Kontrollen sowohl bei $25 \mathrm{mM}$ Glucose $(\hat{=} 100 \%)$ als auch bei $2,5 \%$ keine Unterschiede in der Wachstumsrate (Abb. 3.6 A). Des Weiteren führte die reguläre Glucosekonzentration von $100 \%$ unter Compound B, wie bereits in Abschnitt 3.1.1 beschrieben, zu einem wiedereinsetzenden Wachstum der Parasiten nach etwa 24 h. Eine Erniedrigung der Konzentration auf nur 2,5\% bewirkte unter der gleichzeitigen Zugabe von Compound B jedoch eine drastische Veränderung der Teilungsrate. Bis einschließlich 72 h p. i. konnte ein vollständiger Replikationsstop der Parasiten beobachtet werden (Abb. 3.6 B).

Um die beobachtete Hemmung der Parasitenregeneration in einem weiteren Versuch zu überprüfen, wurde die Replikationsfähigkeit der RH Parasiten im Vergleich zu einer TgGT1 Knock-Out Mutante des RH Stamms (Atggt1) analysiert. Atggtl Parasiten besitzen aufgrund einer Deletion des Glucosetransporters TgGT1 keine Aktivität in der Glucoseaufnahme. Infolge eines verstärkten Glutaminstoffwechsels zeigen die $\Delta$ tggt1 Parasiten jedoch lediglich eine ungefähr 10\%ige Reduktion der Verdopplungsrate und demnach nur einen moderaten Wachstumsdefekt (Blume et al. 2009).
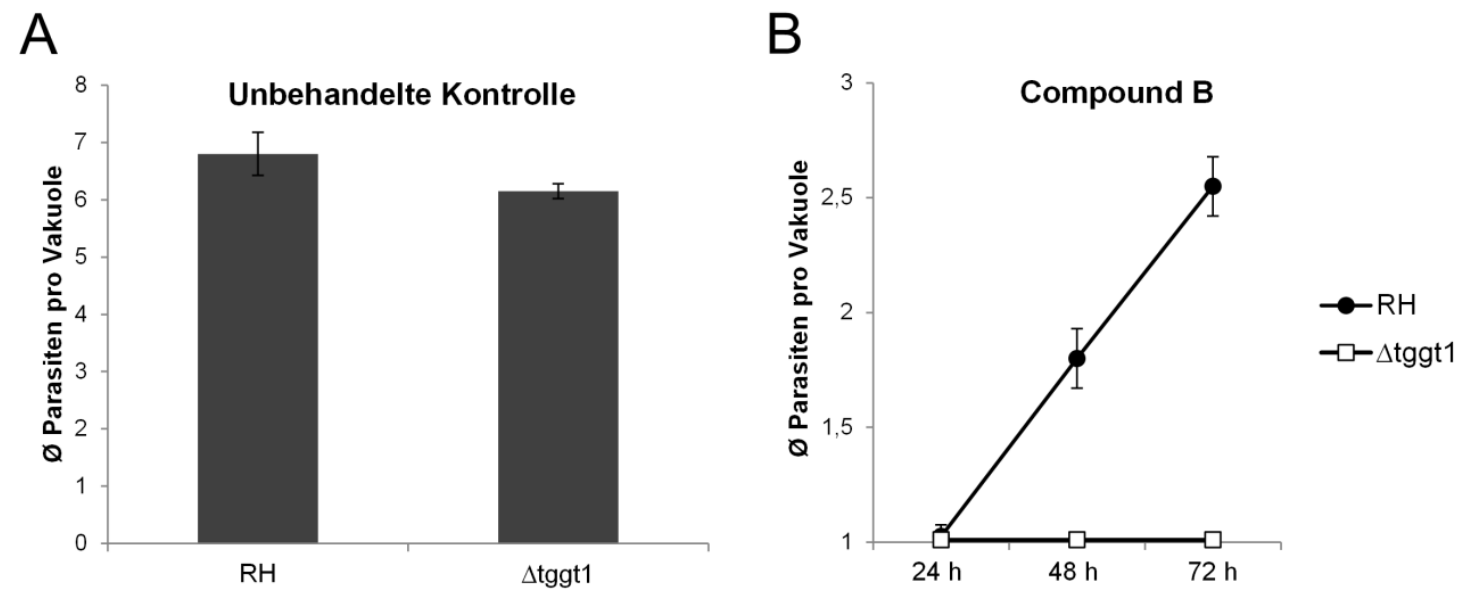

\begin{abstract}
Abbildung 3.7: $\Delta$ tggt1 Parasiten zeigen im Vergleich zum Wildtyp RH Stamm unter einer Behandlung mit Compound B, auch bei einer hohen Glucosekonzentration, eine vollständige Wachstumsinhibierung. Konfluente HFF wurden mit jeweils $\sim 3 \times 10^{4}$ RH und $\Delta$ tggtl Parasiten infiziert und in Zellkulturmedium (mit dialysiertem FCS) mit 4 mM L-Glutamin und 25 mM Glucose kultiviert. Eine Analyse der Parasitenreplikation erfolgte nach Fixierung (A) einer unbehandelten Kontrolle nach 24 h p. i. und (B) einer Behandlung mit $100 \mathrm{nM}$ Compound für $48 \mathrm{~h}$. Die durchschnittliche Anzahl intrazellulärer Parasiten wurde durch Auszählung der Parasiten von mindestens 100 zufällig ausgewählten parasitophoren Vakuolen bestimmt. Die Darstellung der Ergebnisse erfolgt als Mittelwert (MW) \pm Standardabweichung des MW von Proben-Doppelbestimmungen eines repräsentativen Experiments ( $\mathrm{n}=2)$.
\end{abstract}


In Übereinstimmung mit den vorherigen Ergebnissen, wurde das Wachstum der $\Delta$ tggt1 Mutante nach einer Behandlung mit Compound $B$ auch unter einer hohen Glucosekonzentration von $25 \mathrm{mM}$ bis 72 h p. i. vollständig inhibiert (Abb. 3.7 B). Während $\Delta$ tggt1 Parasiten im Vergleich zum RH Stamm unter Compound B einen vollständigen Replikationsstop zeigten, wurde in der unbehandelten Wachstumskontrolle lediglich der beschriebene moderate Wachstumsdefekt ersichtlich (Abb. 3.7 A).

\subsubsection{3L-H11 und 3F-A6 Parasiten zeigen nach einer Hemmung der Glykolyse eine gesteigerte Compound B-Sensitivität}

Ebenso wie der RH Stamm zeigten die Resistenzmutanten nach einer Behandlung mit 1-Hydroxyquinolon-Derivaten erst nach etwa $24 \mathrm{~h}$ eine Regeneration des Wachstums, während sie im späteren Behandlungsverlauf eine deutliche Resistenz aufwiesen. Um den Einfluss eines Glucosemangels auf die 1-Hydroxyquinolon-Resistenz zu untersuchen, wurden die Parasiten in Medium mit einer konstanten Glutaminkonzentration, jedoch unterschiedlichen Glukosekonzentrationen kultiviert.
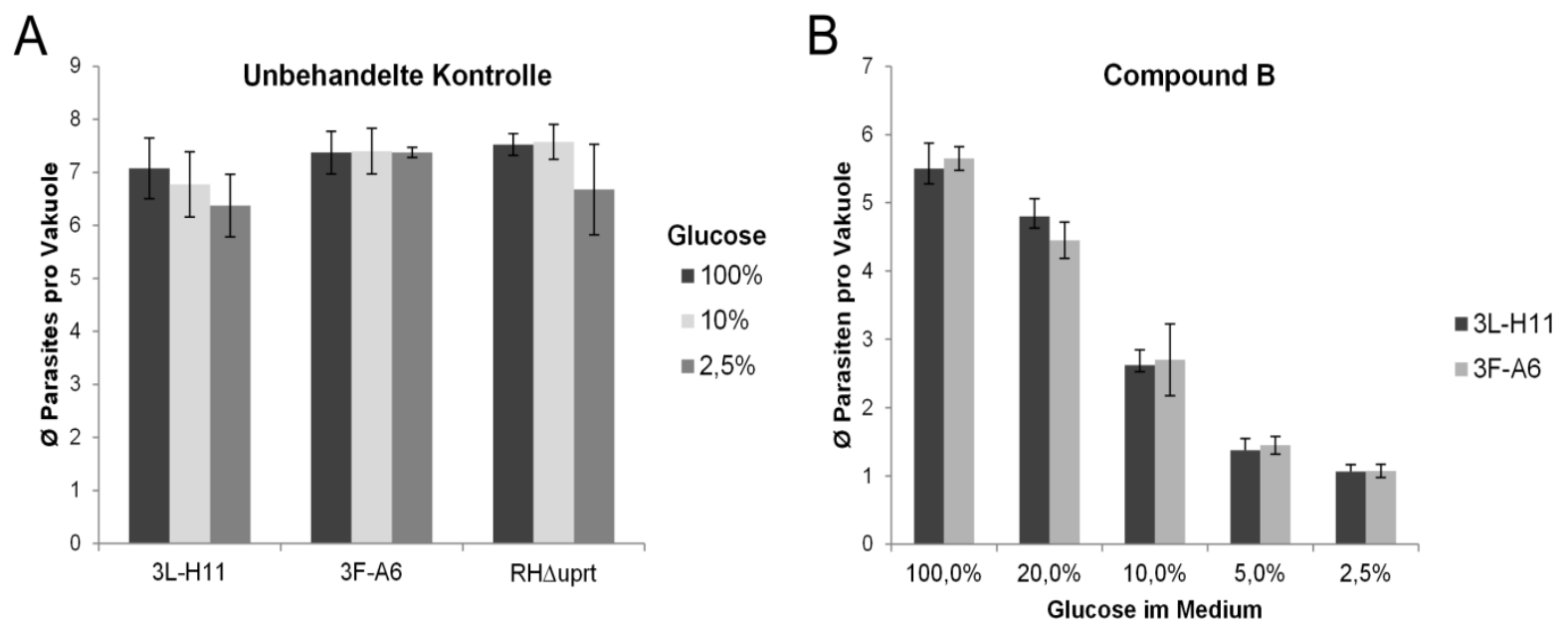

Abbildung 3.8: Unter einem Mangel an Glucose besitzen 3L-H11 und 3F-A6 Parasiten eine deutlich gesteigerte Compound B-Sensitivität. Konfluente HFF wurden mit jeweils $\sim 3 \times 10^{4}$ RH $\Delta$ uprt, 3L-H11 und 3F-A6 Parasiten infiziert und im Falle einer (A) unbehandelten Kontrolle in Zellkulturmedium (mit dialysiertem FCS) mit $4 \mathrm{mM}$ L-Glutamin und $25 \mathrm{mM}(\triangleq 100 \%), 2,5 \mathrm{mM}(\triangleq 10 \%)$ sowie $0,625 \mathrm{mM}(\triangleq 2,5 \%)$ Glucose kultiviert und die Wachstumsrate nach 24 h p. i. bestimmt. (B) Für eine Analyse der Parasitenreplikation nach einer Behandlung mit $100 \mathrm{nM}$ Compound für 48 h, wurden 3L-H11 und 3F-A6 Parasiten mit 4 mM L-Glutamin

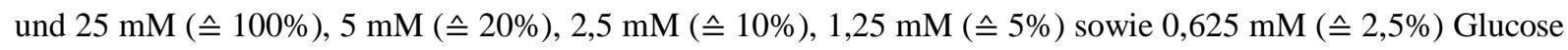
kultiviert. Die durchschnittliche Anzahl intrazellulärer Parasiten wurde durch Auszählung der Parasiten von mindestens 100 zufällig ausgewählten parasitophoren Vakuolen bestimmt. Die Darstellung der Ergebnisse erfolgt als Mittelwert $(\mathrm{MW}) \pm$ Standardabweichung des MW von Proben-Doppelbestimmungen eines repräsentativen Experiments $(\mathrm{n}=2)$. 
Ebenso wie bei RH Parasiten nimmt der Glucoseanteil des Mediums keinen Einfluss auf das Wachstum unbehandelter Kontrollen (Abb. 3.8 A). Beide Resistenzmutanten zeigten sowohl bei $100 \%, 10 \%$ und 2,5\% Glucose eine identische Replikationsrate. Wurden sie jedoch mit Compound B behandelt, konnte eine deutliche Korrelation zwischen der Glucosekonzentration und dem Resistenzniveau nachgewiesen werden (Abb. 3.8 B). Je niedriger der Glucosegehalt war, umso sensitiver reagierten die Parasiten auf eine Behandlung mit Compound B. Bei einer Konzentration von 2,5\% Glucose zeigten die 3L-H11 und 3F-A6 Mutanten entsprechend dem Ausgangsstamm RHAuprt 48 h p. i. sogar eine vollständige Wachstumsinhibierung und damit, ebenso wie RH Parasiten, eine Hemmung der Parasitenregeneration.

Bestätigt wurde diese wechselseitige Beziehung durch eine simultane Behandlung mit Compound B und 2-Deoxy-D-Glucose (2-DOG). Dieser Antimetabolit inhibiert den ersten Schritt der Glykolyse. Anstelle von Glucose wird 2-DOG durch die Hexokinase phosphoryliert, kann anschließend jedoch nicht weiter metabolisiert werden und führt damit zu einer verminderten Glucoseverwertung.
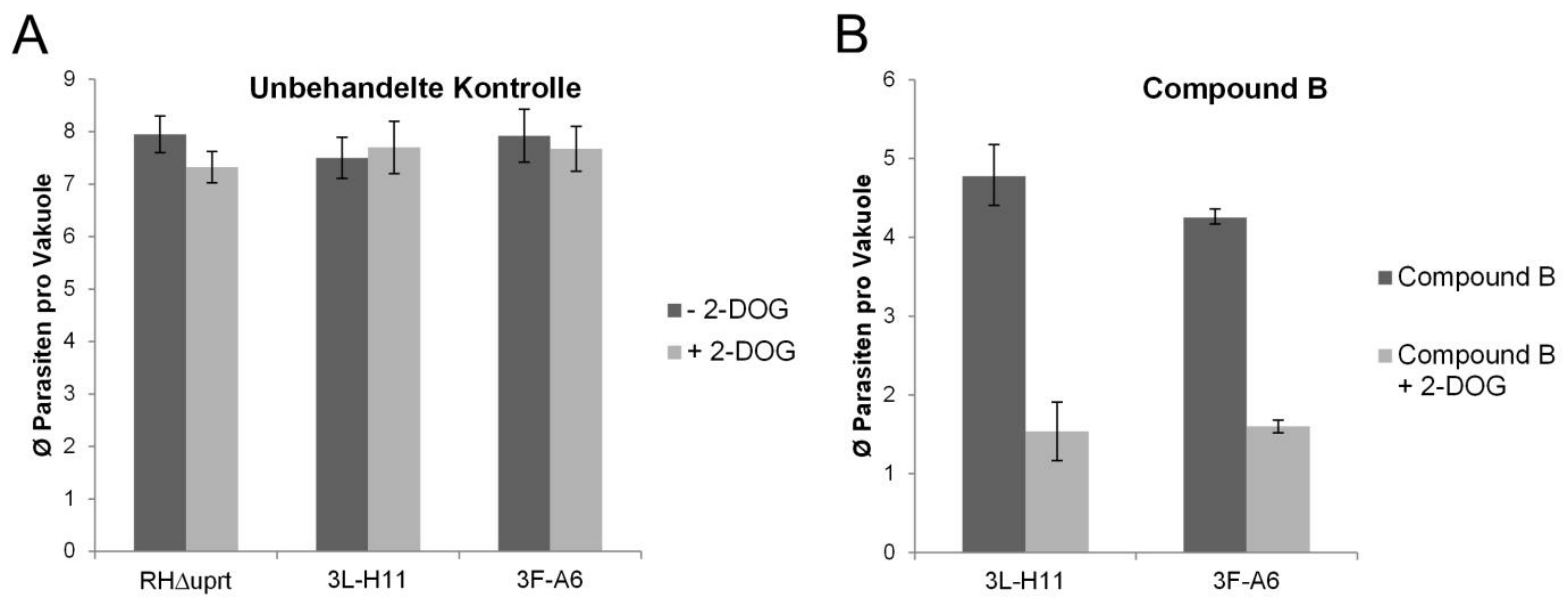

Abbildung 3.9: Eine Inhibierung der Glykolyse durch 2-DOG führt zu einer Reduktion der partiellen Compound B-Resistenz bei 3L-H11 und 3F-A6 Parasiten. Konfluente HFF wurden mit jeweils $\sim 3 \times 10^{4}$ RHAuprt, 3L-H11 und 3F-A6 Parasiten infiziert und im Falle einer unbehandelten Kontrolle (A) in Zellkulturmedium (mit dialysiertem FCS) mit $4 \mathrm{mM} \mathrm{L-Glutamin,} 5 \mathrm{mM}$ Glucose (슨 20\%) und $10 \mathrm{mM}$ 2-DOG kultiviert und die Wachstumsrate nach 24 h p. i. bestimmt. (B) Für eine Analyse der Parasitenreplikation nach einer Behandlung mit $100 \mathrm{nM}$ Compound für $48 \mathrm{~h}$ wurden 3L-H11 und 3F-A6 Parasiten mit $4 \mathrm{mM}$ L-Glutamin, $5 \mathrm{mM}$ Glukose (^20\%) und $10 \mathrm{mM}$ 2-DOG kultiviert. Die durchschnittliche Anzahl intrazellulärer Parasiten wurde durch Auszählung der Parasiten von mindestens 100 zufällig ausgewählten parasitophoren Vakuolen bestimmt. Die Darstellung der Ergebnisse erfolgt als Mittelwert (MW) \pm Standardabweichung des MW von Proben-Doppelbestimmungen eines repräsentativen Experiments $(n=2)$. 
Auf unbehandelte RHAuprt, 3L-H11 und 3F-A6 Parasiten hatte eine Inhibierung der Glykolyse durch 2-DOG keinen Einfluss. Eine Kultivierung der Parasiten ohne bzw. mit 2-DOG führte in beiden Fällen $\mathrm{zu}$ einer vergleichbaren Teilungsrate (Abb. 3.9 A). In Anwesenheit von Compound B wurde die Parasitenreplikation jedoch stark beeinträchtigt. Im Gegensatz zu einer alleinigen Behandlung mit Compound B, kam es bei gleichzeitiger Zugabe von 2-DOG zu einer Reduktion des Wachstums der 3L-H11 und 3F-A6 Mutanten von nahezu 75\% und damit einer deutlichen Zunahme der Compound B-Sensitivität (Abb. 3.9 B).

Basierend auf den vorherigen Ergebnissen zeichnen sich sowohl RH, als auch 3L-H11 und 3F-A6 Parasiten nach einer Behandlung mit Compound B durch eine verstärkte metabolische Abhängigkeit gegenüber Glucose aus. Trotz einer Kultivierung mit Glutamin zeigten RH Parasiten ohne eine ausreichende Versorgung mit Glucose keine Wachstums-Regeneration. Darüber hinaus korrelierte die 1-Hydroxyquinolon-Resistenz der 3L-H11 und 3F-A6 Parasiten mit dem Glucosegehalt des Mediums. Bei sehr niedrigen Konzentrationen konnte, ebenso wie bei dem RH Stamm, eine Inhibition der Parasitenregeneration beobachtet werden. Ein metabolischer Wechsel von oxidativer Phosphorylierung zur Glykolyse scheint unter diesem Aspekt von entscheidender Bedeutung zu sein.

\subsubsection{1-Hydroxyquinolon-sensitive und -resistente Parasiten zeigen keinen Unterschied im Expressionsmuster glykolytischer Gene und des Glucosetransporters TgGT1}

Quantitative RT-PCR Analysen sollten Aufschluss darüber geben, ob die erhöhte Resistenz von 3L-H11 und 3F-A6 Parasiten mit Veränderungen im Expressionsmuster glykolytischer Gene einhergeht. Die Genexpression beider Mutanten wurde dabei durch das konstitutiv exprimierte $\beta$-Tubulin normalisiert und im Vergleich zu RHAuprt Parasiten relativ quantifiziert. Die Quantifizierung der Genexpression, auf mRNA-Ebene, wurde für unbehandelte $24 \mathrm{~h}$ Kontrollen vorgenommen und des Weiteren nach einer Kultivierung der Parasiten mit Compound B für insgesamt 48 h. Weder für die unbehandelte Kontrolle (Abb. 3.10 A) noch nach einer Behandlung mit Compound B (Abb. 3.10 B) konnten Unterschiede im mRNA Expressionsgehalt der Hexokinase (HK), Glucosephosphat-Isomerase (GPI) und beider Isoformen der Triosephosphat-Isomerase (TPI I und TPI II), Phosphoglyceratkinase (PGK I und PGK II) und Pyruvatkinase (PK I und PK II) festgestellt werden. 

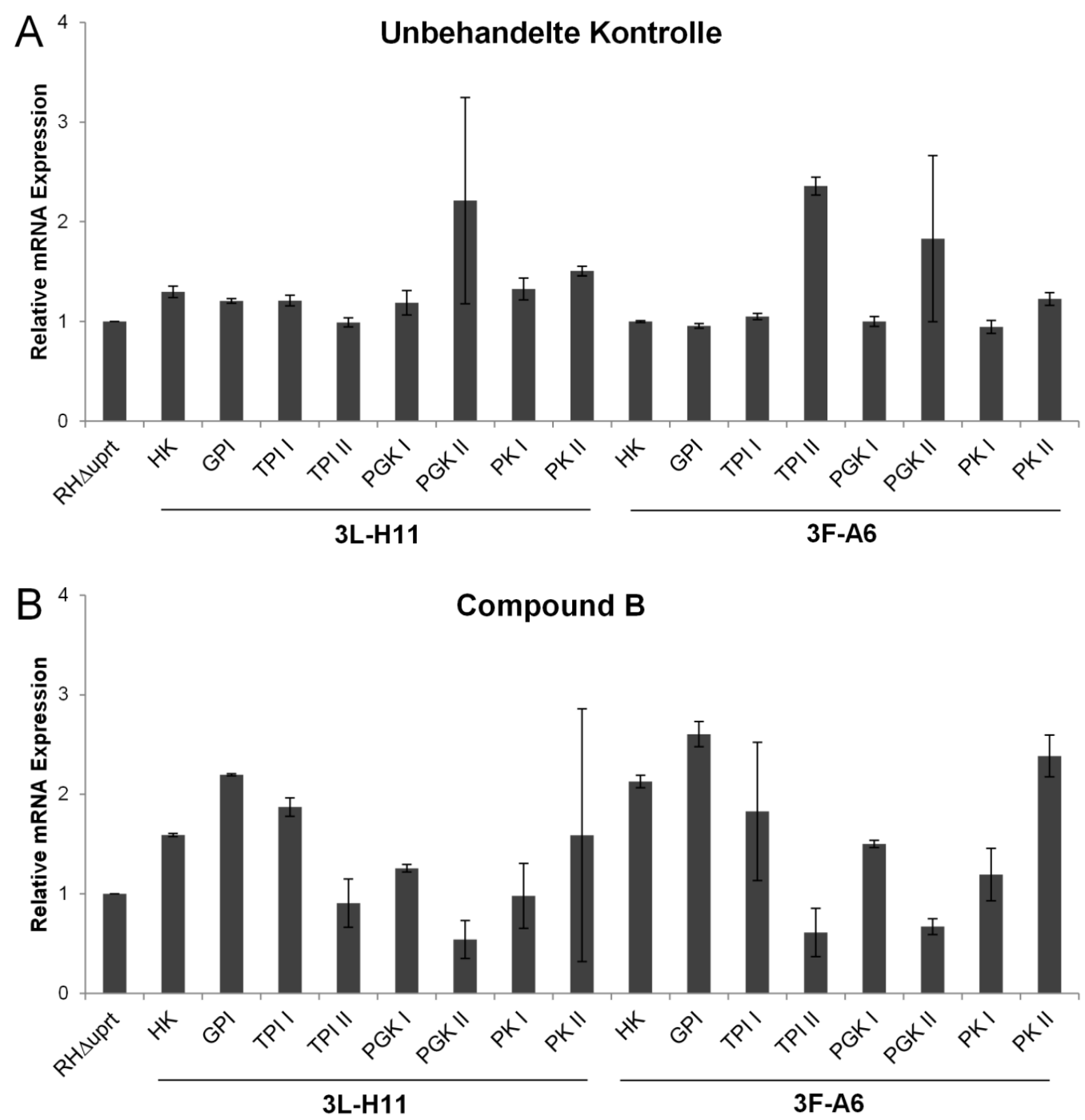

Abbildung 3.10: 3L-H11 und 3F-A6 Parasiten zeigen keine ausgeprägten Veränderungen im Expressionsmuster glykolytischer Gene. 3L-H11 und 3F-A6 Parasiten wurden hinsichtlich der mRNA Genexpression der Hexokinase (HK), Glucosephosphat-Isomerase (GPI), Triosephosphat-Isomerase (TPI I und TPI II), Phosphoglyceratkinase (PGK I und PGK II) und Pyruvatkinase (PK I und PK II) untersucht. Dafür wurde (A) bei unbehandelten Kontrollen $24 \mathrm{~h}$ p. i. und (B) nach einer Behandlung mit $100 \mathrm{nM}$ Compound B für $48 \mathrm{~h}$, Gesamt-RNA isoliert, revers transkribiert und gewonnene cDNA durch LightCycler Real-Time PCR analysiert. Crossing Point ( $\mathrm{Cp}$ ) Werte wurden zur Quantifizierung herangezogen und durch die mRNA Expression von $\beta$-Tubulin normalisiert. Die Genexpression der 3L-H11 und 3F-A6 Mutanten ist als x-fache Änderung der Genexpression gegenüber der unbehandelten Kontrolle der parentalen RH $\Delta$ uprt Mutante angegeben. Die Darstellung der Ergebnisse erfolgt als Mittelwert (MW) \pm Standardabweichung des MW von Proben-Doppelbestimmungen eines repräsentativen Experiments $(n=2)$.

Neben einer Untersuchung der glykolytischen Genexpression wurde weiterhin die Expressionsstärke des auf der Parasitenoberfläche lokalisierten Glucosetransporters TgGT1 untersucht. Zwar wurde bereits ein weiterer, auf der Plasmamembran lokalisierter Transporter beschrieben (TgST2), jedoch ist dieser nicht an einem Import von Glucose beteiligt (Blume et 
al. 2009). Eine Analyse der TgGT1 Expression konnte jedoch weder für unbehandelte Proben, noch nach einer Behandlung mit Compound B für 48 h eine veränderte mRNA Transkriptrate nachweisen (Abb. 3.11).

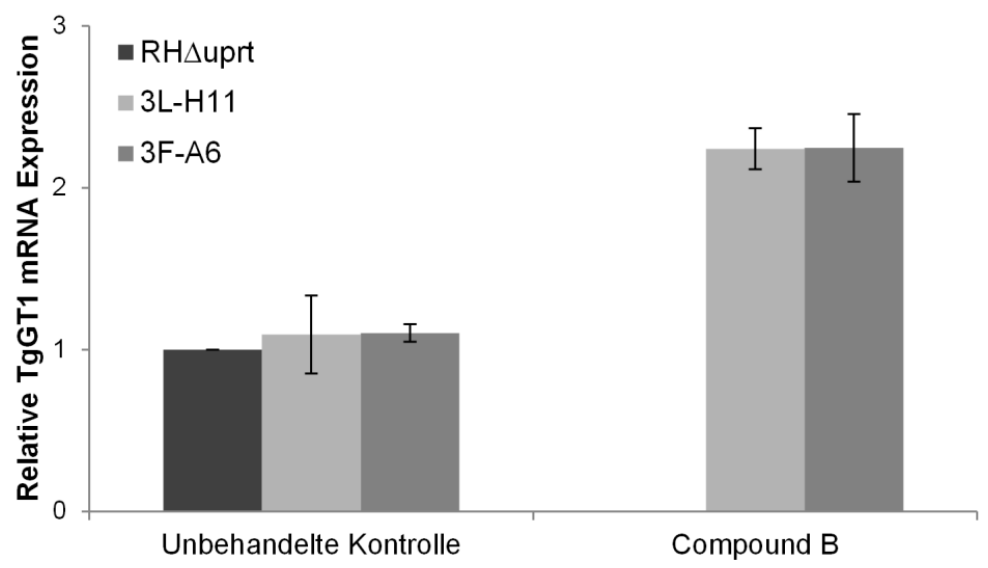

Abbildung 3.11: 3L-H11 und 3F-A6 Parasiten zeigen keine ausgeprägte Veränderung in der Genexpression des Glucosetransporters TgGT1. 3L-H11 und 3F-A6 Parasiten wurden hinsichtlich der mRNA Expression des Glucosetransporters TgGT1 untersucht. Dafür wurde bei unbehandelten Kontrollen 24 h p. i. und nach einer Behandlung mit $100 \mathrm{nM}$ Compound B für $48 \mathrm{~h}$, Gesamt-RNA isoliert, revers transkribiert und gewonnene cDNA durch LightCycler Real-Time PCR analysiert. Crossing Point (Cp) Werte wurden zur Quantifizierung herangezogen und durch die mRNA Expression von $\beta$-Tubulin normalisiert. Die Genexpression der 3L-H11 und 3F-A6 Mutanten ist als x-fache Änderung der Genexpression gegenüber der unbehandelten Kontrolle der parentalen RHAuprt Mutante angegeben. Die Darstellung der Ergebnisse erfolgt als Mittelwert (MW) \pm Standardabweichung des MW von Proben-Doppelbestimmungen eines repräsentativen Experiments $(\mathrm{n}=2)$. 


\subsection{Identifizierung der $T$. gondii Dihydroorotat Dehydrogenase (TgDHODH) als Targetprotein der 1-Hydroxyquinolone}

\subsubsection{Resistenzmutanten zeigen keine Unterschiede im Expressionsgehalt mitochondrialer Dehydrogenasen}

HDQ und Compound B weisen eine strukturelle Ähnlichkeit gegenüber Ubiquinon auf. Im Mittelpunkt der genetischen Identifizierung relevanter Zielstrukturen standen daher vor allem Ubiquinon/Ubiquinol-interagierende Enzyme der mitochondrialen Atmungskette. Entsprechend der Untersuchung der glykolytischen Genexpression wurden beide Resistenzmutanten dabei zunächst hinsichtlich der mRNA Expression der sechs Ubiquinonreduzierenden mitochondrialen Dehydrogenasen untersucht. Darunter beide Isoformen der alternativen Typ II NADH Dehydrogenase (NDH2-I und NDH2-II) sowie die Succinat Dehydrogenase (SDH), Malat:Quinon Oxidoreduktase (MQO), Glycerin-3-Phosphat Dehydrogenase (G3PDH) und Dihydroorotat Dehydrogenase (DHODH). Eine Normalisierung der Genexpression beider Mutanten erfolgte erneut mit $\beta$-Tubulin als Referenzgen und wurde im Vergleich zu RHAuprt Parasiten relativ quantifiziert. Die Quantifizierung der Genexpression, auf mRNA-Ebene, wurde dabei für unbehandelte $24 \mathrm{~h}$ Kontrollen vorgenommen und des Weiteren nach einer Kultivierung der Parasiten mit Compound B für insgesamt 48 h. Dabei konnte weder für die unbehandelte Kontrolle (Abb. 3.12 A) noch nach einer Kultivierung der Parasiten mit Compound $B$ ein veränderter mRNA Expressionsgehalt nachgewiesen werden (Abb. 3.12 B). Sowohl hoch-sensitive RH $\Delta$ uprt Parasiten als auch beide Resistenzmutanten zeigten vergleichbare Expressionslevel aller untersuchten mitochondrialen Dehydrogenasen, eine Überexpression der Gene scheint demnach nicht an der 1-Hydroxyquinolon-Resistenz beteiligt zu sein. 

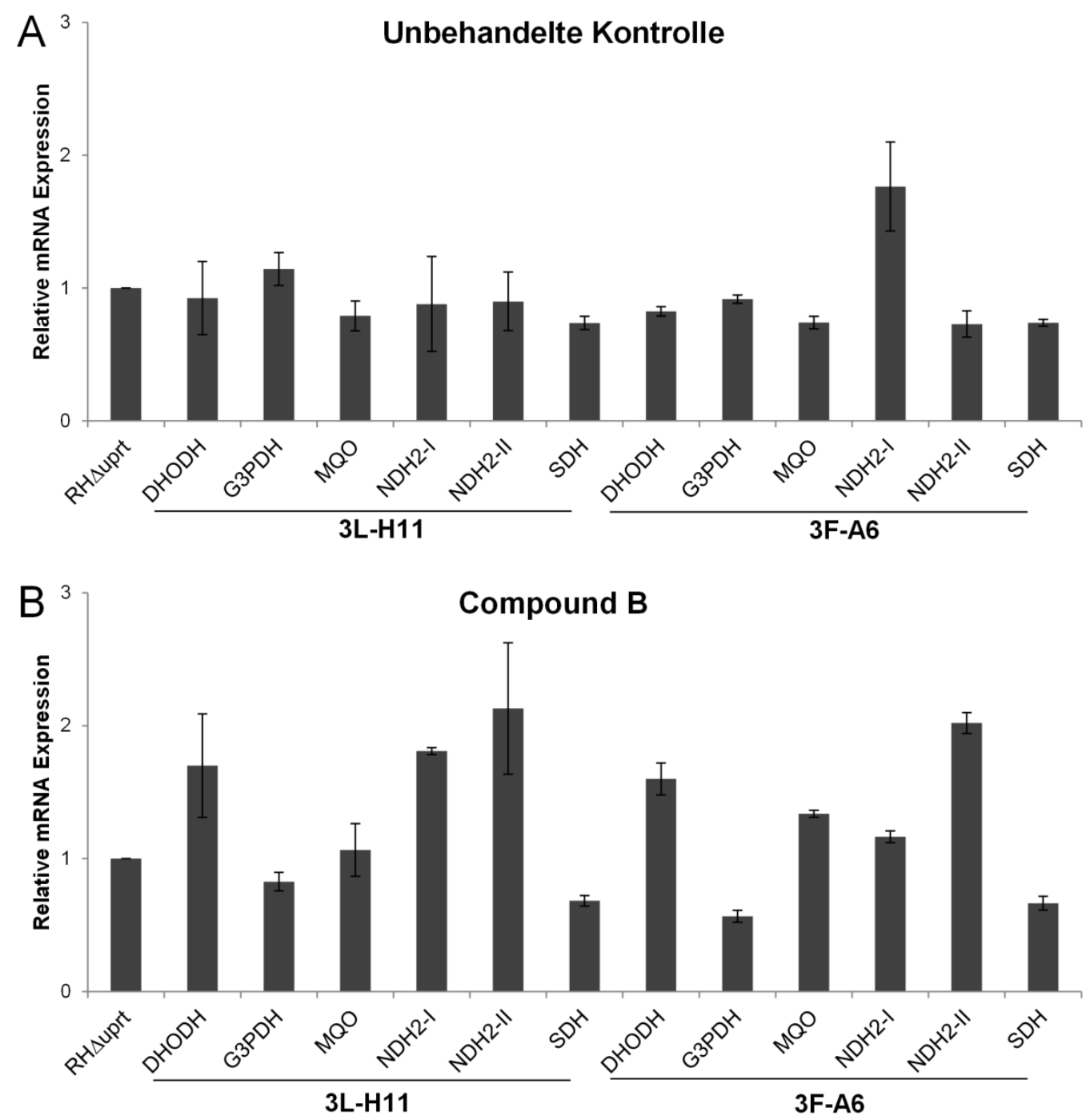

Abbildung 3.12: 3L-H11 und 3F-A6 Parasiten zeigen keine ausgeprägten Veränderungen im Expressionsmuster mitochondrialer Dehydrogenasen. 3L-H11 und 3F-A6 Parasiten wurden hinsichtlich der mRNA Genexpression beider Isoformen der alternativen Typ II NADH Dehydrogenase (NDH2-I und NAH2-II), der Succinat-Dehydrogenase (SDH), Malat:Quinon Oxidoreduktase (MQO), Glycerin-3-Phosphat Dehydrogenase (G3PDH) und Dihydroorotat Dehydrogenase (DHODH) untersucht. Dafür wurde bei (A) unbehandelten Kontrollen 24 h p. i. und (B) nach einer Behandlung mit 100 nM Compound B für 48 h, GesamtRNA isoliert, revers transkribiert und gewonnene cDNA durch LightCycler Real-Time PCR analysiert. Crossing Point (Cp) Werte wurden zur Quantifizierung herangezogen und durch die mRNA Expression von $\beta$-Tubulin normalisiert. Die Genexpression der 3L-H11 und 3F-A6 Mutanten ist als x-fache Änderung der Genexpression gegenüber der unbehandelten Kontrolle der parentalen RHAuprt Mutante angegeben. Die Darstellung der Ergebnisse erfolgt als Mittelwert $(M W) \pm$ Standardabweichung des MW von Proben-Doppelbestimmungen eines repräsentativen Experiments ( $\mathrm{n}=2)$. 


\subsubsection{DNA-Sequenzanalysen identifizieren eine einzelne Mutation der TgDHODH von 3L-H11 und 3F-A6 Parasiten}

Genmodifikationen nehmen bei der Entstehung extrinsischer Resistenzen eine entscheidende Rolle ein. Im Fokus vieler Studien stehen dabei vor allem resistenzassoziierte, nichtsynonyme Punktmutationen. Um mögliche Resistenzmarker der 3L-H11 und 3F-A6 Parasiten $\mathrm{zu}$ identifizieren, wurde daher die kodierende Sequenz aller Ubiquinon-reduzierenden Dehydrogenasen sequenziert und auf Mutationen hin untersucht. Da eine an P. falciparum durchgeführte Studie den Nachweis erbrachte, dass HDQ an die Quinon-Reduktionsseite $\left(\mathrm{Q}_{\mathrm{i}}\right)$

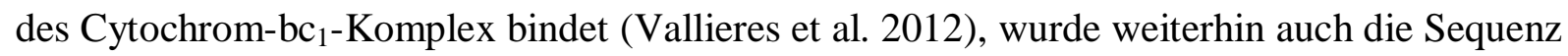
von Cytochrom b analysiert. Eine Überprüfung der Gensequenzen erbrachte keine Veränderungen in der Nukleotid-Abfolge der NDH2-I, NDH2-II, SDH, MQO und G3PDH sowie für Cytochrom b. Interessanterweise konnte jedoch in der kodierenden Sequenz des dhodh Gens (TGGT1_124080) eine einzelne Punktmutation für Nukleotid 980 nachgewiesen werden (Abb. 3.13). Während der RH Stamm und die uprt-Deletionsmutante RH $\Delta u p r t$ ein Adenin (A) aufweisen, besitzen 3L-H11 und 3F-A6 Parasiten an dieser Position ein Guanin (G). In der Folge kommt es dadurch zu einer Aminosäuresubstitution von Asparagin nach Serin des Codons 302 (N302S).

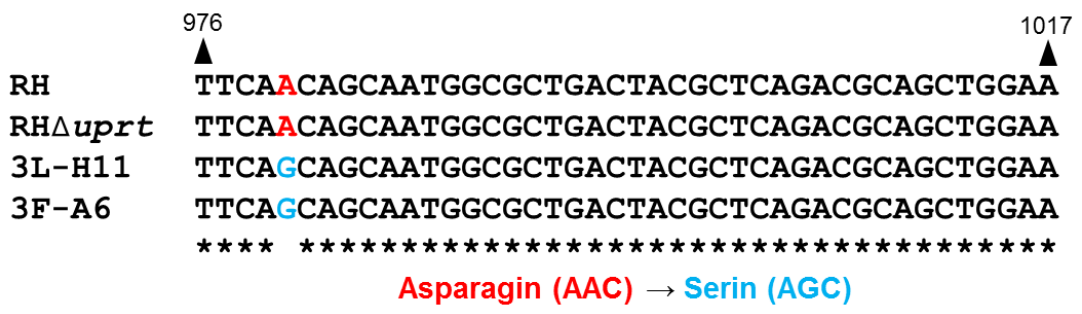

Abbildung 3.13: 3L-H11 und 3F-A6 Parasiten zeigen eine Punktmutation in der kodierenden Sequenz der TgDHODH, bei der es nachfolgend zu einer Aminosäuresubstitution kommt. Ein Alignment der kodierenden Nukleotidsequenz des dhodh Gens von RH, RHAuprt, 3L-H11 und 3F-A6 Parasiten identifizierte eine einzelne Punktmutation des Nukleotids 980 von Adenin (A) nach Guanin (G), die zu einer Aminosäuresubstitution des Codons 302 von Asparagin nach Serin führt (N302S).

\subsubsection{Punktmutation N302S lokalisiert in einem hoch-konserviertem Bereich der kodierenden Sequenz}

Ein Alignment von TgDHODH mit drei homologen Proteinen (Plasmodium falciparum, Homo sapiens und Escherichia coli), deren 3D-Proteinstruktur bereits bekannt ist, sollte Aufschluss über die strukturelle Position der N302S Mutation geben. Dabei zeigte sich, dass das in Position 302 lokalisierte Asparagin (Asn302) der Wildtyp-TgDHODH innerhalb der 
Klasse 2 DHODHn hoch-konserviert ist und in einer Region lokalisiert, welche nicht an der Bildung von Sekundärstrukturen beteiligt ist. Asn302 befindet sich jedoch in direkter Nachbarschaft der ebenfalls konservierten Aminosäuren Gly300 und Phe301, welche Bestandteil des aktiven Zentrums für Dihydroorotat (DHO) sind (Abb. 3.14 A und B). Des Weiteren ergab die Analyse der modifizierten dhodh Gensequenz, dass der von Adenin nach Guanin erfolgte Nukleotidaustausch zur Generierung einer Fnu4HI Restriktionsschnittstelle führt. Mittels Restriktionsfragment-Längenpolymorphismus Analysen (RFLP) wird es dadurch möglich zwischen Wildtyp und mutiertem N302S Allel zu unterschieden (Abb. 3.14 C).

A

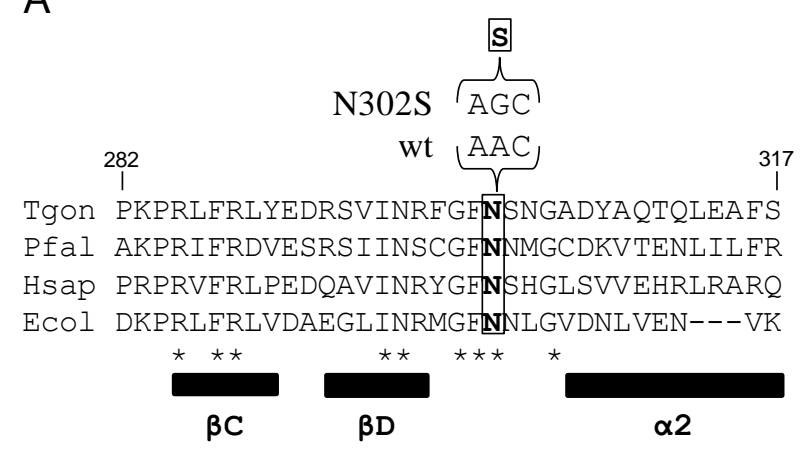

C

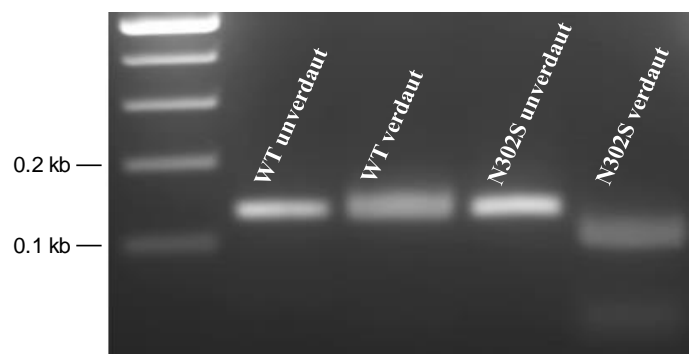

B

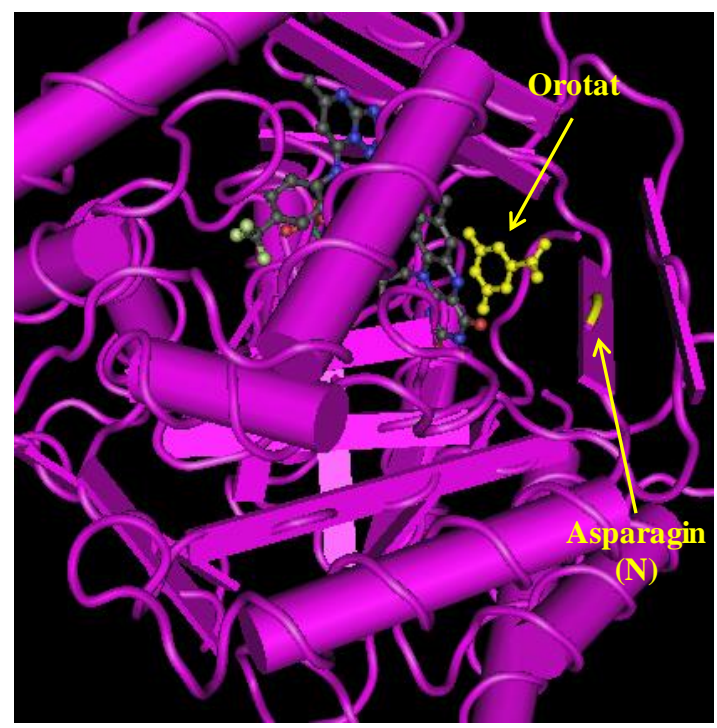

Abbildung 3.14: Punktmutation N302S lokalisiert in einem hoch-konservierten Bereich von TgDHODH. (A) Multiples Alignment der T. gondii DHODH Region von Aminosäure 282-317 mit DHODH Sequenzen von P. falciparum (Pfal), H. sapiens (Hsap) und E. coli (Ecol). Eine einzelne Basen-Substitution in 3L-H11 und 3F-A6 Parasiten führt zu einer N302S Mutation. Asparagin (N) in Position 302 ist innerhalb der Klasse 2 DHODHn hoch konserviert und in einer Region lokalisiert, die nicht an der Bildung von Sekundärstrukturen beteiligt ist. Konservierte Aminosäuren sind mit einem Stern (*) markiert und Sekundärstrukturen (mit $\alpha$ und $\beta$ benannt) durch schwarze Balken hervorgehoben. (B) 3D-Proteinstruktur der DHODH von P. falciparum. Gelb markiert sind das hoch-konservierte Asparagin $(\mathrm{N})$ und das durch die Oxidation von DHO gebildete Orotat. (C) Punktmutation N302S erlaubt eine Unterscheidung des Wildtyp und mutierten N302S Allels durch RFLP Analysen. Eine 132 bp lange Region, die Codon 302 einschließt, wurde mittels PCR von cDNA der Wildtyp und mutierten N302S Parasiten amplifiziert und mit Fnu4HI verdaut. Während das Wildtyp-Fragment unverdaut bleibt, wird das N302S PCR-Fragment in zwei Produkte mit einer Größe von 103 und 29 bp geschnitten. 


\subsubsection{Eine Expression des N302S-Allels vermittelt partielle Resistenz gegenüber 1-Hydroxyquinolonen}

Um die Bedeutung der N302S Punktmutation näher zu untersuchen, wurde das endogene DHODH Wildtyp-Allel direkt am ursprünglichen Locus durch das N302S-Allel ersetzt („Knock-In“-Strategie). Grundlage dieser Gen-Insertion ist eine einfache homologe Rekombination zwischen dem Ziel-Locus und einem homologen DNA Fragment, welches die jeweilige Modifikation enthält. T. gondii weist jedoch eine verstärkte Häufigkeit nicht-homologer Rekombinationsprozesse auf, wodurch gezielte Genmodifikationen nur in sehr zeitintensiven Prozessen erzeugt werden können. Es konnte jedoch nachgewiesen werden, dass RH $\triangle k u 80$ Knock-Out Mutanten durch den Verlust nicht-homologer DNA-Reparaturmechanismen eine hohe Effizienz homologer Rekombinationsereignisse zeigen (Fox et al. 2009). Für eine effektive Selektion resistenter Klone wurde zunächst eine $\Delta$ uprt-Deletionsmutante des RH $\Delta k u 80 \Delta$ hxgprt Stamms hergestellt. RH $\Delta k u 80 \Delta h x g p r t \Delta u p r t$ Parasiten wurden anschließend mit einem XbaI-linearisiertem Targeting-Plasmid transfiziert. Dieses enthielt eine N-terminal verkürzte kodierende Sequenz des N302S-Allels, gefolgt von dem $3^{\text {c }}$ untranslatiertem Bereich (UTR) des Wildtyp-Gens sowie einer HXGPRTResistenzkassette. Eine erfolgreiche Integration des Zielkonstrukts, mittels einer einfachen homologen Rekombination, würde dabei zu einem funktionellen N302S Allel führen, während der überbleibende Rest des Wildtyp-Gens aufgrund einer fehlenden PromoterRegion und einem Startcodon nicht-funktionell ist (Abb. 3.15 A). Als Kontrolle wurde ein gleichermaßen konstruierter Targeting-Vektor, welcher für das Wildtyp-Allel (N302) kodiert, in den dhodh Genlocus eingebracht. Durch MPA und Xanthin selektionierte, stabil transfizierte Klone wurden anschließend mittels PCR-Analysen genomischer DNA untersucht (Abb. 3.15 B). Die jeweiligen Primer-Paare wurden dabei so konstruiert, dass anhand ihrer Bindung im Genom und der Länge des amplifizierten PCR-Produktes eine eindeutige Aussage zum Erfolg des Allelaustauschs getroffen werden konnte. Dabei zeigten N302S Knock-In und N302 Knock-In Parasiten (Kontrolle) in Bezug auf Primerpaar 1+/2- eine

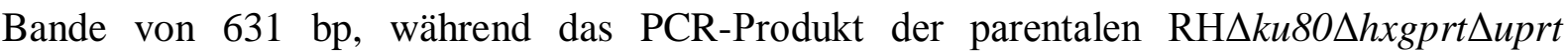
Parasiten bei 1521 bp lag. Entsprechende Ergebnisse zeigten sich auch bei der Amplifizierung mit Primerpaar 1+/3- (824 bp für beide Knock-In Mutanten und 2829 bp für den parentalen Stamm). Weiterhin konnte bezüglich des Primerpaars 4+/5- nur bei den Knock-In Parasiten eine entsprechende Gelbande nachgewiesen werden. Zusätzlich wurde cDNA der N032S KI Parasiten amplifiziert und durch DNA-Sequenzanalysen hinsichtlich der kodierenden Sequenz des dhodh Gens überprüft. Dabei bestätigte das Chromatogramm den Nukleotidaustausch von 
Adenin (A) nach Guanin (G) im Codon 302 und zeigte weiterhin keine Hinweise für eine simultane Expression des Wildtyp-Allels (Abb. 3.15 C).

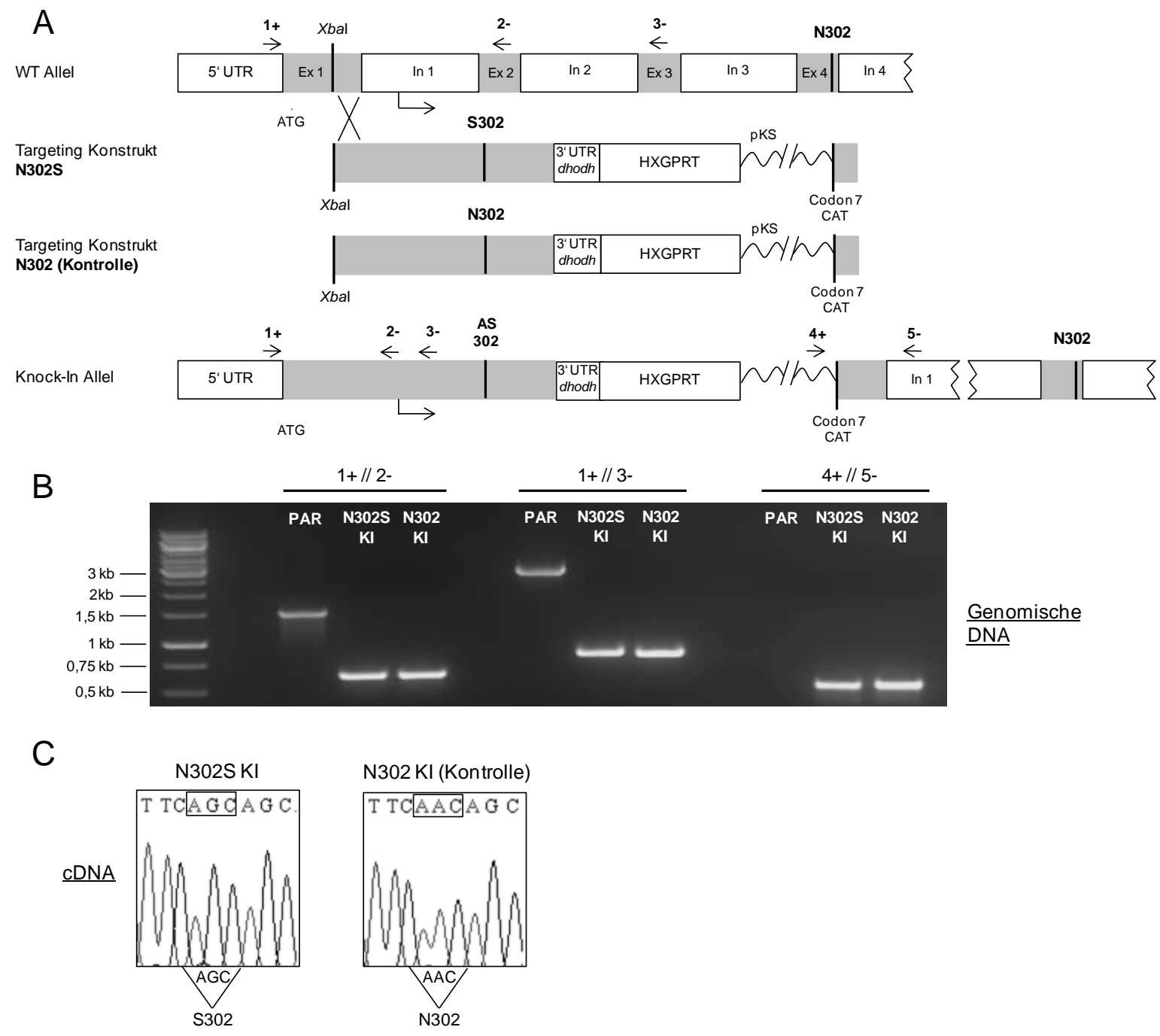

Abbildung 3.15: Generierung einer N302S Knock-In Mutante durch einen Allelaustausch. (A) Schematische Darstellung des endogenen Wildtyp dhodh Locus, des N302S Targeting-Konstrukts, des N302 Kontrollvektors und dem resultierenden Knock-In Allel. Das N302S Targeting-Konstrukt enthält ein N-terminal verkürztes cDNA Fragment welches für das mutierte dhodh Gen mit einem Serin an Position 302 kodiert (S302), während Konstrukt N302 für das Wildtyp-Allel mit einem Asparagin an dieser Position kodiert. Beide Produkte wurden an die dhodh 3'UTR sowie an eine HXGPRT-Resistenzkassette ligiert, welche zur Selektion stabil

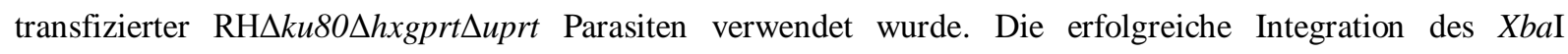
linearisierten Targeting-Vektors, durch eine einfache homologe Rekombination, führt dabei zu einem funktionellen N302S oder N302 Knock-In Allel und einem nicht-funktionellen verkürztem Wildtyp-Allel. Ex, Exon; In, Intron; AS, Aminosäure. (B) Verifizierung des Genotyps. Die Primerpaare 1+/2-, 1+/3- und 4+/5wurden in PCR-Analysen genomischer DNA verwendet um zwischen dem parentalem Stamm

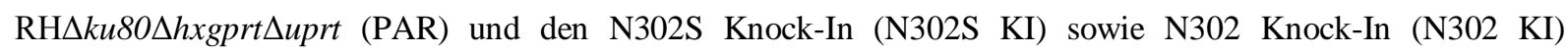
Parasiten zu unterscheiden. (C) Die Identität von Codon 302 der transfizierten Parasiten wurde durch Sequenzierungen der dhodh cDNA analysiert. Das Chromatogramm von N302S Knock-In Parasiten demonstriert die A-zu-G Mutation, welche zu einer Aminosäuresubstitution von Asparagin nach Serin führt. 
Nach Bestätigung einer erfolgreichen Rekombination des endogenen Wildtyp-Allels wurde die Wachstumskinetik des N302S exprimierenden Klons (N302S KI) in Gegenwart von Compound B, HDQ und Atovaquon für insgesamt $60 \mathrm{~h}$ untersucht (Abb. 3.16).

\section{Compound B}

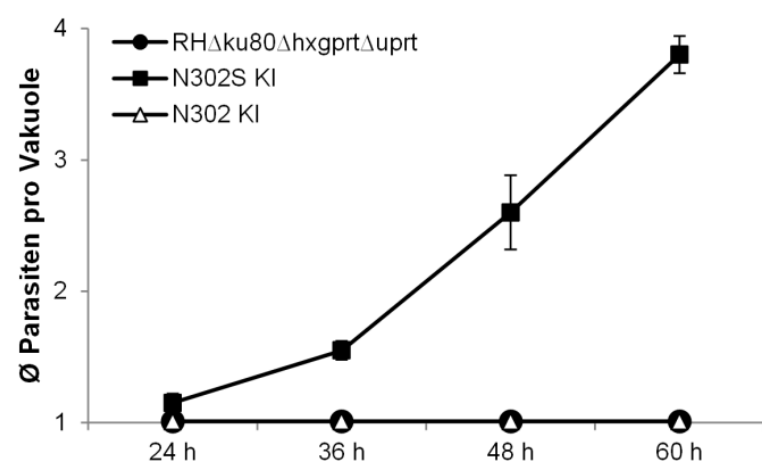

Atovaquon

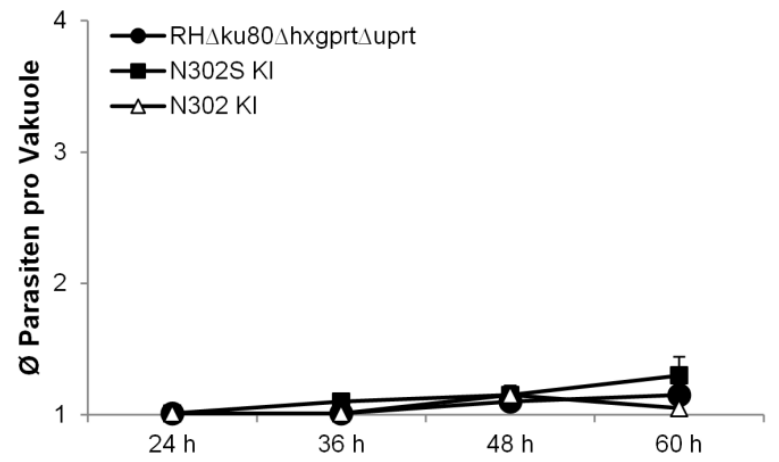

HDQ

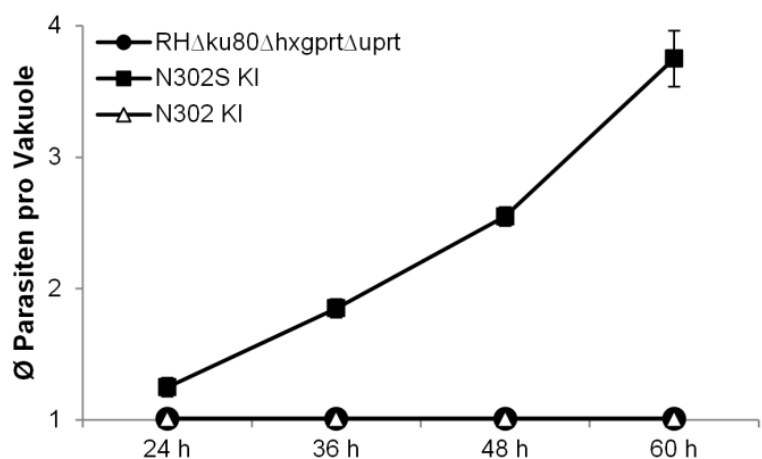

Unbehandelte Kontrolle

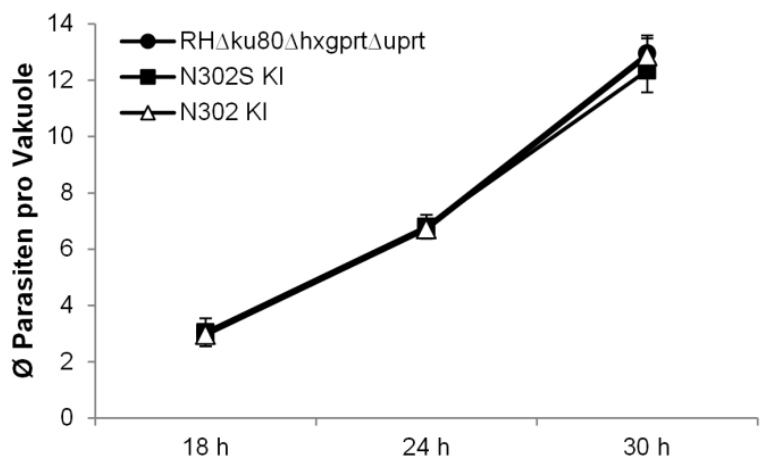

Abbildung 3.16: Das N302S-Allel ist in der Lage eine partielle Resistenz gegenüber 1-Hydroxyquinolonen zu vermitteln. Wachstumskinetiken von dhodh N302S exprimierenden Knock-In Parasiten (N302S KI), dhodh

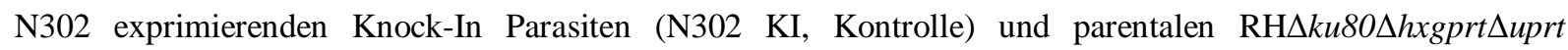
Parasiten unter Behandlung mit Compound B, HDQ und Atovaquon. Eine Analyse der Replikationsrate erfolgte nach 24 h, 36 h, 48 h und 60 h p. i., während eine unbehandelte Wachstumskontrolle nach 18 h, 24 h und 30 h untersucht wurde. Konfluente HFF wurden dazu mit jeweils $\sim 3 \times 10^{4}$ Parasiten infiziert und mit einer Endkonzentration von $100 \mathrm{nM}$ der jeweiligen Compounds behandelt. Alle Proben wurden zu den angegebenen Zeitpunkten fixiert und die durchschnittliche Anzahl intrazellulärer Parasiten durch Auszählung der Parasiten von mindestens 100 zufällig ausgewählten parasitophoren Vakuolen bestimmt. Die Darstellung der Ergebnisse erfolgt als Mittelwert (MW) \pm Standardabweichung des MW von Proben-Doppelbestimmungen eines repräsentativen Experiments $(n=2)$.

Im Vergleich zum parentalen Ausgangsstamm, der unter einer Behandlung mit 1-Hydroxyquinolonen bis 60 h p. i. vollständig inhibiert wurde, zeigten N302S KI Parasiten eine signifikant gesteigerte Resistenz gegenüber Compound B und HDQ. Während jedoch eine Kultivierung der N302S KI Mutante mit HDQ sowie Compound B zu einer deutlich erhöhten Replikationsrate führte, bewirkte die Behandlung mit Atovaquon bei beiden eine 
vergleichbare, sehr starke Wachstumsinhibierung, was wiederum für die Spezifität des Resistenz-Phänotyps spricht. Im Gegensatz dazu wiesen die mit dem Kontroll-Vektor transfizierten Parasiten (N302 KI), entsprechend dem Ausgangsstamm, eine unveränderte Hypersensitivität gegenüber Compound B, HDQ und Atovaquon auf. Ausgehend von den erzielten Ergebnissen konnte nachgewiesen werden, dass eine Expression des mutierten N302S-Allels ausreichend ist um eine partielle Resistenz gegenüber 1-Hydroxyquinolonen zu vermittelt.

Trotz einer Mutation innerhalb des Tgdhodh Gens zeigte die unbehandelte Wachstumskontrolle der N302S KI Parasiten keinen Wachstumsdefekt gegenüber dem

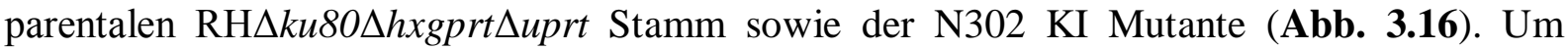
mögliche Beeinträchtigungen der Parasitenfitness über einen längeren Zeitraum zu untersuchen, wurde die Teilungsrate der N302S KI und N302 KI Parasiten daher mit Hilfe von Plaque-Assays, über mehrere Generationen hinweg untersucht. Doch auch 6 Tage p. i. ergab eine Auswertung der durchschnittlichen Plaquefläche keine Unterschiede in der Wachstumsrate der N302S KI Parasiten (Abb. 3.17).

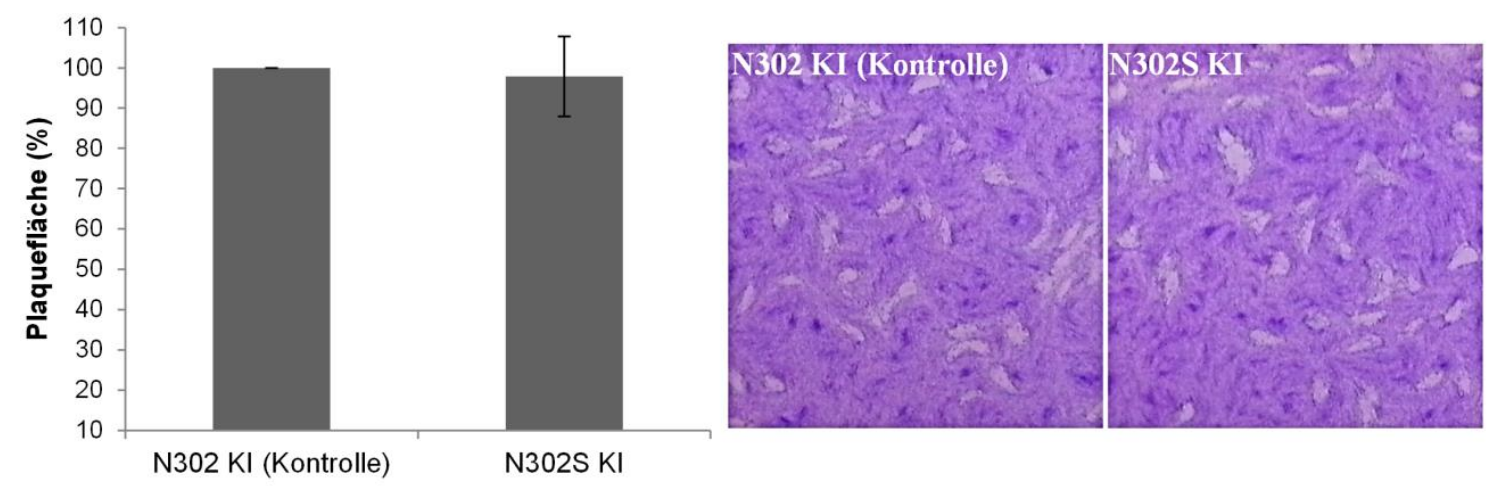

Abbildung 3.17: N302S KI Parasiten zeigen in vitro keinen Wachstumsdefekt. Konfluente HFF wurden mit jeweils 200 N302S KI bzw. N302 KI Parasiten infiziert und 6 Tage p. i. fixiert und mit Kristallviolett gefärbt. Die durchschnittliche Fläche von mindestens 50 zufällig ausgewählten Plaques wurde durch ImageJ berechnet und hinsichtlich der N302S KI Parasiten (Kontrolle, 今100\%) normalisiert. Die Darstellung der Ergebnisse erfolgt als Mittelwert (MW) \pm Standardabweichung des MW eines repräsentativen Experiments $(n=2)$.

\subsubsection{Funktionelle Expression der TgDHODH in Escherichia coli}

Durch eine schnelle Kultivierbarkeit und unkomplizierte Handhabung hat Escherichia coli auch bei der Identifizierung von Wirkstoff-Targets große Bedeutsamkeit erlangt. In Kooperation mit Martin Thiele (2012) wurde, durch eine funktionelle Expression der 
TgDHODH in E. coli, versucht ein Modellsystem zu schaffen, anhand dessen sich künftig 1-Hydroxyquinolon-Derivate schnell und kostengünstig testen lassen.

\subsubsection{Generierung multipler Fusionskonstrukte}

Es wurden insgesamt sechs unterschiedliche TgDHODH Fusionskonstrukte hergestellt (Abb. 3.18) und auf ihre funktionelle Expression in E. coli getestet. Der N-terminale Anteil der $E$. coli $\mathrm{DHODH}(\mathrm{EcDHODH})$ wurde dabei an eine N-terminal verkürzte Sequenz der Wildtyp TgDHODH fusioniert, welcher die mitochondriale Importsequenz fehlte.

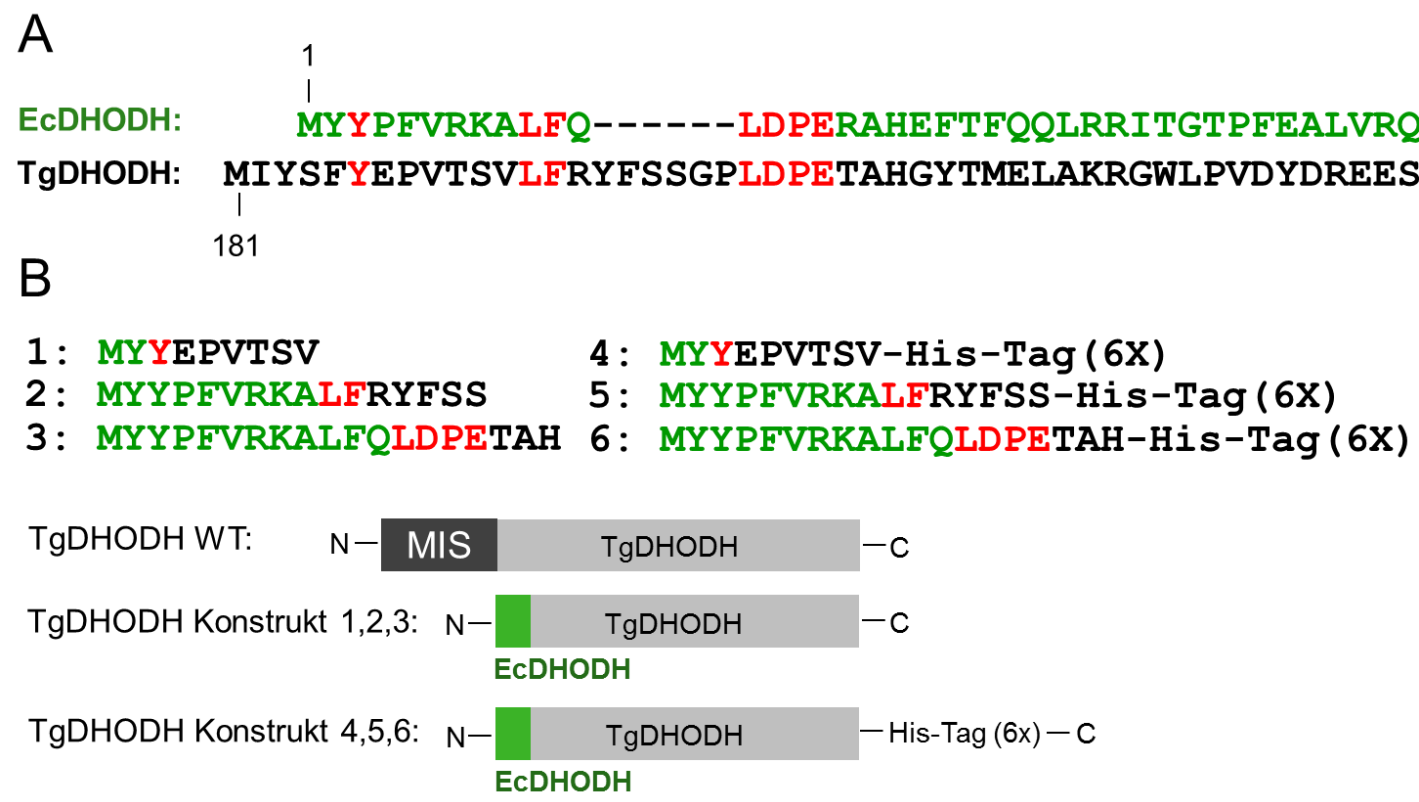

Abbildung 3.18: Schematische Darstellung der Konstruktion unterschiedlicher Fusionsvarianten der $\boldsymbol{E}$. coli DHODH (EcDHODH) und TgDHODH. (A) Alignment der Aminosäuresequenz 181-231 der TgDHODH und der Aminosäuresequenz 1-42 der EcDHODH. Der E. coli Anteil ist grün, der T. gondii Anteil schwarz und homologe Aminosäuren rot markiert. (B) Zur Generierung multipler Fusionskonstrukte wurde der N-terminale Anteil der EcDHODH an eine N-terminal verkürzte Sequenz der Wildtyp TgDHODH fusioniert, welcher die mitochondriale Importsequenz (MIS) fehlte. Die Konstrukte 1-3 unterschieden sich hinsichtlich des EcDHODH Anteils und der Anzahl homologer Aminosäuren. Durch die zusätzliche Fusion eines C-terminalen His-Tags wurden die Konstrukte 4-6 generiert.

Grundlage der Fusionsgenerierung war ein Proteinalignment der EcDHODH und TgDHODH (Abb. 3.18 A). Der Fusionsbereich und die damit verbundene Länge des bakteriellen Anteils wurden durch das Auftreten homologer Aminosäuren festgelegt. Hierbei wurden drei Konstrukte konzipiert, die sich hinsichtlich des N-terminalen EcDHODH Abschnitts und dem Anteil homologer Aminosäuresequenzen voneinander unterschieden. Für eine spätere Aufreinigung einzelner Fusionsproteine wurden die Konstrukte 1 bis 3 zudem in einer zweiten Variante mit einem C-terminalem Histidin-Affinitätstag (His-Tag) versehen (Abb. 
3.18 B). Für die anschließende Exprimierung in E. coli wurden alle Konstrukte in den pASK-IBA16 Vektor kloniert und die Genexpression damit unter die Kontrolle eines Anhydrotetracyclin (AnTc)-induzierbaren Promoters gestellt.

\subsubsection{Komplementierung eines Uracil-auxotrophen $E$. coli Stamms durch TgDHODH}

Die Überprüfung einer funktionellen Expression der jeweiligen Fusionsvarianten erfolgte durch Komplementationsversuche einer DHODH-Defizienzsmutante von E. coli (ATCC 12632). Durch die gestörte Pyrimidin-de-novo-Synthese beruht das Wachstum einzig auf dem Pyrimidin Salvage Pathway, was zu einer Uracil-Auxotrophie dieser Bakterienstamms führt. Eine funktionelle Komplementation durch die AnTc-induzierbare TgDHODH würde diesen Defekt in der Pyrimidin-Biosynthese jedoch aufheben. Zunächst wurde der Ausgangsstamm (in separaten Versuchsansätzen) mit allen sechs Fusionskonstrukten transfomiert und durch ein im pASK-IBA16 Vektor integriertes Ampicillin-Resistenzgen selektioniert. Die anschließende Analyse der Wachstumskontrollen zeigte, wie erwartet, ohne den Zusatz von Uracil oder AnTc keine Bakterienvermehrung (Abb. 3.19). Im Vergleich dazu wurde durch die Supplementation von Uracil bei allen Stämmen ein sehr deutliches und vergleichbares Zellwachstum beobachtet. Hierbei konnte nach 3,5 h eine optische Dichte (OD) zwischen 1,2 und 1,4 gemessen werden. Die Überprüfung einer erfolgreichen Komplementation erfolgte durch die Kultivierung der Bakterien mit M63-Minimalmedium, welches zur Induktion AnTc, jedoch kein Uracil enthielt. Da die Tgdhodh-Genexpression erst durch die Zugabe von AnTc induziert wurde, erfolgte eine Analyse der Zellteilung zusätzlich unter verschiedenen AnTc-Konzentrationen (10, 50 und $200 \mathrm{ng} / \mathrm{ml})$. Unter induzierten Bedingungen konnte für jeden Stamm ein bakterielles Wachstum und damit eine funktionelle Komplementierung nachgewiesen werden (Abb. 3.19). Hinsichtlich der Wachstumskinetik ergaben sich jedoch eindeutige Unterschiede zwischen den einzelnen Bakterienstämmen, was auf funktionelle Unterschiede zwischen den Fusionsvarianten hindeutet. Während die Vermehrung bei Stamm 5 am schwächsten war und nach 3,5 h lediglich eine OD von etwa 0,2 gemessen werden konnte, zeigten Stamm 1, 2 und 6 eine vergleichbare Zellteilung (OD 0,3-0,4). Demgegenüber wurde bei Stamm 3 (OD 0,8) und 4 (OD 0,9) das stärkste Bakterienwachstum beobachtet. Eine Untersuchung der eingesetzten AnTc-Konzentration zeigte keine Unterschiede im Wachstum der Bakterien. Lediglich bei Stamm 4 ließ sich ein moderater Wachstumsvorteil bei 200 ng/ml AnTc nachweisen. 
Stamm 1

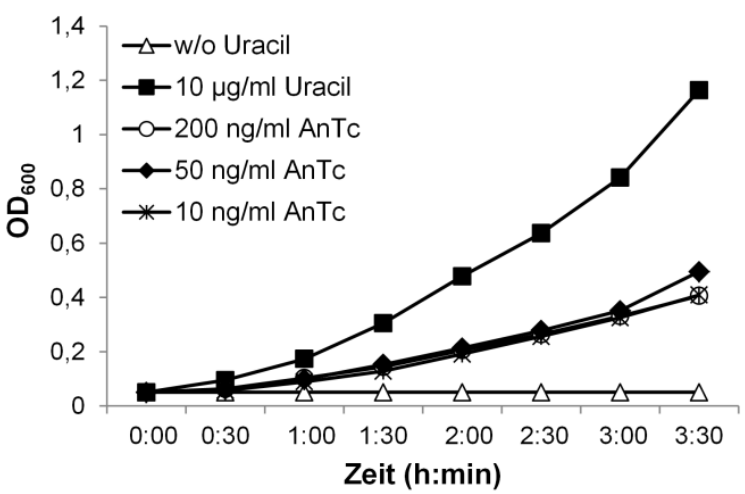

Stamm 3

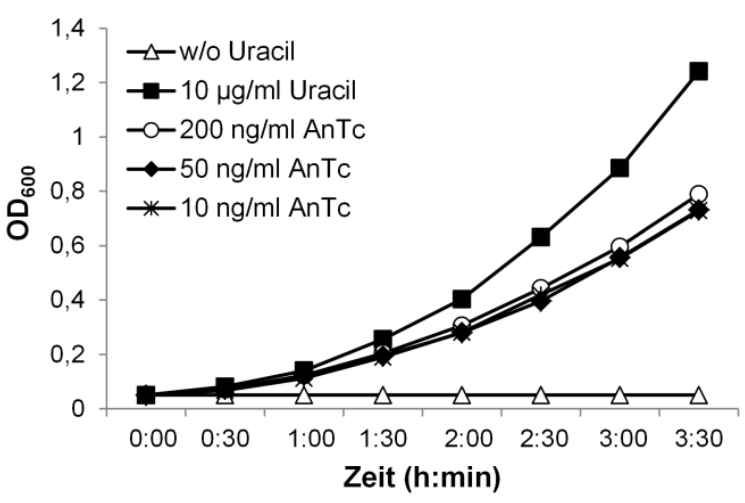

Stamm5

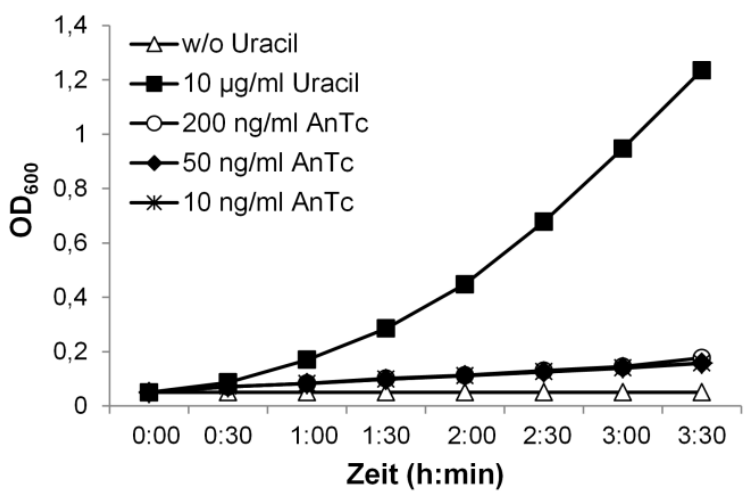

Stamm 2

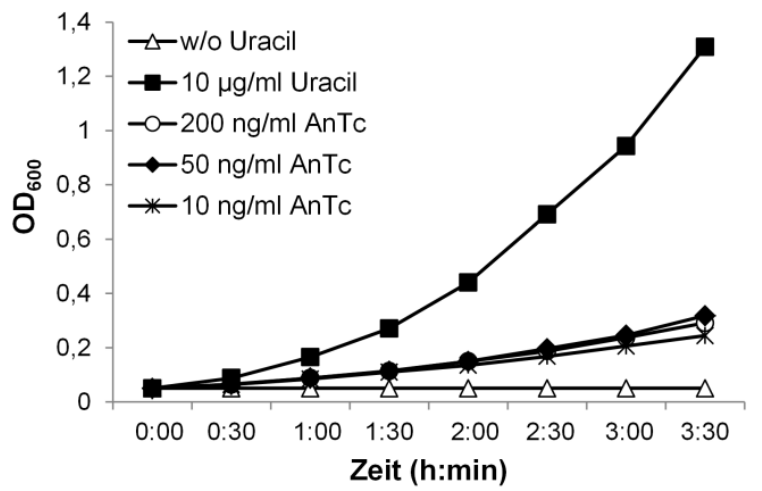

Stamm 4

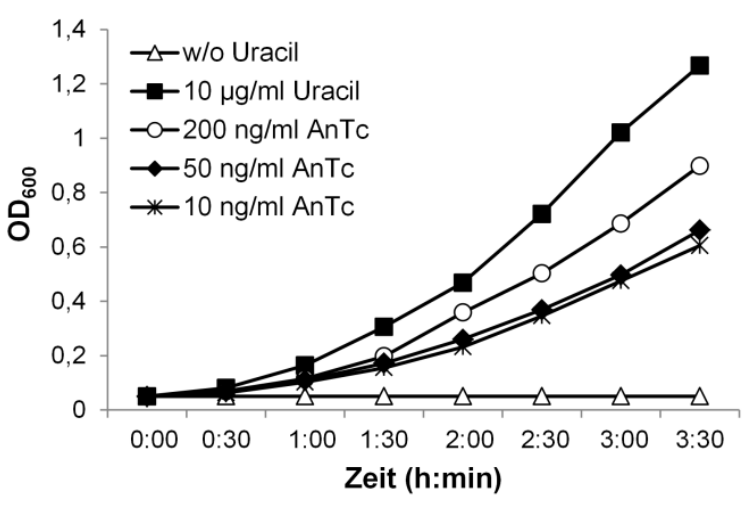

Stamm 6

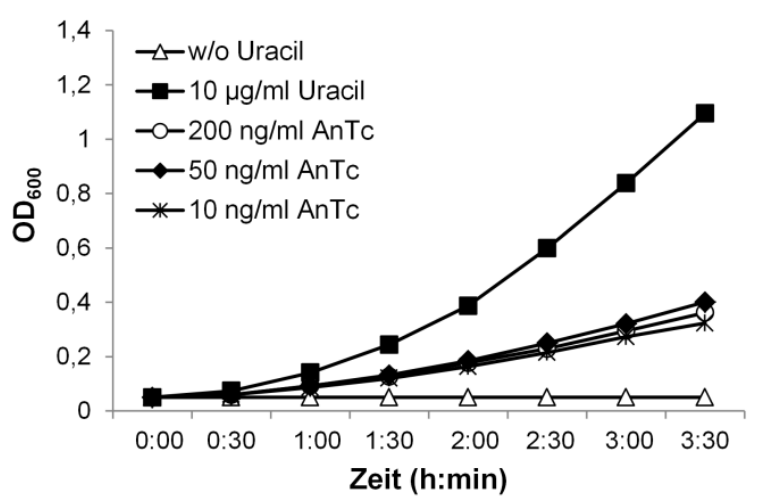

Abbildung 3.19 Eine Expression der Tgdhodh-kodierenden Fusionskonstrukte 1-6 führt zur funktionellen Komplementierung einer Uracil-auxotrophen Mutante von $\boldsymbol{E}$. coli. Zur Überprüfung einer funktionellen Expression der TgDHODH wurden alle sechs Stämme mit einer Ausgangs-OD von 0,05 in M63-Minimalmedium inokuliert und unter Zusatz von 10, 50 und $200 \mathrm{ng} / \mathrm{ml}$ Anhydrotetracyclin (AnTc) bei $37^{\circ} \mathrm{C}$ kultiviert. Die Messung des Bakterienwachstums erfolgte photometrisch bei $600 \mathrm{~nm}$ für insgesamt 3,5 h. Wachstumskontrollen ohne Uracil (w/o, Negativkontrolle) und mit $10 \mu \mathrm{g} / \mathrm{ml}$ Uracil (Positivkontrolle) wurden zeitgleich mitgeführt.

\subsubsection{Sensitivitätstestung gegenüber Compound B}

Mit der Generierung funktionell TgDHODH-exprimierender Bakterienstämme war möglich zu prüfen, ob sich E. coli zum „drug-screening“ von 1-Hydroxyquinolonen eignet. Dazu 
wurden alle sechs Stämme unter induzierten Bedingungen (200 ng/ml AnTc) zusätzlich mit Compound B kultiviert. Um mögliche Unterschiede in der eingesetzten Konzentration zu untersuchen, wurden die Bakterien jeweils mit $10 \mathrm{nM}, 100 \mathrm{nM}$ sowie $1 \mu \mathrm{M}$ Compound $\mathrm{B}$ behandelt. Als repräsentative Beispiele wurden in Abb. 3.20 die Wachstumskinetiken von Stamm 3 und Stamm 4 graphisch dargestellt.
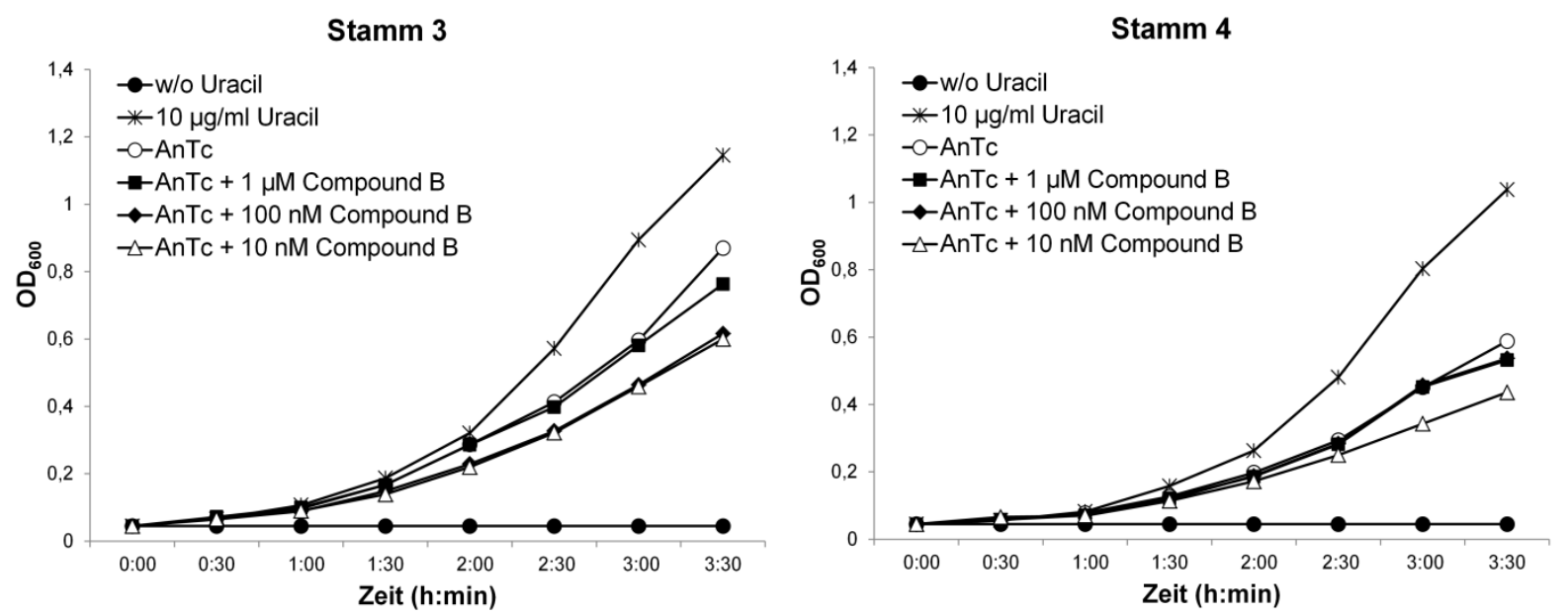

Abbildung 3.20: Durch TgDHODH funktionell komplementierte Bakterien zeigen unter einer Kultivierung mit Compound B keine Wachstumsinhibierung. M63-Minimalmedium wurde mit einer Ausgangs-OD von 0,05 der Stämme 3 und 4 inokuliert und die Bakterien unter Zusatz von $200 \mathrm{ng} / \mathrm{ml}$ Anhydrotetracyclin (AnTc) sowie $10 \mathrm{nM}, 100 \mathrm{nM}$ und $1 \mu \mathrm{M}$ Compound B bei $37^{\circ} \mathrm{C}$ kultiviert. Die Messung des Bakterienwachstum erfolgte photometrisch bei $600 \mathrm{~nm}$ für insgesamt 3,5 h. Wachstumskontrollen ohne Uracil (w/o, Negativkontrolle), mit $10 \mu \mathrm{g} / \mathrm{ml}$ Uracil (Positivkontrolle) und $200 \mathrm{ng} / \mathrm{ml}$ AnTc (unbehandelte Kontrolle) wurden zeitgleich mitgeführt.

Wie bereits gezeigt wurde, wiesen die Bakterien beider Stämme in Anwesenheit von Uracil das stärkste Wachstum auf, ohne Uracil jedoch eine vollständige Wachstumshemmung. Die Behandlung der Bakterien mit Compound B führte jedoch zu keiner Wachstumsinhibierung der TgDHODH-exprimierenden Bakterien. Selbst unter einer für T. gondii stark parasitostatisch wirkenden Konzentration von $1 \mu \mathrm{M}$ Compound B zeigten beide Stämme ein der unbehandelten Kontrolle vergleichbares Wachstum. Eine durch Compound B unbeeinflusste Replikation zeigten auch alle anderen Stämme (nicht dargestellt). Um in einem weiteren Versuch die Wirkung von Compound B unter minimalen AnTc-Konzentrationen zu untersuchen, wurde die Tgdhodh Expression von Stamm 3 und 4 mit jeweils 5 und 10 ng/ml AnTc induziert. Doch auch unter diesen veränderten Induktionsbedingungen wirkte sich Compound B nicht hemmend auf das Bakterienwachstum aus (nicht dargestellt). TgDHODH exprimierende $E$. coli scheinen sich somit nicht als Testsystem für 1-Hydroxyquinolone zu eignen. 


\subsubsection{Biochemische Charakterisierung der TgDHODH als 1-Hydroxyquinolon Target}

Um die inhibitorische Wirkung der 1-Hydroxyquinolone gegenüber TgDHODH durch biochemische Analysen zu belegen und des Weiteren die enzymatischen Eigenschaften der Wildtyp und der mutierten (N302S) DHODH vergleichend zu untersuchen, wurden beide Allele in E. coli exprimiert und durch eine native Aufreinigung, elektrophoretisch und enzymatisch aktive Proteine gewonnen.

\subsubsection{Expression und Aufreinigung His-getaggter TgDHODH aus $E$. coli}

\subsection{C-terminaler His-Tag}

Insgesamt drei der unter Punkt 3.2.4.1 beschriebenen TgDHODH-Fusionskonstrukte wurden mit einem C-terminalen His-Tag generiert. Daher wurde zunächst versucht die Fusionsvarianten 4 und 6 in E. coli BL21-CodonPlus (DE3)-RP Bakterien zu exprimieren. Nach erfolgter Transformation der Bakterien war es das Ziel von Vorversuchen zunächst optimale Expressionskonditionen zu definieren. Dafür wurden die Induktionsbedingungen hinsichtlich der Temperatur und der Zeit variiert und die Bakterien nach einer Induktion mit $200 \mathrm{ng} / \mathrm{ml}$ AnTc für $3 \mathrm{~h}, 6 \mathrm{~h}$ und über Nacht (ÜN) sowie bei Temperatur von $30^{\circ} \mathrm{C}, 37^{\circ} \mathrm{C}$ und bei Raumtemperatur (RT) kultiviert. Ein visueller Vergleich des exprimierten TgDHODH Proteinlevels erfolgte durch SDS-PAGE und Western Blot Analysen mit einem anti-His Antikörper. Dafür wurden die unter den verschiedenen Induktionsbedingungen gewonnenen Bakteriensuspensionen auf eine gemeinsame OD eingestellt, pelletiert und durch Resuspension in SDS-Probenpuffer lysiert.

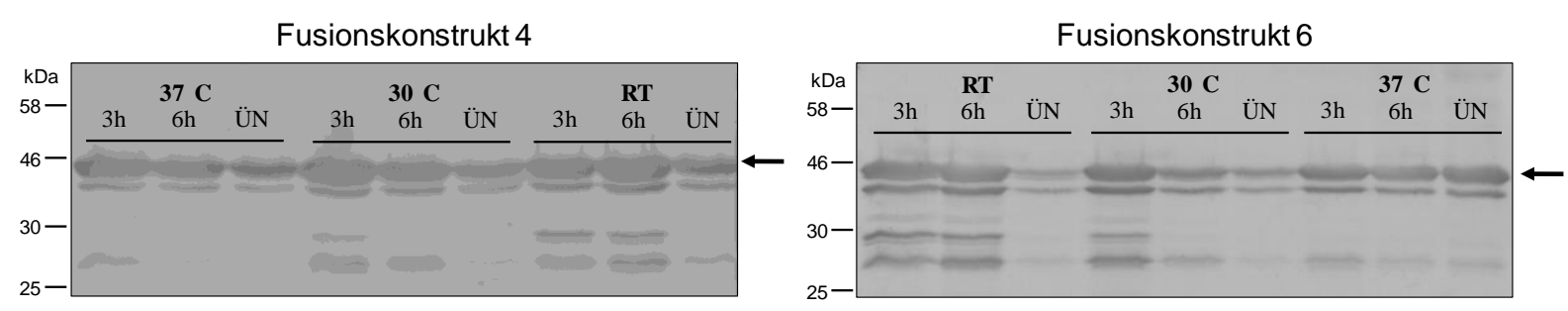

Abbildung 3.21: Western Blot Analysen des TgDHODH Proteinlevels nach Expression der C-terminal His-getaggten Fusionskonstrukte 4 und 6. Die Fusionskonstrukte 4 und 6 wurden in E. coli BL21-CodonPlus (DE3)-RP Bakterien exprimiert und diese nach Induktion mit $200 \mathrm{ng} / \mathrm{ml}$ AnTc unter $37^{\circ} \mathrm{C}, 30^{\circ} \mathrm{C}$ und bei Raumtemperatur (RT) für $3 \mathrm{~h}, 6 \mathrm{~h}$ und über Nacht (ÜN) kultiviert. Für einen visuellen Vergleich der Proteinmenge wurden die Bakteriensuspensionen auf eine gemeinsame OD eingestellt, pelletiert und durch Resuspension in SDS-Probenpuffer lysiert. Das gesamte Bakterienlysat wurde anschließend durch SDS-PAGE (12\% Gel) aufgetrennt und das TgDHODH-Fusionsprotein (Konstrukt 4: 45,9 kDa; Konstrukt 6: 45, 3 kDa) mit Hilfe eines anti-His Antikörpers im Western Blot detektiert. 
Wie in Abb. 3.21 zu erkennen ist, konnte mit beiden Fusionskonstrukten eine deutliche Proteinexpression nachgewiesen werden. Neben der zu erwartenden Proteinbande von etwa $45 \mathrm{kDa}$ wurden jedoch multiple Banden mit einem kleineren Molekulargewicht detektiert. Durch das Auftreten dieser zusätzlichen Proteinbanden wurde die Aufreinigung einer C-terminal getaggten TgDHODH nicht weiter verfolgt.

\subsection{N-terminaler His-Tag}

Zur Expression einer elektrophoretisch reinen TgDHODH wurde die N-terminal verkürzte kodierende Sequenz sowohl des Wildtyp-Allels als auch des N302S-Allels in den pET-16b Vektor kloniert und die N-terminal His-getaggten Konstrukte anschließend in BL21-CodonPlus (DE3)-RP Bakterien exprimiert (Abb. 3.22 A).

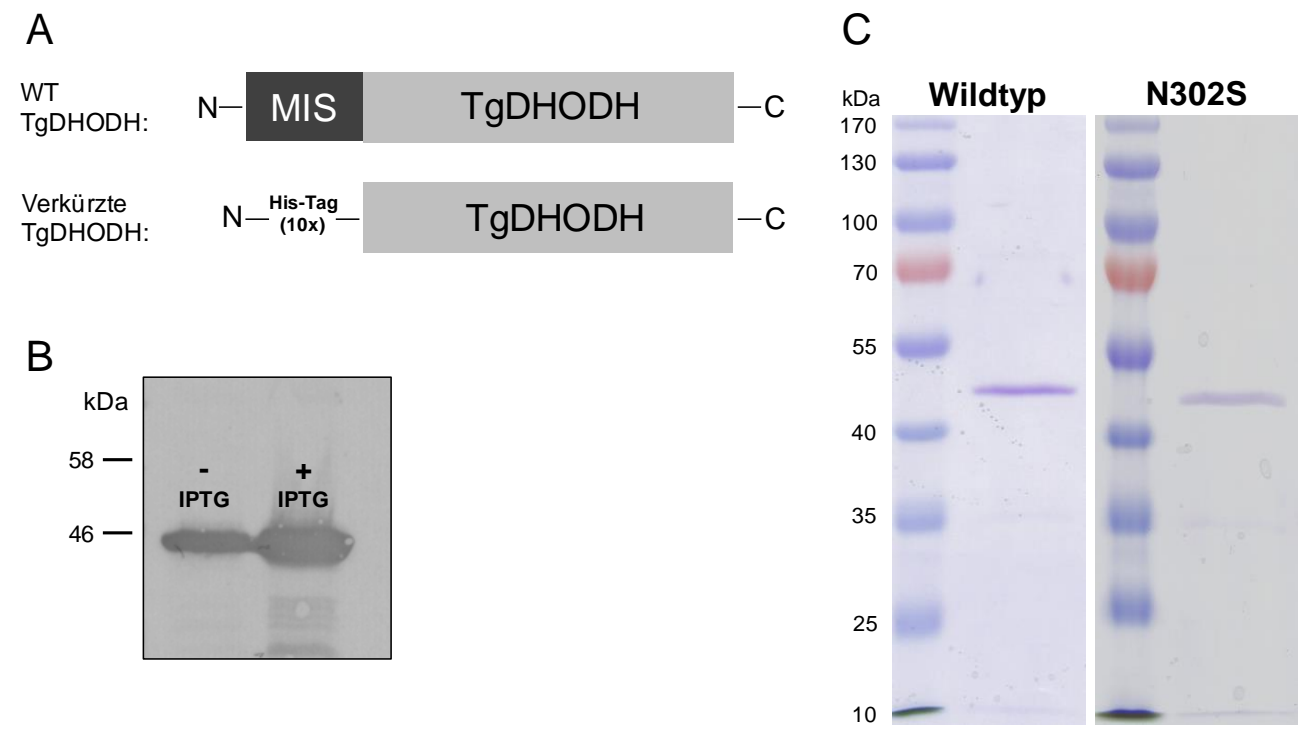

Abbildung 3.22: Expression und Aufreinigung von TgDHODH. (A) Eine N-terminal verkürzte Sequenz des Wildtyp und des mutierten N302S dhodh Gens (Val178-Asp592), denen jeweils die mitochondriale Importsequenz (MIS) fehlte, wurden N-terminal an einen His-tag fusioniert und in E. coli BL21-CodonPlus (DE3)-RP Bakterien exprimiert. (B) Analyse des Expressionslevels der N-terminal getaggten Wildtyp TgDHODH mit (+) und ohne Zugabe (-) von IPTG durch Westen Blot Analysen mit einem anti-His Antikörper. (C) Die Reinheit der Wildtyp und der N302S TgDHODH wurden durch Coomassie-gefärbte 12\%ige SDS-Gele bestimmt.

Bereits ein erster Versuch zur Optimierung der Expressionsbedingungen bestätigte dabei in Western Blot Analysen eine singuläre Bande des Zielproteins von etwa $47 \mathrm{kDa}$ (nicht dargestellt). Es konnte weiterhin gezeigt werden, dass auch ohne Induktion mit Isopropyl- $\beta$ D-thiogalactopyranosid (IPTG) eine ausreichend hohe DHODH Expression erzielt wurde (Abb. 3.22 B). Die Reinheit der unter nativen Bedingungen gewonnenen rekombinanten Proteine wurde elektrophoretisch (SDS-PAGE) mit nachfolgender Coomassie-Färbung 
bestimmt (Abb. 3.22 C). Probemessungen mit denen unter 2.2.8.2 beschriebenen Methoden bestätigten die enzymatische Aktivität der Wildtyp und N302S TgDHODH (nicht dargestellt) und ermöglichten somit eine enzymkinetische Analyse von DHODH als potentielle Zielstruktur der 1-Hydroxyquinolone.

\subsubsection{Die Aktivität von TgDHODH wird direkt durch 1-Hydroxyquinolone inhibiert}

Um einen ersten Einblick in die Inhibitionseigenschaften von HDQ und Compound B zu erhalten, erfolgte zunächst eine Bestimmung der $\mathrm{IC}_{50}$-Werte. Sowohl HDQ als auch Compound B inhibierten die Wildtyp TgDHODH sehr effektiv und wiesen $\mathrm{IC}_{50}$-Werte von jeweils $554 \mathrm{nM}$ und $534 \mathrm{nM}$ auf (Tabelle 3.1). TgDHODH wird demnach durch 1-Hydroxyquinolone direkt inhibiert. Darüber hinaus zeigte die N302S DHODH mit $\mathrm{IC}_{50}$-Werten von jeweils $1635 \mu \mathrm{M}$ und $1627 \mu \mathrm{M}$ eine rund 3-fach erhöhte $\mathrm{IC}_{50}$ gegenüber HDQ und Compound B, was sich graphisch in einer Verschiebung der Dosis-Wirkungskurve zur rechten Seite darstellte (Abb. 3.23).
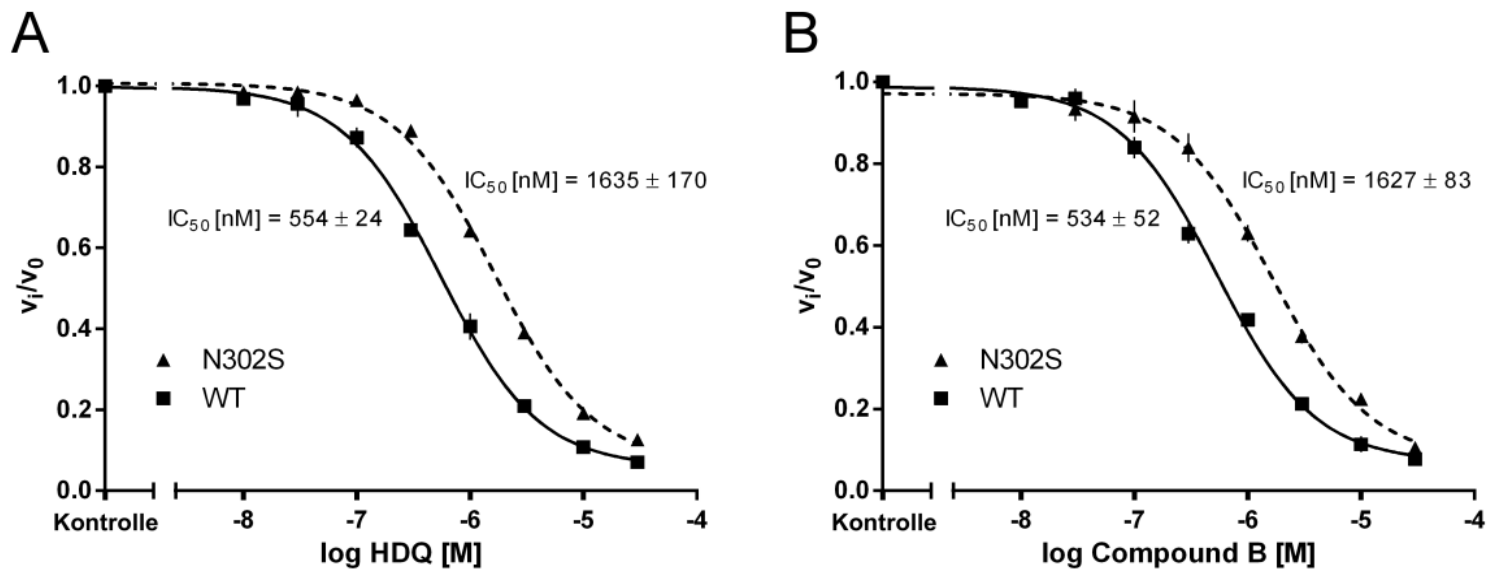

Abbildung 3.23: 1-Hydroxyquinolone sind wirkungsvolle Inhibitoren der Wildtyp TgDHODH Aktivität, zeigen jedoch einen Effektivitätsverlust gegenüber der N302S DHODH. Dosis-Wirkungskurven wurden für die Wildtyp (WT) und die N302S DHODH generiert. Eine Bestimmung der mittleren inhibitorischen Konzentration $\left(\mathrm{IC}_{50}\right.$ ) von (A) HDQ und (B) Compound B erfolgte in Anwesenheit von $1 \mathrm{mM}$ DHO und $100 \mu \mathrm{M}$ $\mathrm{Q}_{\mathrm{D}}$ mit variierenden Inhibitorkonzentrationen von $0,01 \mu \mathrm{M}$ bis $30 \mu \mathrm{M}$. $\mathrm{IC}_{50}$-Werte wurden durch nichtlineareRegressionsanalysen ermittelt. Die unter jeder der einzelnen Inhibitorkonzentrationen gemessene anfängliche Reaktionsgeschwindigkeit $\left(\mathrm{v}_{\mathrm{i}}, \mathrm{y}\right.$-Achse) wurde dabei relativ zu der Enzymaktivität kalkuliert, welche ohne Anwesenheit des Inhibitors gemessen wurde $\left(\mathrm{v}_{0}\right)$ und gegenüber der Inhibitorkonzentration (angegeben in $\mathrm{M}$ ) auf der $\mathrm{x}$-Achse (logarithmische Skalierung) aufgetragen. Jeder Datenpunkt ist als Mittelwert $(\mathrm{MW}) \pm$ Standardfehler des Mittelwertes eines repräsentativen Experiments $(\mathrm{n}=2)$ angegeben. 
Tabelle 3.1: Kinetische Parameter aufgereinigter Wildtyp und N302S TgDHODH und Inhibitionskinetiken von HDQ und Compound B

\begin{tabular}{|c|c|c|c|c|c|c|c|c|c|}
\hline & \multicolumn{5}{|c|}{ Kinetische Parameter } & \multicolumn{4}{|c|}{ Inhibitionskinetiken } \\
\hline & $\begin{array}{c}\mathrm{K}_{\mathrm{M}} \\
\mathrm{DHO} \\
\mu \mathrm{M}\end{array}$ & $\begin{array}{l}\mathrm{K}_{\mathrm{M}} \\
\mathrm{Q}_{\mathrm{D}} \\
\mu \mathrm{M}\end{array}$ & $\begin{array}{c}\mathrm{k}_{\mathrm{cat}} \\
\mathrm{s}^{-1}\end{array}$ & $\begin{array}{c}\mathrm{k}_{\mathrm{cat}} / \mathrm{K}_{\mathrm{M}} \\
\mathrm{DHO} \\
\mathrm{M}^{-1} \mathrm{~s}^{-1}\end{array}$ & $\begin{array}{c}\mathrm{K}_{\mathrm{cat}} / \mathrm{K}_{\mathrm{M}} \\
\mathrm{Q}_{\mathrm{D}} \\
\mathrm{M}^{-1} \mathrm{~s}^{-1}\end{array}$ & $\begin{array}{c}\mathrm{IC}_{50} \\
\mathrm{HDQ} \\
\mathrm{nM}\end{array}$ & $\begin{array}{c}\mathrm{IC}_{50} \\
\text { Comp. B } \\
\mathrm{nM}\end{array}$ & $\begin{array}{c}\mathrm{Ki}^{\prime \mathrm{a}} \\
\mathrm{DHO} \\
\mathrm{nM}\end{array}$ & $\begin{array}{l}\mathrm{Ki}^{\mathrm{a}} \\
\mathrm{Q}_{\mathrm{D}} \\
\mathrm{nM}\end{array}$ \\
\hline WT & $76 \pm 5$ & $37 \pm 3$ & $86 \pm 4$ & $11 \times 10^{5}$ & $23 \times 10^{5}$ & $554 \pm 24$ & $534 \pm 52$ & $418 \pm 30$ & $174 \pm 21$ \\
\hline N302S & $265 \pm 11$ & $15 \pm 2$ & $38 \pm 1$ & $1,4 \times 10^{5}$ & $25 \times 10^{5}$ & $1635 \pm 170$ & $1627 \pm 83$ & $1565 \pm 109$ & $333 \pm 43$ \\
\hline
\end{tabular}

Alle Werte der Tabelle sind als Mittelwert (MW) \pm Standardabweichung des MW angegeben.

${ }^{\mathrm{a}} \mathrm{Ki}$ Werte wurden für Compound B berechnet.

\subsubsection{Compound B ist für $Q_{D}$ ein kompetitiver, für DHO ein unkompetitiver Inhibitor}

Die Bestimmung des Hemmtyps sowie der Inhibitionskonstante $\mathrm{K}_{\mathrm{i}}$ erfolgte für Compound B anhand von Inhibitionskinetiken. Neben einer unbehandelten Kontrolle wurden zusätzlich zwei Konzentration von Compound B (0,25 und 1,5 $\mu \mathrm{M}$ für den Wildtyp sowie 0,8 und 4,8 $\mu \mathrm{M}$ für die N302S Mutante) eingesetzt und die TgDHODH Aktivität unter der Verwendung variabler Konzentrationen von Dihydroorotat (DHO) bzw. Decylubiquinon ( $\left.Q_{D}\right)$ ermittelt. Da DHODH über zwei gesonderte Bindungsstellen verfügt und sowohl mit DHO als auch $\mathrm{Q}_{\mathrm{D}}$ interagiert, wurden inhibitionskinetische Untersuchungen für beide Substrate durchgeführt. Für DHO ergab sich dabei ein unkompetitiver Inhibitionstyp. Bei der unkompetitiven Hemmung wird neben einer Verringerung der apparenten Maximalgeschwindigkeit ( $\left.\mathrm{V}_{\max , \text { app }}\right)$ auch eine Abnahme der apparenten Michaelis-Menten-Konstante ( $\left.\mathrm{K}_{\mathrm{M} \text {, app }}\right)$ beobachtet. In der doppelt-reziproken Darstellung des Lineweaver-Burk-Plots zeigte sich die Reduktion beider Parameter in der Zunahme von $1 / \mathrm{V}_{\max }$ und $1 / \mathrm{K}_{\mathrm{M}}$ mit steigender Inhibitorkonzentration, was sich graphisch als eine Serie paralleler Linien darstellte (Abb. 3.24 A und B). Hinsichtlich der Inhibitionskonstante $\mathrm{K}_{\mathrm{i}}$ ' ergab sich für den Wildtyp eine Konzentration von $418 \mathrm{nM}$, während die N302S TgDHODH mit 1565 nM einen rund 4-fach gesteigerten Wert zeigte (Tabelle 3.1). Aus der inhibitionskinetischen Analyse ging weiterhin hervor, dass Compound $\mathrm{B}$ ein kompetitiver Inhibitor für $\mathrm{Q}_{\mathrm{D}}$ ist. Bei dieser Form der Hemmung kann unter hohen Substratkonzentrationen ein unveränderter Wert für $\mathrm{V}_{\max }$, app beobachtet werden, jedoch nimmt die $\mathrm{K}_{\mathrm{M} \text {, app }}$ in Anwesenheit des Inhibitors zu. In dem doppelt-reziproken LineweaverBurk-Plot stellte sich dies in einem gemeinsamen Ordinatenschnittpunkt aller Geraden bei $1 / \mathrm{V}_{\max }$ dar, während sich der Schnittpunkt der Gerade mit der $\mathrm{x}$-Achse bei steigender Inhibitorkonzentration nach rechts verschob (Abb. 3.24 C und D). Des Weiteren ergaben sich für den Inhibitionsparameter $\mathrm{K}_{\mathrm{i}}$ Werte von $174 \mathrm{nM}$ für die Wildtyp TgDHODH und $333 \mathrm{nM}$ für das mutierte Protein. 

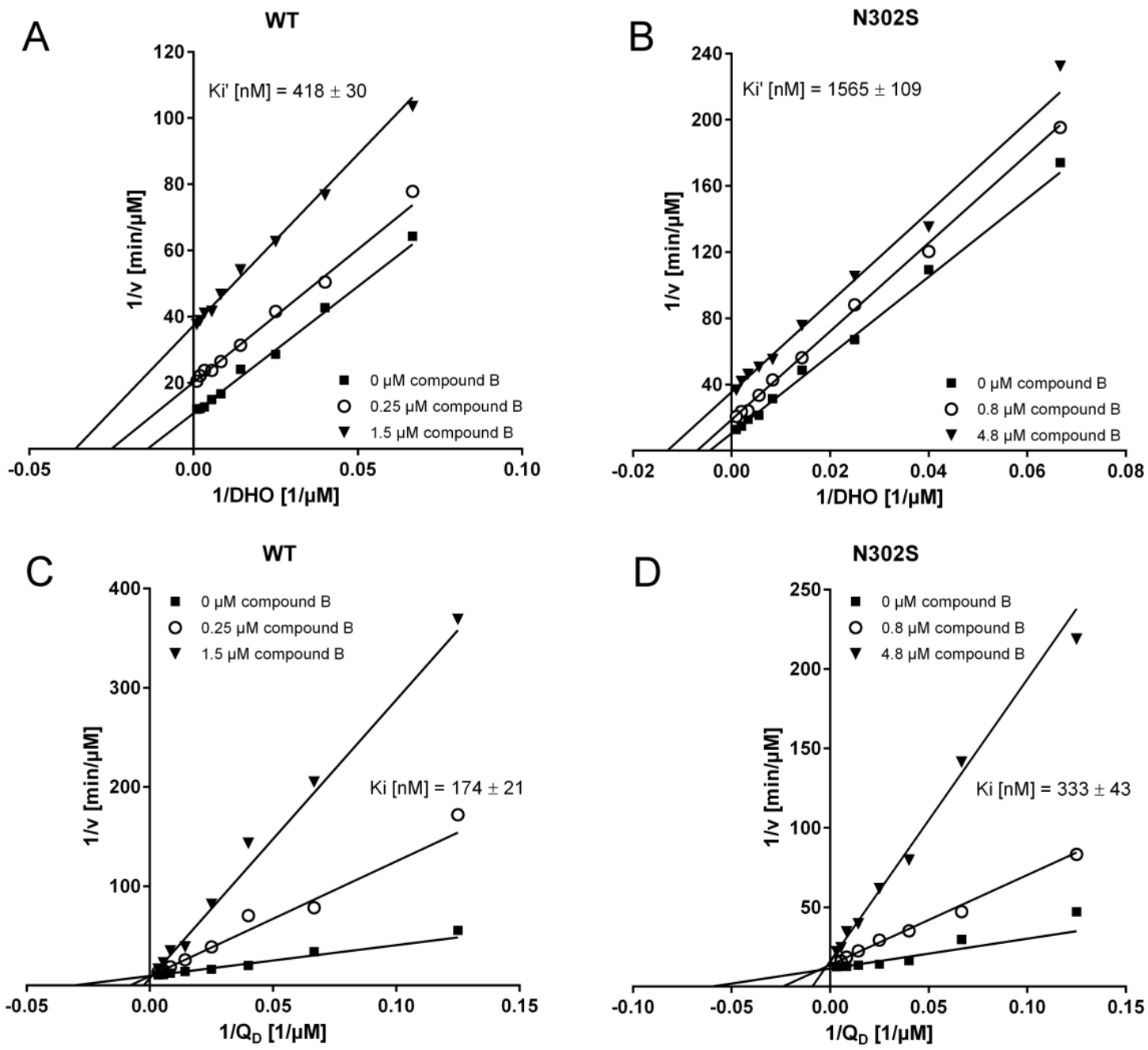

Abbildung 3.24: Inhibitionskinetiken zeigen, dass Compound B ein unkompetitiver Inhibitor für DHO und ein kompetitiver Inhibitor für $\mathbf{Q}_{\mathbf{D}}$ ist. Doppelt-reziproke Auftragung der anfänglichen Reaktionsgeschwindigkeit (v) als Funktion der DHO Konzentration (bei $100 \mu \mathrm{M} \mathrm{Q}_{\mathrm{D}}$ ) und als Funktion der $\mathrm{Q}_{\mathrm{D}}$ Konzentration (bei $1000 \mu \mathrm{M}$ DHO) der Wildtyp DHODH (A und C) und der N302S DHODH (B und D). Die Inhibitionskinetiken wurden für eine unbehandelte Kontrolle und in der Anwesenheit von 0,25 $\mu \mathrm{M}$ und 1,5 $\mu \mathrm{M}$ Compound B für die Wildtyp DHODH sowie 0,8 $\mu \mathrm{M}$ und 4,8 $\mu \mathrm{M}$ Compound B für die N302S DHODH ermittelt. Die doppelt-reziproke Darstellung steht in Übereinstimmung mit dem Wirken von Compound B als ein unkompetitiver Inhibitor für DHO und ein kompetitiver Inhibitor für $Q_{D}$.

\subsubsection{Mutation N302S führt zu einer Reduktion der katalytischen Effizienz gegenüber DHO}

Neben einer Analyse der Inhibitionseigenschaften von HDQ und Compound B wurde geprüft, ob sich hinsichtlich der Michaelis-Menten-Konstante $\left(\mathrm{K}_{\mathrm{M}}\right)$ für $\mathrm{Q}_{\mathrm{D}}$ und DHO sowie der Wechselzahl $\mathrm{k}_{\text {cat }}$ weitere Unterschiede zwischen dem Wildtyp und der N302S TgDHODH nachweisen lassen (Abb. 3.25). Für den Wildtyp ergaben sich dabei $\mathrm{K}_{\mathrm{M}^{-}}$Werte von $76 \mu \mathrm{M}$ für 
DHO und $37 \mu \mathrm{M}$ für $\mathrm{Q}_{\mathrm{D}}$. Zusammen mit einem $\mathrm{k}_{\text {cat }}$-Wert von $86 \mathrm{~s}^{-1}$ konnten somit vergleichbare Werte, wie sie durch Hortua Triana et al. (2012) beschrieben wurden, nachgewiesen werden. Interessanterweise wies die N302S TgDHODH einen verminderten $\mathrm{K}_{\mathrm{M}}$-Wert von $15 \mu \mathrm{M}$ für $\mathrm{Q}_{\mathrm{D}}$ auf. Im Gegensatz dazu ergaben sich für $\mathrm{DHO}$ ein deutlich erhöhter $\mathrm{K}_{\mathrm{M}^{-}}$Wert von $265 \mu \mathrm{M}$ sowie eine Reduktion der Wechselzahl von $50 \%$ auf $38 \mathrm{~s}^{-1}$. Durch eine genauere Betrachtung dieser Parameter konnte in Bezug auf die katalytische Effizienz $\left(\mathrm{k}_{\mathrm{cat}} / \mathrm{K}_{\mathrm{M}}\right)$ der N302S DHODH gegenüber $\mathrm{Q}_{\mathrm{D}}$ keine Veränderung festgestellt werden, jedoch ergab sich für DHO eine ungefähr 8-fache Reduktion der $\mathrm{k}_{\mathrm{cat}} / \mathrm{K}_{\mathrm{M}}$ (Tabelle 3.1).

$$
\text { A }
$$

WT

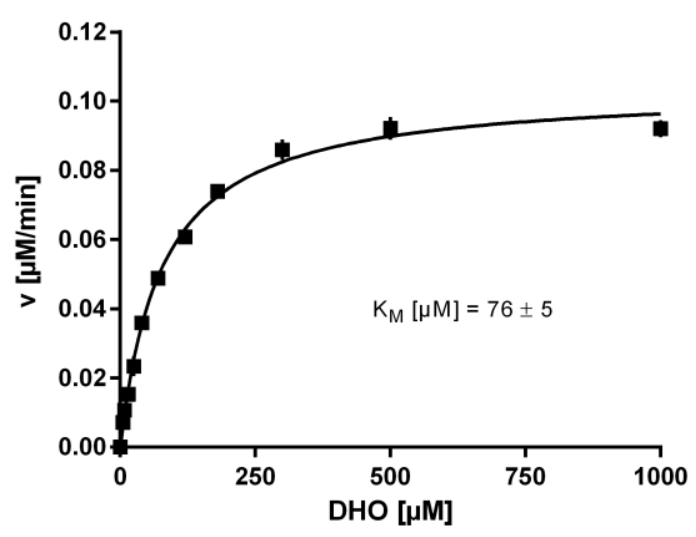

B

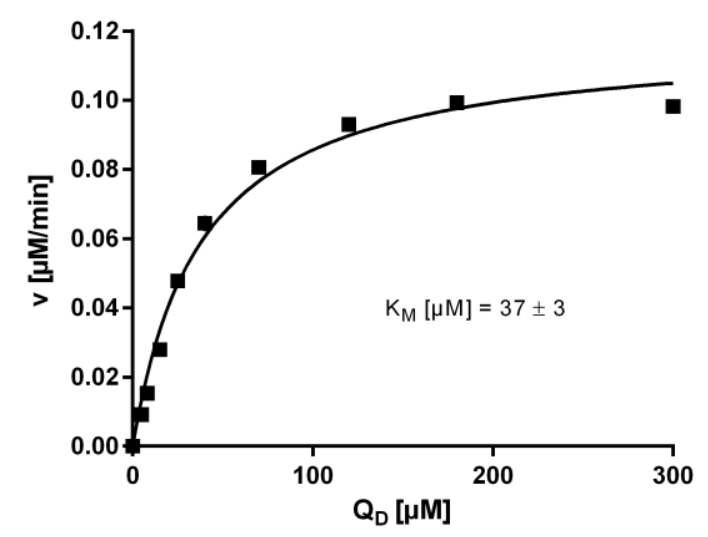

N302S

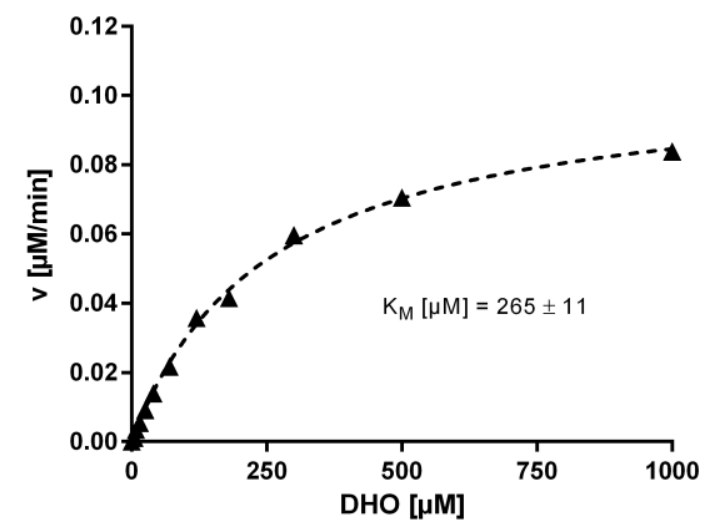

N302S

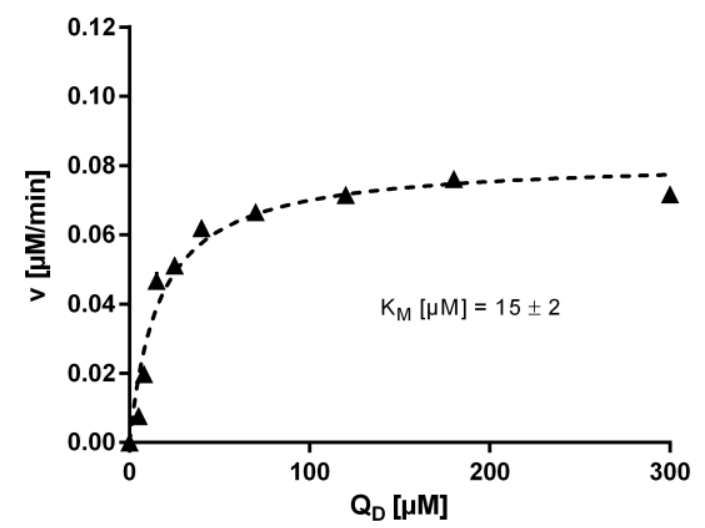

Abbildung 3.25: Die N302S TgDHODH zeigt einen verminderten $K_{M}$-Wert für $Q_{D}$, jedoch einen gesteigerten $\mathbf{K}_{\mathrm{M}}$-Wert für DHO. (A) Die anfängliche Reaktionsgeschwindigkeit ( $v$ in $\mu \mathrm{M} / \mathrm{min}$ ) der Wildtyp DHODH (Quadrate) und der N302S DHODH (Dreiecke) wurde gegen die DHO Konzentration bei konstanter $\mathrm{Q}_{D}$ von $100 \mu \mathrm{M}$ aufgetragen. Die Konzentration von DHO wurde dabei über einen Bereich von 0-1000 $\mu \mathrm{M}$ variiert. (B) Die anfängliche Reaktionsgeschwindigkeit ( $v$ in $\mu \mathrm{M} / \mathrm{min}$ ) der Wildtyp DHODH (Quadrate) und der N302S DHODH (Dreiecke) wurde gegen die $\mathrm{Q}_{\mathrm{D}}$ Konzentration bei konstanter DHO von $1000 \mu \mathrm{M}$ aufgetragen. Die Konzentration von $\mathrm{Q}_{\mathrm{D}}$ wurde dabei über einen Bereich von 0-300 $\mu \mathrm{M}$ variiert. Die Bestimmung der $\mathrm{K}_{\mathrm{M}^{-}}$ Werte erfolgte mittels einer Anpassung der Daten an die Michalis-Menten-Gleichung durch Verwendung nichtlinearer Regressionsanalysen. Die Darstellung der $\mathrm{K}_{\mathrm{M}}$-Werte erfolgt als Mittelwert (MW) \pm Standardabweichung des MW von Proben-Doppelbestimmungen eines repräsentativen Experiments $(n=2)$. 


\subsubsection{Saccharomyces cerevisiae DHODH (ScDHODH) exprimierende $T$. gondii zeigen eine partielle 1-Hydroxyquinolon-Resistenz}

Die TgDHODH nimmt neben einer Schlüsselrolle in der Pyrimidin-de-novo-Synthese eine wichtige strukturelle Funktion in der mitochondrialen Elektronentransportkette (ETC) ein. Während DHODH die einzige Redoxreaktion der Pyrimidin-de-novo-Synthese katalysiert und DHO dabei zu Orotat oxidiert, werden die daraus gewonnenen Elektronen über Ubiquinon direkt in die ETC eingespeist. Ausgehend von den bisherigen Ergebnissen konnte bereits gezeigt werden, dass TgDHODH ein direktes Target der 1-Hydroxyquinolone ist. Unklar ist jedoch ob die beobachtete Wachstumsinhibierung der Parasiten nach einer Behandlung mit HDQ oder Compound B auf die Hemmung der Pyrimidin-de novo-Synthese oder auf eine mögliche Funktionsbeeinträchtigung der ETC zurückzuführen ist. Zur Unterscheidung beider Möglichkeiten wurde die DHODH von Saccharomyces cerevisiae (ScDHODH) in T. gondii exprimiert. Dieses im Zytosol lokalisierte Protein zählt zur Klasse 1 der DHODHn und ist aufgrund seiner Fumarat-reduzierenden Eigenschaft (Nagy et al. 1992) Ubiquinonunabhängig (Abb. 3.26). Eine heterologe und funktionelle Expression der ScDHODH in $T$. gondii würde dabei zu einer Entkopplung der Pyrimidin-de-novo-Synthese von der mitochondrialen Atmungskette führen, wie es bereits bei $P$. falciparum beschrieben wurde (Painter et al. 2007).

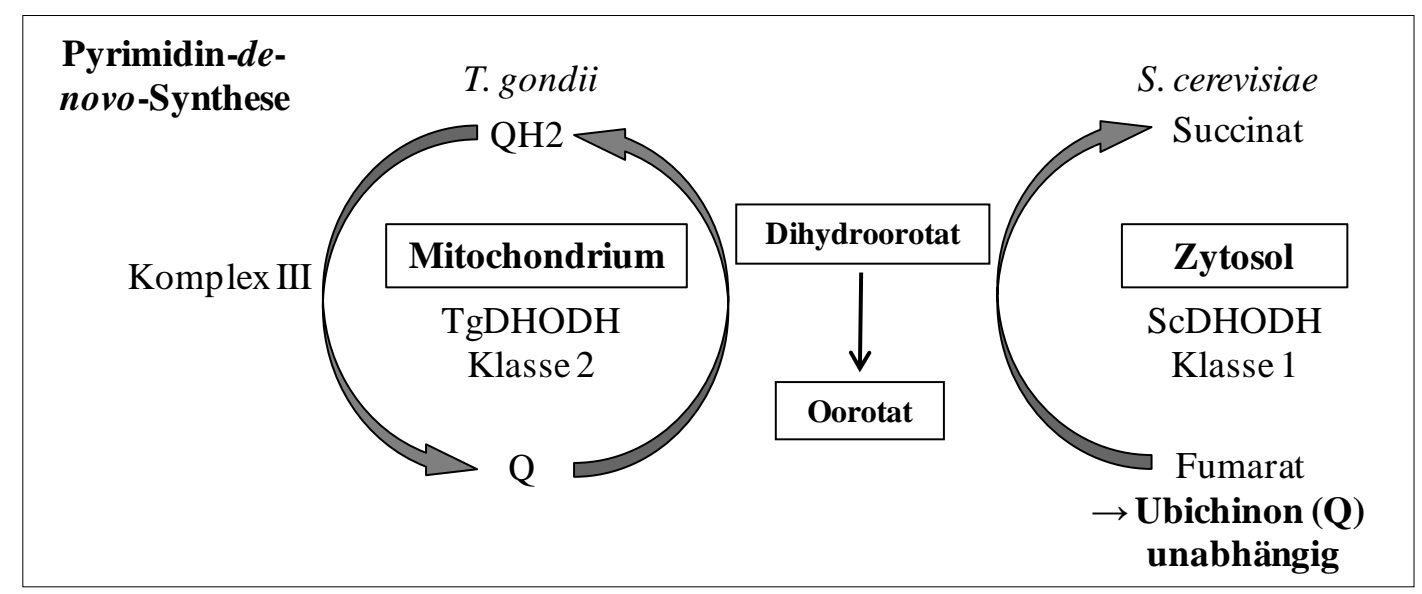

Abbildung 3.26: Schematische Darstellung der durch die zytosolische ScDHODH (Klasse 1) und mitochondriale TgDHODH (Klasse 2) katalysierten enzymatischen Reaktion. 
Ein erster Versuch zur Expression des Scdhodh Gens in RH $\Delta$ uprt Parasiten erfolgte mit Hilfe eines Transfektionsplasmids, bei dem die kodierende Sequenz des Scdhodh Gens unter der Kontrolle eines Tubulin-Promoters exprimiert wurde. Eine zusätzlich in den Vektor eingebrachte Chloramphenicol Acetyltransferase (CAT)-Resistenzkassette diente dabei der Generierung stabil transfizierter Parasiten. RT-PCR Analysen von zwei Einzelklonen (ScDHODH Klon 1 und Klon 2) konnten zwar eine erfolgreiche Transkription nachweisen, jedoch war es nicht möglich die Funktionalität der ScDHODH in Enzym-Aktivitätsassays nachzuweisen (nicht dargestellt).

Unter der Annahme einer möglichen, inkorrekten zellulären Lokalisation des Proteins und um die zytosolische Exprimierung zu gewährleisten, wurde die ScDHODH daher in einem weiteren Versuch mittels eines CAT-Fusionsproteins exprimiert. Dazu wurde das hinter einen Tubulin-Promoter klonierte CAT-ScDHODH Fusionskonstrukt in den RHAhxgprt Stamm transfiziert und stabile Klone mittels einer vorhandenen HXGPRT-Resistenzkassette selektioniert. Zur Durchführung weiterer Versuche wurden zwei Einzelklone (Klon 6 und Klon 7) ausgewählt. Die Bestimmung der zellulären Lokalisation des CAT-ScDHODH Fusionsproteins wurde in Immunfluoreszenztests mit einem anti-CAT Antikörper durchgeführt. Neben der erwarteten zytosolischen Expression ließen sich dabei erste Unterschiede im Expressionslevel des Proteins vermuten. Trotz einer höheren Belichtungszeit zeigte Klon 6 im Vergleich zu Klon 7 eine schwächere Fluoreszenzintensität (Abb. 3.27 A). Die anschließende Immundetektion des Fusionsproteins mittels Western Blot Analysen erfolgte mit Parasitenlysaten der beiden transgenen Klone sowie (als Kontrolle) des parentalen Ausgangsstamms RH $\Delta$ hxgprt. Eine Inkubation der Parasitenlysate mit dem antiCAT Antikörper bestätigte die Proteinexpression ausschließlich für CAT-ScDHODH exprimierende Klone. Durch semi-quantitative Analysen der Bandenintensität, mittels einer densitometrischen Auswertung, konnte zudem eine rund 3-fach gesteigerte Proteinmenge für Klon 7 nachgewiesen werden (Abb. 3.27 B). Der Nachweis des Oberflächen Antigens 1 (SAG1) diente dabei der Normalisierung und als Parasiten-Ladungskontrolle. RT-PCR Analysen bestätigten weiterhin eine um das 9-fach höhere mRNA Expression des Scdhodh Gens für Klon 7, wobei die Genexpression beider Mutanten durch das konstitutiv exprimierte $\beta$-Tubulin normalisiert wurde (Abb. 3.27 C). 

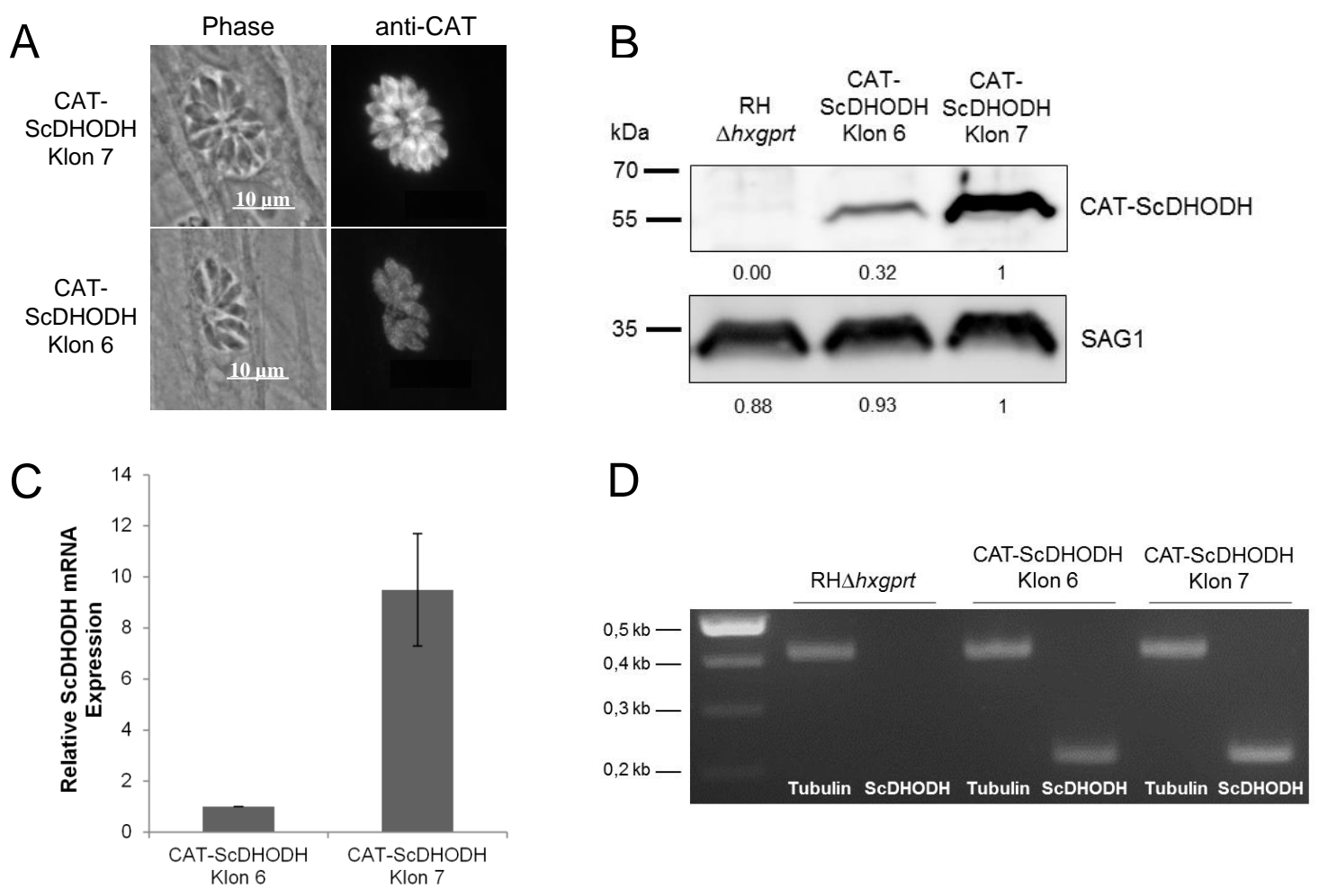

Abbildung 3.27: CAT-ScDHODH exprimierende Klone von $T$. gondii bestätigen eine zytosolische Lokalisation des Fusionsproteins, unterscheiden sich jedoch hinsichtlich der Gen- und Proteinexpression.

(A) Nachweis der zytosolischen Lokalisation des CAT-ScDHODH Fusionsproteins in intrazellulären Parasiten durch indirekte Immunfluoreszenztests mit einem anti-CAT Antikörper. Maßstabsbalken $=10 \mu \mathrm{m}$. (B) Bestimmung des CAT-ScDHODH Proteinlevels durch Western Blot Analysen von Parasitenlysaten mit einem anti-CAT Antikörper. Die Immundetektion des Oberflächen-Antigens 1 (SAG1) der gestrippten Nitrozellulosemembran wurde als Parasiten-Ladungskontrolle verwendet. Die densitometrische Quantifizierung des Proteinlevels erfolgte durch das Programm Multi Gauge V.3.1, relative Werte sind dabei unterhalb der jeweiligen Banden angegeben. (C) CAT-ScDHODH exprimierende Klone 6 und 7 wurden hinsichtlich der mRNA Genexpression untersucht. Dafür wurde $24 \mathrm{~h}$ p. i. Gesamt-RNA isoliert, revers transkribiert und gewonnene cDNA durch LightCycler Real-Time PCR analysiert. Crossing Point (Cp) Werte wurden zur Quantifizierung herangezogen und durch die mRNA Expression von $\beta$-Tubulin normalisiert. Die ScDHODH Genexpression von Klon 7 ist als x-fache Änderung der Genexpression gegenüber Klon 6 angegeben. Die Darstellung der Ergebnisse erfolgt als Mittelwert (MW) \pm Standardabweichung des MW von ProbenDoppelbestimmungen eines repräsentativen Experiments $(n=2)$. (D) Die Überprüfung der RT-PCR Produkte für $\beta$-Tubulin und ScDHODH erfolgte durch Auftrennung in einem 1\%-Agarosegel.

Für beide Klone konnte durch Enzymaktivitätstests eine Funktionalität des CAT-ScDHODH Fusionsproteins nachgewiesen werden (Abb. 3.28). Im Gegensatz $\mathrm{zu}$ den parentalen RHAhxgprt Parasiten zeigten Klon 6 und Klon 7, unter der Zugabe von Fumarat, eine deutliche Reduktion des finalen Elektronenakzeptors DCIP. Inhibitionsversuche mit HDQ und Compound B zeigten weiterhin, dass die Enzymaktivität der Ubiquinon-unabhängigen 
ScDHODH, wie erwartet, trotz sehr hoher Konzentrationen von HDQ und Compound B (10 und $30 \mu \mathrm{M})$ unbeeinflusst blieb.

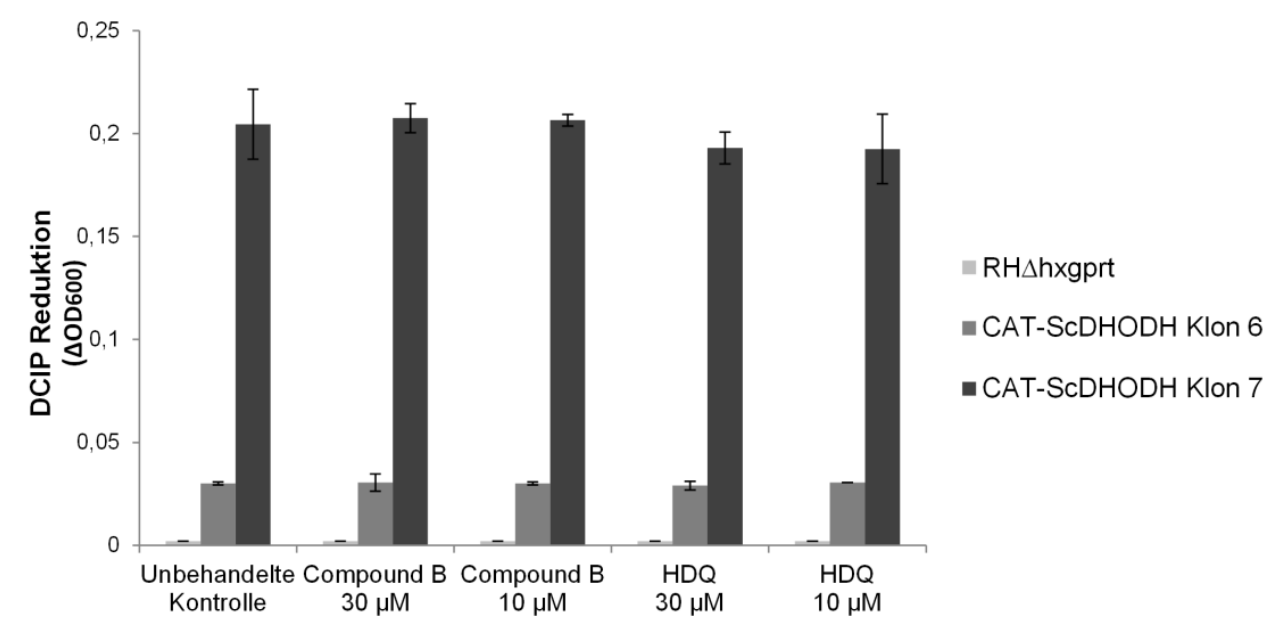

Abbildung 3.28: Compound B und HDQ haben keinen Einfluss auf die Enzymaktivität des CAT-ScDHODH Fusionsproteins. Parasitenlysate der CAT-ScDHODH exprimierenden Klone 6 und 7 wurden hinsichtlich ihrer ScDHODH-Aktivität im Vergleich zum parentalen RHAhxgprt Stamm untersucht. Die Reduktion von DCIP innerhalb einer Minute wurde dabei photometrisch bei $600 \mathrm{~nm}$ mit $1 \mathrm{mM}$ DHO, $1 \mathrm{mM}$ Fumarat und $60 \mu \mathrm{M}$ DCIP gemessen. Der Einfluss von Compound B und HDQ auf die ScDHODH Aktivität wurde unter Konzentrationen von jeweils $30 \mu \mathrm{M}$ und $10 \mu \mathrm{M}$ analysiert. Die Darstellung der Ergebnisse erfolgt als Mittelwert $(\mathrm{MW}) \pm$ Standardabweichung des MW von Proben-Doppelbestimmungen.

Für eine genauere Untersuchung der 1-Hydroquinolon-Sensitivität wurde die Replikationsrate beider Klone nach einer Behandlung mit Compound B und HDQ analysiert.
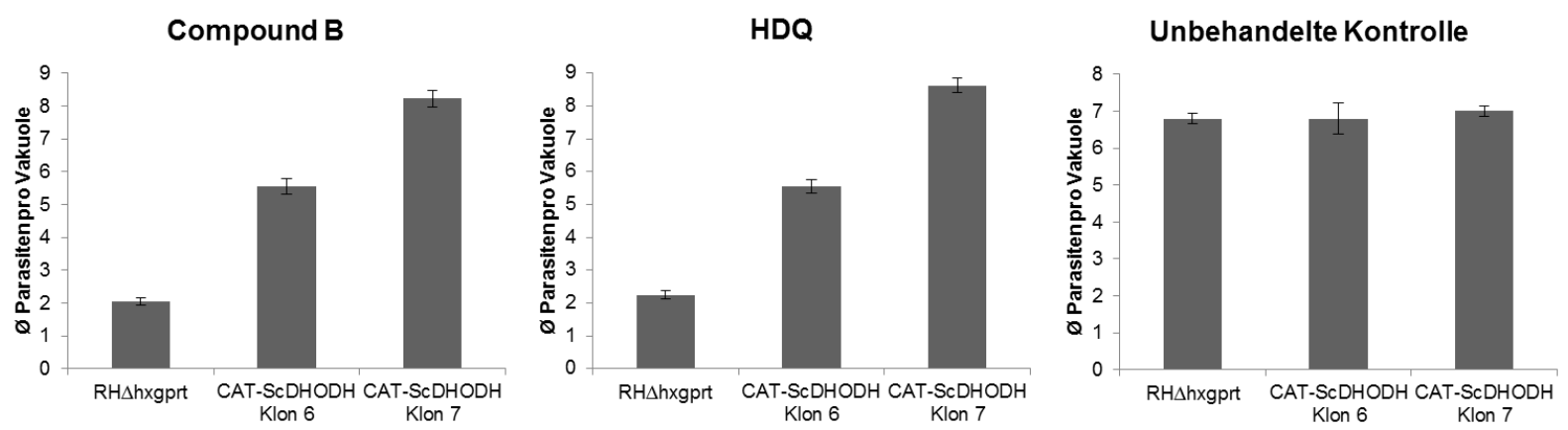

Abbildung 3.29: CAT-ScDHODH exprimierende Parasiten zeigen eine partielle Resistenz gegenüber 1-Hydroxyquinolonen. Replikationsraten CAT-ScDHODH exprimierender Parasiten (Klon 6 und Klon 7), sowie des parentalen RH $\Delta$ hxgprt Stamms wurden $48 \mathrm{~h}$ nach einer Behandlung mit $100 \mathrm{nM}$ Compound B und HDQ bestimmt, während unbehandelte Wachstumskontrollen 24 h p. i. analysiert wurden. Konfluente HFF wurden dazu mit jeweils $\sim 3 \times 10^{4}$ Parasiten infiziert und die durchschnittliche Anzahl intrazellulärer Parasiten durch Auszählung der Parasiten von mindestens 100 zufällig ausgewählten parasitophoren Vakuolen bestimmt. Die Darstellung der Ergebnisse erfolgt als Mittelwert $(M W) \pm$ Standardabweichung des MW von ProbenDoppelbestimmungen eines repräsentativen Experiments $(\mathrm{n}=2)$. 
Während die unbehandelte $24 \mathrm{~h}$ Kontrolle keine Unterschiede in der Parasitenreplikation zeigte, besaßen Klon 6 und Klon 7 im Vergleich zum parentalen Ausgangsstamm RH $\Delta$ hxgprt eine partielle Resistenz gegenüber HDQ und Compound B (Abb. 3.29). In Übereinstimmung mit dem gesteigertem CAT-ScDHODH Expressionslevel zeichnete sich Klon 7, 48 h nach einer Behandlung mit 1-Hydroxyquinolonen, im Vergleich zu Klon 6 zudem durch ein deutlich erhöhtes Wachstum aus. Klon 7 zeigt damit eine der uprt komplementierten 3L-H11 Linie (3L-H11/uprt kompl.) vergleichbare Resistenz gegenüber HDQ und Compound B (Abb. 3.2). Zusammenfassend deutet der Resistenzphänotyp der CAT-ScDHODH exprimierenden Parasiten darauf hin, dass die Inhibition der Pyrimidin-de-novo-Synthese maßgeblich zu dem Inhibitionspotential der 1-Hydroxyquinolone beiträgt. 


\section{Diskussion}

\subsection{TgDHODH als Zielstruktur der 1-Hydroxyquinolone}

Ein stetig zunehmendes und global bedeutsames Problem in der chemotherapeutischen Bekämpfung humanpathogener Mikroorganismen ist das Auftreten von Resistenzen. Doch auch schwere Arzneimittelunverträglichkeiten sowie Rezidive stellen eine nicht zu vernachlässigende Herausforderung dar. Unter den Parasiten geht dabei vor allem Gefahr von der Gruppe der Apicomplexa aus. Dieses Phylum umfasst zahlreiche humanpathogene Arten, zu denen neben Vertretern der Gattung Plasmodium auch Toxoplasma gondii zählt. Eines der größten Hindernisse bei der Behandlung von Malaria ist die besorgniserregende und mitunter rasante Resistenzentwicklung gegenüber in großem Maßstab eingesetzter Medikamente (Travassos and Laufer 2009). So sind heute weitverbreitete Resistenzen gegenüber Chloroquin (White 1992), Atovaquon (Srivastava et al. 1999; Korsinczky et al. 2000) sowie Pyrimethamin und Sulfadoxin (Sibley et al. 2001) bekannt. Doch auch gegenüber neuer Therapeutika wie Artemisinin und seiner Derivate wurden bereits erste Resistenzfälle gemeldet (Phyo et al. 2012; Miotto et al. 2013). Während bisher noch keine Medikamentenresistenzen bei der Therapie einer bestehen Toxoplasmose beschrieben wurden, führen teils sehr schwerwiegende Nebenwirkungen und Reaktivierungen einer bestehenden Infektion, vor allem bei AIDS-Patienten, nicht selten zum Behandlungsversagen (Leport et al. 1988; Porter and Sande 1992; Rothova et al. 1993; Aspinall et al. 2002).

Um eine fortbestehende, effektive und gut verträgliche Therapie zu gewährleisten, ist es daher entscheidend neue antiparasitäre Wirkstoffe zu identifizieren und ihre Wirkungsweise im Detail $\mathrm{zu}$ verstehen. Mit der Suche nach neuen Wirkstoffen wurden kürzlich 1-Hydroxyquinolone, wie 1-Hydroxy-2-Dodecyl-4(1)quinolon (HDQ) und das Derivat Compound B beschrieben, welche das Wachstum von $T$. gondii und $P$. falciparum höchst effektiv im nanomolaren Bereich hemmen (Saleh et al. 2007; Bajohr et al. 2010). Durch Inhibitionskinetiken konnte bereits nachgewiesen werden, dass HDQ die TgNDH2-I von $T$. gondii hemmt, jedoch zeigten $n d h 2-I$ Knock-Out Mutanten nur eine geringfügig reduzierte Wachstumsrate (Lin et al. 2011). Da die wachstumshemmende Wirkung von HDQ wesentlich stärker ist als der inhibitorische Effekt einer $n d h 2$ Deletion, deutete alles darauf hin, dass zusätzliche Target(s) existieren, deren Hemmung zu einer Inhibition des Parasitenwachstums führt. Aufgrund einer strukturellen Ähnlichkeit von HDQ und Compound B gegenüber 


\section{Diskussion}

Ubiquinon, wurden Ubiquinon-reduzierende Dehydrogenasen der mitochondrialen Atmungskette als mögliche Zielstrukturen definiert.

In dieser Arbeit konnte anhand von Resistenzmutanten gezeigt werden, dass die Dihydroorotat Dehydrogenase von T. gondii (TgDHODH) eine wesentliche Zielstruktur der 1-Hydroxyquinolone darstellt. Erste Hinweise der TgDHODH-Inhibition ergaben sich durch den Nachweis einer einzelnen Punktmutation in der kodierenden Sequenz der DHODH bei 3L-H11 und 3F-A6 Parasiten. Durch einen Austausch von Adenin nach Guanin in Codon 302 kommt es nachfolgend zu einer Aminosäuresubstitution von Asparagin nach Serin (N302S). Die Mutation einer einzelnen Aminosäure innerhalb eines Targetproteins ist oftmals ausreichend, um eine Arzneimittelresistenz zu verleihen (Hopkins 2008). Dennoch kann nicht ausgeschlossen werden, dass Resistenzmutanten die durch Behandlung mit einem Mutagen und mehrerer Runden strenger Selektion generiert wurden, multiple Mechanismen benötigen um sich gegen teils sehr hohe Wirkstoffdosen durchsetzen zu können (Borst 1991). Um die Bedeutung der N302S Mutation daher näher zu untersuchen, wurde das endogene Wildtyp-Allel direkt am ursprünglichen Genlocus mittels homologer Rekombination durch das N302S-Allel ausgetauscht. Dabei konnte nachgewiesen werden, dass die Expression des mutierten N302S-Allels zu einer partiellen Resistenz der Parasiten gegenüber HDQ und Compound B führte und die N302S Mutation damit ausreichend ist, den Resistenz-Phänotyp gegenüber 1-Hydroxyquinolonen zu vermitteln. HDQ und Compound B reihen sich damit in eine ganze Serie beschriebener Inhibitoren von DHODH ein. So bildet die Hemmung der humanen DHODH durch das Immunsuppressivum Leflunomid die Grundlage einer effektiven Behandlung der rheumatoiden Arthritis (Fox 1998; Miceli-Richard and Dougados 2003). Leflunomid wird zudem als potentieller Kandidat für eine Behandlung von Psoriasis und des multiplen Myeloms angesehen (Baumann et al. 2009; Boyd 2012). Des Weiteren wurde durch die Hemmung der DHODH von Bakterien, Pilzen, Viren und Parasiten bereits eine Wachstumsinhibierung der Mikroorganismen beschrieben (Hurt et al. 2006; Hoffmann et al. 2011; Vyas and Ghate 2011).

Die Identifizierung der TgDHODH als Zielstruktur von 1-Hydroxyquinolonen wurde durch biochemische Analysen mit aufgereinigten, rekombinanten Enzym bestätigt. Mit $\mathrm{IC}_{50}$-Werten von jeweils $534 \mathrm{nM}$ und $554 \mathrm{nM}$ wirken Compound B und HDQ demnach als affine Inhibitoren der TgDHODH. In dieser Arbeit konnte mit Hilfe von Inhibitionskinetiken gezeigt werden, dass Compound B Dihydroorotat (DHO) unkompetitiv hemmt und demnach nur mit dem bereits gebildeten Enzym-Substrat-Komplex interagieren kann. Aus den kinetischen 


\section{Diskussion}

Daten ging weiterhin hervor, dass Compound $\mathrm{B}$ als kompetitiver Inhibitor von Decylubiquinon $\left(\mathrm{Q}_{\mathrm{D}}\right)$ wirkt und damit als Antagonist von $\mathrm{Q}_{\mathrm{D}}$ um die Bindungsstelle von DHODH konkurriert. Der Wirkungsmechanismus einer kompetitiven Hemmung gegenüber $\mathrm{Q}_{\mathrm{D}}$ steht in Übereinstimmung mit der hier beobachteten 1-Hydroxyquinolon-Resistenz von Parasiten, welche mit der Klasse 1 DHODH von Saccharomyces cerevisiae (ScDHODH) transfiziert wurden. Unter der Verwendung von Fumarat als Elektronenakzeptor verfügt die ScDHODH über eine natürliche Resistenz gegenüber Hemmstoffen, welche als kompetitive Inhibitoren von Ubiquinon wirken, darunter auch Compound B und HDQ. Obwohl die N302S Mutation und die ScDHODH-Expression Resistenz gegenüber 1-Hydroxyquinolonen vermitteln, ist diese nur partiell. Eine vollständige Resistenz kann in diesem Zusammenhang jedoch nicht erwartet werden, da zuvor bereits nachgewiesen wurde, dass HDQ die TgNDH2-I inhibiert (Lin et al. 2008) und einen starken ATP-Mangel induziert (Lin et al. 2009).

Frühere Studien der Arbeitsgruppe konnten einen synergistischen Effekt zwischen HDQ und Atovaquon feststellen (Saleh et al. 2007), welcher auf unterschiedliche Angriffsziele beider Inhibitoren gegenüber dem Ubiquinon/Ubiquinol-Zyklus zurückgeführt wurde. Während Atovaquon durch Bindung an die Ubiquinol-Oxidationsseite $\left(\mathrm{Q}_{0}\right)$ den Cytochrom-bc $\mathrm{c}_{1}$-Komplex der Parasiten inhibiert (Araujo et al. 1991; Fry and Pudney 1992; Kessl et al. 2003), wurde für HDQ eine Inhibierung der Reduktion von Ubiquinon postuliert. Eine erste Bestätigung dafür ergab sich durch den Nachweis der Ubiquinon-reduzierenden TgNDH2-I als Zielstruktur von HDQ (Lin et al. 2008). Trotz ihrer Resistenz gegenüber HDQ und Compound B, wurden 3L-H11, 3F-A6 und N302S KI Parasiten gleichermaßen wie Wildtyp Parasiten durch Atovaquon inhibiert. Die Identifizierung von TgDHODH als Targetstruktur der 1-Hydroxyquinolone und die Tatsache, dass Atovaquon nur einen geringen Effekt auf TgDHODH ausübt (Hortua Triana et al. 2012), unterstützen die Annahme, dass beide Atmungsketteninhibitoren durch unterschiedliche Wirkungsorte des Parasiten agieren. Entsprechend konnten Vallieres et al. (2012) aufzeigen, dass HDQ im Gegensatz zu Atovaquon an die Quinon-Reduktionsseite $\left(\mathrm{Q}_{\mathrm{i}}\right)$ des Cytochrom-bc $\mathrm{c}_{1}-K_{\text {Komplex }}$ von $P$. falciparum bindet und folglich sowohl das Wachstum von Kontrollstämmen als auch Atovaquon-resistenten Parasiten hemmt.

Um 1-Hydroxyquinolon-Derivate zukünftig schnell und ökonomisch als TgDHODH-Inhibitoren testen zu können, wurde TgDHODH funktionell in E. coli exprimiert. Gram-negative Bakterien wie E. coli zeichnen sich ebenso wie Eukaryoten durch die 


\section{Diskussion}

Expression einer Klasse 2 DHODH aus (Rowland et al. 2000), welche mit der zytoplasmatischen Membran des Bakteriums assoziiert ist (Norager et al. 2002; Couto et al. 2008). Ein direkter Nachweis der Funktionalität der TgDHODH-Fusionsproteine wurde dadurch bestätigt, dass die E. coli DHODH-Deletionsmutante (ATCC 12632) durch die Expression der rekombinanten Gene auch ohne Anwesenheit von Uracil wachsen konnte. Demnach scheint für die Funktionalität von TgDHODH keine Assoziation mit der mitochondrialen Membran notwendig zu sein, sondern eine Bindung des Proteins mit der zellulären Membran von E. coli ausreichend. Die anschließende Inkubation mit Compound B zeigte jedoch eine unbeeinflusste Replikationsrate der Bakterien. TgDHODH-exprimierende E. coli scheinen sich somit nicht als Testsystem für 1-Hydroxyquinolone zu eignen. Über die Gründe kann nur spekuliert werden. Es ist jedoch vorstellbar, dass aufgrund einer eingeschränkten Aufnahme nur eine geringe intrazelluläre Konzentration von Compound B erreicht oder dieses durch Effluxmechanismen wieder aus der Zelle heraus transportiert wurde.

\subsubsection{1-Hydroxyquinolone als „Multi-Target” Inhibitoren}

Mit der Identifizierung von TgDHODH als Zielstruktur, hat HDQ bei $T$. gondii demnach mehrere Zielstrukturen, was zudem auch für P. falciparum nachgewiesen werden konnte. So wurde gezeigt, dass HDQ an die Quinon-Reduktionsseite $\left(\mathrm{Q}_{\mathrm{i}}\right)$ des Cytochrom-bc ${ }_{1}-K_{\text {Komplex }}$ von P. falciparum bindet und dass nanomolare Konzentrationen von HDQ ebenso die Aktivität der alternativen NADH Dehydrogenase von $P$. falciparum (PfNDH2) inhibieren (Vallieres et al. 2012). Darüber hinaus konnten Dong et al. (2009) belegen, dass HDQ mit einem $\mathrm{IC}_{50}$-Wert von $4 \mu \mathrm{M}$ ein moderater Inhibitor der DHODH von $P$. falciparum (PfDHODH) ist. Obwohl ausgehend von den inhibitionskinetischen Daten dieser Arbeit bedeutend geringere $\mathrm{IC}_{50}$-Werte für HDQ nachgewiesen wurden $(554 \mathrm{nM})$, ist ein direkter Vergleich beider Studien nur sehr schwer, da neben der Art des Elektronenakzeptoren $\left(Q_{D}\right.$ vs. Coenzym $\mathrm{Q}_{0}$ ) auch unterschiedliche Substratkonzentrationen eingesetzt wurden. Zwar ist der Inhibitionstyp von HDQ gegenüber PfDHODH nicht bekannt, eine nähere Untersuchung wäre dennoch interessant, da die Sequenz der Ubiquinon-bindenden, N-terminalen Domäne der Klasse 2 Enzyme hoch variabel ist und für die Spezies-spezifische Inhibierung von DHODH verantwortlich gemacht wird (Hurt et al. 2006).

HDQ weist demnach die Fähigkeit auf, mehr als nur ein Enzym zu inhibieren und kann somit als Wirkstoff mit einer ausgeprägten Polypharmakologie angesehen werden. Im Vergleich zu 


\section{Diskussion}

einer Inhibierung einzelner Targets gilt der Einsatz solcher „Multitarget-Drugs“, welche gleichzeitig mehrere Zielstrukturen eines Pathogens erfassen, als vielversprechende Strategie bei der Eindämmung von Resistenzentwicklungen (Hopkins et al. 2011; Bottegoni et al. 2012).

\subsection{Die Inhibierung von TgDHODH induziert eine Hemmung der de-novo-Pyrimidinsynthese}

Dihydroorotat Dehydrogenasen können durch Sequenzhomologien in zwei große Klassen unterteilt werden, die sich hinsichtlich der zellulären Lokalisation und des verwendeten Elektronenakzeptors unterscheiden (Bjornberg et al. 1997; Rowland et al. 1997). Klasse 2 DHODHn, wie sie auch bei $T$. gondii und $P$. falciparum auftreten, bilden aufgrund ihrer Ubiquinon-reduzierenden Eigenschaft im Gegensatz zu den Klasse 1 Enzymen ein Bindeglied zwischen der mitochondrialen Elektronentransportkette (ETC) und der Pyrimidin-de-novo-Synthese. Als Flavoenzym katalysiert DHODH im vierten und geschwindigkeitslimitierenden Schritt der Pyrimidin-de-novo-Synthese die Oxidation von Dihydroorotat zu Orotat (Patel et al. 2008). Aufgrund der Generierung von Nukleotiden wird die Inhibierung des de-novo-Synthesewegs und damit auch von DHODH, sei es direkt oder indirekt, als vielversprechendes Target bei der Bekämpfung der Apicomplexa, vor allem von Plasmodien angesehen (Gero and O'Sullivan 1990; Hyde 2007). Während die ETC eine zentrale Funktion im oxidativen Energiestoffwechsel vieler eukaryotischer Zellen einnimmt, darunter auch T. gondii, zeichnet sich das erythrozytäre Stadium von Plasmodium in erster Linie durch eine glykolytische Energiegewinnung aus (Jacobasch et al. 1990; Gardner et al. 2002; Biagini et al. 2006). Dennoch weist die Sensitivität gegenüber Inhibitoren der ETC daraufhin, dass diese unverzichtbar für den Parasiten ist (Mather and Vaidya 2008). Die Mehrzahl aller Organismen ist in der Lage Pyrimidine nicht nur über den de-novo-Syntheseweg zu generieren, sondern weiterhin Pyrimidine auch über einen Salvage Pathway zu verwerten. Dem Genom von Plasmodium fehlen jedoch wichtige Komponenten des Salvage Pathways (Patel et al. 2008), weshalb der Parasit zum Überleben auf eine de-novo-Biosynthese angewiesen ist (Hyde 2007; Davies et al. 2009; Phillips and Rathod 2010; Rodrigues et al. 2010). Tatsächlich konnte für Plasmodium gezeigt werden, dass die wachstumsinhibierende Wirkung von Atovaquon auf einem Verlust der Regeneration von Ubiquinon als Elektronenakzeptor basiert. Aufgrund der Abhängigkeit von DHODH Elektronen auf Ubiquinon zu übertragen, führt die Inhibierung des Cytochrom-bc ${ }_{1}-K_{\text {Komplex }}$ $\mathrm{zu}$ einer indirekten Hemmung der Pyrimidinsynthese (Painter et al. 2007). In 


\section{Diskussion}

Übereinstimmung mit dieser indirekten Inhibierung des de-novo-Synthesewegs kommt es im Anschluss einer Behandlung mit Atovaquon sowohl zu einem Konzentrationsanstieg von Carbamoylaspartat als auch Dihydroorotat und einer Reduktion von UTP, CTP und dTTP (Hammond et al. 1985; Seymour et al. 1997; Biagini et al. 2012). Darüber hinaus wurden kürzlich zwei Triazolopyrimidin-Derivate (Compound 37 und 38) beschrieben, welche PfDHODH und DHODH von P. vivax mit nanomolaren Konzentrationen hemmen, im in vivo Mausmodell hohe Wirksamkeit nachweisen und in vitro inhibitorische Aktivität selbst gegenüber Chloroquin-, Pyrimethamin- und Atovaquon-resistenten Stämmen besitzen (Coteron et al. 2011).

Die endogene, in der inneren Mitochondrienmembran lokalisierte DHODH von T. gondii ist aufgrund der Verwendung von Ubiquinon als Elektronenakzeptor funktionell mit der mitochondrialen Atmungskette verbunden. Daher kann nicht differenziert werden, ob die Wachstumsinhibierung der 1-Hxdroxyquinolone auf eine Hemmung der Pyrimidin-de-novo-Synthese oder auf eine mögliche Funktionsbeeinträchtigung von DHODH innerhalb der ETC zurückzuführen ist. Zur Entkopplung des de-novo-Synthesewegs von der Atmungskette wurde daher die Dihydroorotat Dehydrogenase von S. cerevisiae (ScDHODH) in HDQ-sensitiven Parasiten exprimiert. Diese im Zytosol lokalisierte Klasse 1 DHODH ist aufgrund der Fumarat-reduzierenden Eigenschaft (Nagy et al. 1992) Ubiquinon-unabhängig. Anhand der beobachteten 1-Hydroxyquinolon-Resistenz der transgenen Parasiten konnte bestätigt werden, dass die Inhibition der Pyrimidin-de-novo-Synthese maßgeblich zu dem Inhibitionspotential der 1-Hydroxyquinolone beiträgt. Enzymkinetiken mit Parasitenlysaten der ScDHODH-exprimierenden Klone bestätigten weiterhin eine Unempfindlichkeit der ScDHODH gegenüber HDQ und Compound B, denn trotz sehr hoher Konzentrationen blieb die Enzymaktivität der ScDHODH unbeeinflusst. Aufgrund der ScDHODH-bedingten zytosolischen Umgehung der Pyrimidinsynthese sind die Parasiten trotz einer Inhibierung der endogenen TgDHODH in der Lage sich $\mathrm{zu}$ replizieren. Infolgedessen kann davon ausgegangen werden, dass der Wirkmechanismus der 1-Hydroxyquinolone aus einer Kombination der zuvor beschriebenen Inhibierung der oxidativen Phosphorylierung (Lin et al. 2009) und einer Hemmung der de-novo-Pyrimidinsynthese besteht.

Angesichts der Pyrimidinsynthese nimmt T. gondii innerhalb der Apicomplexa jedoch eine gesonderte Rolle ein und verfügt, im Gegensatz zu Plasmodium, zusätzlich über einen Pyrimidin Salvage Pathway. Basierend auf einer Uracil-Phosphoribosyltransferase (UPRT) wird Uracil dabei in UMP umgewandelt, aus welchem alle weiteren Pyrimidin-Nukleotide 


\section{Diskussion}

synthetisiert werden können (Pfefferkorn and Pfefferkorn 1977; Iltzsch 1993; Carter et al. 1997). Jedoch ist dieser Stoffwechselweg nicht essentiell für den Parasiten, denn uprt Knock-Out Mutanten zeigen in vitro keinen Wachstumsdefekt (Donald and Roos 1995). Da ein Verlust der UPRT-Funktion keinen Einfluss auf das Tachyzoitenwachstum hat, wurde zunächst angenommen, dass die de-novo-Synthese für die Parasitenreplikation zwingend notwendig ist. Tatsächlich führte die Deletion der Carbamoylphosphat Synthetase II (CPSII) zu einer vollständigen Inhibierung der Parasitenreplikation. Unter der Zugabe von Uracil konnte in Zellkulturen jedoch ein dem Wildtyp vergleichbares Wachstum festgestellt werden. Eine Überprüfung der Virulenz zeigte dennoch, dass die Uracil-auxotrophe Mutante in immunkompetenten (BALB/c) sowie immundefizienten (IFN- $\gamma$ Knock-Out) Mäusen vollständig avirulent ist. Der Salvage Pathway von T. gondii ist demnach nicht in der Lage genügend Pyrimidine über die Wirtszelle wiederzuverwerten (Fox and Bzik 2002). Obwohl der de-novo-Syntheseweg für den Parasiten in vitro nicht essentiell ist, konnte das Tgdhodh Gen, selbst unter Anwesenheit von Uracil nicht deletiert werden (Hortua Triana et al. 2012). Mitsamt der Tatsache, dass die Generierung von CPSII (Fox and Bzik 2002) und Orotidin-5'Monophosphat-Decarboxylase (Fox and Bzik 2010) Knock-Out Mutanten möglich war, scheint TgDHODH demnach aus bisher noch ungeklärten Gründen auch in vitro für den Parasiten unerlässlich zu sein (Hortua Triana et al. 2012).

Eine direkte Inhibierung der Pyrimidin-de-novo-Synthese durch 1-Hydroxyquinolone wird auch dadurch bestätigt, dass die RH $\Delta$ uprt Knock-Out Mutante eine gesteigerte Sensitivität gegenüber 1-Hydroxyquinolonen aufzeigte. Durch die Deletion des uprt Gens basiert die für den Parasiten unerlässliche Pyrimidinsynthese allein auf dem de-novo-Weg. Des Weiteren könnte durch eine Hemmung des de-novo-Synthesewegs erklärt werden, warum eine Komplementierung der 3L-H11 Mutante mit dem uprt Gen zu einer nochmals gesteigerten Resistenz führte. Neben einer gegenüber 1-Hydroxyquinolonen resistenten TgDHODH, wären die Parasiten durch UPRT imstande den Pyrimidinspeicher zusätzlich über den Salvage Pathway zu versorgen. Eine durch den Salvage Pathway verstärkte Pyrimidinsynthese könnte ebenso erklären, warum die 3L-H11/uprt kompl. Mutante auch eine verstärkte Resistenz gegenüber Atovaquon zeigte. Hinsichtlich dieses Aspektes ist es jedoch fraglich, warum eine Supplementierung mit Uracil die Parasitenreplikation HDQ-behandelter Tachyzoiten von $T$. gondii nicht zu retten vermag (Lin et al. 2009). Dennoch bestärken frühere Daten der Arbeitsgruppe eine Korrelation zwischen der uprt-Expression und der Sensitivität gegenüber

HDQ. Während die RHAuprt Knock-Out Mutante, wie bereits beschrieben, eine Hypersensitivität aufwies, zeigten uprt komplementierte Parasiten eine dem RH Wildtyp 


\section{Diskussion}

Stamm vergleichbare Wachstumsinhibierung und uprt-überexprimierende Parasiten darüber hinaus eine deutlich verminderte Sensitivität gegenüber HDQ (Sternisek 2009).

\subsection{Einflüsse der N302S Mutation auf enzymkinetische Parameter von TgDHODH}

Anhand der biochemischen Analyse der N302S TgDHODH konnte nachgewiesen werden, dass ein Aminosäureaustausch von Asparagin (Asn) nach Serin (Ser) an Position 302 die Sensitivität gegenüber 1-Hyroxyquinolonen verminderte und zu einer 3-fachen Steigerung der $\mathrm{IC}_{50}$ für Compound $\mathrm{B}(1627 \mu \mathrm{M})$ und HDQ $(1635 \mu \mathrm{M})$ führte. In Übereinstimmung mit den erhöhten $\mathrm{IC}_{50}$-Werten, bewirkte die N302S Mutation gegenüber Compound B einen 2-fach erhöhten Ki-Wert für $\mathrm{Q}_{\mathrm{D}}$ und einen 4-fach erhöhten Ki'-Wert für DHO. Interessanterweise zeigte die N302S DHODH eine 50\%ige Reduktion des $\mathrm{K}_{\mathrm{M}}$-Wertes für $\mathrm{Q}_{\mathrm{D}}$. Während im Gegensatz dazu, der $\mathrm{K}_{\mathrm{M}}$-Wert für DHO rund 3-fach erhöht und die Wechselzahl gegenüber dem Wildtyp-Enzym um 50\% erniedrigt war. Infolgedessen kam es insgesamt zu einer 8-fachen Reduktion der katalytischen Effizienz der N302S DHODH.

Das zentrale strukturelle Element der DHODH aller Klassen besteht aus einer $\alpha / \beta$-Barrel-Domäne. Dieses Strukturmotiv setzt sich aus insgesamt acht parallelen $\beta$-Faltblatt-Strukturen zusammen, welche wiederum von acht $\alpha$-Helices umrundet werden. Diese Domäne beinhaltet sowohl die Bindestelle für FMN als auch die aktive Seite für Dihydroorotat (DHO) und wird am unteren und oberen Ende durch zwei antiparallele $\beta$-Faltblätter bedeckt. Zusätzlich bildet der weitgehend hydrophobe N-terminale Anteil der Klasse 2 Enzyme eine zweite Domäne, welche sich aus zwei $\alpha$-Helices zusammensetzt. Diese lokalisiert oberhalb der katalytischen C-terminalen Domäne in der Nähe der FMN Bindestelle und ist für die Membranassoziation von DHODH verantwortlich (Norager et al. 2002; Hurt et al. 2006). Beide $\alpha$-Helices bilden zusammen einen hydrophoben Trichter, dessen Ende an der FMN Bindestelle lokalisiert und welcher als mögliche Eintrittsstelle für Ubiquinon angesehen wird (Munier-Lehmann et al. 2013). Aufgrund der Tatsache, dass jedoch keine strukturellen Informationen über Ubiquinon-gebundene DHODHn vorliegen, verbleibt die Lokalisierung der Ubiquinon-Bindungsstelle weitgehend ungeklärt (Malmquist et al. 2008).

Dem mutierten Asn302 sind zwei hoch-konservierte Aminosäuren vorangestellt (Phe301 und Gly300), die struktureller Bestandteil des aktiven Zentrums sind und mit Orotat interagieren (Liu et al. 2000; Norager et al. 2002; Deng et al. 2009). Die N302S Mutation beeinträchtigt daher möglicherweise die optimale Positionsausrichtung von Phe301 und Gly300 und könnte 


\section{Diskussion}

damit den erhöhten $\mathrm{K}_{\mathrm{M}}$-Wert für $\mathrm{DHO}$ und die Abnahme der Wechselzahl erklären. Die Auswirkung der N302S Mutation auf die Reduktion des $\mathrm{K}_{\mathrm{M}}$-Wertes für $\mathrm{Q}_{\mathrm{D}}$ ist weniger deutlich. Entsprechend der Wirkung als kompetitive Inhibitoren von Ubiquinon konnten Röntgenstrukturanalysen von Inhibitoren der humanen und E. coli DHODH nachweisen, dass diese in dem aus beiden $\alpha$-Helices gebildeten Trichter der N-terminalen Domäne binden (Liu et al. 2000; Norager et al. 2002). Asn302 ist jedoch weder Teil dieser Ubiquinon-bindenden Struktur noch liegt diese Aminosäure in direkter Umgebung des Trichters. Daten zielgerichteter Mutationen der PfDHODH sprechen jedoch dafür, dass einige Inhibitoren, welche Ubiquinon kompetitiv hemmen, an einer anderen Stelle binden als Ubiquinon selbst (Malmquist et al. 2008). Ihre inhibierende Wirkungsweise wird dadurch erklärt, dass sie eine Konformation des Enzyms stabilisieren, welche unfähig ist Ubiquinon zu binden oder alternativ den Elektronenfluss von FMN zu Ubiquinon blockieren. Entsprechend dieser Vermutung könnte sich auch die Bindungsstelle der 1-Hydroxyquinolone von der UbiquinonBindestelle der TgDHODH unterscheiden. Sollten sich jedoch beide Bindungsstellen überlagern, übt die N302S Mutation möglicherweise weitreichende Effekte auf die Bindung von Ubiquinon aus. Für eine endgültige Bestimmung sind jedoch Röntgenstrukturanalysen der TgDHODH notwendig.

\subsubsection{Mutation N302S wirkt sich auf die katalytische Fitness von TgDHODH aus}

Asn302 ist Teil einer hoch-konservierten Region von DHODH und nur wenige Organismen zeigen Polymorphismen an dieser Position. Das Fehlen von Sequenzvarianten aller Klasse 2 DHODH-exprimierenden Organismen deutet demnach auf einen selektiven Druck hin, Asparagin an dieser Position zu erhalten. Ausgehend von den wachstumskinetischen Daten dieser Arbeit zeigten Tachyzoiten, welche anstelle der Wildtyp DHODH das N302S-Allel exprimieren keine nachweisbare Abnahme der Replikationsrate. Auch Plaque-Assays, durch welche Wachstumsunterschiede über mehrere Generationen hinweg relativ sensitiv erfasst werden können, erbrachten keine signifikanten Abweichungen in der Teilungsrate der Parasiten. Dennoch lassen sich mit beiden Methoden Wachstumsdefekte von 1 bis 2\% nicht ausschließen. Das Resistenzmutationen mit einem solchen Fitness-Defekt der Parasiten einhergehen können, konnte bereits durch Fohl et al. (2003) gezeigt werden. Um Auswirkungen einer Pyrimethamin-Resistenz auf die Parasitenfitness zu untersuchen, wurden in P. falciparum definierte, Resistenz-vermittelnde Mutation der DHFR-TS entsprechend in $T$. gondii exprimiert. Für einen direkten Vergleich der Replikationsrate und eines möglichen Selektionsvorteils wurden dazu in Konkurrenzversuchen Gewebekulturen und Mäuse mit 


\section{Diskussion}

einem Gemisch (1:1) aus Wildtyp-Parasiten und der jeweiligen Resistenzmutante infiziert und das Wachstum über einen Zeitraum von insgesamt 36 Tagen untersucht. Dabei konnte unter anderem für die im Labor isolierte Mutante Arg59+Ser223 ein Wachstumsdefekt von >2.8\% pro Generation, in vitro sowie in vivo, nachgewiesen werden. Entsprechend der Autorenmeinung könnte dies erklären, warum das hochgradig Pyrimethamin-resistente Allel bei Feldisolaten noch nicht nachgewiesen wurde. Parasiten die diese Mutation tragen, würden in Abwesenheit eines kontinuierlichen Selektionsdrucks sehr schnell aus der Population verloren gehen. Möglicherweise spielt die in dieser Arbeit beobachtete, mit der N302S Mutation einhergehende Abnahme der katalytischen Leistungsfähigkeit des Enzyms eine entscheidende Rolle Asparagin zu erhalten. Tatsächlich zeigen die analog in T. gondii exprimierten Allele der häufig beobachteten Pyrimethamin-resistenten Feldisolate von Plasmodium vergleichbare $\mathrm{K}_{\text {cat }}$-Werte wie der Wildtyp. Dagegen weist Mutation Ser233 einen deutlich verminderten $\mathrm{K}_{\text {cat }}$-Wert auf, wodurch die Diskrepanz zwischen Resistenz und kinetischer Fitness $\mathrm{zu}$ hoch erscheint und damit als mögliche Ursache für eine Isolation ausschließlich unter Laborbedingungen angesehen wird (Reynolds and Roos 1998).

\subsection{Metabolische Anpassung 1-Hydroxyquinolon-behandelter Parasiten}

Obwohl Konzentrationen von 100 nM HDQ bzw. Compound B das Parasitenwachstum in den ersten 24 Stunden nahezu vollständig inhibieren, ist diese Hemmkonzentration für $T$. gondii nicht letal (Saleh et al. 2007). Ebenso wie der RH Stamm zeigten die in dieser Arbeit untersuchten Resistenzmutanten im späteren Verlauf der Untersuchung eine Regeneration des Wachstums. Doch während RH Parasiten sich nur verlangsamt replizierten, erholten sich 3L-H11 und 3F-A6 Parasiten sehr viel schneller von der anfänglichen Inhibition und besaßen eine deutliche Resistenz gegenüber 1-Hydroxyquinolonen. Frühere Studien konnten bereits nachweisen, dass das Tachyzoitenwachstum des RH Stamms unmittelbar an eine ausreichende ATP-Generierung durch die oxidative Phosphorylierung gebunden ist, eine Behandlung mit HDQ jedoch $\mathrm{zu}$ einem Zusammenbruch des mitochondrialen Membranpotentials $\left(\Delta \Psi_{\mathrm{m}}\right)$ und damit einer Inhibierung dieses Stoffwechselwegs führt (Lin et al. 2009). Die ursprüngliche Vermutung, dass die HDQ-Resistenz der 3L-H11 und 3F-A6 Parasiten mit einer Repolarisierung des $\Delta \Psi_{\mathrm{m}}$ einhergeht, konnte durch MitoTracker-gefärbte Parasiten widerlegt werden. Beide Resistenzmutanten sind unter der Wirkung von HDQ und Compound B demnach in der Lage, sich trotz eines fehlenden Membranpotentials moderat zu replizieren. Interessanterweise zeigten sowohl 3L-H11 und 3F-A6 Parasiten als auch der RH Stamm, nach einer Behandlung mit Compound B eine verstärkte metabolische Abhängigkeit 


\section{Diskussion}

gegenüber Glucose. Ein verminderter Glucosegehalt des Zellkulturmediums sowie eine Hemmung der Glykolyse durch 2-DOG resultierten in einer gesteigerten Sensitivität der Parasiten gegenüber 1-Hydroxyquinolonen. Unter einer minimalen Glucosekonzentration wurde die Regeneration des Wachstums sowohl beider Mutanten als auch der RH Parasiten vollständig inhibiert. Darüber hinaus zeigten $\Delta t g g t l$ Parasiten eine Hypersensitivität gegenüber Compound B. Im Gegensatz zum RH Wildtyp-Stamm ist diese Mutante, durch eine Deletion des Glucosetransporters TgGT1, nicht in der Lage die im Medium enthaltene Glucose aufzunehmen und zu verwerten (Blume et al. 2009). Es konnte zwar gezeigt werden, dass intrazelluläre $\Delta$ tggt1 Parasiten Glutamin als alternative C-Quelle metabolisieren können und damit ihren Energie- und Kohlenstoffbedarf erhalten (Blume et al. 2009). Das durch die Glutaminolyse produzierte $\alpha$-Ketoglutarat benötigt für die Umsetzung durch den TCA-Zyklus und der damit einhergehenden Produktion von ATP jedoch eine aktive oxidative Phosphorylierung (Polonais and Soldati-Favre 2010). Ein Mangel an Glucose, als bioenergetisches Substrat, kann demnach auch nicht durch Glutamin kompensiert werden. Zusammenfassend deuten die Ergebnisse darauf hin, dass eine Stoffwechselanpassung von oxidativer Phosphorylierung zur Glykolyse stattfindet, welche für die Regeneration des Parasitenwachstums nach einer Behandlung mit 1-Hydroxyquinolonen von entscheidender Bedeutung ist.

Obligat intrazelluläre Parasiten werden im Laufe ihrer recht komplexen Lebenszyklen, durch den Wechsel zwischen verschiedenen Wirten, Organsystemen sowie extrazellulärem und intrazellulärem Milieu, mit variierenden Lebensbedingungen konfrontiert (Pomel et al. 2008). Für das Überleben des Parasiten ist es daher entscheidend seine Kohlenstoffquelle und andere essentielle Nährstoffe von der Wirtszelle zu beziehen (MacRae et al. 2012) und den Energiestoffwechsel an die jeweiligen Bedingungen anzupassen (Ginger 2006). Expressionsanalysen von $P$. falciparum deuten beispielsweise auf einen metabolischen Wechsel von einer glykolytischen Energiegewinnung der asexuellen erythrozytären Phase des Parasiten zur oxidativen Phosphorylierung in Gametozyten hin (Daily et al. 2007; Polonais and Soldati-Favre 2010). Hino et al. (2012) konnten weiterhin zeigen, dass trotz einer Deletion der Flavoprotein-Untereinheit (SDHA) der mitochondrialen Succinat Dehydrogenase (Komplex II), erythrozytäre Parasiten von P. berghei in der Maus ein normales Wachstum zeigen. Jedoch wird die Entstehung des Ookinets dieser Pbsdha(-) Parasiten innerhalb der Mücke erheblich beeinträchtigt und die Parasitentransmission durch eine gescheiterte Oocysten-Bildung blockiert. Demnach scheinen sich Plasmodien dem glucosearmen Milieu des Vektors durch einen Wechsel hin zur oxidativen Phosphorylierung anzupassen. Die 


\section{Diskussion}

Fähigkeit einer Stoffwechselanpassung wurde auch für $T$. gondii beschrieben. Intrazelluläre Tachyzoiten sind zum Erhalt der ATP-Homöostase an eine funktionelle oxidative Phosphorylierung gebunden, denn eine Behandlung mit Oligomycin (einem ATP-Synthase Inhibitor) und HDQ führte zu einer Reduktion der parasitären ATP-Menge von etwa 70\% (Lin 2009). Im Vergleich dazu blieb die Motilität extrazellulärer Parasiten von einer Inhibierung der oxidativen Phosphorylierung weitgehend unbeeinflusst (Pomel et al. 2008), während eine Behandlung mit 2-DOG zu einer drastischen Abnahme des ATP-Gehalts und der Invasionsfähigkeit der Parasiten führte (Lin et al. 2011b). Die Mehrheit der für die Motilität extrazellulärer Parasiten benötigten Energie wird demnach aus der glykolytischen Aktivität gewonnen (Pomel et al. 2008; Lin et al. 2009; Lin et al. 2011b). Dies wird auch dadurch unterstrichen, dass glykolytische Enzyme mit dem Egress aus der Wirtszelle aus dem Zytoplasma der Parasiten zur Pellicula verlagert werden und erst nach Invasion in eine neue Zelle in die zytoplasmatische Verteilung zurückkehren (Pomel et al. 2008).

Im Zuge der in dieser Arbeit gewonnenen Ergebnisse ergibt sich für 1-Hydroxyquinolonsensitive und -resistente Parasiten folgendes Adaptationsmodell (Abb. 4.1): 1-Hydroxyquinolone, wie HDQ und Compound B sind in der Lage die Replikation von $T$. gondii höchst effektiv zu hemmen (Saleh et al. 2007; Bajohr et al. 2010). Dabei besitzen sie in den ersten 24 Stunden der Behandlung die stärkste antiparasitäre Wirkung und führen sowohl bei sensitiven RH und RHAuprt Parasiten aber auch bei Mutanten mit einer partiellen Resistenz (3L-H11, 3F-A6 und 3L-H11/uprt kompl.) zu einer deutlich ausgeprägten Wachstumshemmung. In dieser Anfangsphase führen nanomolare Konzentrationen von HDQ innerhalb von Minuten zu einem Zusammenbruch des mitochondrialen Membranpotentials $\left(\Delta \Psi_{\mathrm{m}}\right)$ und durch eine Inhibition der oxidativen Phosphorylierung zu einem drastischen Verlust des intrazellulären ATP-Gehalts (Lin et al. 2009). Dennoch besitzen 1-Hydroxyquinolone nur eine parasitostatische Wirkung (Saleh et al. 2007; Bajohr et al. 2010), denn mit Ausnahme der RHAuprt Deletionsmutante zeigten alle Parasiten 24 nach einer Behandlung ein wiedereinsetzendes Wachstum. Eine Repolarisierung des $\Delta \Psi_{\mathrm{m}}$ als mögliche Ursache der Regenerationsfähigkeit scheint jedoch nicht in Frage zu kommen, denn die Resistenzmutanten zeigten noch 48 Stunden nach einer Behandlung mit Compound B eine Depolarisierung des $\Delta \Psi_{\mathrm{m}}$. Die Parasiten sind demnach in der Lage sich moderat zu replizieren, ohne das hierfür ein $\Delta \Psi_{\mathrm{m}}$ notwendig wäre. Dagegen zeigten sowohl sensitive als auch resistente Parasiten bei niedrigen Glucosekonzentrationen keine Regeneration des Wachstums, sondern eine vollständige Inhibierung der Parasitenreplikation. Es kann folglich 


\section{Diskussion}

davon ausgegangen werden, dass die Parasiten zur Kompensation des Energiedefizits aus der Atmungskette ihren Stoffwechsel von oxidativer Phosphorylierung hin zur Glykolyse anpassen und sich so von der inhibitorischen Wirkung der 1-Hydroxyquinolone erholen. Doch trotz einer metabolischen Adaption und Regeneration der Parasiten zeigt der RH Stamm im Vergleich zu den Resistenzmutanten eine deutlich verlangsamte Replikation, das Wachstum der RH $\Delta$ uprt Parasiten wird darüber hinaus permanent inhibiert.

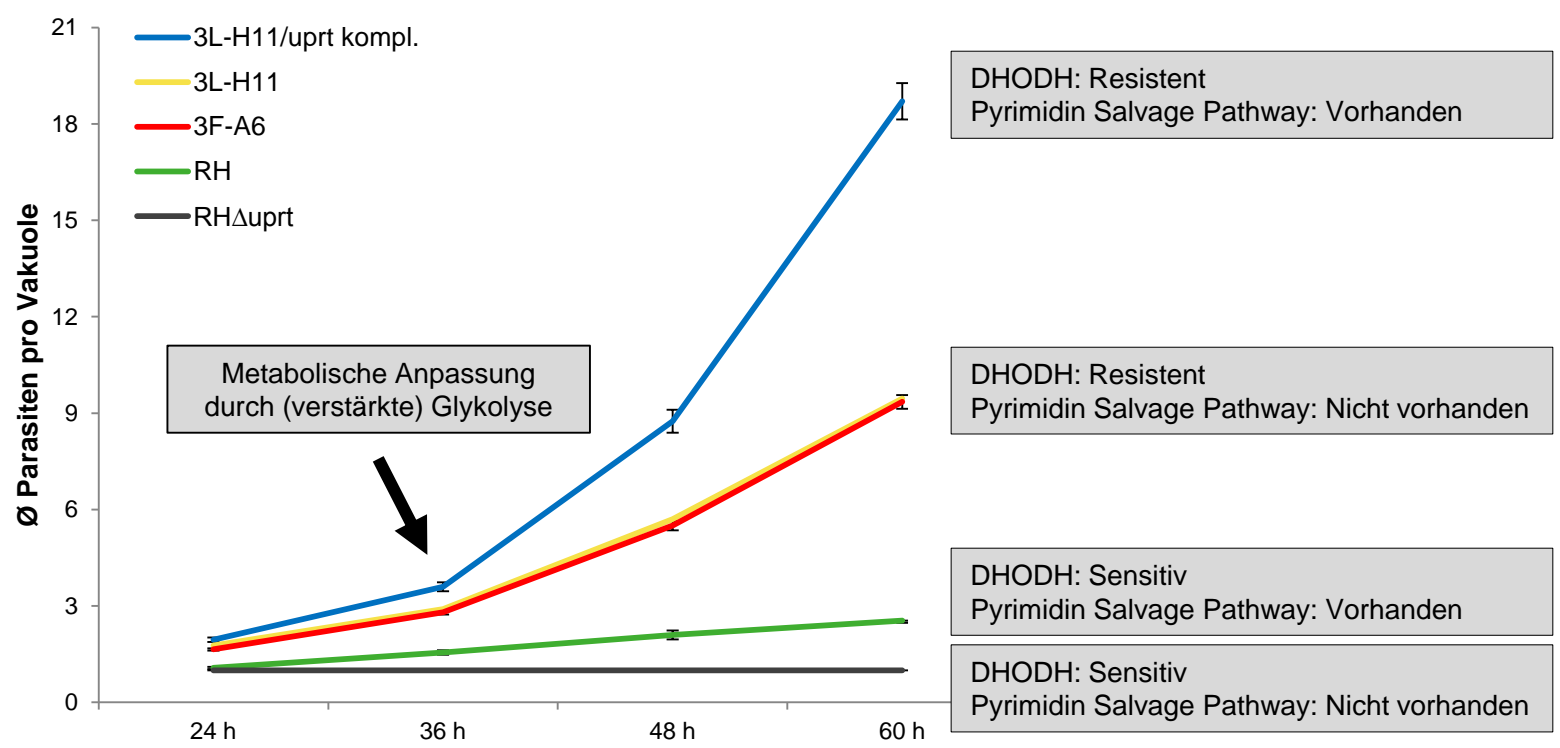

Abbildung 4.1: Adaptationsmodell 1-Hydroxyquinolon-sensitiver Parasiten (RHAuprt und RH) und von Parasiten mit einer partiellen 1-Hydroxyquinolon-Resistenz (3F-A6, 3L-H11 und 3L-H11/uprt kompl.).

Neben der Hemmung des Energiemetabolismus lassen sich die verschiedenen Wachstumskinetiken der untersuchten Parasiten durch einen weiteren Wirkmechanismus der 1-Hydroxyquinolone erklären. In dieser Arbeit konnte sehr deutlich gezeigt werden, dass 1-Hydroxyquinolone, durch eine direkte Hemmung der TgDHODH, die Pyrimidin-de-novo-Synthese von T. gondii inhibieren. RHAuprt Parasiten sind aufgrund der Unterbrechung des Salvage Pathway darauf angewiesen Pyrimidine allein durch den de-novo-Weg zu generieren. Folglich kann davon ausgegangen werden, dass die gesteigerte Sensitivität gegenüber 1-Hydroxyquinolonen darauf beruht, dass HDQ und Compound B durch eine Hemmung von DHODH die Pyrimidinsynthese der Parasiten inhibieren. RH Parasiten besitzen zwar gleichermaßen wie die RHAuprt Knock-Out Mutante eine 1-Hydroxyquinolon-sensitive DHODH, sie können ihren Pyrimidinspeicher jedoch über den Salvage Pathway versorgen und sich damit (wenn auch deutlich verlangsamt) replizieren. 3L-H11, 3F-A6 und 3L-H11/uprt kompl. Parasiten weisen aufgrund der N302S Mutation in der kodierenden Sequenz der DHODH eine 1-Hydroxyquinolon-resistente DHODH auf und 


\section{Diskussion}

sind daher in der Lage Pyrimidine auch weiterhin über den de-novo-Syntheseweg herzustellen. Des Weiteren führt eine Komplementierung der 3L-H11 Mutante mit dem uprt Gen zu einer nochmals gesteigerten Teilungsrate, denn neben der de-novo-Biosynthese sind sie imstande Pyrimidine zusätzlich über den Salvage Pathway zu synthetisieren. 


\section{Zusammenfassung}

1-Hydroxyquinolone wurden kürzlich als effektive Inhibitoren der Toxoplasma gondii Replikation beschrieben. Dabei konnte bereits gezeigt werden, dass 1-Hydroxyquinolone, wie HDQ und Compound B, die Aktivität der alternativen NADH Dehydrogenase und somit die Atmungskette von $T$. gondii inhibieren. Die phänotypische Charakterisierung von ndh2-I Knock-Out Mutanten deutete jedoch darauf hin, dass die wachstumshemmende Wirkung der 1-Hydroxyquinolone auf einer Inhibition zusätzlicher Target(s) basiert.

Im Rahmen dieser Arbeit konnte die Dihydroorotat Dehydrogenase von T. gondii (TgDHODH), welche den vierten Schritt der Pyrimidin-de-novo-Synthese katalysiert, als neue Zielstruktur der 1-Hydroxyquinolone identifiziert werden. Durch T. gondii Mutanten, die eine partielle Resistenz gegenüber diesen Wirkstoffen aufweisen, wurde das Genexpressionsprofil und die kodierende Sequenz aller Ubiquinon-reduzierenden mitochondrialen Dehydrogenasen, welche als relevante Angriffsziele der 1-Hydroxyquinolone gelten, analysiert. Während sich aus der quantitativen RT-PCR Analyse keine signifikanten Unterschiede im mRNA Expressionsgehalt der Enzyme zeigten, konnte mit Hilfe von DNA-Sequenzierungen eine einzelne Punktmutation im Codon 302 der kodierenden Sequenz der TgDHODH nachgewiesen werden. In Folge dieser Mutation kommt es in der Nähe der Dihydroorotat-Bindungsstelle zu einer Aminosäuresubstitution des konservierten Asparagins durch Serin. Durch einen Austausch des dhodh Wildtyp-Allels mit dem N302S-Allel, mit Hilfe einer „Knock-In“ Strategie, konnte nachgewiesen werden, dass die Expression des N302S-Allels ausreichend ist, um den partiellen Resistenz-Phänotyp zu vermitteln. Enzymkinetiken der in E. coli exprimierten und aufgereinigten Wildtyp und N302S TgDHODH konnten weiterhin zeigen, dass die Aktivität des Wildtyp Proteins durch nanomolare Konzentrationen der 1-Hydroxyquinolone inhibiert wird, während die $\mathrm{IC}_{50}$-Werte der N302S Mutante signifikant erhöht waren. Aus den inhibitionskinetischen Analysen ging zudem hervor, dass 1-Hydroxyquinolone als kompetitive Inhibitoren des Elektronenakzeptors QD wirken, während sich für Dihydroorotat ein unkompetitiver Inhibitionstyp ergab.

TgDHODH ist in der inneren mitochondrialen Membran lokalisiert und stellt aufgrund des Elektronentransfers von Dihydroorotat auf Ubiquinon ein funktionelles Bindeglied zwischen der mitochondrialen Atmungskette und der Pyrimidin-de-novo-Synthese dar. Zur Unterscheidung, ob die wachstumshemmende Wirkung der nachgewiesenen 
DHODH-Inhibition auf einem Wegfall der Elektroneneinspeisung in die Atmungskette beruht, oder auf einer Inhibierung der de-novo-Pyrimidinsynthese, wurden beide Stoffwechselwege durch die Expression der Ubiquinon-unabhängigen Saccharomyces cerevisiae DHODH (ScDHODH) voneinander entkoppelt. Die heterologe Expression der 1-Hydroxyquinolon-unempfindlichen ScDHODH in $T$. gondii sollte dabei, auch unter Anwesenheit von HDQ oder Compound B, zu einer Wiederherstellung der de-novo-Pyrimidinsynthese führen. Mit dem Nachweis einer deutlich erhöhten Resistenz dieser transgenen Parasiten gegenüber HDQ und Compound B konnte gezeigt werden, dass die Inhibition der Pyrimidin-de-novo-Synthese maßgeblich $\mathrm{zu}$ dem Inhibitionspotential der 1-Hydroxyquinolone beiträgt. Somit werden durch 1-Hydroxyquinolone zwei wichtige Stoffwechselwege direkt inhibiert: die oxidative Phosphorylierung und die Pyrimidin-de-novo-Synthese.

1-Hydroxyquinolon-behandelte Parasiten zeichnen sich hinsichtlich der Wachstumskinetik durch ein biphasisches Bild aus. Unabhängig von der Sensitivität oder Resistenz gegenüber 1-Hydroxyquinolonen charakterisiert sich die anfängliche Phase ( 0 bis 24 Stunden) durch eine nahezu vollständige Wachstumsinhibierung. In der nachfolgenden Behandlungsdauer zeigen die Resistenzmutanten und zu einem deutlich geringeren Ausmaß auch Wildtyp Parasiten ein wiedereinsetzendes Wachstum. Die Regenerationsfähigkeit ist dabei nicht an ein nachweisbares mitochondriales Membranpotential gebunden, jedoch weisen die Parasiten eine verstärkte metabolische Abhängigkeit gegenüber Glucose auf. So konnte gezeigt werden, dass die Regeneration des Parasitenwachstums durch einen verminderten Glucosegehalt des Zellkulturmediums sowie die Behandlung mit einem Glykolyseinhibitor verhindert wird. Demnach scheint die Behandlung von T. gondii mit HDQ oder Compound B einen metabolischen Wechsel von oxidativer Phosphorylierung zur Glykolyse zu induzieren, durch welchen das aus der 1-Hydroxyquinolon-Behandlung resultierende Energiedefizit teilweise kompensiert werden kann. 


\section{Summary}

1-hydroxyquinolones were recently described as effective inhibitors of Toxoplasma gondii replication. These compounds (e.g. HDQ and compound B) were previously shown to inhibit the alternative NADH dehydrogenase (NADH2-I) activity and thus the respiratory chain of $T$. gondii. However, the phenotype of ndh2-I knock-out mutants suggested the presence of additional target(s).

In this study, the fourth enzyme of de novo pyrimidine biosynthesis, the $T$. gondii dihydroorotate dehydrogenase (TgDHODH), was identified as a novel 1-hydroxyquinolone target. T. gondii mutants with a partial resistance phenotype towards 1-hydroxyquinolones were used to analyze the expression profile and the coding sequence of all ubiquinone-reducing mitochondrial dehydrogenases, which are the likely targets of 1-hydroxyquinolones. Quantitative RT-PCR analysis revealed no significant differences in the mRNA expression level of these enzymes. However, DNA-sequencing identified a single point mutation in codon 302 of the TgDHODH coding sequence that changes a conserved asparagine into serine in the vicinity of the dihydroorotate binding site. This mutation is sufficient to confer the partial drug resistance phenotype, as shown by replacement of the wild type allele with the N302S allele, using a "knock-in" strategy. Enzyme kinetics of E. coli expressed and purified wild type and N302S TgDHODH revealed an inhibition of the wild type enzyme activity by nanomolar concentrations of 1-hydroxyquinolones, while the $\mathrm{IC}_{50} \mathrm{~s}$ for the N302S mutant were significantly increased. Furthermore, inhibition kinetics demonstrated that 1-hydroxyquinolones act as competitive inhibitors for the electron acceptor $\mathrm{Q}_{\mathrm{D}}$, but as uncompetitive inhibitors for dihydroorotate.

TgDHODH is localized in the inner mitochondrial membrane, and is linking the pyrimidine de novo pathway to the mitochondrial respiratory chain by transferring electrons from dihydroorotate to ubiquinone. To distinguish whether the lack of TgDHODH-mediated electron transfer or the inhibition of de novo pyrimidine biosynthesis is responsible for growth inhibition, both pathways were uncoupled by expression of the ubiquinone independent Saccharomyces cerevisiae DHODH (ScDHODH). Heterologous expression of the 1-hydroxyquinolone-insensitive ScDHODH in T. gondii should lead to a restoration of de novo pyrimidine biosynthesis in the presence of HDQ and compound $\mathrm{B}$. These parasites showed a strongly increased resistance towards 1-hydroxyquinolones, demonstrating that 


\section{Summary}

inhibition of pyrimidine de novo synthesis significantly contributes to the growth inhibitory potential of 1-hydroxyquinolones in T. gondii. 1-hydroxyquinolones thus directly inhibit two important metabolic pathways: oxidative phosphorylation and pyrimidine de novo synthesis.

The growth kinetics of drug treated parasites is characterized by a biphasic pattern, with an initial phase ( $\sim 0$ to 24 hours) in which the parasites - independent of their resistance or sensitivity to 1-hydroxyquinolones - show an almost complete growth inhibition. In the later phase of treatment, drug-resistant mutants - and to a much lower extent also wild type parasites - start replicating again. This growth recovery is occurring in the absence of a detectable mitochondrial membrane potential. However, parasites possess a strong dependency on glucose metabolism. A decrease of glucose in the tissue culture medium, and a treatment with a glycolytic inhibitor both prevented the growth recovery. Thus, 1-hydroxyquinolone treatment seems to induce a metabolic shift from oxidative phosphorylation towards glycolysis, which can partly restore the energy production. 


\section{Literaturverzeichnis}

Abrahamsen, M. S., T. J. Templeton, S. Enomoto, J. E. Abrahante, G. Zhu, C. A. Lancto, M. Deng, C. Liu, G. Widmer, S. Tzipori, G. A. Buck, P. Xu, A. T. Bankier, P. H. Dear, B. A. Konfortov, H. F. Spriggs, L. Iyer, V. Anantharaman, L. Aravind and V. Kapur (2004). "Complete genome sequence of the apicomplexan, Cryptosporidium parvum." Science 304(5669): 441-445.

Ajioka, J. W. and D. Soldati (2007). "20. Nucleotides and Amino Acids." In: Toxoplasma Molecular And Cellular Biology(Horizon Bioscience): $365 \mathrm{ff}$.

Araujo, F. G., J. Huskinson and J. S. Remington (1991). "Remarkable in vitro and in vivo activities of the hydroxynaphthoquinone 566C80 against tachyzoites and tissue cysts of Toxoplasma gondii." Antimicrob Agents Chemother 35(2): 293-299.

Asai, T., W. J. O'Sullivan, M. Kobayashi, A. M. Gero, M. Yokogawa and M. Tatibana (1983). "Enzymes of the de novo pyrimidine biosynthetic pathway in Toxoplasma gondii." Mol Biochem Parasitol 7(2): 89-100.

Aspinall, T. V., D. H. Joynson, E. Guy, J. E. Hyde and P. F. Sims (2002). "The molecular basis of sulfonamide resistance in Toxoplasma gondii and implications for the clinical management of toxoplasmosis." J Infect Dis 185(11): 1637-1643.

Bader, B., W. Knecht, M. Fries and M. Loffler (1998). "Expression, purification, and characterization of histidine-tagged rat and human flavoenzyme dihydroorotate dehydrogenase." Protein Expr Purif 13(3): 414-422.

Bajohr, L. L., L. Ma, C. Platte, O. Liesenfeld, L. F. Tietze, U. Gross and W. Bohne (2010). "In vitro and in vivo activities of 1-hydroxy-2-alkyl-4(1H)quinolone derivatives against Toxoplasma gondii." Antimicrob Agents Chemother 54(1): 517-521.

Baldwin, J., A. M. Farajallah, N. A. Malmquist, P. K. Rathod and M. A. Phillips (2002). "Malarial dihydroorotate dehydrogenase. Substrate and inhibitor specificity." J Biol Chem 277(44): 41827-41834.

Baldwin, J., C. H. Michnoff, N. A. Malmquist, J. White, M. G. Roth, P. K. Rathod and M. A. Phillips (2005). "High-throughput screening for potent and selective inhibitors of Plasmodium falciparum dihydroorotate dehydrogenase." J Biol Chem 280(23): 2184721853.

Bartlett, J. G., P. G. Auwaerter and P. A. Pham (2011). "Pathogens - Parasites." In: John Hopkins ABX Guide. Diagnosis and Treatment of Infectious Diseases 3. Auflage (2012)(Jones and Bartlett Learning): $384 \mathrm{f}$.

Baum, J., A. T. Papenfuss, B. Baum, T. P. Speed and A. F. Cowman (2006). "Regulation of apicomplexan actin-based motility." Nat Rev Microbiol 4(8): 621-628.

Baumann, P., S. Mandl-Weber, A. Volkl, C. Adam, I. Bumeder, F. Oduncu and R. Schmidmaier (2009). "Dihydroorotate dehydrogenase inhibitor A771726 (leflunomide) induces apoptosis and diminishes proliferation of multiple myeloma cells." Mol Cancer Ther 8(2): 366-375.

Biagini, G. A., N. Fisher, A. E. Shone, M. A. Mubaraki, A. Srivastava, A. Hill, T. Antoine, A. J. Warman, J. Davies, C. Pidathala, R. K. Amewu, S. C. Leung, R. Sharma, P. Gibbons, D. W. Hong, B. Pacorel, A. S. Lawrenson, S. Charoensutthivarakul, L. Taylor, O. Berger, A. Mbekeani, P. A. Stocks, G. L. Nixon, J. Chadwick, J. Hemingway, M. J. Delves, R. E. Sinden, A. M. Zeeman, C. H. Kocken, N. G. Berry, P. M. O'Neill and S. A. Ward (2012). "Generation of quinolone antimalarials targeting the Plasmodium falciparum mitochondrial respiratory chain for the treatment and prophylaxis of malaria." Proc Natl Acad Sci U S A 109(21): 8298-8303. 
Biagini, G. A., P. Viriyavejakul, M. O'Neill P, P. G. Bray and S. A. Ward (2006). "Functional characterization and target validation of alternative complex I of Plasmodium falciparum mitochondria." Antimicrob Agents Chemother 50(5): 1841-1851.

Bjornberg, O., P. Rowland, S. Larsen and K. F. Jensen (1997). "Active site of dihydroorotate dehydrogenase A from Lactococcus lactis investigated by chemical modification and mutagenesis." Biochemistry 36(51): 16197-16205.

Blume, M., D. Rodriguez-Contreras, S. Landfear, T. Fleige, D. Soldati-Favre, R. Lucius and N. Gupta (2009). "Host-derived glucose and its transporter in the obligate intracellular pathogen Toxoplasma gondii are dispensable by glutaminolysis." Proc Natl Acad Sci U S A 106(31): 12998-13003.

Borst, P. (1991). "Genetic mechanisms of drug resistance. A review." Acta Oncol 30(1): 87105.

Bottegoni, G., A. D. Favia, M. Recanatini and A. Cavalli (2012). "The role of fragment-based and computational methods in polypharmacology." Drug Discov Today 17(1-2): 2334.

Boyd, A. S. (2012). "Leflunomide in dermatology." J Am Acad Dermatol 66(4): 673-679.

Brodt, H. (2012). "C. Spezieller Teil: Erreger - Parasitäre Erkrankungen." In: Stille, Brodt HR. Antibiotika-Therapie. Klinik und Praxis der antiinfektiösen Behandlung 12. Auflage(Schattauer Verlag Stuttgart): $856 \mathrm{ff}$.

Carter, D., R. G. Donald, D. Roos and B. Ullman (1997). "Expression, purification, and characterization of uracil phosphoribosyltransferase from Toxoplasma gondii." $\underline{\text { Mol }}$ Biochem Parasitol 87(2): 137-144.

Cesbron-Delauw, M. F., C. Gendrin, L. Travier, P. Ruffiot and C. Mercier (2008). "Apicomplexa in mammalian cells: trafficking to the parasitophorous vacuole." Traffic 9(5): 657-664.

Contini, C. (2008). "Clinical and diagnostic management of toxoplasmosis in the immunocompromised patient." Parassitologia 50(1-2): 45-50.

Coteron, J. M., M. Marco, J. Esquivias, X. Deng, K. L. White, J. White, M. Koltun, F. El Mazouni, S. Kokkonda, K. Katneni, R. Bhamidipati, D. M. Shackleford, I. AnguloBarturen, S. B. Ferrer, M. B. Jimenez-Diaz, F. J. Gamo, E. J. Goldsmith, W. N. Charman, I. Bathurst, D. Floyd, D. Matthews, J. N. Burrows, P. K. Rathod, S. A. Charman and M. A. Phillips (2011). "Structure-guided lead optimization of triazolopyrimidine-ring substituents identifies potent Plasmodium falciparum dihydroorotate dehydrogenase inhibitors with clinical candidate potential." J Med Chem 54(15): 5540-5561.

Couto, S. G., M. C. Nonato and A. J. Costa-Filho (2008). "Defects in vesicle core induced by escherichia coli dihydroorotate dehydrogenase." Biophys J 94(5): 1746-1753.

Daily, J. P., D. Scanfeld, N. Pochet, K. Le Roch, D. Plouffe, M. Kamal, O. Sarr, S. Mboup, O. Ndir, D. Wypij, K. Levasseur, E. Thomas, P. Tamayo, C. Dong, Y. Zhou, E. S. Lander, D. Ndiaye, D. Wirth, E. A. Winzeler, J. P. Mesirov and A. Regev (2007). "Distinct physiological states of Plasmodium falciparum in malaria-infected patients." Nature 450(7172): 1091-1095.

Daneshvar, C., T. M. Davis, J. Cox-Singh, M. Z. Rafa'ee, S. K. Zakaria, P. C. Divis and B. Singh (2010). "Clinical and parasitological response to oral chloroquine and primaquine in uncomplicated human Plasmodium knowlesi infections." Malar J 9: 238.

Darde, M. L. (2008). "Toxoplasma gondii, "new" genotypes and virulence." Parasite 15(3): 366-371.

Davies, M., T. Heikkila, G. A. McConkey, C. W. Fishwick, M. R. Parsons and A. P. Johnson (2009). "Structure-based design, synthesis, and characterization of inhibitors of human 
and Plasmodium falciparum dihydroorotate dehydrogenases." J Med Chem 52(9): 2683-2693.

Delwiche, C. F. and J. D. Palmer (1997). "The origin of plastids and their spread via secondary symbiosis." Pl. Sys. Evol. (Suppl.) 11: 53-86.

Deng, X., R. Gujjar, F. El Mazouni, W. Kaminsky, N. A. Malmquist, E. J. Goldsmith, P. K. Rathod and M. A. Phillips (2009). "Structural plasticity of malaria dihydroorotate dehydrogenase allows selective binding of diverse chemical scaffolds." J Biol Chem 284(39): 26999-27009.

Denton, H., S. M. Brown, C. W. Roberts, J. Alexander, V. McDonald, K. W. Thong and G. H. Coombs (1996). "Comparison of the phosphofructokinase and pyruvate kinase activities of Cryptosporidium parvum, Eimeria tenella and Toxoplasma gondii." Mol Biochem Parasitol 76(1-2): 23-29.

Divo, A. A., T. G. Geary, J. B. Jensen and H. Ginsburg (1985). "The mitochondrion of Plasmodium falciparum visualized by rhodamine 123 fluorescence." J Protozool 32(3): 442-446.

Dobrowolski, J. M., V. B. Carruthers and L. D. Sibley (1997). "Participation of myosin in gliding motility and host cell invasion by Toxoplasma gondii." Mol Microbiol 26(1): 163-173.

Donald, R. G. and D. S. Roos (1995). "Insertional mutagenesis and marker rescue in a protozoan parasite: cloning of the uracil phosphoribosyltransferase locus from Toxoplasma gondii." Proc Natl Acad Sci U S A 92(12): 5749-5753.

Dondorp, A. M., F. Nosten, P. Yi, D. Das, A. P. Phyo, J. Tarning, K. M. Lwin, F. Ariey, W. Hanpithakpong, S. J. Lee, P. Ringwald, K. Silamut, M. Imwong, K. Chotivanich, P. Lim, T. Herdman, S. S. An, S. Yeung, P. Singhasivanon, N. P. Day, N. Lindegardh, D. Socheat and N. J. White (2009). "Artemisinin resistance in Plasmodium falciparum malaria." N Engl J Med 361(5): 455-467.

Dong, C. K., V. Patel, J. C. Yang, J. D. Dvorin, M. T. Duraisingh, J. Clardy and D. F. Wirth (2009). "Type II NADH dehydrogenase of the respiratory chain of Plasmodium falciparum and its inhibitors." Bioorg Med Chem Lett 19(3): 972-975.

Dubey, J. P. (1988). "Long-term persistence of Toxoplasma gondii in tissues of pigs inoculated with $T$ gondii oocysts and effect of freezing on viability of tissue cysts in pork." Am J Vet Res 49(6): 910-913.

Dubey, J. P. (1997). "Tissue cyst tropism in Toxoplasma gondii: a comparison of tissue cyst formation in organs of cats, and rodents fed oocysts." Parasitology 115 ( Pt 1): 15-20.

Dubey, J. P. (1998b). "Advances in the life cycle of Toxoplasma gondii." Int J Parasitol 28(7): 1019-1024.

Dubey, J. P., D. S. Lindsay and C. A. Speer (1998). "Structures of Toxoplasma gondii tachyzoites, bradyzoites, and sporozoites and biology and development of tissue cysts." Clin Microbiol Rev 11(2): 267-299.

Dubremetz, J. F. (1998). "Host cell invasion by Toxoplasma gondii." Trends Microbiol 6(1): 27-30.

Dyall, S. D. and P. J. Johnson (2000). "Origins of hydrogenosomes and mitochondria: evolution and organelle biogenesis." Curr Opin Microbiol 3(4): 404-411.

Eschemann, A., A. Galkin, W. Oettmeier, U. Brandt and S. Kerscher (2005). "HDQ (1hydroxy-2-dodecyl-4(1H)quinolone), a high affinity inhibitor for mitochondrial alternative NADH dehydrogenase: evidence for a ping-pong mechanism." J Biol Chem 280(5): 3138-3142.

Fichera, M. E. and D. S. Roos (1997). "A plastid organelle as a drug target in apicomplexan parasites." Nature 390(6658): 407-409.

Fleige, T., K. Fischer, D. J. Ferguson, U. Gross and W. Bohne (2007). "Carbohydrate metabolism in the Toxoplasma gondii apicoplast: localization of three glycolytic 
isoenzymes, the single pyruvate dehydrogenase complex, and a plastid phosphate translocator." Eukaryot Cell 6(6): 984-996.

Fleige, T., N. Pfaff, U. Gross and W. Bohne (2008). "Localisation of gluconeogenesis and tricarboxylic acid (TCA)-cycle enzymes and first functional analysis of the TCA cycle in Toxoplasma gondii." Int J Parasitol 38(10): 1121-1132.

Fohl, L. M. and D. S. Roos (2003). "Fitness effects of DHFR-TS mutations associated with pyrimethamine resistance in apicomplexan parasites." Mol Microbiol 50(4): 13191327.

Foth, B. J., L. M. Stimmler, E. Handman, B. S. Crabb, A. N. Hodder and G. I. McFadden (2005). "The malaria parasite Plasmodium falciparum has only one pyruvate dehydrogenase complex, which is located in the apicoplast." Mol Microbiol 55(1): 3953.

Foulon, W., A. Naessens and D. Ho-Yen (2000). "Prevention of congenital toxoplasmosis." J Perinat Med 28(5): 337-345.

Fox, B. A. and D. J. Bzik (2002). "De novo pyrimidine biosynthesis is required for virulence of Toxoplasma gondii." Nature 415(6874): 926-929.

Fox, B. A. and D. J. Bzik (2010). "Avirulent uracil auxotrophs based on disruption of orotidine-5'-monophosphate decarboxylase elicit protective immunity to Toxoplasma gondii." Infect Immun 78(9): 3744-3752.

Fox, B. A., J. G. Ristuccia, J. P. Gigley and D. J. Bzik (2009). "Efficient gene replacements in Toxoplasma gondii strains deficient for nonhomologous end joining." Eukaryot Cell 8(4): 520-529.

Fox, R. I. (1998). "Mechanism of action of leflunomide in rheumatoid arthritis." J Rheumatol Suppl 53: 20-26.

Frenkel, J. K., A. Ruiz and M. Chinchilla (1975). "Soil survival of toxoplasma oocysts in Kansas and Costa Rica." Am J Trop Med Hyg 24(3): 439-443.

Fry, M. and M. Pudney (1992). "Site of action of the antimalarial hydroxynaphthoquinone, 2[trans-4-(4'-chlorophenyl) cyclohexyl]-3-hydroxy-1,4-naphthoquinone (566C80)." Biochem Pharmacol 43(7): 1545-1553.

Fry, M., E. Webb and M. Pudney (1990). "Effect of mitochondrial inhibitors on adenosinetriphosphate levels in Plasmodium falciparum." Comp Biochem Physiol B 96(4): 775-782.

Fujioka, H. and M. Aikawa (2002). "Structure and life cycle." Chem Immunol 80: 1-26.

Gardner, M. J., N. Hall, E. Fung, O. White, M. Berriman, R. W. Hyman, J. M. Carlton, A. Pain, K. E. Nelson, S. Bowman, I. T. Paulsen, K. James, J. A. Eisen, K. Rutherford, S. L. Salzberg, A. Craig, S. Kyes, M. S. Chan, V. Nene, S. J. Shallom, B. Suh, J. Peterson, S. Angiuoli, M. Pertea, J. Allen, J. Selengut, D. Haft, M. W. Mather, A. B. Vaidya, D. M. Martin, A. H. Fairlamb, M. J. Fraunholz, D. S. Roos, S. A. Ralph, G. I. McFadden, L. M. Cummings, G. M. Subramanian, C. Mungall, J. C. Venter, D. J. Carucci, S. L. Hoffman, C. Newbold, R. W. Davis, C. M. Fraser and B. Barrell (2002). "Genome sequence of the human malaria parasite Plasmodium falciparum." Nature 419(6906): 498-511.

Gero, A. M. and W. J. O'Sullivan (1990). "Purines and pyrimidines in malarial parasites." Blood Cells 16(2-3): 467-484; discussion 485-498.

Gilbert, R., H. K. Tan, S. Cliffe, E. Guy and M. Stanford (2006). "Symptomatic toxoplasma infection due to congenital and postnatally acquired infection." Arch Dis Child 91(6): 495-498.

Ginger, M. L. (2006). "Niche metabolism in parasitic protozoa." Philos Trans R Soc Lond B Biol Sci 361(1465): 101-118.

Goodman, C. D., V. Su and G. I. McFadden (2007). "The effects of anti-bacterials on the malaria parasite Plasmodium falciparum." Mol Biochem Parasitol 152(2): 181-191. 
Grobusch, M. P. and P. G. Kremsner (2005). "Uncomplicated malaria." Curr Top Microbiol Immunol 295: 83-104.

Gubbels, M. J. and M. T. Duraisingh (2012). "Evolution of apicomplexan secretory organelles." Int J Parasitol 42(12): 1071-1081.

Gubbels, M. J., C. Li and B. Striepen (2003). "High-throughput growth assay for Toxoplasma gondii using yellow fluorescent protein." Antimicrob Agents Chemother 47(1): 309316.

Hakansson, S., H. Morisaki, J. Heuser and L. D. Sibley (1999). "Time-lapse video microscopy of gliding motility in Toxoplasma gondii reveals a novel, biphasic mechanism of cell locomotion." Mol Biol Cell 10(11): 3539-3547.

Hammond, D. J., J. R. Burchell and M. Pudney (1985). "Inhibition of pyrimidine biosynthesis de novo in Plasmodium falciparum by 2-(4-t-butylcyclohexyl)-3-hydroxy-1,4naphthoquinone in vitro." Mol Biochem Parasitol 14(1): 97-109.

Harker, K. S., N. Ueno, T. Wang, C. Bonhomme, W. Liu and M. B. Lodoen (2013). "Toxoplasma gondii modulates the dynamics of human monocyte adhesion to vascular endothelium under fluidic shear stress." J Leukoc Biol 93(5): 789-800.

Haverkos, H. W. (1987). "Assessment of therapy for toxoplasma encephalitis. The TE Study Group." Am J Med 82(5): 907-914.

Hill, B., J. Kilsby, G. W. Rogerson, R. T. McIntosh and C. D. Ginger (1981). "The enzymes of pyrimidine biosynthesis in a range of parasitic protozoa and helminths." Mol Biochem Parasitol 2(3-4): 123-134.

Hill, D. E., S. Chirukandoth and J. P. Dubey (2005). "Biology and epidemiology of Toxoplasma gondii in man and animals." Anim Health Res Rev 6(1): 41-61.

Hino, A., M. Hirai, T. Q. Tanaka, Y. Watanabe, H. Matsuoka and K. Kita (2012). "Critical roles of the mitochondrial complex II in oocyst formation of rodent malaria parasite Plasmodium berghei." J Biochem 152(3): 259-268.

Hoffmann, H. H., A. Kunz, V. A. Simon, P. Palese and M. L. Shaw (2011). "Broad-spectrum antiviral that interferes with de novo pyrimidine biosynthesis." Proc Natl Acad Sci U S A 108(14): 5777-5782.

Hopkins, A. L. (2008). "Network pharmacology: the next paradigm in drug discovery." Nat Chem Biol 4(11): 682-690.

Hopkins, A. L., G. R. Bickerton, I. M. Carruthers, S. K. Boyer, H. Rubin and J. P. Overington (2011). "Rapid analysis of pharmacology for infectious diseases." Curr Top Med Chem 11(10): 1292-1300.

Hortua Triana, M. A., M. H. Huynh, M. F. Garavito, B. A. Fox, D. J. Bzik, V. B. Carruthers, M. Loffler and B. H. Zimmermann (2012). "Biochemical and molecular characterization of the pyrimidine biosynthetic enzyme dihydroorotate dehydrogenase from Toxoplasma gondii." Mol Biochem Parasitol 184(2): 71-81.

Howe, D. K. and L. D. Sibley (1995). "Toxoplasma gondii comprises three clonal lineages: correlation of parasite genotype with human disease." J Infect Dis 172(6): 1561-1566.

$\mathrm{Hu}$, K., J. Johnson, L. Florens, M. Fraunholz, S. Suravajjala, C. DiLullo, J. Yates, D. S. Roos and J. M. Murray (2006). "Cytoskeletal components of an invasion machine--the apical complex of Toxoplasma gondii." PLoS Pathog 2(2): e13.

Hurt, D. E., J. Widom and J. Clardy (2006). "Structure of Plasmodium falciparum dihydroorotate dehydrogenase with a bound inhibitor." Acta Crystallogr D Biol Crystallogr 62(Pt 3): 312-323.

Hyde, J. E. (2007). "Targeting purine and pyrimidine metabolism in human apicomplexan parasites." Curr Drug Targets 8(1): 31-47.

Iltzsch, M. H. (1993). "Pyrimidine salvage pathways in Toxoplasma gondii." J Eukaryot Microbiol 40(1): 24-28. 
Israelski, D. M., J. S. Chmiel, L. Poggensee, J. P. Phair and J. S. Remington (1993). "Prevalence of Toxoplasma infection in a cohort of homosexual men at risk of AIDS and toxoplasmic encephalitis." J Acquir Immune Defic Syndr 6(4): 414-418.

Jacobasch, G., D. Buckwitz, C. Gerth and R. Thamm (1990). "Regulation of the energy metabolism of Plasmodium berghei." Biomed Biochim Acta 49(2-3): S289-294.

Janouskovec, J., A. Horak, M. Obornik, J. Lukes and P. J. Keeling (2010). "A common red algal origin of the apicomplexan, dinoflagellate, and heterokont plastids." Proc Natl Acad Sci U S A 107(24): 10949-10954.

Jones, L. A., J. Alexander and C. W. Roberts (2006). "Ocular toxoplasmosis: in the storm of the eye." Parasite Immunol 28(12): 635-642.

Kappagoda, S., U. Singh and B. G. Blackburn (2011). "Antiparasitic therapy." Mayo Clin Proc 86(6): 561-583.

Kerscher, S. J. (2000). "Diversity and origin of alternative NADH:ubiquinone oxidoreductases." Biochim Biophys Acta 1459(2-3): 274-283.

Kessl, J. J., B. B. Lange, T. Merbitz-Zahradnik, K. Zwicker, P. Hill, B. Meunier, H. Palsdottir, C. Hunte, S. Meshnick and B. L. Trumpower (2003). "Molecular basis for atovaquone binding to the cytochrome bc1 complex." J Biol Chem 278(33): 3131231318.

Kim, K. and L. M. Weiss (2004). "Toxoplasma gondii: the model apicomplexan." Int J Parasitol 34(3): 423-432.

Kohler, S., C. F. Delwiche, P. W. Denny, L. G. Tilney, P. Webster, R. J. Wilson, J. D. Palmer and D. S. Roos (1997). "A plastid of probable green algal origin in Apicomplexan parasites." Science 275(5305): 1485-1489.

Korsinczky, M., N. Chen, B. Kotecka, A. Saul, K. Rieckmann and Q. Cheng (2000). "Mutations in Plasmodium falciparum cytochrome $\mathrm{b}$ that are associated with atovaquone resistance are located at a putative drug-binding site." Antimicrob Agents Chemother 44(8): 2100-2108.

Lamikanra, A. A., D. Brown, A. Potocnik, C. Casals-Pascual, J. Langhorne and D. J. Roberts (2007). "Malarial anemia: of mice and men." Blood 110(1): 18-28.

Lemgruber, L. and P. Lupetti (2012). "Crystalloid body, refractile body and virus-like particles in Apicomplexa: what is in there?" Parasitology 139(3): 285-293.

Leport, C., F. Raffi, S. Matheron, C. Katlama, B. Regnier, A. G. Saimot, C. Marche, C. Vedrenne and J. L. Vilde (1988). "Treatment of central nervous system toxoplasmosis with pyrimethamine/sulfadiazine combination in 35 patients with the acquired immunodeficiency syndrome. Efficacy of long-term continuous therapy." Am J Med 84(1): 94-100.

Levine, N. D., J. O. Corliss, F. E. Cox, G. Deroux, J. Grain, B. M. Honigberg, G. F. Leedale, A. R. Loeblich, 3rd, J. Lom, D. Lynn, E. G. Merinfeld, F. C. Page, G. Poljansky, V. Sprague, J. Vavra and F. G. Wallace (1980). "A newly revised classification of the protozoa." J Protozool 27(1): 37-58.

Lin, S. S., M. Blume, N. von Ahsen, U. Gross and W. Bohne (2011b). "Extracellular Toxoplasma gondii tachyzoites do not require carbon source uptake for ATP maintenance, gliding motility and invasion in the first hour of their extracellular life." Int J Parasitol 41(8): 835-841.

Lin, S. S., U. Gross and W. Bohne (2009). "Type II NADH dehydrogenase inhibitor 1hydroxy-2-dodecyl-4(1H)quinolone leads to collapse of mitochondrial innermembrane potential and ATP depletion in Toxoplasma gondii." Eukaryot Cell 8(6): 877-887.

Lin, S. S., U. Gross and W. Bohne (2011). "Two internal type II NADH dehydrogenases of Toxoplasma gondii are both required for optimal tachyzoite growth." Mol Microbiol 82(1): 209-221. 
Lin, S. S., S. Kerscher, A. Saleh, U. Brandt, U. Gross and W. Bohne (2008). "The Toxoplasma gondii type-II NADH dehydrogenase TgNDH2-I is inhibited by 1hydroxy-2-alkyl-4(1H)quinolones." Biochim Biophys Acta 1777(11): 1455-1462.

Liu, S., E. A. Neidhardt, T. H. Grossman, T. Ocain and J. Clardy (2000). "Structures of human dihydroorotate dehydrogenase in complex with antiproliferative agents." Structure 8(1): 25-33.

MacRae, J. I., L. Sheiner, A. Nahid, C. Tonkin, B. Striepen and M. J. McConville (2012). "Mitochondrial metabolism of glucose and glutamine is required for intracellular growth of Toxoplasma gondii." Cell Host Microbe 12(5): 682-692.

Malmquist, N. A., R. Gujjar, P. K. Rathod and M. A. Phillips (2008). "Analysis of flavin oxidation and electron-transfer inhibition in Plasmodium falciparum dihydroorotate dehydrogenase." Biochemistry 47(8): 2466-2475.

Mather, M. W., K. W. Henry and A. B. Vaidya (2007). "Mitochondrial drug targets in apicomplexan parasites." Curr Drug Targets 8(1): 49-60.

Mather, M. W. and A. B. Vaidya (2008). "Mitochondria in malaria and related parasites: ancient, diverse and streamlined." J Bioenerg Biomembr 40(5): 425-433.

McFadden, D. C., M. Camps and J. C. Boothroyd (2001). "Resistance as a tool in the study of old and new drug targets in Toxoplasma." Drug Resist Updat 4(2): 79-84.

Meissner, M., D. J. Ferguson and F. Frischknecht (2013). "Invasion factors of apicomplexan parasites: essential or redundant?" Curr Opin Microbiol.

Melo, E. J., M. Attias and W. De Souza (2000). "The single mitochondrion of tachyzoites of Toxoplasma gondii." J Struct Biol 130(1): 27-33.

Miceli-Richard, C. and M. Dougados (2003). "Leflunomide for the treatment of rheumatoid arthritis." Expert Opin Pharmacother 4(6): 987-997.

Miotto, O., J. Almagro-Garcia, M. Manske, B. Macinnis, S. Campino, K. A. Rockett, C. Amaratunga, P. Lim, S. Suon, S. Sreng, J. M. Anderson, S. Duong, C. Nguon, C. M. Chuor, D. Saunders, Y. Se, C. Lon, M. M. Fukuda, L. Amenga-Etego, A. V. Hodgson, V. Asoala, M. Imwong, S. Takala-Harrison, F. Nosten, X. Z. Su, P. Ringwald, F. Ariey, C. Dolecek, T. T. Hien, M. F. Boni, C. Q. Thai, A. Amambua-Ngwa, D. J. Conway, A. A. Djimde, O. K. Doumbo, I. Zongo, J. B. Ouedraogo, D. Alcock, E. Drury, S. Auburn, O. Koch, M. Sanders, C. Hubbart, G. Maslen, V. Ruano-Rubio, D. Jyothi, A. Miles, J. O'Brien, C. Gamble, S. O. Oyola, J. C. Rayner, C. I. Newbold, M. Berriman, C. C. Spencer, G. McVean, N. P. Day, N. J. White, D. Bethell, A. M. Dondorp, C. V. Plowe, R. M. Fairhurst and D. P. Kwiatkowski (2013). "Multiple populations of artemisinin-resistant Plasmodium falciparum in Cambodia." Nat Genet 45(6): 648-655.

Montoya, J. G. and O. Liesenfeld (2004). "Toxoplasmosis." Lancet 363(9425): 1965-1976.

Morisaki, J. H., J. E. Heuser and L. D. Sibley (1995). "Invasion of Toxoplasma gondii occurs by active penetration of the host cell." J Cell Sci 108 ( Pt 6): 2457-2464.

Morrissette, N. S. and L. D. Sibley (2002). "Cytoskeleton of apicomplexan parasites." Microbiol Mol Biol Rev 66(1): 21-38; table of contents.

Munier-Lehmann, H., P. O. Vidalain, F. Tangy and Y. L. Janin (2013). "On dihydroorotate dehydrogenases and their inhibitors and uses." J Med Chem 56(8): 3148-3167.

Murray, C. J., L. C. Rosenfeld, S. S. Lim, K. G. Andrews, K. J. Foreman, D. Haring, N. Fullman, M. Naghavi, R. Lozano and A. D. Lopez (2012). "Global malaria mortality between 1980 and 2010: a systematic analysis." Lancet 379(9814): 413-431.

Nagy, M., F. Lacroute and D. Thomas (1992). "Divergent evolution of pyrimidine biosynthesis between anaerobic and aerobic yeasts." Proc Natl Acad Sci U S A 89(19): 8966-8970.

Naujoks, B. (2008). "Inhibierung der Toxoplasma-gondii-Replikation durch Hemmung der mitochondrialen Atmungskette." Medizinische Dissertation Universität Göttingen. 
Nishi, M., K. Hu, J. M. Murray and D. S. Roos (2008). "Organellar dynamics during the cell cycle of Toxoplasma gondii." J Cell Sci 121(Pt 9): 1559-1568.

Noedl, H., Y. Se, K. Schaecher, B. L. Smith, D. Socheat and M. M. Fukuda (2008). "Evidence of artemisinin-resistant malaria in western Cambodia." N Engl J Med 359(24): 26192620.

Norager, S., K. F. Jensen, O. Bjornberg and S. Larsen (2002). "E. coli dihydroorotate dehydrogenase reveals structural and functional distinctions between different classes of dihydroorotate dehydrogenases." Structure 10(9): 1211-1223.

Painter, H. J., J. M. Morrisey, M. W. Mather and A. B. Vaidya (2007). "Specific role of mitochondrial electron transport in blood-stage Plasmodium falciparum." Nature 446(7131): 88-91.

Parsons, M., A. Karnataki, J. E. Feagin and A. DeRocher (2007). "Protein trafficking to the apicoplast: deciphering the apicomplexan solution to secondary endosymbiosis." Eukaryot Cell 6(7): 1081-1088.

Patel, V., M. Booker, M. Kramer, L. Ross, C. A. Celatka, L. M. Kennedy, J. D. Dvorin, M. T. Duraisingh, P. Sliz, D. F. Wirth and J. Clardy (2008). "Identification and characterization of small molecule inhibitors of Plasmodium falciparum dihydroorotate dehydrogenase." J Biol Chem 283(50): 35078-35085.

Pfefferkorn, E. R. and L. C. Pfefferkorn (1977). "Toxoplasma gondii: characterization of a mutant resistant to 5-fluorodeoxyuridine." Exp Parasitol 42(1): 44-55.

Phillips, M. A. and P. K. Rathod (2010). "Plasmodium dihydroorotate dehydrogenase: a promising target for novel anti-malarial chemotherapy." Infect Disord Drug Targets 10(3): 226-239.

Phyo, A. P., S. Nkhoma, K. Stepniewska, E. A. Ashley, S. Nair, R. McGready, C. ler Moo, S. Al-Saai, A. M. Dondorp, K. M. Lwin, P. Singhasivanon, N. P. Day, N. J. White, T. J. Anderson and F. Nosten (2012). "Emergence of artemisinin-resistant malaria on the western border of Thailand: a longitudinal study." Lancet 379(9830): 1960-1966.

Polonais, V. and D. Soldati-Favre (2010). "Versatility in the acquisition of energy and carbon sources by the Apicomplexa." Biol Cell 102(8): 435-445.

Pomel, S., F. C. Luk and C. J. Beckers (2008). "Host cell egress and invasion induce marked relocations of glycolytic enzymes in Toxoplasma gondii tachyzoites." PLoS Pathog 4(10): e1000188.

Porter, S. B. and M. A. Sande (1992). "Toxoplasmosis of the central nervous system in the acquired immunodeficiency syndrome." N Engl J Med 327(23): 1643-1648.

Radke, J. R. and M. W. White (1999). "Expression of herpes simplex virus thymidine kinase in Toxoplasma gondii attenuates tachyzoite virulence in mice." Infect Immun 67(10): 5292-5297.

Ralph, S. A., M. C. D'Ombrain and G. I. McFadden (2001). "The apicoplast as an antimalarial drug target." Drug Resist Updat 4(3): 145-151.

Ralph, S. A., G. G. van Dooren, R. F. Waller, M. J. Crawford, M. J. Fraunholz, B. J. Foth, C. J. Tonkin, D. S. Roos and G. I. McFadden (2004). "Tropical infectious diseases: metabolic maps and functions of the Plasmodium falciparum apicoplast." Nat Rev Microbiol 2(3): 203-216.

Renold, C., A. Sugar, J. P. Chave, L. Perrin, J. Delavelle, G. Pizzolato, P. Burkhard, V. Gabriel and B. Hirschel (1992). "Toxoplasma encephalitis in patients with the acquired immunodeficiency syndrome." Medicine (Baltimore) 71(4): 224-239.

Reynolds, M. G. and D. S. Roos (1998). "A biochemical and genetic model for parasite resistance to antifolates. Toxoplasma gondii provides insights into pyrimethamine and cycloguanil resistance in Plasmodium falciparum." J Biol Chem 273(6): 3461-3469. 
Rodrigues, T., F. Lopes and R. Moreira (2010). "Inhibitors of the mitochondrial electron transport chain and de novo pyrimidine biosynthesis as antimalarials: The present status." Curr Med Chem 17(10): 929-956.

Roos, D. S., R. G. Donald, N. S. Morrissette and A. L. Moulton (1994). "Molecular tools for genetic dissection of the protozoan parasite Toxoplasma gondii." Methods Cell Biol 45: 27-63.

Roth, E. F., Jr., M. C. Calvin, I. Max-Audit, J. Rosa and R. Rosa (1988). "The enzymes of the glycolytic pathway in erythrocytes infected with Plasmodium falciparum malaria parasites." Blood 72(6): 1922-1925.

Rothova, A., C. Meenken, H. J. Buitenhuis, C. J. Brinkman, G. S. Baarsma, T. N. Boen-Tan, P. T. de Jong, N. Klaassen-Broekema, C. M. Schweitzer, Z. Timmerman and et al. (1993). "Therapy for ocular toxoplasmosis." Am J Ophthalmol 115(4): 517-523.

Rowland, P., F. S. Nielsen, K. F. Jensen and S. Larsen (1997). "The crystal structure of the flavin containing enzyme dihydroorotate dehydrogenase A from Lactococcus lactis." Structure 5(2): 239-252.

Rowland, P., S. Norager, K. F. Jensen and S. Larsen (2000). "Crystallization and preliminary X-ray studies of membrane-associated Escherichia coli dihydroorotate dehydrogenase." Acta Crystallogr D Biol Crystallogr 56(Pt 5): 659-661.

Saadatnia, G. and M. Golkar (2012). "A review on human toxoplasmosis." Scand J Infect Dis 44(11): 805-814.

Saleh, A., J. Friesen, S. Baumeister, U. Gross and W. Bohne (2007). "Growth inhibition of Toxoplasma gondii and Plasmodium falciparum by nanomolar concentrations of 1hydroxy-2-dodecyl-4(1H)quinolone, a high-affinity inhibitor of alternative (type II) NADH dehydrogenases." Antimicrob Agents Chemother 51(4): 1217-1222.

Saliba, K. J. and K. Kirk (2001). "Nutrient acquisition by intracellular apicomplexan parasites: staying in for dinner." Int J Parasitol 31(12): 1321-1330.

Seeber, F., J. Limenitakis and D. Soldati-Favre (2008). "Apicomplexan mitochondrial metabolism: a story of gains, losses and retentions." Trends Parasitol 24(10): 468-478.

Seymour, K. K., A. E. Yeo, K. H. Rieckmann and R. I. Christopherson (1997). "dCTP levels are maintained in Plasmodium falciparum subjected to pyrimidine deficiency or excess." Ann Trop Med Parasitol 91(6): 603-609.

Sherman, I. W. (1979). "Biochemistry of Plasmodium (malarial parasites)." Microbiol Rev 43(4): 453-495.

Shiflett, A. M. and P. J. Johnson (2010). "Mitochondrion-related organelles in eukaryotic protists." Annu Rev Microbiol 64: 409-429.

Sibley, C. H., J. E. Hyde, P. F. Sims, C. V. Plowe, J. G. Kublin, E. K. Mberu, A. F. Cowman, P. A. Winstanley, W. M. Watkins and A. M. Nzila (2001). "Pyrimethaminesulfadoxine resistance in Plasmodium falciparum: what next?" Trends Parasitol 17(12): 582-588.

Sibley, L. D. (2011). "Invasion and intracellular survival by protozoan parasites." Immunol Rev 240(1): 72-91.

Siden-Kiamos, I., A. Ecker, S. Nyback, C. Louis, R. E. Sinden and O. Billker (2006). "Plasmodium berghei calcium-dependent protein kinase 3 is required for ookinete gliding motility and mosquito midgut invasion." Mol Microbiol 60(6): 1355-1363.

Singh, B. and C. Daneshvar (2013). "Human infections and detection of Plasmodium knowlesi." Clin Microbiol Rev 26(2): 165-184.

Soldati-Favre, D. (2008). "Molecular dissection of host cell invasion by the apicomplexans: the glideosome." Parasite 15(3): 197-205.

Soldati, D., J. F. Dubremetz and M. Lebrun (2001). "Microneme proteins: structural and functional requirements to promote adhesion and invasion by the apicomplexan parasite Toxoplasma gondii." Int J Parasitol 31(12): 1293-1302. 
Srivastava, I. K., J. M. Morrisey, E. Darrouzet, F. Daldal and A. B. Vaidya (1999). "Resistance mutations reveal the atovaquone-binding domain of cytochrome $b$ in malaria parasites." Mol Microbiol 33(4): 704-711.

Srivastava, I. K., H. Rottenberg and A. B. Vaidya (1997). "Atovaquone, a broad spectrum antiparasitic drug, collapses mitochondrial membrane potential in a malarial parasite." J Biol Chem 272(7): 3961-3966.

Sternisek, P. (2009). "Einfluss des Pyrimidin Salvage Pathway Enzyms UPRT auf die Senstivität von Toxoplasma gondii gegenüber Inhibitoren der Atmungskette." Diplomarbeit Universität Göttingen.

Striepen, B. (2011). "The apicoplast: a red alga in human parasites." Essays Biochem 51: 111125.

Suzuki, Y., X. Wang, B. S. Jortner, L. Payne, Y. Ni, S. A. Michie, B. Xu, T. Kudo and S. Perkins (2010). "Removal of Toxoplasma gondii cysts from the brain by perforinmediated activity of CD8+ T cells." Am J Pathol 176(4): 1607-1613.

Taylor, S. M., M. E. Molyneux, D. L. Simel, S. R. Meshnick and J. J. Juliano (2010). "Does this patient have malaria?" JAMA 304(18): 2048-2056.

Tenter, A. M., A. R. Heckeroth and L. M. Weiss (2000). "Toxoplasma gondii: from animals to humans." Int J Parasitol 30(12-13): 1217-1258.

Thiele, M., J. Hegewald, U. Groß and W. Bohne (2012). "Heterologous expression of Toxoplasma gondii dihydroorotate dehydrogenase in E. coli." Posterpräsentation anlässlich der 64. Jahrestagung der Deutschen Gesellschaft für Hygiene und Mikrobiologie (DGHM).

Tietze, L. F. and L. Ma (2010). "Synthesis of novel 1-Hydroxyquinolones with high antitoxoplasma activity " Heterocycles 82(1): 377-396.

Tomley, F. M. and D. S. Soldati (2001). "Mix and match modules: structure and function of microneme proteins in apicomplexan parasites." Trends Parasitol 17(2): 81-88.

Travassos, M. A. and M. K. Laufer (2009). "Resistance to antimalarial drugs: molecular, pharmacologic, and clinical considerations." Pediatr Res 65(5 Pt 2): 64R-70R.

Unno, A., K. Suzuki, X. Xuan, Y. Nishikawa, K. Kitoh and Y. Takashima (2008). "Dissemination of extracellular and intracellular Toxoplasma gondii tachyzoites in the blood flow." Parasitol Int 57(4): 515-518.

Uyemura, S. A., S. Luo, M. Vieira, S. N. Moreno and R. Docampo (2004). "Oxidative phosphorylation and rotenone-insensitive malate- and NADH-quinone oxidoreductases in Plasmodium yoelii yoelii mitochondria in situ." $\mathrm{J}$ Biol Chem 279(1): 385-393.

Vaidya, A. B., M. S. Lashgari, L. G. Pologe and J. Morrisey (1993). "Structural features of Plasmodium cytochrome $\mathrm{b}$ that may underlie susceptibility to 8 -aminoquinolines and hydroxynaphthoquinones." Mol Biochem Parasitol 58(1): 33-42.

Vaidya, A. B. and M. W. Mather (2009). "Mitochondrial evolution and functions in malaria parasites." Annu Rev Microbiol 63: 249-267.

Vallieres, C., N. Fisher, T. Antoine, M. Al-Helal, P. Stocks, N. G. Berry, A. S. Lawrenson, S. A. Ward, P. M. O'Neill, G. A. Biagini and B. Meunier (2012). "HDQ, a potent inhibitor of Plasmodium falciparum proliferation, binds to the quinone reduction site of the cytochrome bc1 complex." Antimicrob Agents Chemother 56(7): 3739-3747.

van Dooren, G. G. and B. Striepen (2013). "The Algal Past and Parasite Present of the Apicoplast." Annu Rev Microbiol.

Vanderberg, J. P., S. Chew and M. J. Stewart (1990). "Plasmodium sporozoite interactions with macrophages in vitro: a videomicroscopic analysis." J Protozool 37(6): 528-536.

Vercesi, A. E., C. O. Rodrigues, S. A. Uyemura, L. Zhong and S. N. Moreno (1998). "Respiration and oxidative phosphorylation in the apicomplexan parasite Toxoplasma gondii." J Biol Chem 273(47): 31040-31047. 
Vyas, V. K. and M. Ghate (2011). "Recent developments in the medicinal chemistry and therapeutic potential of dihydroorotate dehydrogenase (DHODH) inhibitors." Mini Rev Med Chem 11(12): 1039-1055.

Waller, R. F., P. J. Keeling, G. G. van Dooren and G. I. McFadden (2003). "Comment on "A green algal apicoplast ancestor"." Science 301(5629): 49; author reply 49.

Wang, J., L. Huang, J. Li, Q. Fan, Y. Long, Y. Li and B. Zhou (2010). "Artemisinin directly targets malarial mitochondria through its specific mitochondrial activation." PLoS One 5(3): e9582.

Weiss, L. M. and J. P. Dubey (2009). "Toxoplasmosis: A history of clinical observations." Int J Parasitol 39(8): 895-901.

Weiss, L. M. and K. Kim (2000). "The development and biology of bradyzoites of Toxoplasma gondii." Front Biosci 5: D391-405.

Weissig, V., T. S. Vetro-Widenhouse and T. C. Rowe (1997). "Topoisomerase II inhibitors induce cleavage of nuclear and $35-\mathrm{kb}$ plastid DNAs in the malarial parasite Plasmodium falciparum." DNA Cell Biol 16(12): 1483-1492.

White, N. J. (1992). "Antimalarial drug resistance: the pace quickens." J Antimicrob Chemother 30(5): 571-585.

White, N. J. (2008). "Plasmodium knowlesi: the fifth human malaria parasite." Clin Infect Dis 46(2): 172-173.

WHO (2012). "World Malaria Report 2012." Geneva, Switzerland World Health Organization.

Wilson, R. J. and D. H. Williamson (1997). "Extrachromosomal DNA in the Apicomplexa." Microbiol Mol Biol Rev 61(1): 1-16.

Wongsrichanalai, C. and S. R. Meshnick (2008). "Declining artesunate-mefloquine efficacy against falciparum malaria on the Cambodia-Thailand border." Emerg Infect Dis 14(5): 716-719.

Xu, P., G. Widmer, Y. Wang, L. S. Ozaki, J. M. Alves, M. G. Serrano, D. Puiu, P. Manque, D. Akiyoshi, A. J. Mackey, W. R. Pearson, P. H. Dear, A. T. Bankier, D. L. Peterson, M. S. Abrahamsen, V. Kapur, S. Tzipori and G. A. Buck (2004). "The genome of Cryptosporidium hominis." Nature 431(7012): 1107-1112.

Yin, G., M. Qin, X. Liu, J. Suo and X. Suo (2013). "Expression of Toxoplasma gondii dense granule protein7 (GRA7) in Eimeria tenella." Parasitol Res 112(5): 2105-2109.

Zameitat, E., Z. Gojkovic, W. Knecht, J. Piskur and M. Loffler (2006). "Biochemical characterization of recombinant dihydroorotate dehydrogenase from the opportunistic pathogenic yeast Candida albicans." FEBS J 273(14): 3183-3191.

Zucker, J. R., T. K. Ruebush, 2nd, C. Obonyo, J. Otieno and C. C. Campbell (2003). "The mortality consequences of the continued use of chloroquine in Africa: experience in Siaya, western Kenya." Am J Trop Med Hyg 68(4): 386-390. 


\section{Publikation}

Hegewald, J., Gross, U., Bohne, W., 2013. Identification of dihydroorotate dehydrogenase as a relevant drug target for 1-hydroxyquinolones in Toxoplasma gondii. Mol Biochem Parasitol 190(1): 6-15.

\section{Kongressbeiträge}

Hegewald, J., Gross, U., Bohne, W. The mode of action of 1-hydroxyquinolones on Toxoplasma gondii. $14^{\text {th }}$ Drug Design \& Development Seminar der Deutschen Gesellschaft für Parasitologie (DGP), 11.04 - 13.04. 2013, Würzburg.

Hegewald, J., Gross, U., Bohne, W. Investigations on the mode of action of 1-hydroxy-2alkyl-4(1H)quinolones on Toxoplasma gondi. 64. Jahrestagung der Deutschen Gesellschaft für Hygiene und Mikrobiologie (DGHM), 30.09 - 03.10. 2012, Hamburg.

Thiele, M., Hegewald, J., Gross, U., Bohne, W. Heterologous expression of Toxoplasma gondii dihydroorotate dehydrogenase in E. coli. 64. Jahrestagung der Deutschen Gesellschaft für Hygiene und Mikrobiologie (DGHM), 30.09 - 03.10. 2012, Hamburg.

Hegewald, J., Gross, U., Bohne, W. Identification of resistance determinants for 1-hydroxy-2alkyl-4(1H)quinolones in Toxoplasma gondii. Gemeinsame Tagung der Deutschen Gesellschaft für Tropenmedizin und Internationale Gesundheit (DTG) und Deutschen Gesellschaft für Parasitologie (DGP), 15.03 - 17. 03. 2012, Heidelberg. 


\section{Lebenslauf}

Name: $\quad$ Jana Hegewald

Geburtsdatum: $\quad 12.08 .1984$

Geburtsort: $\quad$ Erfurt

Familienstand: ledig

Staatsangehörigkeit: deutsch

Schule:

09/1991 - 08/1995 Grundschule Erfurt

08/1995 - 06/2003 Heinrich-Mann-Gymnasium Erfurt

\section{Studium (Diplom-Biologie):}

04/2004 - 03/2007 Johannes Gutenberg-Universität Mainz, Grundstudium Diplomvorprüfung: 11/2006

04/2007 - 10/2010 Eberhard Karls Universität Tübingen, Hauptstudium (Hauptfach: Zoologie, Nebenfächer: Med. Mikrobiologie, Parasitologie) Diplomprüfung: 10/2010

09/2009 - 10/2010 Diplomarbeit am Institut für Tropenmedizin der Universität Tübingen, mit Forschungsaufenthalten in der Außenstation Togo, unter Prof. Dr. Peter Soboslay über das Thema:

Untersuchungen der Zytokin- und Chemokinproduktion bei Plasmodium falciparum infizierten Malariapatienten sowie polyparasitierten Kindern

\section{Promotion:}

Seit 10/2010 am Institut für Medizinische Mikrobiologie des Universitätsklinikums Göttingen über das Thema:

Identifizierung und Charakterisierung der Dihydroorotat Dehydrogenase als Zielstruktur von 1-Hydroxyquinolonen in Toxoplasma gondii 